UNIVERSIDADE DE SÃO PAULO

FACULDADE DE ECONOMIA, ADMINISTRAÇÃO E CONTABILIDADE DEPARTAMENTO DE ADMINISTRAÇÃO

PROGRAMA DE PÓS-GRADUAÇÃO EM ADMINISTRAÇÃO

ANÁLISE DAS CARACTERÍSTICAS DAS CARTEIRAS ACIONÁRIAS, DAS ESTRATÉGIAS DE GESTÃO E DOS RETORNOS DOS FUNDOS DE PREVIDÊNCIA PRIVADA COMPLEMENTAR PGBL/VGBL QUE INVESTEM EM RENDA VARIÁVEL

Carlos Eduardo Furlanetti

Orientador: Prof. Dr. José Roberto Securato

SÃO PAULO

2018 
Prof. Dr. Vahan Agopyan

Reitor da Universidade de São Paulo

Prof. Dr. Adalberto Américo Fischmann

Diretor da Faculdade de Economia, Administração e Contabilidade

Prof. Dr. Moacir de Miranda Oliveira Júnior

Chefe do Departamento de Administração

Prof. Dr. Moacir de Miranda Oliveira Júnior

Coordenador do Programa de Pós-Graduação em Administração 


\title{
ANÁLISE DAS CARACTERÍSTICAS DAS CARTEIRAS ACIONÁRIAS, DAS ESTRATÉGIAS DE GESTÃO E DOS RETORNOS DOS FUNDOS DE PREVIDÊNCIA PRIVADA COMPLEMENTAR PGBL/VGBL QUE INVESTEM EM RENDA VARIÁVEL
}

Tese apresentada ao Departamento de Administração da Faculdade de Economia, Administração e Contabilidade da Universidade de São Paulo como requisito para a obtenção do título de Doutor em Ciências.

Orientador: Prof. Dr. José Roberto Securato

\author{
Versão Corrigida \\ (versão original disponível na Biblioteca da Faculdade de Economia, Administração e Contabilidade) \\ SÃO PAULO


FICHA CATALOGRÁFICA

Elaborada por Martha Ribeiro Neves de Vasconcellos - CRB-8/5994 Seção de Processamento Técnico do SBD/FEA/USP

\section{Furlanetti, Carlos Eduardo}

Análise das características das carteiras acionárias, das estratégias de gestão e dos retornos dos fundos de previdência privada complementar PGBL/VGBL que investem em renda variável / Carlos Eduardo Furlanetti. - São Paulo, 2018.

$142 \mathrm{p}$.

Tese (Doutorado) - Universidade de São Paulo, 2018.

Orientador: José Roberto Securato

1. Previdência privada 2. Fundo aberto 3 . Estratégia dos fundos de previdência 4. Taxas de administração 5. PGBL/VGBL I. Universidade de São Paulo. Faculdade de Economia, Administração e Contabilidade. II. Título.

CDD - 368.37 
Dedico esta tese à minha filha, Lara, e à minha esposa, Fernanda, pelo amor, humor, apoio e

paciência. 



\section{AGRADECIMENTOS}

Primeiramente agradeço aos meus familiares: à minha mãe, Isaltina, minha maior referência, por ter forjado o meu caráter, com amor, apoio, sacrifício e crença no meu potencial; ao meu pai, Mário, pelo exemplo de honestidade e trabalho; à minha filha, Lara, por fazer tudo valer a pena e por me ensinar diariamente sobre a alegria de estarmos vivos; à minha esposa, Fernanda, pelo apoio e companheirismo incondicionais; aos meus irmãos mais velhos, Conceição, Marinho e Cleide, pela amizade e suporte; à minha sogra, Suzana, e ao meu sogro, Jorge, obrigado pela confiança. Enfim, agradeço a todos os meus familiares: cunhados, primos, tios e sobrinhos.

Agradeço imensamente ao meu orientador, Prof. Dr. José Roberto Securato, por todos os ensinamentos e oportunidades que tem me proporcionado nesses anos de prazeroso convívio. Quando penso em me tornar um professor melhor, é em você que busco as principais referências.

Agradeço muitíssimo à Profa. Dra. Fabiana Lopes e ao Prof. Dr. José Roberto Savoia pelas valiosas contribuições a este trabalho. Provocado pela disciplina Sistemas de Previdência, por vocês ministrada, é que escolhi o tema desta pesquisa.

Agradeço ao meu orientador no início dessa jornada, o Prof. Dr. Eduardo Kayo, pela qualidade dos ensinamentos introdutórios de econometria e pela generosidade.

Agradeço ao Prof. Dr. Claudio Felisoni de Angelo pelo apoio incondicional, amizade e confiança no meu trabalho.

Agradeço à Profa. Dra. Alessandra Montini e ao Prof. Dr. Nuno Fouto pela amizade, apoio e dicas. Ao Prof. Dr. Adolpho Canton e ao Prof. Dr. Luiz Paulo Fávero agradeço pelas excelentes aulas de estatística e de análise multivariada de dados.

Agradeço aos meus amigos e colegas de trabalho do Laboratório de Finanças (Labfin) e do Programa de Administração do Varejo (Provar), núcleos de destaque da Fundação Instituto de Administração (FIA), pela ajuda, apoio, entrega, companheirismo e torcida. É um verdadeiro privilégio conviver diariamente com vocês.

Agradeço à minha colega de trabalho, Prof. Dra. Érica Custódia de Oliveira, pelos comentários e sugestões para melhoria desta tese.

Agradeço ao meu colega de FEA/USP, orientando do Prof. Fávero, Marco Aurélio, pela ajuda inicial na escolha da técnica utilizada para análise dos dados.

Agradeço aos funcionários da FEA/USP pelo apoio e por tornar a nossa vida mais fácil. Meu muito obrigado a todos. 

"Esta é a verdade: a vida começa quando a gente compreende que ela não dura muito"

Millôr Fernandes 



\section{RESUMO}

Este trabalho teve como objetivo principal desenvolver um modelo para estimar o retorno anual de fundos privados de previdência complementar, PGBL/VGBL, que investiram em ativos de renda variável, entre 2007 e 2015. As variáveis utilizadas para discriminar as estratégias implementadas pelos gestores de fundos foram o beta do portfólio de ações, a taxa de administração cobrada pelo fundo e a porcentagem do patrimônio do fundo aplicada em ativos de renda variável. Os dados de 671 fundos diferentes foram extraídos do banco de dados Economática ${ }^{\circledR}$. Os fundos estavam associados a 29 administradoras diferentes. Com esses dados, foi possível investigar a composição das carteiras de ações dos fundos administrados pelas principais instituições financeiras que operam no mercado brasileiro. Cada uma das principais administradoras de fundos manteve, no período, um padrão de seleção de portfólio de ativos de renda variável: a composição das carteiras acionárias de boa parte dos fundos pertencentes a uma mesma administradora, quando não idêntica, apresentou alto grau de similaridade. Para verificar se houve alguma diferenciação na estratégia de gerenciamento de fundos entre as principais administradoras, foram aplicados testes multivariados de igualdade de Wald. Foram encontradas diferenças estatisticamente significantes nas médias das variáveis que discriminaram estratégias de gestão dos fundos, dentro de um intervalo de confiança de $95 \%$, em pelo menos uma das cinco principais administradoras de fundos. Os retornos anuais médios dos fundos, obtidos no período, estavam positiva e fortemente correlacionados ao principal índice de mercado de ações do Brasil, o Ibovespa. Esta descoberta indica uma possível passividade no gerenciamento de fundos, conforme encontrado por outros estudos acadêmicos. Especificamente, os fundos PGBL/VGBL com investimentos em ativos de renda variável que foram administrados pela administradora Itaú Unibanco SA obtiveram melhor desempenho médio, quando os retornos foram ajustados aos riscos incorridos. Para ajustar os retornos anuais ao risco, este trabalho apresentou, com base em um conjunto de premissas descritas no capítulo introdutório, uma metodologia que simplifica o cálculo das betas dos fundos, permitindo ordená-los com base em desempenhos ajustados ao risco. O modelo encontrado para estimar os retornos anuais dos fundos foi obtido por meio da técnica de regressão multinível com dados em painel. Tal modelo apontou, dentro do domínio temporal do estudo, que a cada ponto percentual adicional de taxa de administração cobrada pela instituição financeira, a estimativa de retorno ao investidor de determinado fundo era reduzida em um ponto percentual. Esta descoberta é mais uma evidência de passividade na gestão de fundos. Finalmente, a variação dos retornos anuais dos fundos é explicada principalmente pela variação na interação entre a porcentagem do patrimônio do fundo investido em ativos de renda variável e o retorno anual do Ibovespa.

Palavras-chave: Previdência privada; Fundo aberto; Estratégia dos fundos de previdência; Taxas de administração; PGBL/VGBL. 


\begin{abstract}
This work aimed to develop a model for estimating the annual return of the most popular private retirement funds in the Brazilian market, PGBL/VGBL funds, that invested in variable-income assets, between 2007 and 2015. The variables used to discriminate the strategies implemented by the fund managers were the beta of the stock portfolio, the management fee charged by the fund, and the percentage of the fund assets applied in variable-income assets. Data from 671 different funds were extracted from the Economática ${ }^{\circledR}$ database. The funds were associated to 29 different financial institutions. With these data, it was possible to investigate the composition of the stock portfolios of the funds held by the main financial institutions that operate in the Brazilian market. Each of the main financial institutions maintained a pattern of portfolio selection for variable-income assets in the period: the composition of the equity portfolios of most of the funds managed by the same financial institution, when not identical, presented a high level of similarity. In order to verify if there was any differentiation in the fund management strategy among the main financial institutions, multivariate Wald equality tests were applied. Statistically significant differences in the average of the variables that discriminated fund strategies were found, within a 95\% confidence interval, in at least one of the top fund financial institutions. The average annual returns of the funds obtained in the period were positive and strongly correlated to the main stock market index of Brazil, the Ibovespa. This finding indicates a possible passivity in fund management, as found by other academic studies. Specifically, the PGBL/VGBL funds with investments in variable-income assets that were managed by Itau Unibanco SA obtained better average performance over the almost whole period, when returns were adjusted to the incurred risks. In order to adjust the annual returns to risk, this work presented, based on a set of assumptions described in the introductory chapter, a methodology that simplifies the calculation of the betas of the funds, allowing to order them based on risk adjusted performances. The model found to estimate the annual returns of the funds was obtained through the multilevel regression technique with data in panel. Such a model pointed out - within the time domain of the study - that at each additional percentage point of management fee charged by the financial institution, the estimated return on the investor of a given fund was reduced by the same one percentage point. This finding is one more evidence of passivity in fund management. Finally, the variation of the annual returns of the funds is mainly explained by the variation in the interaction between the percentage of the fund equity invested in variable-income assets and the annual return of the Ibovespa.
\end{abstract}

Keywords: Pension funds; Return of pension funds; Strategy of pension funds; Administration fees; Brazilian pension funds $P G B L / V G B L$. 



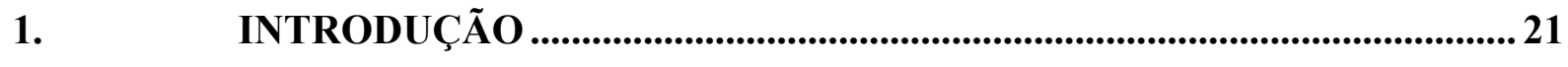

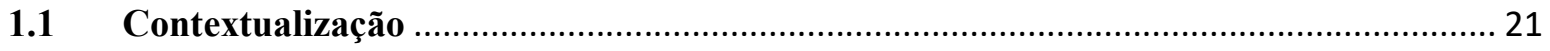

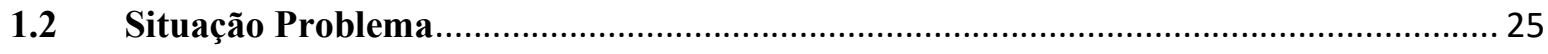

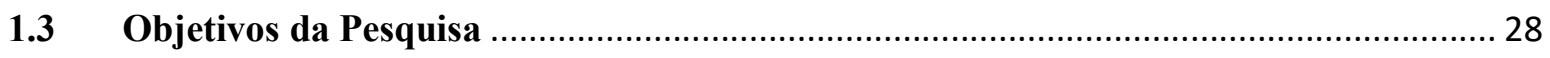

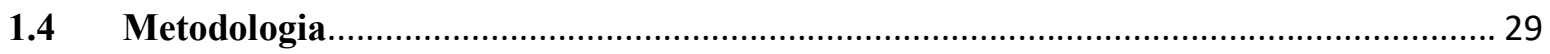

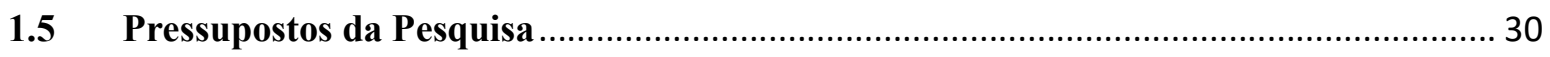

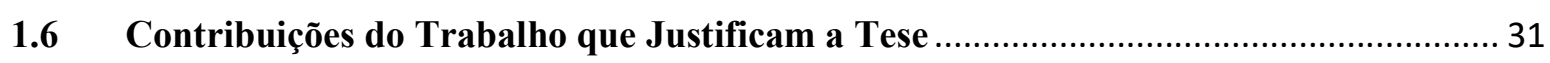

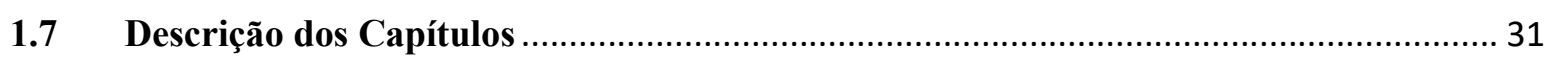

2. FUNDAMENTAÇÃO TÉORICA E HIPÓSTESES DA PESQUISA ......... 33

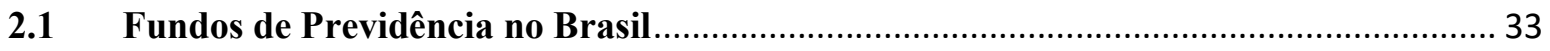

2.2 Ajuste dos Retornos de Carteiras de Investimento ao Risco …….................................. 44

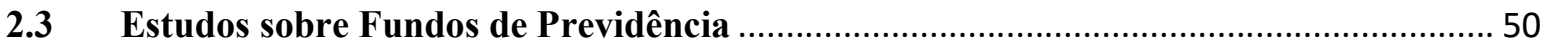

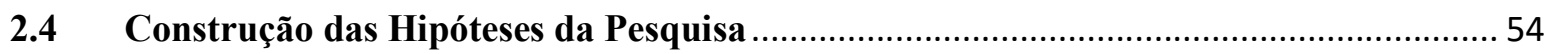

3. DESCRIÇÃO DO MÉTODO DE PESQUISA ...........................................55

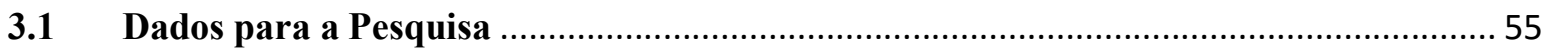

3.2 Procedimentos para Tratamento dos Dados ................................................................... 59

4. ANÁLISES DOS DADOS PARA ATENDER AOS OBJETIVOS

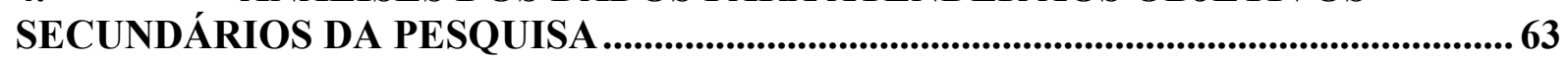

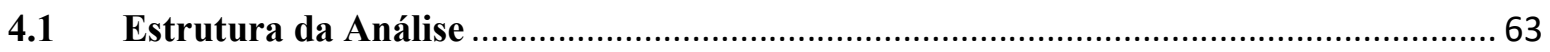

4.2 Explorando os Dados Gerais para Entender a População Estudada …........................ 63

4.3 Explorando os Dados das 5 Principais Administradoras de Fundos PGBL/VGBL...... 75

4.4 Análise Estatística das Estratégias de Gestão Adotadas pelas 5 Maiores

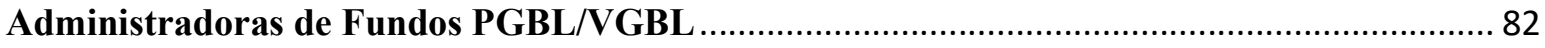

4.4.1 Análise dos Betas Médios das Carteiras Acionárias.............................................. 82

4.4.2 Análise das Médias das Taxas de Administração ..................................................... 85

4.4.3 Análise do Percentual Médio do Patrimônio Investido em Renda Variável........... 88

4.4.4 Análise dos Retornos Médios Anuais .................................................................. 91 
5. MODELO PROPOSTO. 103

5.1 Evidências sobre as Características dos Fundos PGBL/VGBL Estudados................... 103

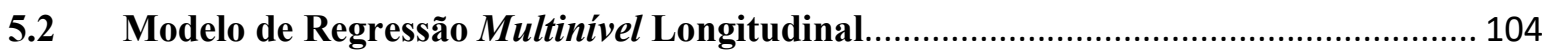

5.3 Desenvolvimento do Modelo de Regressão Multínvel Longitudinal .............................. 106

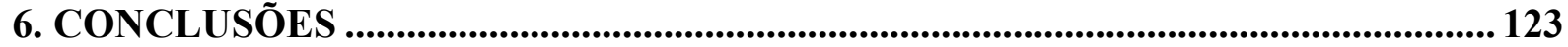

6.1 Principais Descobertas e Respostas às Perguntas de Pesquisa ...................................... 123

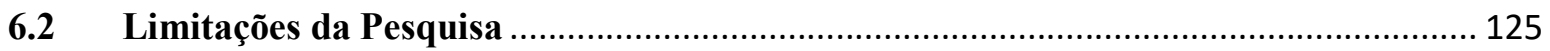

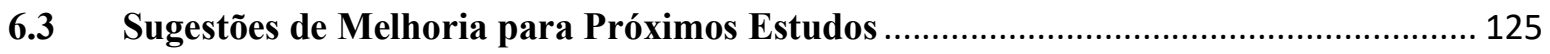

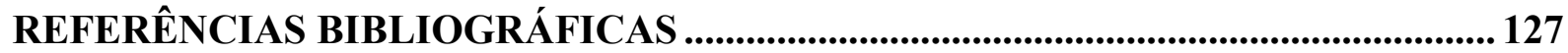

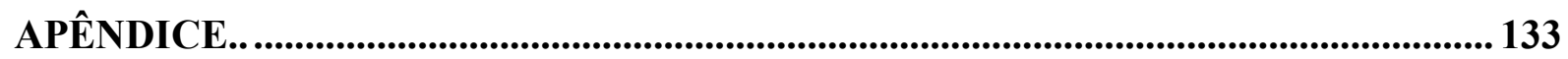




\section{LISTA DE ABREVIATURAS E SIGLAS}

AFP: Administradoras de Fundos de Pensão (Chile)

ANBIMA: Associação Brasileira das Entidades dos Mercados Financeiro e de Capitais

CAPM: Modelo de Precificação de Ativos ou, em inglês, Capital Asset Pricing Model

CLT: Consolidação das Leis do Trabalho

CNSP: Conselho Nacional de Seguros Privados

CPMF: Contribuição Provisória sobre Movimentação Financeira

BD: Benefício Definido

CD: Contribuição Definida

CGPC: Conselho de Gestão de Previdência Complementar

CV: Contribuição Variável

EAPC: Entidades Abertas de Previdência Complementar

EFPC: Entidades Fechadas de Previdência Complementar

FENAPREVI: Federação Nacional de Previdência Privada e Vida

FAPI: Fundo de Aposentadoria Programada Individual

FICFI: Fundos de Investimento em Cotas de Fundos de Investimento

FIE: Fundo de Investimento Especialmente Constituído

INSS: Instituto Nacional do Seguro Social

I.R.P.F: Imposto de Renda Pessoa Física

IBOVESPA: Índice acionário da BM\&F-Bovespa (atual B3).

IRA: Individual Retirement Account

IS: Índice de Sharpe

IT: Índice de Treynor

MQO: Mínimos Quadrados Ordinários

PAGP: Plano com Atualização Garantida e Performance

PGBL: Plano Gerador de Benefícios Livres

PP: Previdência Privada

PREVIC: Superintendência Nacional de Previdência Complementar

PRGP: Plano com Remuneração Garantida e Performance

PRI: Plano de Renda Imediata

PRSA: Plano com Remuneração Garantida e Performance sem Atualização

PS: Previdência Social 
RF: Renda Fixa

RGPS: Regime Geral de Previdência Social

RPPS: Regime Próprio de Previdência Social

RV: Renda variável

SELIC: Sistema Especial de Liquidação e Custódia

SUSEP: Superintendência de Seguros Privados

VAGP: Vida com Atualização Garantida e Performance

VGBL: Vida Gerador de Benefícios Livres

VRGP: Vida com Remuneração Garantida e Performance

VRI: Vida com Renda Imediata

VRSA: Vida com Remuneração Garantida e Performance sem Atualização 


\section{LISTA DE QUADROS}

Quadro 1 - Objetivos Principal e Secundários ....................................................................... 28

Quadro 2 - Modalidades de Benefícios dos Planos Privados de Previdência......................... 37

Quadro 3 - Tipos de Benefícios dos Planos de Previdência Privada ....................................... 37

Quadro 4 - Opções de Resgate dos Fundos Privados de Previdência ...................................... 38

Quadro 5 - Classe dos Títulos dos Fundos de Previdência Privada........................................ 39

Quadro 6 - Modalidades dos Fundos de Previdência - Família PGBL .................................... 40

Quadro 7 - Planos de Previdência com Cobertura por Sobrevivência .................................... 41

Quadro 8 - Classificação dos Fundos de Previdência - ANBIMA ……….............................. 42

Quadro 9 - Objetivos, Resultados Esperados e Hipóteses da Pesquisa ................................... 54

Quadro 10 - Descrição dos dados - Screening de Fundos - Economática............................... 55

Quadro 11 - Descrição dos dados - Screening de Ações - Economática ................................. 56

Quadro 12 - Dados Calculados ou Modificados pelo Autor.................................................... 57

Quadro 13 - Objetivos, Hipóteses e Técnicas Utilizadas no Trabalho .................................... 61 


\section{LISTA DE TABELAS}

Tabela 1 - Índice de crescimento do percentual da população de 65 ou mais anos (entre 2005 e 2015)

Tabela 2 - Evolução das Captações Brutas Anuais dos Planos Abertos de Previdência Complementar..... 24

Tabela 3 - Patrimônio Total dos Fundos ao Final dos Anos de 2007 a 2015 .......................... 36

Tabela 4 - Quantidade de Fundos PGBL/VGBL com Renda Variável................................... 64

Tabela 5 - Posição Acionária por Administradora - Fundos PGBL/VGBL com Renda Variável 65

Tabela 6 - Posição Acionária sobre o Total - Principais Administradoras - Fundos PGBL/VGBL com RV 68

Tabela 7 - Descrição Carteiras Acionárias - Fundos PGBL/VGBL com Renda Variável (Todas Administradoras).

Tabela 8 - Descrição Carteiras Acionárias - Fundos PGBL/VGBL com Renda Variável (5 Maiores Administradoras). .70

Tabela 9 - Ações Mais Relevantes na Carteira Consolidada de Todos os Fundos PGBL/VGBL 等

Tabela 10 - Carteira Acionária Mais Frequente - Bradesco - Dezembro de 2015 …............. 77

Tabela 11 - Carteira Acionária Mais Frequente - BB Dtvm S.A - Dezembro de 2015 ......... 78

Tabela 12 - Carteira Acionária Mais Frequente - Itaú Unibanco SA - Dezembro de 2015 ... 79

Tabela 13 - Carteira Acionária Mais Frequente - Caixa - Dezembro de 2015 ..................... 80

Tabela 14 - Carteira Acionária Mais Frequente - Banco Santander (Brasil) SA - Dezembro de 2015 . .80

Tabela 15 - Fundos PGBL/VGBL das Cinco Administradoras - Percentual de Uso da Carteira Mais Frequente (\% sobre Quantidade)..... 81

Tabela 16 - Fundos PGBL/VGBL das Cinco Administradoras - Percentual de Uso da Carteira Mais Frequente (\% sobre Valor da Posição Acionária) ........................................................... 81

Tabela 17 - Testes de Igualdade - Betas Médios dos Fundos .............................................. 84

Tabela 18 - Estatísticas Descritivas - Taxas de Administração Máximas (5 Maiores

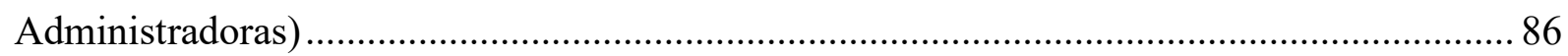

Tabela 19 - Testes de Igualdade - Média das Taxas de Administração Máximas.................. 88

Tabela 20 - Testes de Igualdade - Média do Percentual do Patrimônio do Fundo Investido em

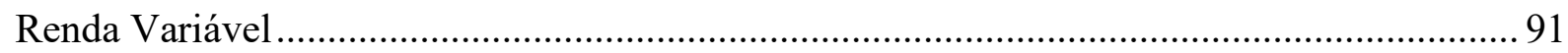

Tabela 21 - Testes de Igualdade - Retorno Anual dos Fundos............................................. 93

Tabela 22 - Comparação do Fator de Retorno Médio Acumulado - Fundos PGBL/VGBL com Renda Variável

Tabela 23 - Média do Retorno Médio Anual Ajustado ao Risco - Fundos PGBL/VGBL com

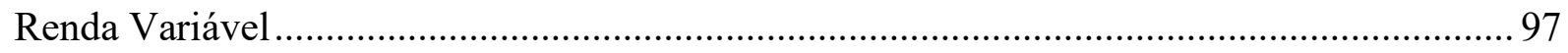

Tabela 24 - Teste de Igualdade - Retorno Médio Ajustado ao Risco..................................... 98

Tabela 25 - Teste de Igualdade - Retorno Médio Ajustado ao Risco (Itaú Unibanco SA e Bradesco) 
Tabela 26- Percentual do Patrimônio Investido em Renda Variável por Classificação Anbima 101

Tabela 27 - Resultados Regressão Multinível - Modelo Nulo ............................................ 110

Tabela 28 - Resultados Regressão Multinível - Modelo Empírico........................................ 111

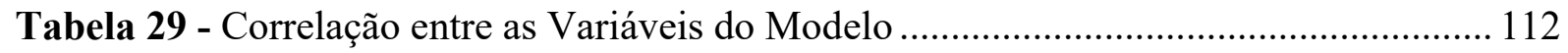

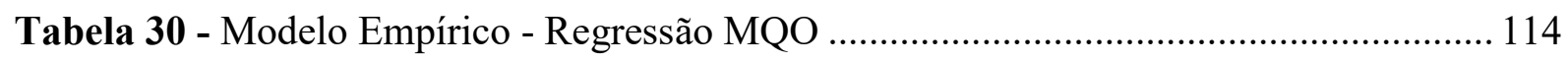




\section{LISTA DE GRÁFICOS}

Gráfico 1 - Percentual da população com 65 ou mais anos (1965 e 2015)

Gráfico 2 - Evolução das Captações Líquidas do Fundos PGBL/VGBL com Renda Variável

Gráfico 3 - Captações Líquidas Todas as Modalidades de Fundos Abertos de Previdência .. 67

Gráfico 4 - Fator de rentabilidade acumulada SELIC x Ibovespa - Base: 31/12/2006 = 1 ... 68

Gráfico 5 - Quantidade de Ações Distintas Mais Frequentes - Fundos PGBL/VGBL x

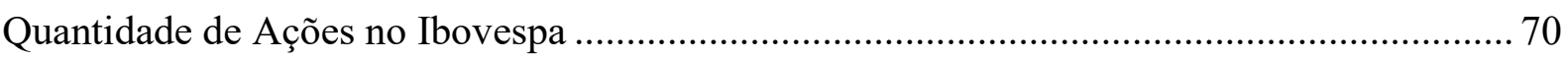

Gráfico 6 - Participação da Ação Petrobrás PN (PETR4) na Carteira Consolidada dos Fundos

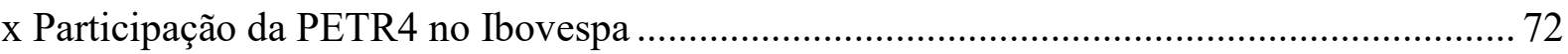

Gráfico 7- Retornos Médios de Todos os Fundos PGBL/VGBL com RV x SELIC x Ibovespa

74

Gráfico 8 - Comparação entre os Retornos Médios Anuais (Todos os Fundos x Fundos das 5 Maiores Administradoras) .75

Gráfico 9 - Comparação entre os Retornos Médios Anuais (Todas as Administradoras x 5 Maiores Administradoras x Carteiras Iguais ou Semelhantes das 5 Maiores Administradoras)

Gráfico 10 - Beta Médio das Carteiras dos Fundos PGBL/VGBL com Renda Variável (5 Maiores Administradoras)

Gráfico 11 - Percentual Médio de Renda Variável - Carteiras Iguais ou Semelhantes - Fundos PGBL/VGBL

Gráfico 12 - Percentual Médio de Renda Variável dos Fundos PGBL/VGBL- 5 Maiores Administradoras

Gráfico 13 - Retorno Médio Anual dos Fundos PGBL/VGBL com Renda Variável (5 Maiores Administradoras)

Gráfico 14 - Eficácia do Modelo Empírico (Todos os Fundos) ............................................. 115

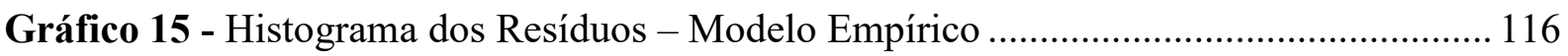

Gráfico 16 - Eficácia do Modelo Empírico (Bradesco) .......................................................... 117

Gráfico 17 - Eficácia do Modelo Empírico (BB Dvtm S.A) ................................................ 117

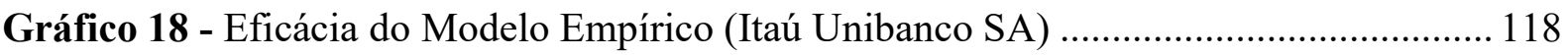

Gráfico 19 - Eficácia do Modelo Empírico (Caixa) ............................................................. 118

Gráfico 20 - Eficácia do Modelo Empírico (Banco Santander (Brasil) SA).......................... 119

Gráfico 21 - Eficácia do Modelo Empírico - Retornos Médios (Todos os Fundos)............. 119

Gráfico 22 - Eficácia do Modelo Empírico - Retornos Médios (5 Maiores Administradoras)

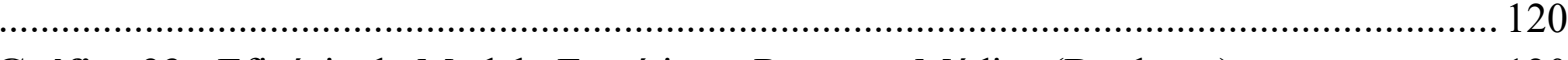

Gráfico 23 - Eficácia do Modelo Empírico - Retornos Médios (Bradesco) .......................... 120

Gráfico 24 - Eficácia do Modelo Empírico - Retornos Médios (BB Dtvm S.A) ................. 121

Gráfico 25 - Eficácia do Modelo Empírico - Retornos Médios (Itaú Unibanco SA) ........... 121

Gráfico 26 - Eficácia do Modelo Empírico - Retornos Médios (Caixa)............................... 122

Gráfico 27 - Eficácia do Modelo Empírico - Retornos Médios (Banco Santander (Brasil) SA) 


\section{LISTA DE FIGURAS}

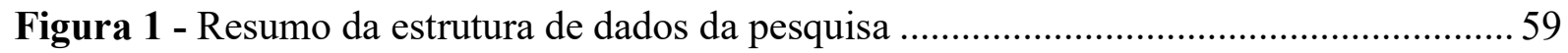

Figura 2 - Esquema de agregação dos objetos de pesquisa em níveis (Raudenbush e Bryk, 2002). 


\section{INTRODUÇÃO}

\subsection{Contextualização}

O efeito do envelhecimento da população sobre as contas públicas de vários países tem sido objeto de preocupação de acadêmicos, analistas, agentes públicos e privados, em todo o mundo. Tal mudança demográfica, resultado da combinação de baixas taxas de natalidade e do aumento da expectativa de vida da população, sinaliza um horizonte de potencial e contínua elevação dos gastos públicos, em especial nas áreas de saúde e previdência social, aumentando os riscos de solvência dos sistemas atuais de financiamento e de oferta de serviços públicos.

Em alguns países emergentes, a velocidade de crescimento relativo da parcela de indivíduos com idade igual ou superior a sessenta e cinco anos sobre a população total é alarmante, quando comparada a determinados países desenvolvidos. Na França, por exemplo, foram necessários aproximadamente cento e vinte anos, entre 1860 e 1980, para a população de idosos sair de 7\% para 14\% de sua população total. Na Suécia, esse caminho levou cerca de oitenta anos, entre 1890 e 1970. Nos Estados Unidos, foram consumidos sessenta anos, entre 1950 e 2010, aproximadamente. No entanto, estimativas apontam que países como China, Tailândia e Brasil não precisarão nem mesmo de trinta anos para realizarem esse percurso. No Brasil, a população de idosos representava, em 2010, cerca de 7\% de sua população total. Estima-se que esse percentual dobre até 2030 (KINSELLA \& HE, 2009).

Dados do World Bank (2017) expressam a aceleração do envelhecimento da população mundial, como mostra o Gráfico 1, a seguir: 


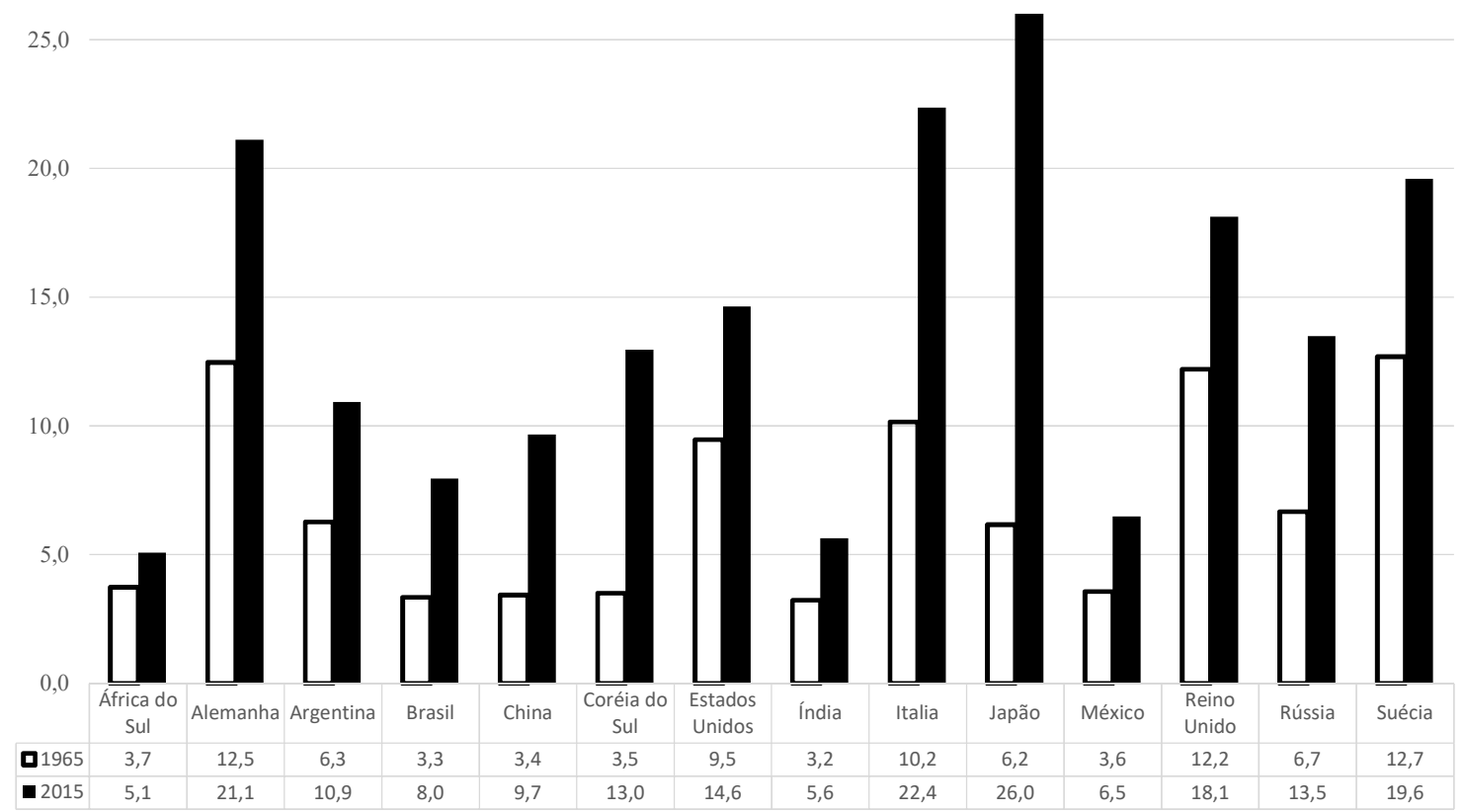

Gráfico 1 - Percentual da população com 65 ou mais anos (1965 e 2015)

Fonte: World Bank-DataBank

Elaborado pelo autor

Entre 1965 e 2015, o percentual da população total com idade igual ou superior a 65 anos (65+), no Brasil, foi multiplicado por 2,4 (de 3,3\% para 8,0\%). Na China, no mesmo período, o fator de multiplicação foi de aproximadamente 2,9 vezes. Rússia, 2,0 vezes. Coréia do Sul, 3,7 vezes. Enquanto que nos Estados Unidos, Reino Unido e Suécia esse fator ficou ao redor de 1,5 vezes. Japão (4,2 vezes); Itália (2,2 vezes); México (1,8 vezes); Alemanha e Argentina (1,7 vezes, aproximadamente) e África do Sul (1,4 vezes) completam o quadro de países apresentados no gráfico anterior.

Já quando se observa a evolução mais recente - de 2005 a 2015 - o Brasil, entre os países analisados no gráfico anterior, apresentou o segundo maior índice de crescimento do percentual da população com 65 ou mais anos - calculado pela divisão do percentual de 2015 pelo percentual de 2005 - ficando atrás apenas da Coréia do Sul, conforme mostra a Tabela 1, a seguir: 
Tabela 1 - Índice de crescimento do percentual da população de 65 ou mais anos (entre 2005 e 2015)

\begin{tabular}{lccc}
\hline \multicolumn{1}{c}{ País es } & $\mathbf{2 0 0 5}$ & $\mathbf{2 0 1 5}$ & Índice de Crescimento \\
\hline Coréia do Sul & 8,9 & 13,0 & 1,46 \\
Brasil & 5,9 & 8,0 & 1,35 \\
Japão & 19,7 & 26,0 & 1,32 \\
China & 7,7 & 9,7 & 1,26 \\
México & 5,4 & 6,5 & 1,21 \\
Estados Unidos & 12,3 & 14,6 & 1,19 \\
Índia & 4,8 & 5,6 & 1,18 \\
África do Sul & 4,3 & 5,1 & 1,17 \\
Itália & 19,5 & 22,4 & 1,14 \\
Suécia & 17,3 & 19,6 & 1,13 \\
Reino Unido & 16,0 & 18,1 & 1,13 \\
Alemanha & 18,9 & 21,1 & 1,12 \\
Argentina & 10,1 & 10,9 & 1,08 \\
Rússia & 13,8 & 13,5 & 0,98 \\
\hline Fonte: World Bank/ DataBank & \\
Tabela elaborada pelo autor &
\end{tabular}

Nesse contexto de rápida mudança demográfica e de pertinentes dúvidas e questionamentos sobre a sustentabilidade do sistema público previdenciário, observa-se, no Brasil, crescentes discussões sobre a necessidade de se reformar os sistemas de aposentadoria no país. Em meio a muitas discussões nesse sentido, nas últimas décadas, tem-se observado o crescimento consistente da demanda por planos privados de aposentadoria complementar, cuja adesão é aberta ao público em geral, em especial, por meio de fundos geridos, em maior proporção, por grandes bancos de varejo e seguradoras, como mais adiante será apresentado.

Instituídas pela Lei $\mathrm{n}^{\circ}$ 6.435, de 15 de julho de 1977, como parte integrante do sistema de previdência brasileiro, entidades privadas obtiveram competência para criar planos de aposentadoria complementar aos regimes públicos previdenciários oferecidos. A criação desse tipo de plano, cuja adesão dos seus participantes ocorre de forma voluntária, estabeleceu instrumento alternativo de poupança de longo prazo com o propósito de garantir complementação de renda previdenciária aos seus participantes.

As entidades privadas de previdência complementar são classificadas pela legislação em entidades fechadas e abertas. As Entidades Fechadas de Previdência Complementar - EFPC são instituições sem fins lucrativos, organizadas como sociedades civis ou fundações, autorizadas a oferecer e administrar planos de previdência complementar a funcionários de uma ou mais empresas, ou a grupos formados por sindicados ou por associações profissionais. Já as 
Entidades Abertas de Previdência Complementar - EAPC - são instituições com fins lucrativos, organizadas como sociedades anônimas, autorizadas a oferecer a indivíduos e empresas planos privados de previdência complementar.

Segundo dados da Superintendência de Seguros Privados (SUSEP, 2017) - autarquia federal, vinculada ao Ministério da Fazenda, responsável pela supervisão das empresas de seguros gerais, previdência privada e vida, saúde suplementar e capitalização, as contribuições feitas, em 2016, no Brasil, por titulares dos planos abertos de previdência complementar, totalizaram R\$ 117,5 bilhões, representando um aumento de 18,7\% sobre o que foi registrado em 2015 . Nos últimos anos, conforme apresentado na Tabela 2, a seguir, o total de contribuições tem crescido consistentemente e de forma relevante. Em 2003, as contribuições representavam cerca de $0,5 \%$ do Produto Interno Bruto (PIB) brasileiro. Em 2016, representaram aproximadamente $0,9 \%$.

Tabela 2 - Evolução das Captações Brutas Anuais dos Planos Abertos de Previdência Complementar

\begin{tabular}{lccc}
\hline Ano & $\begin{array}{c}\text { Receitas } \\
\text { (em R\$ Bilhões) }\end{array}$ & $\begin{array}{c}\text { Variação } \\
\text { Anual }\end{array}$ & \% PIB \\
\hline 2003 & 14,9 & - & $0,4 \%$ \\
\hline 2004 & 18,6 & $25,2 \%$ & $0,5 \%$ \\
\hline 2005 & 19,5 & $4,7 \%$ & $0,4 \%$ \\
\hline 2006 & 22,6 & $16,0 \%$ & $0,5 \%$ \\
\hline 2007 & 28,1 & $24,4 \%$ & $0,5 \%$ \\
\hline 2008 & 31,8 & $13,2 \%$ & $0,5 \%$ \\
\hline 2009 & 38,7 & $21,6 \%$ & $0,6 \%$ \\
\hline 2010 & 46,1 & $19,1 \%$ & $0,6 \%$ \\
\hline 2011 & 53,7 & $16,6 \%$ & $0,6 \%$ \\
\hline 2012 & 70,6 & $31,4 \%$ & $0,7 \%$ \\
\hline 2013 & 74,0 & $4,7 \%$ & $0,7 \%$ \\
\hline 2014 & 83,7 & $13,2 \%$ & $0,7 \%$ \\
\hline 2015 & 99,0 & $18,3 \%$ & $0,8 \%$ \\
\hline 2016 & 117,5 & $18,7 \%$ & $0,9 \%$ \\
\hline Fonte: SUSEP & & \\
\hline Tabela elaborada pelo autor & & \\
\hline
\end{tabular}

De acordo com a Federação Nacional de Previdência Privada e Vida (FENAPREVI, 2017), ao final de 2016, existiam no Brasil cerca de 13 milhões de indivíduos que possuíam planos privados de previdência complementar aberta, sendo que aproximadamente $3 / 4$ (três quartos) desse total são de participantes de planos individuais e o restante de planos empresariais ou de associações. Das contribuições realizadas em 2016, cerca de $92 \%$ do total foram destinadas à 
modalidade Vida Gerador de Benefícios Livres - VGBL - indicada para quem não tem como se beneficiar da dedutibilidade prevista na legislação do Imposto de Renda Pessoa Física (I.R.P.F) ou, ainda, para quem busca um produto com características de um seguro de vida. Cerca de 7\% das contribuições de 2016 foram direcionadas à modalidade Plano Gerador de Benefícios Livres - PGBL - recomendada para quem tem como se beneficiar da dedutibilidade prevista na legislação do I.R.P.F. O restante, pouco relevante, foi destinado a outras modalidades.

\subsection{Situação Problema}

Além da disciplina e do sacrifício para formação de poupança individual, que ocorre por meio da realização de aportes financeiros ao longo do período de contribuição, a geração de riqueza dos cotista/segurados de fundos abertos privados de previdência depende da capacidade do gestor/administrador do fundo investido em alocar adequadamente os recursos a ele confiados, auferindo retornos que se acumulam para a produção de maior, ou menor, nível de fluxos de caixa a ser resgatado pelo cotista/beneficiário, no futuro, no período de obtenção dos benefícios.

Como contraprestação aos serviços profissionais de gestão de recursos realizados a terceiros, instituições gestoras cobram desses uma taxa de administração, entre outras cobranças que podem ser realizadas. Apesar de não existir uma promessa ou garantia de retorno mínimo, assume-se tacitamente, então, nessa relação, que a entidade gestora, por motivos de capacitação e economia de escala, é capaz de produzir retornos, descontadas as taxas cobradas e ajustados ao nível de risco previamente combinado com o investidor, que sejam minimamente iguais ao que o investidor obteria se ele próprio resolvesse administrar seus investimentos para aposentadoria. Além disso, como mais adiante será detalhado, foram criados, no Brasil, mecanismos legais e tributários para incentivar e facilitar essa forma de acumulação de poupança de longo prazo para as pessoas.

Ao administrarem recursos de terceiros com o propósito de garantir renda futura aos seus cotistas/segurados, fundos abertos de previdência complementar deveriam zelar pela adequada assunção de riscos nos investimentos que realizam. De forma geral, a maior parte das 
contribuições realizadas pelos participantes desses fundos, por força dos respectivos regulamentos a que estão submetidos, é aplicada em ativos de baixo risco, em especial, em títulos públicos de renda fixa. No entanto, existem planos que preveem em seu regulamento a possibilidade de aplicação de parcela, ou da totalidade, das contribuições líquidas dos cotistas em ativos de renda variável, como ações de empresas ou ainda em cotas de outros fundos que, por ventura, mantenham posições acionárias em sua carteira de investimentos. Por sua vez, os investimentos em ações, ou em fundos que mantenham ações, feitos por esses fundos também estão sujeitos a restrições normativas e regulamentares no sentido de mitigar riscos aos seus cotistas/segurados. Muitas dessas restrições estão ligadas às características do ativo investido, como, por exemplo, ao atendimento a certos padrões de governança corporativa ou a sua presença em determinado índice acionário de referência no mercado, tal qual o Índice Bovespa, o Ibovespa.

Some-se ao até aqui exposto, como já abordado, o forte questionamento sobre a sustentabilidade do atual sistema público de previdência social, objeto de intenso debate na sociedade brasileira, com proposta de reforma que estava pronta para ser votada pelo Congresso Nacional, época de depósito desta tese, e ver-se-á à frente o grande potencial de crescimento desse mercado de fundos abertos privados de previdência complementar, que como visto, tem crescido, há mais de uma década, pelo menos, muito acima da evolução do Produto Interno Bruto do país, a taxas que consistentemente ultrapassam os dois dígitos.

Um elemento adicional de potencialização da relevância do objeto de estudo desta pesquisa pode se dar pela possível queda da taxa básica de juros reais da economia brasileira. Como exercício de pensamento, poder-se-ia imaginar que, em algum ponto no futuro, haja convergência da taxa básica de juros real da economia brasileira para patamar compatível ao de outras economias de porte e condições de riscos similares. Na ocorrência desse cenário, na perspectiva de se buscar maiores retornos, a procura por investimentos mais arriscados pode crescer, com especial efeito sobre os fundos abertos de previdência complementar que realizem investimentos, ao menos de parte do seu patrimônio, em renda variável.

Pela relevância do assunto, pesquisadores no Brasil e no mundo têm se debruçado a entender, entre outras coisas, o efetivo valor dos serviços prestados pelas administradoras/gestores de 
fundos (AMARAL, 2013; BRITO, 2016; DOELLMAN \& SARDARLI, 2016; CREMERS, FERREIRA, MATOS \& STARKS; 2016).

Brito (2016) apresentou elementos que indicam que as principais administradoras do mercado brasileiro cobravam taxas de administração mais elevadas para gerir fundos de previdência complementar PGBL/VGBL compostos, com investimentos em renda fixa e renda variável, do que as taxas cobradas para a gestão de fundos abertos de previdência complementar com investimentos somente em ativos de renda fixa. Destacou que a grande maioria dos fundos abertos de previdência compostos apresentou retornos que refletiam o puro acompanhamento, na proporção da alocação do seu patrimônio, da valorização de uma carteira conservadora de ativos de renda fixa e de um índice acionário, como o Ibovespa, indicando uma postura passiva na gestão dos fundos, o que não justificaria, portanto, a cobrança de taxas de administração mais altas, o que Campani e Brito (2018) denominam, conforme expresso em parte do título de seu artigo, como "passividade a preços de fundos ativos".

Amaral (2013) comparou os retornos ajustados ao risco dos fundos abertos de previdência, com investimentos exclusivos em ativos de renda fixa, em relação aos fundos tradicionais de renda fixa, entre janeiro de 2005 e dezembro de 2011, demonstrando que os fundos abertos de previdência tiveram desempenho estatisticamente inferior ao desempenho dos fundos tradicionais, apesar dos benefícios fiscais a que estão submetidos.

A relação entre taxas de administração cobradas e os retornos alcançados, além da investigação sobre outros problemas de agência surgidos na relação entre o gestor e o cotista/segurado, tem sido estudada, amiúde, por acadêmicos do mundo todo, como será visto no próximo capítulo.

Até onde o autor desta tese pode averiguar, nenhum trabalho publicado no Brasil se dedicou a investigar, em detalhe, a composição exata das carteiras acionárias investidas pelos fundos PGBL/VGBL. Quais seriam ações escolhidas pelos fundos? Em quais proporções? Há diferenças entre as carteiras acionárias mantidas, direta e indiretamente, pelas principais administradoras do país ou será que todas seguem o mesmo índice, o Ibovespa, por exemplo?

Sabe-se ainda que é prática na gestão de fundos das principais administradoras o uso de fundos espelhos. Tais fundos são criados para receber investimentos de outros fundos (FICFI - Fundos 
de Investimento em Cotas de Fundos de Investimento), replicando a composição do portfólio de investimento entre diversos fundos mantidos pela administradora.

Também é conhecido, por meio de trabalhos acadêmicos publicados, examinados no próximo capítulo, que a taxa de administração não está associada ao retorno de um fundo, dado que as taxas são cobradas no Brasil mais em função dos volumes investidos pelo cotista/segurado do que pela complexidade ou esforço para se obter maiores desempenhos.

\subsection{Objetivos da Pesquisa}

Pelo exposto nas seções anteriores, este trabalho se propõe a investigar as características do mercado de fundos abertos de previdência complementar, nas suas modalidades mais frequentes e representativas - VGBL/PGBL, que tenham mantido parcela de seu patrimônio em investimentos de renda variável. O Quadro 1, a seguir, explicita e concatena o objetivo principal aos objetivos secundários desta tese:

Quadro 1 - Objetivos Principal e Secundários

Objetivo principal: Desenvolver modelo de estimativa do retorno anual dos fundos PGBL/VGBL com investimentos em renda variável, entre 2007 e 2015, em função de variáveis que discriminam as estratégias executadas pelas administradoras de fundos.

\begin{tabular}{|c|c|c|c|c|}
\hline \multicolumn{5}{|c|}{ Objetivos secundários: Discriminar as estratégias sob controle do gestor } \\
\hline $\begin{array}{l}\text { 1. Analisar as } \\
\text { composições das carteiras } \\
\text { acionárias dos fundos } \\
\text { PGBL/VGBL das } \\
\text { principais administradoras } \\
\text { de fundos do país. }\end{array}$ & $\begin{array}{l}\text { 2. Verificar se existe } \\
\text { diferença entre o } \\
\text { percentual de alocação do } \\
\text { patrimônio em renda } \\
\text { variável entre os fundos } \\
\text { PGBL/VGBL com } \\
\text { investimentos em renda } \\
\text { variável administrados } \\
\text { pelas principais } \\
\text { administradoras de fundos } \\
\text { do país. }\end{array}$ & $\begin{array}{l}\text { 3. Verificar se existe } \\
\text { diferença entre o beta } \\
\text { médio das carteiras } \\
\text { acionárias dos fundos } \\
\text { PGBL/VGBL com } \\
\text { investimentos em renda } \\
\text { variável administrados } \\
\text { pelas principais } \\
\text { administradoras de fundos } \\
\text { do país. }\end{array}$ & $\begin{array}{l}\text { 4. Verificar se existe } \\
\text { diferença entre as taxas de } \\
\text { administração máximas } \\
\text { cobradas pelos fundos } \\
\text { PGBL/VGBL com } \\
\text { investimentos em renda } \\
\text { variável administrados } \\
\text { pelas principais } \\
\text { administradoras de fundos } \\
\text { do país. }\end{array}$ & $\begin{array}{l}\text { 5. Verificar se existe } \\
\text { diferença entre o retorno } \\
\text { médio anual dos fundos } \\
\text { PGBL/VGBL com } \\
\text { investimentos em renda } \\
\text { variável administrados } \\
\text { pelas principais } \\
\text { administradoras de fundos } \\
\text { do país. }\end{array}$ \\
\hline
\end{tabular}

Quadro elaborado pelo autor

As questões derivadas dos objetivos desta pesquisa são:

- Quão parecidas são as composições acionárias de fundos PGBL/VGBL pertencentes a uma mesma administradora de fundos? 
- Os percentuais médios, em relação ao patrimônio, investidos em renda variável pelos fundos PGBL/VGBL das principais administradoras do país são estatisticamente iguais?

- Os betas médios das carteiras dos fundos PGBL/VGBL com investimentos em renda variável, pertencentes às principais administradoras de fundos do país, são estatisticamente iguais?

- Os retornos anuais dos fundos PGBL/VGBL com investimentos em renda variável das principais administradoras de fundos do país são estatisticamente iguais?

- As taxas de administração dos fundos PGBL/VGBL com investimentos em renda variável das principais administradoras de fundos do país são iguais entre si?

- É possível especificar um modelo empírico para explicar parte relevante dos retornos auferidos pelos PGBL/VGBL com investimentos em renda variável?

- Por fim, os retornos médios anuais ajustados ao risco de fundos PGBL/VGBL com investimentos em renda variável, pertencentes às principais administradoras de fundos do país, são estatisticamente iguais?

\subsection{Metodologia}

Marconi e Lakatos (2010, p. 65) definem método como "[...] conjunto das atividades sistemáticas e racionais que, com maior segurança e economia, permite alcançar o objetivo conhecimentos válidos e verdadeiros, traçando o caminho a ser seguido [...]”. Nesse sentido, serão detalhadas, em capítulo específico, as etapas realizadas para se atingir o objetivo proposto neste trabalho, incluindo a coleta e as características dos dados utilizados, bem como os procedimentos de análise que culminarão nos resultados apresentados.

Dentro das classificações descritas por Gil (2008), esta pesquisa pode ser considerada exploratória, dado que investiga profundamente o objeto definido, suscitando a formulação de hipóteses e/ou identificação de padrões. Ao mesmo tempo, este estudo também pode ser caracterizado como uma pesquisa explicativa, dado que se propõe a formular modelo que explique de forma geral os retornos anuais dos fundos analisados.

Para cumprir o seu objetivo, este trabalho adotou enfoque eminentemente quantitativo, com procedimentos estatísticos que combinam o desenvolvimento, elaborado pelo autor desta tese, de sequência particular de atividades e análises, a referências externas de outros trabalhos, 
especialmente no que tange à técnica de regressão utilizada - regressão multinível com dados em painel, tal como descrito por Raudenbush e Bryk (2002), Santos (2013) e Fávero e Belfiore (2017).

No entanto, apesar do enfoque quantitativo desta pesquisa, cabe salientar que foi impossível, por maior que tenha sido o esforço aqui empregado, descrever os fenômenos com total imparcialidade, pois infelizmente não se pode eliminar completamente a subjetividade presente em julgamentos em ciências sociais (GRINNELL; UNRAU, 2010).

\subsection{Pressupostos da Pesquisa}

Este trabalho assumiu um conjunto de pressupostos, a seguir apresentado:

1. A parcela do patrimônio dos fundos PGBL/VGBL não investida em renda variável foi alocada em títulos de renda fixa atrelados à variação da taxa do Sistema Especial de Liquidação e Custódia - SELIC, considerada a taxa livre de risco da economia brasileira, como explicado no capítulo 2.

2. As variáveis utilizadas na especificação do modelo empírico de estimação dos retornos anuais referem-se sempre aos valores relativos ao final de cada ano. De sorte que foi assumido que as mudanças nos valores das variáveis discriminadoras das estratégias dos fundos, entre o início e o fim do ano, tiveram pouca influência nos resultados apresentados.

3. As taxas de administração utilizadas foram as taxas máximas extraídas da base de dados da Economática ${ }^{\circledR}$ e servem como proxy da taxa de administração média efetivamente cobrada dos cotistas.

Evidentemente, esses pressupostos estão no cerne das propostas de melhoria que serão apresentadas no capítulo dedicado às conclusões desta pesquisa. No entanto, o sentido das descobertas, na maior parte dos casos, tende a permanecer válido. Testes com variáveis defasadas, por exemplo, foram realizados, apesar de não apresentados, e apresentaram menor aderência na explicação dos retornos dos fundos. 


\subsection{Contribuições do Trabalho que Justificam a Tese}

Como já dito, até onde o autor desta tese conseguiu verificar, este é o primeiro trabalho no Brasil que explicita a composição acionária das carteiras de renda variável dos fundos PGBL/VGBL, mesmo quando o investimento do fundo tenha sido realizado em cotas de outro fundo, que por ventura tenha mantido investimento em ações em seu portfólio. Trata-se de funcionalidade relativamente recente e pouco explorada da base de dados da Economática ${ }$. Com isso, conseguiu-se identificar, pela primeira vez, o grau de similaridade entre as carteiras acionárias dos fundos das principais administradoras de fundos do país.

O conhecimento da composição exata das ações de empresas mantidas, direta ou indiretamente, pelos fundos PGBL/VGBL possibilitou o cálculo dos coeficientes beta de suas carteiras acionárias. Este é o primeiro trabalho no Brasil que apresenta essa informação para essa modalidade de fundos.

Como derivação do pressuposto de que a parte do patrimônio dos fundos não aplicada em renda variável foi aplicada em ativos livre de risco, o cálculo dos coeficientes beta dos fundos pôde ser, facilmente, realizado. De sorte que foi possível formular uma simplificação do índice de Treynor (1965) como uma forma alternativa de ordenar os retornos dos fundos com base nos riscos assumidos pelo gestor - o que adiante será melhor explicado.

A pesquisa apresentou ainda um modelo de estimativa dos retornos anuais dos fundos PGBL/VGBL que reforça as evidências apresentadas por outros pesquisadores brasileiros sobre o excessivo custo das taxas de administração cobradas no país para investimentos nessas modalidades de fundos. Tal modelo foi obtido a partir da aplicação de técnica pouco explorada em trabalhos acadêmicos no país: regressão multinível longitudinal, sendo essa mais uma contribuição desta pesquisa.

Por fim, o presente trabalho investigou parte relevante das estratégias adotadas pelas principais administradoras de fundos PGBL/VBGL com investimentos em renda variável, testando e comprovando a existência de diferenciação entre elas.

\subsection{Descrição dos Capítulos}

Este trabalho está organizado em seis capítulos, conforme descrito, a seguir.

O primeiro capítulo desta tese ofereceu ao leitor um rápido panorama sobre a questão previdenciária no Brasil e no mundo. Procurou com isso demonstrar a relevância do assunto abordado para, na sequência, formular o conjunto de objetivos da pesquisa, descrevendo rapidamente a metodologia que será utilizada. Nesse capítulo, foram declaradas ainda as premissas assumidas para a elaboração do estudo, e descritas, a juízo do autor, as principais contribuições acadêmicas do presente trabalho. 
O capítulo 2 apresenta o referencial teórico para o desenvolvimento das hipóteses de pesquisa, descrevendo sucintamente o mercado de fundos abertos de previdência complementar. Apresenta ainda alguns mecanismos e teorias para se ajustar o risco de fundos de investimento. Por fim, apresenta e discute trabalhos intrinsicamente ligados aos propósitos desta tese.

O capítulo 3 detalha os procedimentos metodológicos desenvolvidos para se atingir os objetivos de pesquisa, descrevendo a coleta de dados e os próprios dados em si, além dos procedimentos preparatórios para as análises dos resultados.

O capítulo 4 analisa os dados detalhadamente e procura endereçar e responder aos objetivos secundários definidos nesta pesquisa, testando-se as hipóteses formuladas, mais especificamente quanto às variáveis que discriminam as estratégias adotadas pelas principais administradoras de fundos.

O capítulo 5 endereça o objetivo principal desta tese, formulando e testando um modelo para se estimar os retornos anuais dos fundos PGBL/VGBL com investimentos em renda variável.

O capítulo 6 apresenta as conclusões desta pesquisa, incluindo as principais descobertas, suas limitações e propostas de melhoria para estudos futuros. 


\section{FUNDAMENTAÇÃO TÉORICA E HIPÓSTESES DA PESQUISA}

\subsection{Fundos de Previdência no Brasil}

Apesar de iniciativas esparsas, durante o século XIX, como a criação dos fundos de pensão para funcionários da Imprensa, do Ministério da Fazenda, dos Correios e da Marinha, é somente no início dos anos 20 do século XX que o sistema previdenciário público brasileiro, como hoje se conhece, começou a tomar forma. O marco histórico é a publicação do Decreto 4.682, em 24 de janeiro de 1923, conhecido com Lei Elói Chaves (BELTRÃO; LEME; MENDONÇA \& SUGAHARA, 2004). Nascido na cidade de Pindamonhangaba, interior do estado de São Paulo, Elói Chaves foi empresário, banqueiro, proprietário rural e político brasileiro, com negócios concentrados na região de Jundiaí, também no estado de São Paulo.

Tal decreto foi resultado da transformação da economia brasileira, em especial do avanço de sua industrialização entre o final do século XIX e início do século XX, endereçando preocupação social crescente quanto à garantia de renda para o indivíduo no momento de perda de sua capacidade de gerar riqueza com o próprio trabalho.

Entre a Lei Elói Chaves e os dias atuais, o sistema público de previdência social passou por diversas mudanças estruturais, com a criação e consolidação de dois regimes públicos próprios e obrigatórios: um dedicado aos trabalhadores do setor privado, que é o Regime Geral de Previdência Social - RGPS - ordenado pela lei $n^{0}$ 8.213, de 24 de julho de 1991 e suas alterações, e o outro vinculado aos servidores públicos, que é o Regime Próprio de Previdência Social - RPPS, conforme determina o artigo 40 da Constituição Federal e suas alterações.

O financiamento do RGPS se dá pelo sistema de repartição simples, em regime de caixa, no qual os empregados que estão na ativa realizam contribuições que são usadas para garantir os pagamentos aos inativos. Nesse regime, os benefícios são definidos (BD). Os inativos/beneficiários recebem renda mensal que varia dentro de uma faixa estipulada pelo Instituto Nacional do Seguro Social - INSS - que, em 02/01/2018, tinha mínimo de R\$ 954,00 e teto de $\mathrm{R} \$ 5.645,80$. 
O financiamento e as regras de aposentadoria do RPPS sofreram, nas últimas décadas, diversas mudanças introduzidas por meio de promulgações de emendas constitucionais, em especial a partir de 1998. Assim, o RPPS abriga beneficiários e potenciais beneficiários sob distintas regras. Até a edição da Emenda Constitucional no 20/1998, por exemplo, não se exigia permanência mínima no serviço e cargo públicos para aposentadoria no RPPS, de modo que existiam casos de pessoas que passavam a maior parte de seu período laboral sob o RGPS, migrando para o serviço público um pouco antes de atingir o tempo mínimo de contribuição para se aposentar - podendo assim obter a aposentadoria sob as regras do RPPS, que incluía o direito a receber a remuneração integral do último cargo ocupado, inclusive com paridade ao salário recebido pelos servidores da ativa. A Emenda Constitucional $n^{0} 41 / 2003$ alterou o cálculo do benefício concedido em função de contribuições realizadas, limitando parcialmente, ao menos, o crescimento do déficit do RPPS. A Emeda Constitucional n ${ }^{\circ} 47 / 2005$ introduziu o conceito de solidariedade ao sistema de financiamento - a partir dessa emenda, inativos do RPPS que recebem acima do teto do INSS também foram obrigados a realizar contribuições para o regime.

Seja como for, as mudanças demográficas apresentadas no capítulo de introdução deste trabalho colocam em xeque essa forma de financiamento. Como já dito, gastos crescentes com previdência nos orçamentos de todos os entes federativos - União, Estados e Municípios limitam a capacidade dos governos de prover serviços públicos e realizar investimentos. Segundo o Ministério da Fazenda, somente, em 2017, o déficit dos dois regimes de previdência, geral e próprio, ficou em $\mathrm{R} \$ 268,8$ bilhões, algo em torno de 4,1\% do Produto Interno Bruto (PIB) do Brasil. Em 2017, com dados acumulados até setembro, os gastos da União com benefícios a aposentados consumiram mais de $13 \%$ do PIB e representaram sozinhos cerca de $53 \%$ dos gastos primários federais, lembrando apenas que nos gastos primários não são incluídas as despesas com a dívida pública que representaram mais de um terço dos gastos públicos federais totais, no período.

Tal problema não é exclusivo ao Brasil e tampouco é novo. Há décadas muito países enfrentam o desafio de reformar seus sistemas de financiamento previdenciário público, incluindo, como feito no Chile em 1981, a migração do modelo de pagamento de benefícios baseado exclusivamente em benefícios previamente definidos (BD) para modelo cujo benefício futuro 
do participante esteja vinculado ao sucesso da capitalização, em contas individuais ou coletivas, dos aportes realizados ao sistema. Ou seja, nesse modelo as contribuições são definidas (CD), enquanto os benefícios são dependentes da capacidade de gestão dos recursos que são aportados no sistema. Portanto, no modelo de contribuições definidas, teoricamente, não existiria a possibilidade de haver déficit, como é possível no modelo de benefícios definidos. Por outro lado, o modelo de contribuições definidas demanda, ou deveria demandar, a adoção de maior nível de governança e regulação para mitigação dos latentes e potencialmente devastadores riscos ligados aos conflitos de agência inerentes ao modelo. No Chile, por exemplo, após quase quatro décadas da adoção de modelo pioneiro no mundo, baseado em contribuições definidas, movimentos contrários ao sistema têm ganhado força. Segundo matéria do Jornal El País, publicada em 18/02/2017, os protestos nas ruas têm reunido dezenas de milhares de pessoas que se opõem às Administradoras de Fundos de Pensão - AFP. Segundo o jornal, 91\% dos aposentados pelo sistema recebiam menos de R\$ 760 (235 dólares) por mês e os valores representam, na maioria dos casos, ao redor de 34\% da média das remunerações mensais recebidas nos últimos 10 anos antes do contribuinte se aposentar. Adicionalmente, matéria do Jornal O Estado de São Paulo, de 02/08/2017, destaca que o fraco desempenho dos fundos de pensão chilenos pode ser explicado pelas altas taxas de administração cobradas pelas AFP's, que segundo o jornal, corroem o rendimento dos fundos no longo prazo.

Além dos regimes previdenciários públicos, existe, no Brasil, como já mencionado no capítulo introdutório deste trabalho, o regime previdenciário complementar. Tal regime, que está sob gestão de entidades privadas, fechadas e abertas, permite a acumulação de riqueza de seus contribuintes por meio de aportes financeiros facultativos a planos de investimentos para aposentadoria, conforme o planejamento financeiro de cada indivíduo. As entidades fechadas de previdência complementar - EFPC - são reguladas pela Superintendência Nacional de Previdência Complementar - PREVIC - autarquia vinculada ao Ministério da Fazenda. Já as entidades abertas de previdência complementar - EAPC - seguem a normatização do Conselho Nacional de Seguros Privados - CNSP - e são fiscalizadas pela Superintendência de Seguros Privados - SUSEP -, autarquia vinculada ao Ministério da Fazenda.

A Tabela 3, a seguir, mostra a relevância anual da participação do total de fundos de previdência privada e dos fundos de previdência analisados neste estudo - PGBL/VGBL com investimentos em renda variável - RV - em termos de patrimônio. Observa-se que os fundos de previdência 
mais que dobraram a sua participação no mercado de fundos de investimento, no período de oito anos. Enquanto a participação dos fundos estudados, PGBL/VGBL com RV, oscilaram bastante durante o período.

Tabela 3 - Patrimônio Total dos Fundos ao Final dos Anos de 2007 a 2015

\begin{tabular}{ccccccc}
\hline Mês/Ano & $\begin{array}{c}\text { Todas os } \\
\text { Tipos } \\
\text { de Fundos }\end{array}$ & $\begin{array}{c}\text { Fundos } \\
\text { Previdência }\end{array}$ & $\begin{array}{c}\text { \% Fundos } \\
\text { Previdência } \\
\text { sobre o Total } \\
\text { (Todas os } \\
\text { Tipos) }\end{array}$ & $\begin{array}{c}\text { Fundos } \\
\text { PGBL/VGBL } \\
\text { com RV }\end{array}$ & $\begin{array}{c}\text { \% } \\
\text { PGB/VGBL } \\
\text { com RV sobre } \\
\text { Total (Fundos } \\
\text { Previdência) }\end{array}$ & $\begin{array}{c}\text { PGBL/VGBL RV sobre } \\
\text { Total (Todos } \\
\text { os Tipos) }\end{array}$ \\
\hline dezembro-07 & 1.159 .917 & 92.560 & $8,0 \%$ & 24.543 & $26,5 \%$ & $2,1 \%$ \\
\hline dezembro-08 & 1.125 .884 & 111.371 & $9,9 \%$ & 25.975 & $23,3 \%$ & $2,3 \%$ \\
\hline dezembro-09 & 1.403 .114 & 148.974 & $10,6 \%$ & 43.587 & $29,3 \%$ & $3,1 \%$ \\
\hline dezembro-10 & 1.671 .300 & 184.071 & $11,0 \%$ & 55.456 & $30,1 \%$ & $3,3 \%$ \\
\hline dezembro-11 & 1.941 .402 & 230.952 & $11,9 \%$ & 47.626 & $20,6 \%$ & $2,5 \%$ \\
\hline dezembro-12 & 2.270 .303 & 291.739 & $12,9 \%$ & 49.817 & $17,1 \%$ & $2,2 \%$ \\
\hline dezembro-13 & 2.469 .352 & 330.907 & $13,4 \%$ & 44.280 & $13,4 \%$ & $1,8 \%$ \\
\hline dezembro-14 & 2.690 .612 & 399.781 & $14,9 \%$ & 40.270 & $10,1 \%$ & $1,5 \%$ \\
\hline dezembro-15 & 2.993 .576 & 490.247 & $16,4 \%$ & 35.194 & $7,2 \%$ & $1,2 \%$ \\
\hline
\end{tabular}

Fonte: Anbima / Economática

Valores em Milhões de Reais

Tabela elaborada pelo autor

O prazo coberto pelos planos de previdência complementar compreende duas fases. Uma de capitalização das contribuições, que vai da entrada do cotista/segurado no plano até o início do pagamento dos seus benefícios. A outra fase diz respeito ao período de pagamento dos benefícios, conforme termos do contrato entre cotista/segurado e a entidade gestora do plano.

A Resolução n ${ }^{0}$ 16/05 do Conselho de Gestão de Previdência Complementar - CGPC - define que são três as modalidades permitidas de oferta de planos de previdência pelas entidades privadas de previdência complementar. São elas: Benefício Definido (BD), Contribuição Definida (CD) e Contribuição Variável (CV). De todo modo, cabe registrar, que em função dos riscos inerentes, é cada vez menos frequente a oferta de planos do tipo BD. O Quadro 2, a seguir, apresenta definições resumidas de cada modalidade: 
Quadro 2 - Modalidades de Benefícios dos Planos Privados de Previdência

\begin{tabular}{|l|l|}
\hline Benefício Definido (BD) & $\begin{array}{l}\text { O regulamento ou contrato define quanto o participante vai receber de } \\
\text { benefício após a fase de acumulação do direito. Os riscos ficam com a } \\
\text { patrocinadora ou com a seguradora. }\end{array}$ \\
\hline Contribuição Definida (CD) & $\begin{array}{l}\text { As contribuições ao fundo são estabelecidas por meio de condições } \\
\text { previamente acordadas no contrato ou regulamento do plano. Assim o } \\
\text { participante sabe quanto vai custear durante o período de diferimento. No } \\
\text { entanto, os benefícios dependem, essencialmente, da rentabilidade dos } \\
\text { investimentos realizados. No caso dos planos de previdência privada, o risco } \\
\text { fica com os participantes. }\end{array}$ \\
\hline Contribuição Variável (CV) & $\begin{array}{l}\text { As contribuições ao fundo e a sua periodicidade são definidas pelo } \\
\text { participante, nos termos do contrato ou regulamento. Assim como os planos } \\
\text { CD, os benefícios dos planos CV também dependem do sucesso da gestão } \\
\text { do fundo, sendo que os riscos também recaem sobre os participantes. }\end{array}$ \\
\hline
\end{tabular}

Quadro elaborado pelo autor

Conforme descrito no website da SUSEP (2017), os planos previdenciários possuem os tipos básicos de benefício como mostra o Quadro 3, a seguir:

Quadro 3 - Tipos de Benefícios dos Planos de Previdência Privada

\begin{tabular}{|l|l|}
\hline Renda por sobrevivência & $\begin{array}{l}\text { Renda a ser paga ao participante do plano que sobreviver ao } \\
\text { prazo de diferimento contratado, geralmente denominada de } \\
\text { aposentadoria. }\end{array}$ \\
\hline Renda por invalidez & $\begin{array}{l}\text { Renda a ser paga ao participante em decorrência de sua invalidez } \\
\text { total e permanente ocorrida durante o período de cobertura e } \\
\text { depois de cumprido o período de carência estabelecido no plano. }\end{array}$ \\
\hline Pensão por morte & $\begin{array}{l}\text { Renda a ser paga ao(s) beneficiário(s) indicado(s) na proposta de } \\
\text { inscrição em decorrência da morte do participante ocorrida } \\
\text { durante o período de cobertura e depois de cumprido o período } \\
\text { de carência estabelecido no plano. }\end{array}$ \\
\hline Pecúlio por morte & $\begin{array}{l}\text { Importância em dinheiro, pagável de uma só vez ao(s) } \\
\text { beneficiário(s) indicado(s) na proposta de inscrição, em } \\
\text { decorrência da morte do participante ocorrida durante o período } \\
\text { de cobertura e depois de cumprido o período de carência } \\
\text { estabelecido no plano. }\end{array}$ \\
\hline Pecúlio por invalidez & $\begin{array}{l}\text { Importância em dinheiro, pagável de uma só vez ao próprio } \\
\text { participante, em decorrência de sua invalidez total e permanente } \\
\text { ocorrida durante o período de cobertura e depois de cumprido o } \\
\text { período de carência estabelecido no plano. }\end{array}$ \\
\hline
\end{tabular}

Quadro elaborado pelo autor com informações da SUSEP

Nos planos oferecidos pelas EAPC, cumprida a fase de capitalização, o segurado/cotista poderá optar, conforme definido no regulamento do plano, sobre a forma que pretende receber a renda 
que foi acumulada. O Quadro 4, a seguir, apresenta as opções de resgate dos fundos, conforme descrito no website da SUSEP (2017):

Quadro 4 - Opções de Resgate dos Fundos Privados de Previdência

\begin{tabular}{|c|c|}
\hline Renda mensal vitalícia & $\begin{array}{l}\text { Consiste em uma renda paga vitalícia e exclusivamente ao participante a partir da data de } \\
\text { concessão do benefício. O benefício cessa com o falecimento do participante. }\end{array}$ \\
\hline $\begin{array}{l}\text { Renda } \\
\text { temporária }\end{array}$ & $\begin{array}{l}\text { Consiste em uma renda paga temporária e exclusivamente ao participante. O benefício cessa } \\
\text { com o falecimento do participante ou o fim da temporariedade contratada, o que ocorrer } \\
\text { primeiro. }\end{array}$ \\
\hline $\begin{array}{l}\text { Renda mensal vitalícia } \\
\text { com prazo mínimo } \\
\text { garantido }\end{array}$ & $\begin{array}{l}\text { Consiste em uma renda paga vitaliciamente ao participante a partir da data da concessão do } \\
\text { benefício, sendo garantida aos beneficiários da seguinte forma: (a) no momento da inscrição, o } \\
\text { participante escolherá um prazo mínimo de garantia que será indicado na proposta de inscrição; } \\
\text { (b) o prazo mínimo da garantia é contado a partir da data do início do recebimento do benefício } \\
\text { pelo participante; (c) se durante o período de percepção do benefício ocorrer o falecimento do } \\
\text { participante, antes de ter completado o prazo mínimo de garantia escolhido, o benefício será } \\
\text { pago aos beneficiários conforme os percentuais indicados na proposta de inscrição, pelo período } \\
\text { restante do prazo mínimo de garantia; (d) no caso de falecimento do participante, após o prazo } \\
\text { mínimo garantido escolhido, o benefício ficará automaticamente cancelado sem que seja devida } \\
\text { qualquer devolução, indenização ou compensação de qualquer espécie ou natureza aos } \\
\text { beneficiários; (e) no caso de um dos beneficiários falecer antes de ter sido completado o prazo } \\
\text { mínimo de garantia, o valor da renda será rateado entre os beneficiários remanescentes até o } \\
\text { vencimento do prazo mínimo garantido, e (f) não havendo qualquer beneficiário remanescente, } \\
\text { a renda será paga aos sucessores legítimos do participante, pelo prazo restante da garantia. }\end{array}$ \\
\hline $\begin{array}{l}\text { Renda mensal vitalícia } \\
\text { reversível ao } \\
\text { beneficiário indicado }\end{array}$ & $\begin{array}{l}\text { Consiste em uma renda paga vitaliciamente ao participante a partir da data de concessão do } \\
\text { benefício escolhida. Ocorrendo o falecimento do participante, durante a percepção desta renda, } \\
\text { o percentual do seu valor estabelecido na proposta de inscrição será revertido vitaliciamente ao } \\
\text { beneficiário indicado. Na hipótese de falecimento do beneficiário, antes do participante e durante } \\
\text { o período de percepção da renda, a reversibilidade do benefício estará extinta sem direito a } \\
\text { compensações ou devoluções dos valores pagos. No caso do beneficiário falecer, após já ter } \\
\text { iniciado o recebimento da renda, o benefício estará extinto. }\end{array}$ \\
\hline $\begin{array}{l}\text { Renda mensal vitalícia } \\
\text { reversível ao cônjuge } \\
\text { com continuidade aos } \\
\text { menores }\end{array}$ & $\begin{array}{l}\text { Consiste em uma renda paga vitaliciamente ao participante a partir da data de concessão do } \\
\text { benefício escolhida. Ocorrendo o falecimento do participante, durante a percepção desta renda, } \\
\text { o percentual do seu valor estabelecido na proposta de inscrição será revertido vitaliciamente ao } \\
\text { cônjuge e na falta deste, reversível temporariamente ao(s) menor(es) até que complete(m) a } \\
\text { idade para maioridade }(18,21 \text { ou } 24) \text { estabelecida no regulamento e conforme o percentual de } \\
\text { reversão estabelecido. }\end{array}$ \\
\hline Pagamento único & $\begin{array}{l}\text { No primeiro dia útil seguinte à data prevista para o término do período de diferimento, será } \\
\text { concedido ao participante benefício sob a forma de pagamento único, calculado com base no } \\
\text { saldo de provisão matemática de benefícios a conceder verificado ao término daquele período. }\end{array}$ \\
\hline $\begin{array}{l}\text { Renda mensal por } \\
\text { prazo certo }\end{array}$ & $\begin{array}{l}\text { Consiste em uma renda mensal a ser paga por um prazo pré-estabelecido ao } \\
\text { participante/assistido. Na proposta de inscrição, o participante indicará o prazo máximo, em } \\
\text { meses, contado a partir da data de concessão do benefício, em que será efetuado o pagamento } \\
\text { da renda. Se, durante o período de pagamento do benefício, ocorrer o falecimento do } \\
\text { participante/assistido antes da conclusão do prazo indicado, o benefício será pago ao beneficiário } \\
\text { (ou beneficiários), na proporção de rateio estabelecida, pelo período restante do prazo } \\
\text { determinado. O pagamento da renda cessará com o término do prazo estabelecido. Na hipótese } \\
\text { de um dos beneficiários falecer, a parte a ele destinada será paga aos sucessores legítimos, } \\
\text { observada a legislação vigente. Na falta de beneficiário nomeado, a renda será paga aos } \\
\text { sucessores legítimos do participante-assistido, observada a legislação vigente. Não havendo } \\
\text { beneficiário nomeado ou, ainda, em caso de falecimento de beneficiário, a renda será } \\
\text { provisionada mensalmente, durante o decorrer do restante do prazo determinado, sendo o saldo } \\
\text { corrigido pelo índice de atualização de valores previsto no regulamento do plano contratado, até } \\
\text { que identificados os sucessores legítimos a quem deverão ser pagos o saldo provisionado e, se } \\
\text { for o caso, os remanescentes pagamentos mensais. }\end{array}$ \\
\hline
\end{tabular}

Quadro elaborado pelo autor com informações da SUSEP 
Os fundos, objeto deste trabalho, PGBL - Plano Gerador de Benefício Livre e VGBL - Vida Gerador de Benefício Livre, conforme Circular SUSEP 338/07, são estruturados na forma de Fundos de Investimento Especialmente Constituídos (FIE), vinculados a sociedades seguradoras e entidades abertas de previdência complementar. Tais fundos recebem as contribuições realizadas pelos segurados/cotistas do plano, e sua administração é segregada dos demais ativos das instituições comercializadoras. São fundos que não utilizam remuneração fixa, tampouco oferecem garantia de rendimentos.

Como já observado no capítulo 1, os fundos PGBL e VGBL constituem os principais produtos de previdência privada complementar aberta ofertados no mercado brasileiro. Tais fundos são muito parecidos entre si, sendo que as principais diferenças estão ligadas a aspectos tributários e no formato dos contratos. Quanto à classe de títulos que compõem a carteira de investimentos do fundo, o cotista/segurado tem três opções a escolher, conforme Quadro 5, a seguir:

Quadro 5 - Classe dos Títulos dos Fundos de Previdência Privada

\begin{tabular}{|l|l|}
\hline Renda Fixa & $\begin{array}{l}\text { Fundos com } 100 \% \text { dos recursos estão aplicados em títulos de renda fixa, que ainda podem } \\
\text { ser subdivididos em (a) títulos públicos emitidos pelo Tesouro Nacional e/ou Banco Central } \\
\text { (Bacen), e b) créditos privados, como Certificados de Depósito Bancário (CDB) e } \\
\text { debêntures, entre outros. }\end{array}$ \\
\hline $\begin{array}{l}\text { Composto ou } \\
\text { Multimercado }\end{array}$ & Fundos com até 49\% dos recursos podem estar aplicados em renda variável. \\
\hline Acões & $\begin{array}{l}\text { Fundos com, no mínimo, 67\% da carteira em ações à vista, bônus ou recibos de } \\
\text { subscrição, certificados de depósito de ações, cotas de fundos de ações, cotas dos fundos } \\
\text { de índice de ações e Brazilian Depositary Receipts, classificados como nível I, II e III. O } \\
\text { hedge cambial da parcela de ativos no exterior, se houver, é facultativo ao gestor. }\end{array}$ \\
\hline
\end{tabular}

O PGBL é um produto de previdência complementar, constituído na forma de fundo de investimento no qual os cotistas realizam aportes mensais ou único para resgate total ou diferido, mensalmente, a partir do final do período de capitalização do fundo. Tal produto permite ao cotista a dedutibilidade na sua declaração de imposto de renda anual, quando feita na modalidade completa, limitada até $12 \%$ da renda tributável. A tributação do fundo PGBL é feita somente no resgate e tem como base de cálculo o montante resgatado, que incluí, além do principal, correção monetária e juros.

Apesar de comercialização muito menos frequente, existem outras modalidades de planos de aposentadoria da família do PGBL, conforme mostra o Quadro 6, a seguir. Vale lembrar que os fundos VGBL enquadram-se em outra categoria: a de seguros de vida - mais adiante abordada. 
Quadro 6 - Modalidades dos Fundos de Previdência - Família PGBL

\begin{tabular}{|c|c|}
\hline Planos & Definição \\
\hline $\begin{array}{l}\text { PGBL - PLANO GERADOR DE } \\
\text { BENEFÍCIO LIVRE }\end{array}$ & $\begin{array}{l}\text { O critério de remuneração da provisão matemática de benefícios } \\
\text { a conceder é a rentabilidade da carteira de investimentos do FIE } \\
\text { instituído para o plano. O Plano PGBL poderá ter sua carteira de } \\
\text { investimentos estruturada sob as seguintes modalidades: } \\
\text { Soberano (títulos do governo), Renda Fixa ou Composto (até } \\
49 \% \text { em Renda Variável). }\end{array}$ \\
\hline $\begin{array}{l}\text { PRGP - PLANO COM } \\
\text { REMUNERAÇÃO GARANTIDA E } \\
\text { PERFORMANCE }\end{array}$ & $\begin{array}{l}\text { Garante remuneração por taxa de juros efetiva anual e índice de } \\
\text { atualização de valores, conforme regulamento. Durante o período } \\
\text { de diferimento, haverá apuração de resultados financeiros. O } \\
\text { percentual de reversão de resultados financeiros estará previsto } \\
\text { no regulamento. A apuração de resultados financeiros à época de } \\
\text { concessão do benefício é facultativa, podendo ser utilizado o } \\
\text { mesmo FIE do período de diferimento. }\end{array}$ \\
\hline $\begin{array}{l}\text { PAGP - PLANO COM } \\
\text { ATUALIZAÇÃO GARANTIDA E } \\
\text { PERFORMANCE }\end{array}$ & $\begin{array}{l}\text { Garante remuneração por índice de atualização de valores, } \\
\text { conforme regulamento. Durante o período de diferimento, haverá } \\
\text { apuração de resultados financeiros. O percentual de reversão de } \\
\text { resultados financeiros estará previsto em regulamento. A } \\
\text { apuração de resultados financeiros à época de concessão do } \\
\text { benefício é facultativa, podendo ser utilizado o mesmo FIE do } \\
\text { período de diferimento. }\end{array}$ \\
\hline $\begin{array}{l}\text { PRSA - PLANO COM } \\
\text { REMUNERAÇÃO GARANTIDA E } \\
\text { PERFORMANCE SEM } \\
\text { ATUALIZAÇÃO }\end{array}$ & $\begin{array}{l}\text { Garante remuneração por taxa de juros nominal anual, conforme } \\
\text { regulamento. Durante o período de diferimento, haverá apuração } \\
\text { de resultados financeiros. O percentual de reversão de resultados } \\
\text { financeiros estará previsto em regulamento e não poderá ser } \\
\text { inferior a } 95 \% \text {. A apuração de resultados financeiros à época de } \\
\text { concessão do benefício é facultativa, podendo ser utilizado o } \\
\text { mesmo FIE do período de diferimento. }\end{array}$ \\
\hline $\begin{array}{l}\text { PRI - PLANO DE RENDA } \\
\text { IMEDIATA }\end{array}$ & $\begin{array}{l}\text { O pagamento começa logo após o aporte único, sob a forma de } \\
\text { renda imediata. A apuração de resultados financeiros é } \\
\text { facultativa. O percentual de reversão de resultados financeiros } \\
\text { estará previsto em regulamento. }\end{array}$ \\
\hline
\end{tabular}

Quadro elaborado pelo autor com informações da SUSEP

A Resolução 49/2001 do CNSP regulou os planos de previdência com cobertura por sobrevivência, definindo critérios para a operação de planos com características de seguro de vida. Essa resolução permitiu a criação dos planos VGBL, produto que passou a dominar o mercado de planos abertos de previdência complementar no Brasil. O VGBL pode ser entendido como uma derivação do PGBL, que foi criado em 1997.

Diferentemente dos planos de aposentadoria PGBL, os planos VGBL têm características de seguro de vida e suas contribuições não podem ser deduzidas na declaração anual de imposto de renda de pessoas. Além da Resolução 49/2001, outras resoluções do CNSP, como a 140/2005 e a 148/2006 também ordenam essa modalidade de planos. Assim como o PGBL, o pagamento do imposto se dá somente no resgate dos benefícios, no entanto, no caso dos planos VGBL, o 
imposto incide apenas sobre o rendimento do fundo. Os fundos VGBL são recomendados, portanto, para quem realiza a declaração anual de imposto de renda em sua forma simplificada.

O VGBL é disparado, como já visto, o produto de previdência privada complementar de maior demanda no mercado, representando cerca 92\% dos aportes realizados, em 2016, nesse mercado. No entanto, existem outros planos com cobertura por sobrevivência, conforme permitido pela SUSEP (2017). O Quadro 7, a seguir, mostra os planos padrão dessa modalidade:

Quadro 7 - Planos de Previdência com Cobertura por Sobrevivência

\begin{tabular}{|c|c|}
\hline Plano & SEP \\
\hline $\begin{array}{ll}\text { Vida } & \text { Gerador } \\
\text { de } & \text { Benefício } \\
\text { Livre } & (\text { VGBL) }\end{array}$ & $\begin{array}{l}\text { Os planos denominados (sob a sigla) VGBL, durante o período de diferimento, terão como critério de } \\
\text { remuneração da provisão matemática de benefícios a conceder, a rentabilidade da carteira de } \\
\text { investimentos do(s) FIE(s) instituído(s) no(s) qual(is) esteja(m) aplicada(s) a totalidade dos respectivos } \\
\text { recursos, sem garantia de remuneração mínima e de atualização de valores e sempre estruturados na } \\
\text { modalidade de contribuição variável. }\end{array}$ \\
\hline $\begin{array}{l}\text { Vida com } \\
\text { Remuneração } \\
\text { Garantida e } \\
\text { Performance } \\
\text { (VRGP) }\end{array}$ & $\begin{array}{l}\text { Os planos denominados (sob a sigla) VRGP garantirão, durante o período de diferimento, remuneração } \\
\text { dos recursos da provisão matemática de benefícios a conceder, por taxa de juros efetiva anual e índice } \\
\text { de atualização de valores, os quais deverão estar previstos em seu regulamento. Durante o período de } \\
\text { diferimento, haverá apuração de resultados financeiros. O percentual de reversão de resultados } \\
\text { financeiros estará previsto no regulamento. }\end{array}$ \\
\hline $\begin{array}{l}\text { Vida com } \\
\text { Remuneração } \\
\text { Garantida e } \\
\text { Performance } \\
\text { sem } \\
\text { Atualização } \\
\text { (VRSA) }\end{array}$ & $\begin{array}{l}\text { Os planos denominados (sob a sigla) VRSA garantirão, durante o período de diferimento, remuneração } \\
\text { dos recursos da provisão matemática de benefícios a conceder, por taxa de juros, o qual estará previsto } \\
\text { em Regulamento. Durante o período de diferimento, haverá apuração de resultados financeiros. O } \\
\text { percentual de reversão de resultados financeiros estará previsto em regulamento e não poderá ser inferior } \\
\text { a } 95 \% \text {. }\end{array}$ \\
\hline $\begin{array}{l}\text { Vida com } \\
\text { Atualização } \\
\text { Garantida e } \\
\text { Performance } \\
\text { (VAGP) }\end{array}$ & $\begin{array}{l}\text { Os planos denominados (sob a sigla) VAGP garantirão, durante o período de diferimento, atualização } \\
\text { dos recursos da provisão matemática de benefícios a conceder, por índice de atualização de valores, o } \\
\text { qual estará previsto em Regulamento. Durante o período de diferimento, haverá apuração de resultados } \\
\text { financeiros. O percentual de reversão de resultados financeiros estará previsto em regulamento. }\end{array}$ \\
\hline $\begin{array}{l}\text { Vida com } \\
\text { Renda } \\
\text { Imediata (VRI) }\end{array}$ & $\begin{array}{l}\text { Os planos denominados (sobre a sigla) VRI garantirão, mediante prêmio único, o pagamento de capital } \\
\text { segurado sob a forma de renda imediata. }\end{array}$ \\
\hline Dotal Puro & $\begin{array}{l}\text { Quando garantir aos segurados, durante o período de diferimento, remuneração por meio da contratação } \\
\text { de índice de atualização de valores, taxa de juros e, opcionalmente, tábua biométrica, sem reversão de } \\
\text { resultados financeiros, sendo o capital segurado pago ao segurado sobrevivente ao término do período } \\
\text { de diferimento. Esses planos são sempre estruturados na modalidade de benefício definido. }\end{array}$ \\
\hline Dotal Misto & $\begin{array}{l}\text { Quando garantir aos segurados, durante o período de diferimento, remuneração por meio da contratação } \\
\text { de índice de atualização de valores, taxa de juros e, opcionalmente, tábua biométrica, sem reversão de } \\
\text { resultados financeiros, sendo o capital segurado pago em função da sobrevivência do segurado ao } \\
\text { período de diferimento ou de sua morte ocorrida durante aquele período. Esses planos são sempre } \\
\text { estruturados na modalidade de benefício definido. }\end{array}$ \\
\hline $\begin{array}{l}\text { Dotal Misto } \\
\text { com } \\
\text { Performance }\end{array}$ & $\begin{array}{l}\text { Quando garantir aos segurados, durante o período de diferimento, remuneração por meio da contratação } \\
\text { de índice de atualização de valores, taxa de juros e, opcionalmente, tábua biométrica, com reversão, } \\
\text { parcial ou total, de resultados financeiros, sendo o capital segurado pago em função da sobrevivência do } \\
\text { segurado ao período de diferimento ou de sua morte ocorrida durante aquele período. Esses planos são } \\
\text { sempre estruturados na modalidade de benefício definido. }\end{array}$ \\
\hline
\end{tabular}


Os fundos de investimentos previdenciários, no período analisado, eram classificados, segundo a Associação Brasileira das Entidades dos Mercados Financeiro e de Capitais (ANBIMA, 2015), conforme Quadro 8, a seguir:

Quadro 8 - Classificação dos Fundos de Previdência - ANBIMA

\begin{tabular}{|c|c|}
\hline Classificação do Fundo Previdenciário & Descrição \\
\hline Previdência Renda Fixa & $\begin{array}{l}\text { Fundos que buscam retorno ao realizar investimentos em ativos } \\
\text { de renda fixa, executando estratégias baseadas em variação das } \\
\text { curvas de juros e índice de preços do mercado doméstico. Não } \\
\text { são permitidas estratégias baseadas em tomada de risco em } \\
\text { moeda estrangeira ou de renda variável/ }\end{array}$ \\
\hline Previdência Multimercados & $\begin{array}{l}\text { Fundos que buscam retorno no longo prazo ao realizar } \\
\text { investimentos em diversas classes de ativos - renda fixa, ações, } \\
\text { câmbio. O percentual aplicado em cada classe de ativo não é } \\
\text { fixo, obedecendo o limite máximo de } 49 \% \text { de aplicação em } \\
\text { renda variável. }\end{array}$ \\
\hline $\begin{array}{l}\text { Previdência Balanceados - até 15; 15-30; } \\
\text { acima de } 30\end{array}$ & $\begin{array}{l}\text { Fundos que buscam retorno no longo prazo ao realizarem } \\
\text { investimentos em diversas classes de ativos. Devem explicitar } \\
\text { o percentual de cada classe de ativo com o qual devem ser } \\
\text { comparados ou intervalo definido de percentual de alocação em } \\
\text { renda variável. São três as faixas de investimento em renda } \\
\text { variável - até } 15 \% \text { ou de } 15 \% \text { a } 30 \% \text { ou mais de } 30 \% \text { do } \\
\text { patrimônio do fundo. }\end{array}$ \\
\hline Previdência Ações & $\begin{array}{l}\text { Fundos que devem manter, no mínimo, } 67 \% \text { da carteira em } \\
\text { ações. Esse tipo de fundo não é diretamente comercializado, } \\
\text { recebe aplicações de outros fundos de previdência aberta. }\end{array}$ \\
\hline Previdência Data-Alvo & $\begin{array}{l}\text { Fundos que buscam retorno em um prazo ou data-alvo definida, } \\
\text { ao realizar investimentos em diversas classes de ativos. Na } \\
\text { medida que se aproxima da data-alvo, esses fundos têm o } \\
\text { compromisso de reduzir sua exposição ao risco, diminuindo, } \\
\text { por exemplo, o percentual do patrimônio aplicado em renda } \\
\text { variável. }\end{array}$ \\
\hline
\end{tabular}

Quadro elaborado pelo autor com informações ANBIMA 
Os planos privados de aposentadoria complementar gozam de vantagens exclusivas oferecidas pelo governo aos investidores/cotistas/segurados, tais como:

i. Ausência de come-cotas durante toda a fase de acumulação. O come-cotas funciona do seguinte modo: nos meses de maio e novembro a Receita Federal cobra impostos sobre os ganhos, não resgatados, ocorridos nos últimos 6 meses de investimento dos fundos tradicionais. Essas cobranças são feitas na forma de redução proporcional do número de cotas detidas pelo investidor. A não cobrança de come-cotas nos fundos de previdência privada é um benefício extraordinário para a acumulação de riqueza no longo prazo em razão dos efeitos da capitalização a juros compostos.

ii. Postergação do pagamento do I.R. sobre até $12 \%$ da renda bruta, no caso dos fundos PGBL.

iii. Possibilidade de aplicação de tabela regressiva de Imposto de Renda, com alíquota que pode chegar a apenas $10 \%$, caso o montante tenha sido investido por 10 anos ou mais;

iv. Planejamento de herança, no caso dos fundos VGBL, pois o montante oriundo dessa modalidade de plano não é incluído no inventário, ficando isento do imposto de transmissão de heranças ou doações.

A remuneração paga às entidades abertas privadas de previdência pelos serviços de gestão do fundo de previdência é conhecida como taxa de administração, que é um valor obtido por meio de aplicação de percentual pré-definido sobre os aportes/prêmios realizados no fundo, cobrada em base diária. Outra remuneração, conhecida como carregamento é a importância destinada a atender às despesas administrativas e de comercialização do plano. O carregamento, quando cobrado pelo fundo, pode variar, segundo define a SUSEP (2017), de 10\% a 30\% do total de prêmios/aportes realizados. Essa cobrança pode acontecer nas datas dos aportes - taxa de entrada - ou no momento dos resgates - taxa de saída - ou, ainda, na ocasião da portabilidade dos recursos para outro fundo. 
Em alguns fundos, cabe registrar, pode existir ainda uma cobrança extraordinária em função do desempenho de gestor, caso o retorno do fundo supere a taxa de retorno de referência préestabelecida no regulamento.

Seja como for, as taxas de administração e de carregamento afetam diretamente o retorno do fundo, podendo representar, a depender de sua magnitude, enorme diferença no montante a ser resgatado pelo cotista/segurado, no futuro. Em especial, a relação custo-benefício para o investidor das taxas de administração cobradas pelas entidades gestoras tem sido objeto de análises acadêmicas, tais como visto em Amaral (2013), Brito (2016) e Cremers, Ferreira, Matos e Starks (2016), entre outros, assim como é tangencialmente investigada neste presente trabalho.

\subsection{Ajuste dos Retornos de Carteiras de Investimento ao Risco}

Parte do risco de se investir isoladamente em uma única empresa pode ser eliminado quando esse ativo é combinado a uma carteira de investimentos que detenha outros ativos, conforme apresentado por Markowitz (1952). Essa é uma das vantagens da diversificação presente na grande maioria dos fundos de investimento, em especial dos fundos de previdência que investem parte do seu patrimônio em ações de empresas.

Os benefícios da diversificação, no entanto, não se dão somente pela combinação pura e simples dos ativos em uma carteira de investimentos. Na verdade, os benefícios dependem do exame da correlação entre os retornos históricos dos ativos combinados, o que exige do gestor, por certo, capacidade para a montagem das estratégias de investimento.

No entanto, nem todo o risco pode ser eliminado por meio do processo de diversificação de investimentos, pois existe uma parte do risco que é sistêmica, sujeita às condições gerais de mercado. Tais condições se apresentam, particularmente, por eventos que fogem ao controle das organizações e dos agentes econômicos, como, por exemplo, o surgimento de crises econômicas. 
Mediante a aceitação de um conjunto de premissas, Sharpe (1964) desenvolveu modelo com o propósito de relacionar retornos e riscos de ativos quando combinados em portfólios de investimento. Tal modelo, batizado de CAPM - Modelo de Precificação de Ativos ou, em inglês, Capital Asset Pricing Model - é a seguir apresentado.

$$
R_{i}=K_{R F}+\left(R_{M}-R_{R F}\right) x \beta_{i}
$$

Onde:

$R_{i}$ é o retorno esperado do ativo $\mathrm{i}$;

$K_{R F}$ é a taxa livre de risco;

$R_{M}$ é o retorno esperado da carteira de mercado;

$\left(R_{M}-R_{R F}\right)$ é igual ao prêmio de risco de mercado.

$\beta_{i}$ é o coeficiente que compara quanto que um ativo $i$ é afetado em seu risco em relação ao risco de mercado.

Conforme destacam Ross, Westerfield, Jordan e Lamb (2013, p. 401), a taxa de juros paga por títulos públicos de menor prazo de vencimento, as chamadas letras, pode ser considerada como a taxa livre de risco da economia de um país. O motivo econômico é que tais títulos estariam livres do risco de inadimplência, em seu curto ciclo de vida, pois o governo, em tese, sempre poderia aumentar os impostos para pagar essas dívidas. No Brasil, a taxa de juros atrelada aos títulos públicos de curto prazo é a taxa do Sistema Especial de Liquidação e Custódia - SELIC, motivo pelo qual a variação anual dessa taxa foi utilizada neste estudo como a taxa livre de risco.

O beta de um ativo $\left(\beta_{i}\right)$ é um coeficiente dado pela covariância entre os retornos de um ativo $\left(R_{i}\right)$ e os retornos do mercado $\left(R_{M}\right),\left(\operatorname{cov}\left(R_{i}, R_{M}\right)\right)$, dividida pela variância dos retornos de mercado $\left(\sigma^{2} M\right)$, como mostrado a seguir.

$$
\beta_{i}=\frac{\operatorname{cov}\left(R_{i}, R_{M}\right)}{\sigma_{M}^{2}}
$$

Já o beta de uma carteira é igual a média ponderada dos betas de cada ativo que a compõe. De modo que os betas das carteiras acionárias dos fundos aqui estudados foram calculados pelo 
somatório do produto entre participação percentual da ação $k$ no fundo $i$ e o beta da ação $k$, ambos ao final do ano $t$.

Entretanto, a medida de desempenho relativo entre fundos de investimentos, como os fundos abertos de previdência, normalmente se dá quando se ajusta o retorno ao respectivo risco assumido pelo gestor. Nesse sentido, Treynor (1965) apresentou uma medida que ajusta o prêmio de risco utilizando o beta da carteira como divisor, como pode ser visto a seguir:

$$
I T=\frac{\left(R_{c}-K_{R F}\right)}{\beta_{c}}
$$

Onde:

$I T$ é o Índice de Treynor

$R_{c}$ é o retorno médio esperado da carteira

$K_{R F}$ é o retorno livre de risco

$\beta_{c}$ é o beta da carteira

Assim, para Treynor (1965), entre várias carteiras de investimento, a que apresentar o maior IT, é a que tem melhor desempenho no quesito retorno por unidade de risco assumida. No Brasil, especificamente, com o desempenho do mercado acionário bastante instável, mesmo quando se observa um espectro de tempo mais dilatado, o Índice de Treynor dos fundos muitas vezes pode ficar negativo, perdendo sua significação econômica. Outro ponto de atenção sobre o uso do IT é que o beta da carteira deveria ser obtido relativamente ao desempenho que se pretende superar. Ou seja, para fundos de renda fixa o cálculo do beta deveria assumir uma referência do mercado específico, tal qual o desempenho da SELIC. No caso de uma carteira de ações, o beta deveria ser calculado relativamente a um índice, tal qual o Ibovespa, por exemplo. Ressalta-se aqui que o índice utilizado neste trabalho para ordenamento do desempenho ajustado ao risco incorrido pelos fundos não deixa de ser uma simplificação do $I T$, como mais adiante será visto.

Já Sharpe (1966) apresentou uma medida com o propósito de realizar um ajuste no retorno em função do risco assumido pelo gestor, conforme fórmula a seguir:

$$
I S=\frac{\left(R_{C}-K_{R F}\right)}{\sigma_{c}}
$$

onde: 
IS é o Índice de Sharpe

$R_{c}$ é o retorno médio esperado da carteira

$K_{R F}$ é a taxa de retorno livre de risco

$\sigma_{c}$ é o desvio-padrão dos retornos da carteira

O IS calcula o prêmio por unidade de risco assumido - sistemático e não-sistemático. De modo que carteiras com maior $I S$ são as que apresentam os melhores resultados. No Brasil, como já dito, o Índice de Sharpe dos fundos muitas vezes fica negativo, também perdendo sua significação econômica.

Jensen (1968) apresentou um indicador de desempenho para o gestor de carteira, assumindo válidas todas as premissas do modelo CAPM. O alpha de Jensen, como ficou conhecida a medida por ele proposta, é obtida pela seguinte expressão:

$$
\alpha_{j}=\left(R_{c}-K_{R F}\right)-\beta_{c} x\left(R_{M}-K_{R F}\right)
$$

sendo que:

$\alpha_{j}$ é o alpha de Jensen;

$R_{c}$ é o retorno obtido pela carteira;

$K_{R F}$ é a taxa livre de risco;

$\beta_{c}$ é o beta da carteira, e

$R_{M}$ é o retorno da carteira teórica de mercado (Benchmark)

Portanto, o alpha de Jensen mede o excedente de retorno obtido pela carteira em relação ao retorno marginal calculado pelo modelo $C A P M$. Por esse indicador, em teoria, bons gestores seriam capazes de criar alphas positvos.

Sortino e Van Der Meer (1991) propuseram um ajuste no Índice de Sharpe (1966). No cálculo de seu índice de retorno por unidade de risco assumido, o desvio-padrão, no denominador da fórmula, só considera as observações nas quais o retorno da carteira tenha sido menor do que o retorno mínimo esperado - downside deviation. Com isso, chega-se a seguinte expressão para o índice: 


$$
\text { Sortino }=\frac{\left(R_{c}-K_{m r}\right)}{\delta_{c}}
$$

Em que:

Sortino é o Índice de Sortino;

$R_{c}$ é o retorno médio esperado da carteira;

$K_{m r}$ é a taxa de retorno mínima requerida;

$\delta_{c}$ é o desvio-padrão que considera apenas os retornos da carteira que tenham sido inferiores ao mínimo requerido.

Na sequência, Sharpe (1994) conceitua uma nova versão de seu índice (Sharpe Selection Rate, $S S R$ ), na qual substituiu a taxa livre de risco por um benchmark do retorno auferido pelo mercado. Também inova no denominador do novo índice, ao usar o desvio padrão da diferença entre o retorno da carteira e o retorno do mercado.

$$
S S R=\frac{\left(R_{c}-R_{M}\right)}{\sigma_{(c-M)}}
$$

Onde:

SSR é o Índice revisado de Sharpe (Sharpe Selection Rate)

$R_{c}$ é o retorno médio da carteira

$R_{M}$ é a taxa de retorno da carteira de mercado

$\sigma_{(c-M)}$ é o desvio-padrão das diferenças entre os retornos da carteira e os retornos do benchmark.

Já Modigliani e Modigliani (1997) apresentam um novo indicador de desempenho $\left(M^{2}\right)$ com o propósito de capturar o retorno marginal de dada carteira após ajustá-la ao risco da carteira teórica de mercado, assumindo que a carteira do investidor/fundo/gestor seja uma função da dispersão de resultados produzidos pela carteira teórica de mercado, conforme construção a seguir:

$$
\sigma_{M}=\Delta \% x \sigma_{c}
$$

De modo que: 


$$
\Delta \%=\frac{\sigma_{M}}{\sigma_{c}}
$$

Onde:

$\Delta \%$ é o fator de alavancagem entre o risco do mercado e o risco da carteira;

$\sigma_{M}$ é o desvio-padrão dos retornos da carteira de mercado;

$\sigma_{c}$ é o desvio-padrão dos retornos da carteira.

Portanto, o retorno da carteira ajustado ao risco é representado pela seguinte equação:

$$
R_{c a}=\frac{\sigma_{M}}{\sigma_{c}} \times R_{c}+\left(1-\frac{\sigma_{M}}{\sigma_{c}}\right) \times K_{R F}
$$

Sendo:

$R_{c a}$ é o retorno da carteira ajustado ao risco;

$R_{c}$ é o retorno da carteira;

$K_{R F}$ é a taxa livre de risco.

De modo que a medida $M^{2}$ é a diferença entre o retorno da carteira ajustado ao risco e o retorno da carteira de mercado, conforme fórmula abaixo:

$$
M^{2}=R_{c a}-R_{M}
$$

Portanto, $\mathrm{M}^{2}$ positivos indicam a capacidade do gestor de superar o mercado, já realizado o ajuste do retorno ao risco assumido.

Sharpe (1992) desenvolveu um modelo para identificar indiretamente as principais fontes de risco assumidas por um gestor de fundos. O modelo proposto recebeu o nome de Return Based Style ou Análise de Estilo Baseado no Retorno. A ideia central é que relevante parte dos riscos de uma carteira estaria relacionada às classes de ativos investidas pelos fundos. Essas classes de ativos estariam divididas em doze grupos. Cada grupo estaria associado a um índice que representaria o mercado de uma classe de ativo distinta. Por exemplo, há classes distintas para títulos públicos de curto, médio e longo prazos. Há classe para títulos corporativos, como debêntures; outras, para grupos de ações e assim por diante. Por meio do uso de regressões lineares múltiplas, busca-se encontrar os pesos de cada classe de ativo investido pelo fundo na 
explicação de seus resultados históricos. Com isso, torna-se possível, entre outras coisas, o monitoramento da execução da política de investimentos definida no regulamento do fundo, bem como identificar o grau de atividade ou passividade do gestor do fundo.

Para registro, o modelo proposto neste trabalho não deixa de ser uma simplificação da ideia de retorno baseada em estilo, assumindo-se aqui que existem apenas duas classes relevantes investidas pelos fundos PGBL/VGBL estudados: a parte arriscada, investida em ações, direta ou indiretamente, e a parcela não arriscada, que aqui foi considerada como integralmente investida em ativos livres de risco atrelados à taxa Selic. Além disso, a taxa de administração e o beta da carteira acionária também foram utilizados como variáveis explicativas, como mais adiante será apresentado.

\subsection{Estudos sobre Fundos de Previdência}

Muito embora a temática tenha ganhado relevância econômica e social no Brasil, o volume de pesquisas acadêmicas sobre fundos abertos de previdência privada no país ainda é pequeno. Em outros países, especialmente nos Estados Unidos, a produção acadêmica sobre o assunto tem sido mais profícua e tem ganhado mais relevância.

Em especial, muitos estudos analisam as mais populares modalidades de planos de previdência privada nos Estados Unidos, o Individual Retirement Account - IRA - e o 401(k). A principal diferença entre essas modalidades é que os planos IRA são individuais, e os 401(k) são planos coletivos oferecidos pelas empresas aos seus funcionários. Tais planos permitem a dedutibilidade dos aportes anuais realizados pelo participante em sua declaração de impostos de renda. No entanto, por esse motivo, o montante de aportes anual é limitado. No caso dos planos 401(k), o modelo mais comum de gestão é o próprio funcionário ficar no controle da alocação dos recursos a partir de uma plataforma de investimentos com menu de opções prédefinido pela administradora contratada pelo empregador. Há ainda o modelo no qual a gestão é totalmente entregue a uma gestão profissional, como acontece no Brasil.

Nos Estados Unidos, os conflitos de agência entre os gestores dos fundos e os participantes têm sido tema recorrente das pesquisas, bem como a análise da relação custo-benefício das taxas de administração cobradas pelos gestores dados os serviços entregues aos clientes. Essa 
recorrência de estudos é aderente à relevância desse mercado na economia norte-americana e à tradição do país no respeito aos direitos dos consumidores.

Recentemente, Pool, Sialm e Stefanescu (2016) estudaram o possível conflito de interesses no caso de provedores de serviços da indústria americana de fundos 401(k) que configuram as opções de menu de investimentos aos participantes dos planos. Encontraram evidências de que tais provedores de serviços tendem a proteger os fundos a eles ligados, em detrimento dos interesses dos cotistas/segurados.

Doellman e Sardarli (2016) encontraram evidências, ao analisarem pequenos e médios fundos 401(k) geridos por 400 administradores, de que quanto maior é a taxa de administração cobrada pelo fundo, menor é o resultado entregue ao cotista/segurado, em especial quando a gestão está ligada a bancos comerciais e companhias de seguro. Assim como Pool, Sialm e Stefanescu (2016), os autores também discutiram o conflito de agência entre gestores e poupadores, refletindo preocupação acadêmica comum ligada aos interesses dos pequenos investidores.

Sialm e Starks (2012) comentam que um gestor de fundo mútuo, no mercado norte-americano, deveria se preocupar com os impostos, mantendo em carteira os ativos com maior ganho de capital, vendendo os ativos que apresentem perdas e, por fim, evitando o investimento em empresas que pagam muitos dividendos, tudo no sentido de retardar o recolhimento de impostos, que capitalizados ao patrimônio, podem produzir melhores retornos no longo prazo, mantidas todas as demais variáveis constantes, evidentemente. Nota-se, portanto, que a não cobrança do come-cotas para fundos privados de previdência, no Brasil, é uma vantagem extraordinária no sentido de vinculação da cobrança dos impostos somente no resgate.

Sialm, Starks e Zhang (2015) analisaram o comportamento do fluxo monetário em fundos mútuos, no período de 1997 a 2010, entre investidores de fundos previdenciários patrocinados por seus empregadores, na modalidade contribuição definida, e os fluxos dos demais investidores não vinculados a planos patrocinados por empregadores. Nesse estudo, uma das hipóteses era que o investidor de fundos previdenciários, por inércia e pela expectativa de retorno em horizonte mais longo, tenderia a realizar menores mudanças em seus investimentos. No entanto, as evidências encontradas apontaram para o oposto, sendo que uma das possíveis razões para a descoberta foi a frequente mudança no menu de opções de investimento disponível aos funcionários, com trocas de fundos de pobre desempenho por aqueles com melhor histórico de resultados. 
Cremers, Ferreira, Matos e Starks (2016) estudaram fundos mútuos passivos e ativos em 32 países buscando entender, entre outras coisas, a relação entre taxas de administração cobradas e os respectivos desempenhos, com especial destaque para os contextos concorrenciais de cada país como determinantes para os preços dos serviços de administração de fundos. Mostram nesse estudo que houve crescimento da participação dos fundos explicitamente indexados, saltando de $14 \%$, em 2002, para $22 \%$, em 2010. No entanto, apontam que outros $20 \%$ de participação do mercado de fundos mútuos, em 2010, poderiam ser atribuídos a fundos que implicitamente adotam estratégias passivas de investimento por meio de acompanhamento índices, mas que, no entanto, explicitamente, vendem-se como gestores ativos. Concluem ainda os autores que quanto menor é o grau de explicitação da verdadeira passividade dos fundos em um país, menor é o benefício gerado para o conjunto de investidores em termos de menores taxas de administração. Apontam também que mudanças na legislação previdenciária realizadas pelos países estudados aceleram e facilitam a migração de sistemas baseados em benefícios definidos para sistemas de previdência orientados a contribuições definidas, com capitalização da poupança realizada pelos cotistas/segurados.

Muito embora Cremers et al (2016) não tenham estudado o mercado brasileiro, especificamente, os dados e as pesquisas sobre os fundos previdenciários contidos nesta pesquisa apontam para um mercado com gestão bastante passiva, no entanto, com taxas de administração cobradas mais altas, compatíveis às taxas de uma gestão ativa.

No Brasil, Cardoso (2006) estudou a existência de persistência de desempenho dos fundos PGBL/VGBL e Fundo de Aposentadoria Programada Individual - FAPI, entre janeiro de 2001 a dezembro de 2004. Analisou 41 fundos balanceados, 16 fundos multimercados com renda variável e 35 fundos renda fixa, divididos em dois períodos: 2001/2002 e 2003/2004. Nesse estudo, só utilizou fundos que sobreviveram a todo o período. Concluiu não ser possível afirmar que um determinado fundo consiga repetir no futuro o desempenho obtido no passado. Também analisou a influência da taxa de administração nos resultados dos fundos, mostrando não existir influência da taxa de administração na persistência de desempenho entre os dois períodos analisados.

Silva (2010) analisou os impactos do aumento da longevidade no equilíbrio técnico dos planos privados de previdência complementar, concluindo que a não adoção do aumento da expectativa de vida na constituição de provisões técnicas dos planos de previdência pode expor 
entidades fechadas e abertas de previdência complementar a riscos pouco suportáveis no longo prazo.

Amaral (2013) estudou o desempenho de fundos de renda fixa, entre 2005 e 2011, concluindo que os retornos dos fundos de renda fixa tradicionais foram superiores aos apresentados pelos fundos privados de previdência complementar. Em sua pesquisa, apesar do baixo desempenho relativo, observou que as taxas de administração cobradas pelos fundos de previdência são mais altas, sendo uma das principais razões para o fraco desempenho relativo dos fundos abertos de previdência em relação aos fundos tradicionais.

Brito (2016) estudou a relação entre taxas de administração cobradas e o estilo de gestão dos fundos abertos de previdência complementar. Para tal analisou, entre 2009 e 2015, uma amostra composta por 15 fundos, sendo três de cada uma das cinco principais administradoras de fundos abertos de previdência complementar. Seus resultados indicam passividade na gestão dos fundos, especialmente os fundos que realizam investimentos em ativos de renda variável. Destacou que os fundos compostos com renda variável cobram taxas de administração mais altas. Concluiu ainda que os benefícios tributários concedidos pelo governo aos investidores de fundos abertos de previdência complementar são consumidos pelas taxas de administração cobradas. Por fim, demonstrou a possibilidade de se montar, facilmente, uma carteira passiva com investimentos que produziria retornos brutos ajustados ao risco similares aos obtidos pelos fundos PGBL/VGBL, porém a taxas de administração mais baixas, gerando maior retorno ao investidor. 


\subsection{Construção das Hipóteses da Pesquisa}

Com base nos objetivos deste trabalho e na revisão da literatura é apresentado a seguir o Quadro 9 que concatena os objetivos, à revisão da literatura e à formulação das hipóteses desta pesquisa.

Quadro 9 - Objetivos, Resultados Esperados e Hipóteses da Pesquisa

Objetivo principal: Desenvolver modelo de estimativa do retorno anual dos fundos PGBL/VGBL com investimentos em renda variável, entre 2007 e 2015, em função de variáveis que discriminam as estratégias executadas pelas administradoras de fundos.

Objetivos secundários: Discriminar as estratégias sob controle do gestor

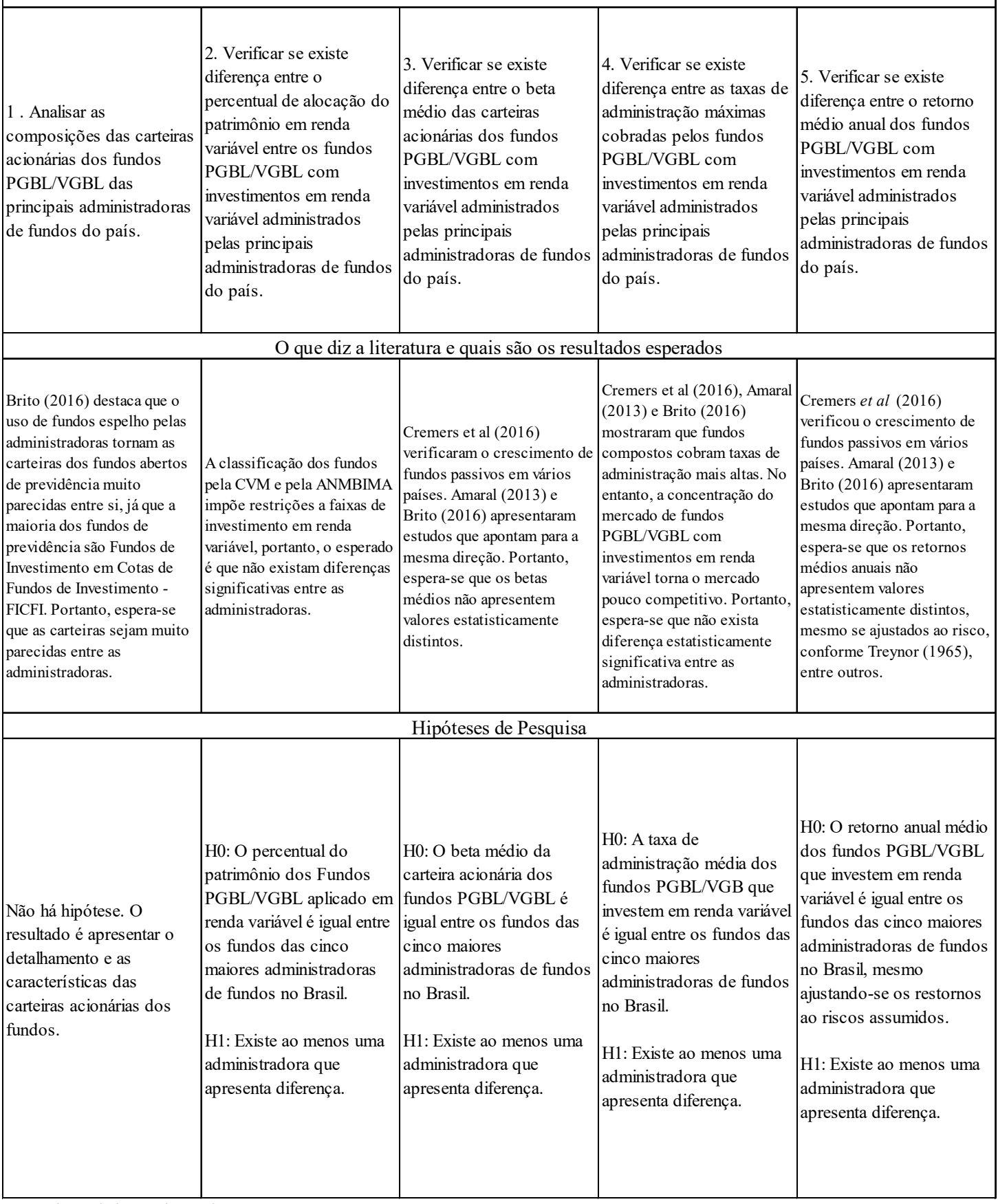

Quadro elaborado pelo autor 


\section{DESCRIÇÃO DO MÉTODO DE PESQUISA}

\subsection{Dados para a Pesquisa}

Considerando os objetivos do presente estudo, foram levantados por meio da base de Fundos da plataforma Economática ${ }^{\circledR}$, disponível na biblioteca da Faculdade de Economia, Administração e Ciências Contábeis e Atuariais da Universidade de São Paulo (FEA/USP), dados sobre todos os 671 fundos de previdência PGBL/VGBL que mantiveram em suas carteiras de investimentos ações de empresas, diretamente, e/ou ativos de renda variável atrelados a ações de empresas, indiretamente, ao final de cada um dos anos de 2007 a 2015, ofertados ao público pelo sistema financeiro brasileiro. Portanto, trata-se de base de dados sem viés de sobrevivência, pois contém fundos ativos e cancelados durante o período. O Quadro 10 a seguir apresenta a descrição desses dados:

Quadro 10 - Descrição dos dados - Screening de Fundos - Economática

\begin{tabular}{|c|c|c|c|}
\hline Nome do Dado & Tipo & Formato & Descrição \\
\hline Nome_Fundo & str40 & $\% 40 \mathrm{~s}$ & Nome_Fundo \\
\hline AtivoCancelado & str9 & $\% 9 \mathrm{~s}$ & Se o fundo está ativo ou cancelado \\
\hline CNPJ & str14 & $\% 14 \mathrm{~s}$ & CNPJ \\
\hline ClassifAmbimaAntiga & str39 & $\% 39 \mathrm{~s}$ & ClassifAmbimaAntiga \\
\hline Gestora & str 40 & $\% 40 \mathrm{~s}$ & Instituição Gestora do fundo \\
\hline CodFundo & str13 & $\% 13 \mathrm{~s}$ & CodFundo \\
\hline Previdencia & str13 & $\% 13 \mathrm{~s}$ & Previdencia \\
\hline Ano & int & $\% 10.0 \mathrm{~g}$ & Ano \\
\hline PosiçãoAcion & double & $\% 10.0 \mathrm{gc}$ & $\begin{array}{l}\text { Valor de mercado da posição acionaria mantida mantida pelo fundo em } \\
\text { determinado ativo, em dado ano }\end{array}$ \\
\hline ClassificaoAnbima & str40 & $\% 40 \mathrm{~s}$ & Classificação Anbima \\
\hline ClasseAnbima & str13 & $\% 13 \mathrm{~s}$ & Classe Anbima \\
\hline CategoriaAnbima & str20 & $\% 20 \mathrm{~s}$ & Categoria Ambima \\
\hline SubcategoriaAnbima & str20 & $\% 20 \mathrm{~s}$ & Subcategoria Anbima \\
\hline ClassifCVM & str20 & $\% 20 \mathrm{~s}$ & Classificação dos fundos pela CVM \\
\hline SubclasseCVM & str19 & $\% 19 \mathrm{~s}$ & Subclasse CVM \\
\hline Administradora & str40 & $\% 40$ s & Administradora do Fundo \\
\hline DistribuidorCotas & str99 & $\% 99 \mathrm{~s}$ & Distribuidor das Cotas do Fundo \\
\hline DiretorRespons & str35 & $\% 35 \mathrm{~s}$ & Diretor Responsável pelo Fundo \\
\hline ServTesouraria & str35 & $\% 35 \mathrm{~s}$ & Instituição que realiza os serviços de tesouraria do Fundo \\
\hline Benchmark & str20 & $\% 20 \mathrm{~s}$ & Qual o benchmark que o fundo persegue, se persegue \\
\hline Alavancado & str3 & $\% 9 \mathrm{~s}$ & Se o fundo é alavancado ou não \\
\hline TaxaAdmMax & double & $\% 14.2 \mathrm{fc}$ & Taxa de Administração Máxima \\
\hline CobraTxPerform & str3 & $\% 9 \mathrm{~s}$ & Se o fundo cobra taxa de performance \\
\hline TxPerform & str100 & $\% 100 \mathrm{~s}$ & Qual a taxa de performace cobrada \\
\hline RegraTxPerform & str100 & $\% 100 \mathrm{~s}$ & Qual a regra para cobrança da taxa de performance \\
\hline Periodo_Tx_Perform & int & $\% 10.0 \mathrm{~g}$ & Período para apuração da taxa de perfomance \\
\hline ChaveFundoAno & str17 & $\% 17 \mathrm{~s}$ & Chave primária que combina o fundo e o ano \\
\hline RetornoFundo & double & $\% 14.2 \mathrm{fc}$ & Retorno anual do fundo (não só com as aplicações em renda variável) \\
\hline CaptLiq & double & $\% 10.0 \mathrm{gc}$ & Captação Líquida = diferença entre as contribuições e os resgates no ano \\
\hline CaptBruta & double & $\% 10.0 \mathrm{gc}$ & Captação Bruta = somatório das contribuições para o fundo no ano \\
\hline PatrimFundo & double & $\% 10.0 \mathrm{gc}$ & $\begin{array}{l}\text { Patrimônio do Fundo (inclui todos os investimentos, inclusive em renda } \\
\text { variável) }\end{array}$ \\
\hline
\end{tabular}

Fonte: Economática

Quadro elaborado pelo autor 
Da BM\&FBovespa, atual B3, foi obtido o histórico da composição acionária do índice referência de mercado, o Ibovespa, ao final de cada um dos anos entre 2007 e 2015, bem como a valorização anual do índice.

Os dados sobre as ações das empresas investidas (betas, ativos totais, imobilizados, patrimônios líquidos, lucros líquidos, valores de mercado, endividamentos, etc) foram extraídos do screening da base de Ações da Economática ${ }^{\circledR}$. O Quadro 11 abaixo descreve esses dados:

Quadro 11 - Descrição dos dados - Screening de Ações - Economática

\begin{tabular}{|c|c|c|c|}
\hline Nome da Variável & Tipo & Formato & Descrição \\
\hline CodigoAcao & str8 & $\% 9 \mathrm{~s}$ & Código da ação \\
\hline ChaveCodAcaoAno & str20 & $\% 20 \mathrm{~s}$ & Chave Código da Acao e Ano \\
\hline Nome_Empresa & str50 & $\% 50 \mathrm{~s}$ & Nome da Empresa \\
\hline Classe & $\operatorname{str} 11$ & $\% 11 \mathrm{~s}$ & Classe da Ação \\
\hline SetorEconomatica & str18 & $\% 18 \mathrm{~s}$ & Setor Economática ao qual a empresa pertence \\
\hline DeprAmor & double & $\% 10.0 \mathrm{gc}$ & Depreciação e amorização annual \\
\hline VlrMerc & double & $\% 10.0 \mathrm{gc}$ & $\begin{array}{l}\text { Valor de Mercado = Preço da ação x qtde de ações (quando há mais de uma } \\
\text { classe ação, os resultados são somados) }\end{array}$ \\
\hline EBIT & double & $\% 10.0 \mathrm{gc}$ & Resultado operacional antes de juros e impostos \\
\hline EBITDA & double & $\% 10.0 \mathrm{gc}$ & Resultado operacional antes juros, impostos, depreciação e amortização \\
\hline Capex & double & $\% 10.0 \mathrm{gc}$ & Valor do Capex annual \\
\hline LucroLiq & double & $\% 10.0 \mathrm{gc}$ & Lucro Líquido \\
\hline Imob & double & $\% 10.0 \mathrm{gc}$ & Valor do imobilizado \\
\hline Intang & double & $\% 10.0 \mathrm{gc}$ & Valor do intangivel \\
\hline CxOper & double & $\% 10.0 \mathrm{gc}$ & Fluxo de Caixa Operacional do Ano \\
\hline AtivoTotal & double & $\% 10.0 \mathrm{gc}$ & Ativo Total \\
\hline PatrLiq & double & $\% 10.0 \mathrm{gc}$ & Patrimônio Líquido da empresa \\
\hline EmprFinLP & double & $\% 10.0 \mathrm{gc}$ & Empréstimos e Financiamento de Longo Prazo \\
\hline EmprFinCP & double & $\% 10.0 \mathrm{gc}$ & Empréstimos e Financiamento de Curto Prazo \\
\hline $\mathrm{DivBr}$ & double & $\% 10.0 \mathrm{gc}$ & $\begin{array}{l}\text { Dívida Bruta = somatório dos empréstimos e financiamentos (EmprFinCP + } \\
\text { EmprFinLP) }\end{array}$ \\
\hline QtdeAcoes & double & $\% 10.0 \mathrm{gc}$ & Qtde de ações \\
\hline Receita & double & $\% 10.0 \mathrm{gc}$ & Receita Líquida Total no ano \\
\hline LAIR & double & $\% 10.0 \mathrm{gc}$ & Lucro antes dos impostos sobre a renda \\
\hline Estoque & double & $\% 10.0 \mathrm{gc}$ & Estoque \\
\hline Fech & double & $\% 10.0 \mathrm{~g}$ & Cotação de fechamento da ação, ajustada a proventos (inclusive dividendos) \\
\hline LucroBr & double & $\% 10.0 \mathrm{gc}$ & Lucro Bruto \\
\hline PrVPA & double & $\% 14.2 \mathrm{fc}$ & Relação Preço da Ação / Preço Patrimonial da Ação \\
\hline PrLucro & double & $\% 14.2 \mathrm{fc}$ & Relação Preço da Ação / Lucro por Ação \\
\hline Beta & double & $\% 14.2 \mathrm{fc}$ & Beta calculado com base em preços diários dos últimos 24 meses \\
\hline VPA & double & $\% 10.0 \mathrm{~g}$ & Valor Patrimonial da Ação \\
\hline DividporAcao & double & $\% 10.0 \mathrm{~g}$ & Dividendos por Ação \\
\hline VaRd & double & $\% 14.2 \mathrm{fc}$ & Value at Risk calculado com base em preços diários dos últimos 12 meses \\
\hline VolNeglAno & double & $\% 10.0 \mathrm{gc}$ & Volume Negociado da Ação nos últimos 12 meses \\
\hline DivLiq & double & $\% 10.0 \mathrm{~g}$ & Dívida Líquida = Dívida Bruta - Ativos Circulantes Financeiros \\
\hline
\end{tabular}

Fonte: Economática

Quadro elaborado pelo autor 
A valorização anual da SELIC durante o período analisado foi obtida do Banco Central do Brasil (BACEN, 2017). O valor do patrimônio de todos os tipos de fundos e de todos os fundos de previdência, durante o período, foram obtidos da Associação Brasileira das Entidades dos Mercados Financeiro e de Capitais (ANBIMA).

O Quadro 12 abaixo apresenta algumas variáveis que foram calculadas ou modificadas pelo autor deste trabalho:

Quadro 12 - Dados Calculados ou Modificados pelo Autor

\begin{tabular}{|l|c|c|l|}
\hline Nome da Variável & Tipo & Formato & Descrição \\
\hline ConcatFundoAcao & str9 & $\% 9 \mathrm{~s}$ & $\begin{array}{l}\text { Chave usada para uso em dados em painel. Concatena cada fundo a uma ação } \\
\text { (chave única) }\end{array}$ \\
\hline Id_ConcatFundo & float & $\% 9.0 \mathrm{~g}$ & $\begin{array}{l}\text { Id para Chave usada para uso em dados em painel. Para uso para configurar o } \\
\text { painel de dados no Stata }\end{array}$ \\
\hline perc_rv & float & $\% 9.0 \mathrm{~g}$ & Percentual de renda variável investido pelo fundo = PosiçãoAcion/PatrimFundo \\
\hline perc_rf & float & $\% 9.0 \mathrm{~g}$ & Proxy do percentual de renda fixo investido pelo fundo = (100 - perc_rv) \\
\hline perc_rv_Ibovespa & float & $\% 9.0 \mathrm{~g}$ & perc_rv x valorização anual do Ibovespa / 100 \\
\hline perc_rf_Selic & float & $\% 9.0 \mathrm{~g}$ & perc_rf x valorização anual da Selic / 100 \\
\hline BetaCart & float & $\% 99.0 \mathrm{~g}$ & $\begin{array}{l}\text { Beta da Carteira do Fundo = soma do produto entre participação acionária de } \\
\text { cada ação dentro de um fundo e o beta da ação }\end{array}$ \\
\hline RetornoAcao & float & $\% 9.0 \mathrm{~g}$ & Valorização anual da ação (ajustada a proventos, inclusive dividendos) \\
\hline opslucrativ & float & $\% 9.0 \mathrm{~g}$ & EBITDA/Ativo Total \\
\hline lucrativ & float & $\% 9.0 \mathrm{~g}$ & Lucro Líquido / Patrimônio Líquido \\
\hline Mtb & float & $\% 9.0 \mathrm{~g}$ & (VlrMerc + DivBr)/AtivoTotal \\
\hline tangib & float & $\% 9.0 \mathrm{~g}$ & $\mathrm{Imob} /$ AtivoTotal \\
\hline EndivB & float & $\% 9.0 \mathrm{~g}$ & DivBr/(DivBr + PatrLiq) \\
\hline EndivM & float & $\% 9.0 \mathrm{~g}$ & DivBr/(DivBr + VlrMerc) \\
\hline lnAtivoTotal & float & $\% 9.0 \mathrm{~g}$ & Log Neperiano do Ativo Total (proxy para tamanho da empresa) \\
\hline lnVlrMerc & float & $\% 99.0 \mathrm{~g}$ & Log Neperiano do Valor de Mercado do PL de uma empresa em dado ano \\
\hline
\end{tabular}

Fonte: Economática

Quadro elaborado pelo autor

Os dados foram, então, organizados em duas bases, inseridas no software de tratamento estatístico de dados Stata ${ }^{\circledR}$, versão 13.1, da seguinte forma:

a) Uma base de dados, mais completa, que contém a posição de cada ação presente em cada fundo PGBL/VGBL, ao final de cada um dos anos compreendidos nesta pesquisa, além de dados qualitativos e quantitativos que descrevem os respectivos fundos. A essa base também foram acoplados dados qualitativos e quantitativos referentes a cada ação presente na carteira de cada fundo, incluindo a participação de cada ação na carteira teórica do Ibovespa, ao final de cada ano. Por meio desse banco de dados, foi possível 
investigar, em detalhe, em quais ações distintas, e suas respectivas proporções na carteira acionária, cada fundo PGBL/VGBL mantinha seus investimentos, ao final de cada ano. Também foi possível, por meio dessa base, estudar as similaridades e padrões entre as carteiras acionárias dos fundos. Por fim, essa base de dados permitiu o cálculo do beta de cada carteira acionária de cada fundo. Para que o leitor visualize mais facilmente a estrutura dessa base de dados, é só imaginar que cada registro, linha, do banco de dados apresenta dados de uma ação $k$ pertencente a determinado fundo $i$, no final de um ano $t$. Logo, a combinação ação ${ }_{k}$-fundo $i$ é a unidade cujas variações foram observadas ao longo dos anos, conforme estrutura clássica de um painel longo de dados. No caso específico trata-se de um painel desbalanceado, no sentido de que nem todas as combinações ação-fundo possuem dados para todos os anos.

b) A outra base considerada, chamada aqui de sintética, com dados consolidados dos fundos, com a inclusão dos betas das carteiras acionárias calculados por meio do banco de dados descrito no item a). Nessa base, cada registro é referente a dados qualitativos e quantitativos do fundo $i$ ao final de um ano $t$, também em formato clássico de painel longo de dados desbalanceado, cuja unidade de observação ao longo do tempo é o fundo. A essa base foram adicionadas ainda as valorizações anuais do Ibovespa e da SELIC. De modo que essa é a base que foi usada para geração do modelo empírico de estimativa dos retornos anuais dos fundos.

A Figura 1, apresentada a seguir, resume a estrutura dos dados, conforme descrito: 


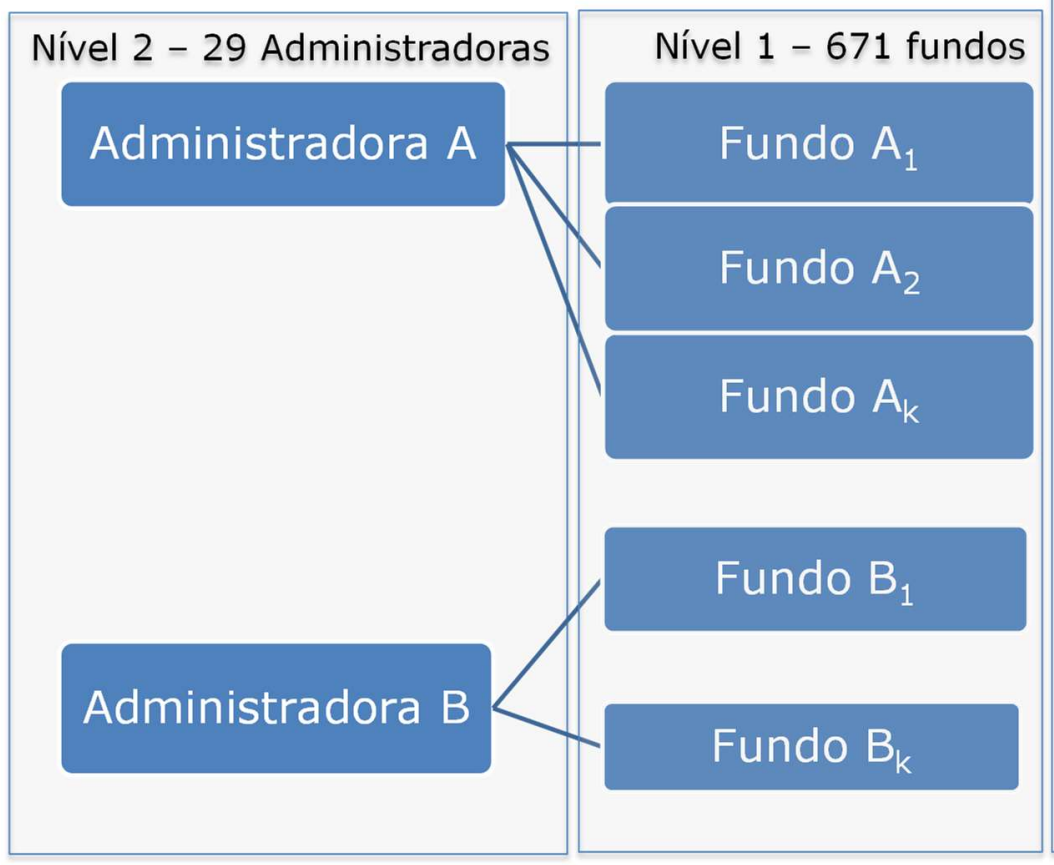

\begin{tabular}{c}
\hline Ano... \\
2007 Ano \\
Base Completa: ...; \\
posição acionária; \\
presença e peso da \\
ação no Ibovespa => \\
permitiu cálculo do \\
beta da carteira \\
acionária de cada \\
fundo) \\
Base Sintética \\
(retorno; taxa de \\
administração; \\
patrimônio do fundo; \\
\% do Patrim aplicado \\
em renda variável; \\
beta da carteira \\
acionária; ibov; SELIC)
\end{tabular}

Figura 1 - Resumo da estrutura de dados da pesquisa Figura elaborada pelo autor

\subsection{Procedimentos para Tratamento dos Dados}

Numa primeira etapa da análise dos dados, foram elaboradas tabelas e gráficos que apresentaram uma visão panorâmica do mercado de fundos, mostrando a relevância dos principais atores. Combinado a essa visão mais abrangente, seguiu-se no caminho de explorar as características das carteiras acionárias mantidas pelos fundos PGBL/VGBL ao final de cada ano contido neste estudo. De modo que foram levantadas as composições acionárias de cada fundo e analisadas suas particularidades, características e padrões.

Assim, para cada ano, as carteiras acionárias dos fundos mantidos pelas principais administradoras foram analisadas, detalhadamente, bem como os seus resultados; nível de risco, medido pelo beta da carteira; taxas de administração máximas cobradas de seus cotistas, além dos seus percentuais do patrimônio aplicados em renda variável e fixa, ao final de cada ano.

Feitas essas análises, assumindo-se, por conservadorismo, a existência de heterogeneidade das covariâncias das séries comparáveis testadas, por meio da aplicação do teste de igualdade de médias de Wald, foi possível comparar as estratégias dos gestores dos fundos das cinco principais administradoras de fundos, bem como seus retornos anuais médios para verificar se 
existiram diferenças estatisticamente significantes entre eles - respondendo-se a parte das perguntas de pesquisa aqui colocadas.

Respondidas as questões mais ligadas às estratégias e padrões de gestão, seguiu-se no caminho de especificação e validação de um modelo de estimação dos retornos anuais dos fundos. Para isso, cabe destacar, foi utilizada a estrutura da base de dados sintética. Como já comentado, ela está organizada em hierarquias que agrupam os dados de unidades cujas observações ocorrem em diferentes pontos do tempo. Esse tipo de organização enseja a possibilidade do uso de técnica específica de regressão que captura efeitos fixos e aleatórios, simultaneamente, ligados a um ou mais níveis de organização dos dados. No caso do banco de dados sintético, os fundos estão vinculados a administradoras de fundos, entre outras possibilidades de agrupamento existentes. Portanto, abriu-se a oportunidade para a verificação da pertinência ou não do uso de regressões multinível com dados em painel, as quais se assemelham aos modelos clássicos em painel - que utilizam o ajuste pela minimização dos quadrados ordinários dos resíduos - MQO - porém com especificidades que auxiliam a compreender quanto cada agrupamento pode explicar no comportamento da variável ligada ao indivíduo, nesse caso específico, ao retorno anual de cada fundo ao final de determinado ano, conforme pergunta de pesquisa definida anteriormente.

Por ser técnica ainda pouco explorada em trabalhos acadêmicos nacionais, são apresentadas maiores informações sobre modelos multinível com dados em painel no apêndice A a este trabalho.

O Quadro 13, a seguir, concatena os objetivos às hipóteses de pesquisa com base na literatura, bem como às técnicas utilizadas para se aceitar ou rejeitar as hipóteses formuladas. 
Quadro 13 - Objetivos, Hipóteses e Técnicas Utilizadas no Trabalho

Objetivo principal: Desenvolver modelo de estimativa do retorno anual dos fundos PGBL/VGBL com investimentos em renda variável, entre 2007 e 2015, em função de variáveis que discriminam as estratégias executadas pelas administradoras de fundos.

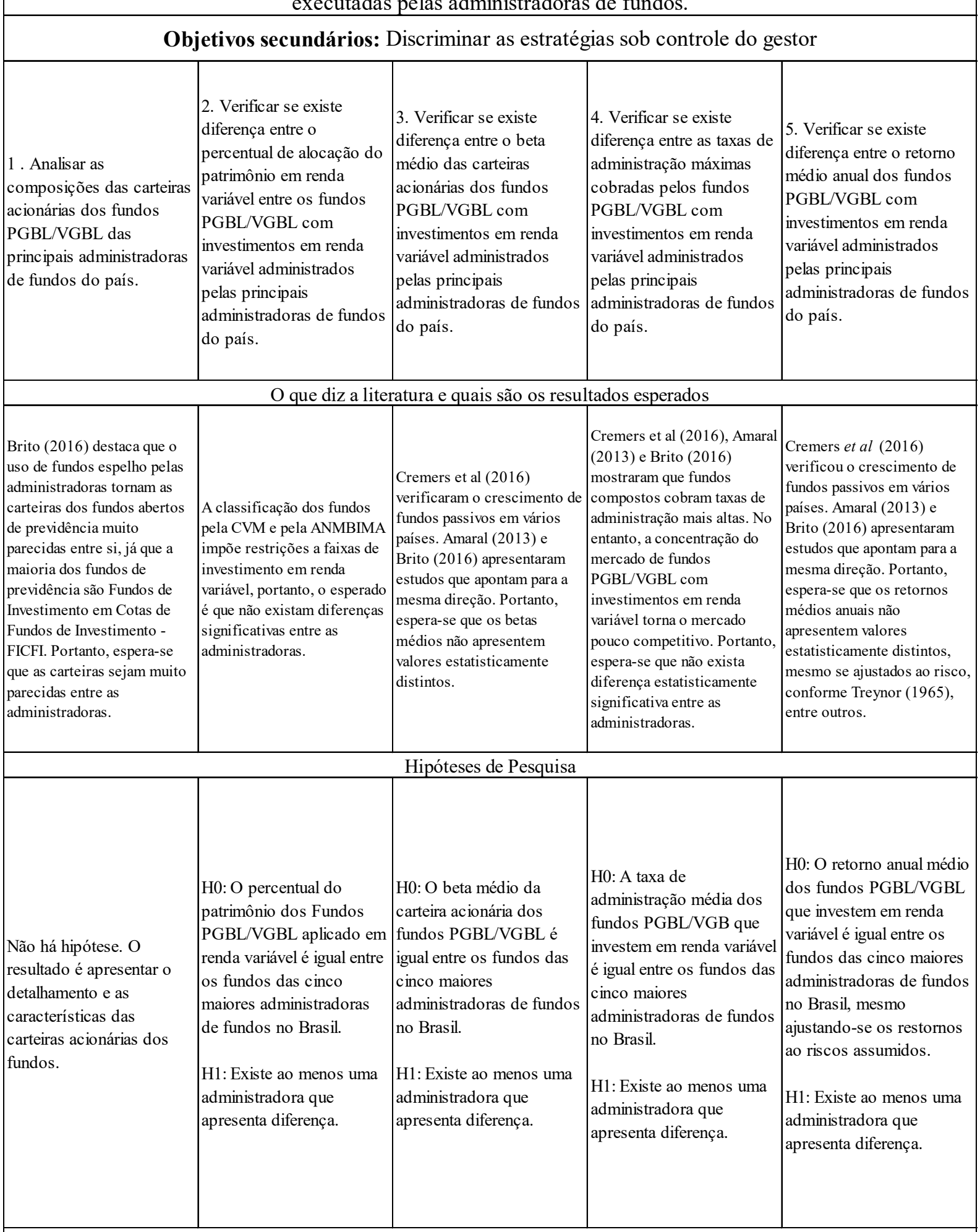

Técnica usada para se atingir o objetivo principal: regressão multinível com dados em painel, conforme Raudenbush e Bryk (2002), Santos (2013) e Fávero e Belfiore (2017). Técnica usada para se atingir os objetivos secundários: teste de média de Wald. 


\section{ANÁLISES DOS DADOS PARA ATENDER AOS OBJETIVOS SECUNDÁRIOS DA PESQUISA}

\subsection{Estrutura da Análise}

Os dados da pesquisa foram analisados a partir de uma visão mais abrangente, tomando-se o conjunto de todos os fundos abertos de previdência complementar nas modalidades PGBL/VGBL que mantiveram, direta ou indiretamente, posições acionárias ao final de qualquer um dos anos de 2007 a 2015. Essa visão mais abrangente é oferecida por meio da apresentação de tabelas e gráficos com estatísticas descritivas consolidadas de todos esses fundos. Essas estatísticas estão divididas em dois grupos, a saber: a) o que descreve a magnitude da população e subpopulações dos fundos estudados, e b) o que aborda as características das carteiras acionárias mantidas pelos fundos estudados. Na prática, o desenvolvimento deste trabalho combinará análises desses dois grupos para construção do enredo de comprovação da tese aqui proposta.

Cabe destacar que, das primeiras análises de dados, observou-se claramente a concentração do mercado estudado sob domínio de poucas instituições financeiras, todas ligadas aos principais bancos comerciais de varejo que atuam no mercado brasileiro. Portanto, este trabalho apresentará em muitas ocasiões a análise de dados segmentados dessas administradoras.

Tal concentração de foco na realização de análises, como será visto, permitiu a exposição mais profunda dos dados, o que facilitou a identificação de padrões e e/ou particularidades nas características e na gestão das carteiras acionárias mantidas por fundos PGBL/VGBL oferecidos no país. Essa concentração também foi necessária para o cumprimento dos objetivos secundários desta tese.

De tal sorte que, por sua relevância e a partir dos primeiros sinais apontados pelos dados, esse recorte, com frequência, buscou oferecer, do ponto de vista didático, a base para a construção da narrativa lógica para a escolha da técnica, teorização e validação da especificação do modelo econométrico desenvolvido para buscar responder à questão formulada neste trabalho. Tal modelo empírico propõe-se ser válido para o conjunto total dos fundos aqui estudados, dentro do domínio temporal definido, conforme será detalhado na segunda seção deste capítulo, muito embora existam diferenças que possibilitarão a realização de novas pesquisas.

\subsection{Explorando os Dados Gerais para Entender a População Estudada}

A Tabela 4, a seguir, mostra a evolução anual da quantidade de fundos por administradora, ordenada decrescentemente pelo número médio de fundos objeto desta pesquisa. No total, 
foram observados dados de 671 fundos únicos que apresentaram posições acionárias em ao menos um dos anos, durante o período analisado.

Tabela 4 - Quantidade de Fundos PGBL/VGBL com Renda Variável

\begin{tabular}{|c|c|c|c|c|c|c|c|c|c|c|c|}
\hline$\#$ & Administradora & 2007 & 2008 & 2009 & 2010 & 2011 & 2012 & 2013 & 2014 & 2015 & Média \\
\hline 1 & Itau Unibanco SA & 34 & 40 & 56 & 79 & 100 & 136 & 143 & 126 & 93 & 90 \\
\hline 2 & Bradesco & 23 & 23 & 27 & 32 & 40 & 49 & 59 & 55 & 53 & 40 \\
\hline 3 & Bem Dtvm & 20 & 25 & 29 & 36 & 42 & 47 & 51 & 50 & 52 & 39 \\
\hline 4 & BB Dtvm S.A & 13 & 21 & 23 & 26 & 27 & 30 & 39 & 39 & 36 & 28 \\
\hline \multirow[t]{2}{*}{5} & HSBC & 14 & 20 & 22 & 30 & 31 & 28 & 27 & 32 & 26 & 26 \\
\hline & Subtotal 1 & 104 & 129 & 157 & 203 & 240 & 290 & 319 & 302 & 260 & 223 \\
\hline 6 & Sul America Investimentos Dtvm & 9 & 12 & 13 & 15 & 21 & 23 & 24 & 26 & 27 & 19 \\
\hline 7 & Banco Santander (Brasil) SA & 10 & 12 & 17 & 18 & 18 & 25 & 17 & 20 & 15 & 17 \\
\hline 8 & BNY Mellon Servicos Financeiros Dtvm SA & 5 & 4 & 6 & 11 & 20 & 22 & 27 & 22 & 19 & 15 \\
\hline 9 & Banco Itaucard SA & 11 & 10 & 14 & 24 & 19 & 16 & 11 & 2 & 0 & 12 \\
\hline & Caixa & 4 & 7 & 7 & 7 & 7 & 16 & 16 & 16 & 16 & 11 \\
\hline & Intrag & 5 & 8 & 8 & 9 & 10 & 12 & 13 & 14 & 13 & 10 \\
\hline 12 & BTG Pactual Servicos Financeiros SA Dtvr & 5 & 9 & 10 & 10 & 10 & 10 & 11 & 11 & 12 & 10 \\
\hline 13 & Western Asset & 2 & 9 & 9 & 11 & 11 & 11 & 11 & 11 & 12 & 10 \\
\hline 14 & Js Gestao de Investimento & 3 & 5 & 5 & 5 & 7 & 10 & 14 & 14 & 15 & 9 \\
\hline 15 & Credit Suisse Hedging Griffo Cor Val S.A & 1 & 2 & 2 & 6 & 6 & 5 & 6 & 11 & 20 & 7 \\
\hline 16 & Alfa & 3 & 4 & 8 & 8 & 7 & 7 & 7 & 7 & 7 & 6 \\
\hline 17 & Citibank & 3 & 5 & 6 & 7 & 6 & 9 & 7 & 5 & 6 & 6 \\
\hline 18 & BNP Paribas & 3 & 3 & 3 & 3 & 5 & 7 & 7 & 7 & 8 & 5 \\
\hline 19 & Banco Cooperativo Sicredi SA & 3 & 4 & 4 & 4 & 3 & 3 & 3 & 3 & 3 & 3 \\
\hline 20 & Votorantim Asset & 2 & 2 & 2 & 2 & 2 & 2 & 0 & 9 & 8 & 3 \\
\hline 21 & Banco Fator & 1 & 2 & 2 & 2 & 2 & 2 & 2 & 2 & 1 & 2 \\
\hline 22 & JP Morgan & 0 & 0 & 0 & 0 & 2 & 2 & 2 & 2 & 2 & 1 \\
\hline 23 & Mercantil do Brasil Corretora S A Ctvm & 1 & 1 & 1 & 1 & 1 & 1 & 1 & 1 & 1 & 1 \\
\hline 24 & Js Adm Recursos & 0 & 0 & 1 & 1 & 1 & 1 & 2 & 2 & 0 & 1 \\
\hline 25 & Solidus Ccvm & 0 & 0 & 1 & 1 & 1 & 1 & 1 & 0 & 0 & 1 \\
\hline 26 & Santander Brasil Asset Manag Dtvm SA & 1 & 1 & 1 & 0 & 0 & 0 & 0 & 0 & 0 & 0 \\
\hline 27 & Infinity Cetvm SA & 0 & 0 & 0 & 1 & 1 & 1 & 0 & 0 & 0 & 0 \\
\hline 28 & Santander Securities Services Brasil & 0 & 0 & 0 & 0 & 0 & 0 & 0 & 1 & 1 & 0 \\
\hline 29 & Schroder Invest. Manag. Brasil Dtvm & 1 & 1 & 0 & 0 & 0 & 0 & 0 & 0 & 0 & 0 \\
\hline & Santander Asset Management Dtvm & 1 & 0 & 0 & 0 & 0 & 0 & 0 & 0 & 0 & 0 \\
\hline & Subtotal 2 & 74 & 101 & 120 & 146 & 160 & 186 & 182 & 186 & 186 & 149 \\
\hline & Total & 178 & 230 & 277 & 349 & 400 & 476 & 501 & 488 & 446 & 372 \\
\hline
\end{tabular}

Fonte: Economática

Tabela preparada pelo autor

Considerando que a grande maioria dos fundos abertos de previdência complementar pode ser cotista de outros fundos de investimento (FICFI - Fundos de Investimento em Cotas de Fundos de Investimentos), as participações acionárias desses fundos foram obtidas inclusive pelo método indireto, ou seja, considerando-se as suas participações nas cotas de outros fundos investidos. Por exemplo, se um fundo PGBL/VGBL possuísse, na data analisada, 10\% das cotas de um fundo que mantivesse investimentos em ações, então, foi considerado, neste estudo, que $10 \%$ da posição acionária em cada ativo detido por esse fundo pertencia, por equivalência patrimonial, ao fundo de previdência investidor. Por essa abordagem, foi possível identificar qual a proporção de cada ação dentro da carteira de renda variável de cada fundo ao longo do período analisado. 
Dessa forma, visando dar maior fluidez à leitura deste trabalho, a partir desse ponto, todas as vezes em que for utilizada a expressão participação acionária, tratar-se-á de participação acionária direta e indireta mantida pelos fundos, como já descrito.

A Tabela 5, a seguir, mostra a posição acionária, em milhares de reais, mantida pelos fundos PGBL/VGBL, organizadas por relevância da posição média mantida no período, de cada uma das administradoras de fundos presentes na base de dados. Os números mostram uma posição acionária média de mais de $\mathrm{R} \$ 12,7$ bilhões, no período, com mínimo de $\mathrm{R} \$ 7,3$ bilhões, em 2007, e máximo de R\$20,1 bilhões, em 2010.

Tabela 5 - Posição Acionária por Administradora - Fundos PGBL/VGBL com Renda Variável

\begin{tabular}{|c|c|c|c|c|c|c|c|c|c|c|}
\hline \# Administradora & 2007 & 2008 & 2009 & 2010 & 2011 & 2012 & 2013 & 2014 & 2015 & Média \\
\hline 1 Bradesco & 3.502 .489 & 3.096 .271 & 5.306 .751 & 6.730 .113 & 4.686 .869 & 4.382 .414 & 3.554 .715 & 3.037 .574 & 2.284 .403 & 4.064 .622 \\
\hline 2 BB Dtvm S.A & 583.622 & 828.757 & 2.057 .822 & 3.857 .025 & 3.839 .035 & 4.429 .279 & 3.847 .661 & 3.392 .091 & 2.351 .944 & 2.798 .582 \\
\hline 3 Itau Unibanco SA & 1.069 .007 & 1.281 .688 & 1.863 .596 & 2.752 .680 & 3.099 .643 & 2.782 .852 & 1.633 .403 & 1.156 .273 & 841.639 & 1.831 .198 \\
\hline 4 Caixa & 547.477 & 640.657 & 1.059 .189 & 1.614 .448 & 1.338 .522 & 1.281 .960 & 1.078 .324 & 882.648 & 740.616 & 1.020 .427 \\
\hline 5 Banco Santander (Brasil) SA & 137.309 & 315.932 & 1.176 .191 & 1.607 .056 & 1.016 .135 & 1.136 .029 & 763.835 & 600.988 & 487.444 & 804.546 \\
\hline Subtotal 1 & 5.839 .904 & 6.163 .304 & 11.463 .550 & 16.561 .322 & 13.980 .205 & 14.012 .534 & 10.877 .938 & 9.069 .574 & 6.706 .045 & 10.519 .375 \\
\hline 6 HSBC & 356.568 & 320.108 & 679.887 & 954.281 & 697.363 & 680.612 & 574.133 & 509.482 & 372.853 & 571.699 \\
\hline 7 Bem Dtvm & 320.099 & 309.347 & 477.721 & 615.693 & 587.327 & 659.859 & 671.613 & 632.603 & 412.281 & 520.727 \\
\hline 8 Banco Itaucard SA & 507.090 & 480.703 & 767.206 & 938.394 & 95.990 & 53.958 & 26.227 & 9.778 & 0 & 319.927 \\
\hline 9 Sul America Investimentos Dtvm & 41.282 & 77.546 & 156.629 & 242.343 & 230.530 & 232.550 & 205.788 & 156.312 & 143.582 & 165.173 \\
\hline 10 Js Gestao de Investimento & 94.160 & 118.837 & 142.324 & 233.787 & 168.136 & 149.053 & 102.076 & 91.237 & 66.826 & 129.604 \\
\hline 11 Western Asset & 24.946 & 27.723 & 69.671 & 127.338 & 122.500 & 135.357 & 109.332 & 78.691 & 56.106 & 83.518 \\
\hline 12 Intrag & 26.980 & 29.705 & 33.608 & 46.660 & 92.394 & 107.883 & 150.366 & 120.380 & 110.978 & 79.884 \\
\hline 13 Citibank & 3.942 & 7.839 & 73.548 & 124.086 & 97.243 & 115.488 & 101.116 & 58.051 & 22.499 & 67.090 \\
\hline 14 BNY Mellon Servicos Financeiros Dtvm SA & 20.147 & 11.978 & 23.121 & 40.662 & 60.586 & 58.381 & 73.132 & 107.293 & 152.464 & 60.863 \\
\hline 15 Alfa & 16.899 & 37.673 & 54.096 & 62.550 & 56.662 & 53.936 & 43.159 & 29.714 & 19.306 & 41.555 \\
\hline 16 Credit Suisse Hedging Griffo Cor Val S.A & 12.773 & 7.713 & 12.544 & 37.756 & 43.079 & 31.676 & 28.759 & 39.894 & 38.009 & 28.023 \\
\hline 17 BTG Pactual Servicos Financeiros SA Dtvr & 35.856 & 16.005 & 20.194 & 29.130 & 23.266 & 26.803 & 25.670 & 23.041 & 14.819 & 23.865 \\
\hline 18 Banco Cooperativo Sicredi SA & 3.957 & 6.777 & 11.710 & 16.696 & 13.591 & 17.180 & 14.216 & 14.884 & 16.565 & 12.842 \\
\hline 19 Votorantim Asset & 3.108 & 5.860 & 10.308 & 12.437 & 7.734 & 13.145 & 0 & 31.402 & 24.520 & 12.057 \\
\hline 20 JP Morgan & 0 & 0 & 0 & 0 & 17.740 & 19.277 & 16.916 & 14.241 & 13.551 & 9.080 \\
\hline 21 Banco Fator & 3.211 & 1.310 & 9.304 & 16.243 & 12.126 & 8.669 & 12.457 & 6.790 & 5.063 & 8.352 \\
\hline 22 BNP Paribas & 3.218 & 2.934 & 4.341 & 5.196 & 4.881 & 11.253 & 7.344 & 8.369 & 6.885 & 6.047 \\
\hline 23 Solidus Ccvm & 0 & 0 & 2.300 & 5.340 & 4.705 & 5.312 & 5.754 & 0 & 0 & 2.601 \\
\hline 24 Mercantil do Brasil Corretora S A Ctvm & 221 & 904 & 1.591 & 1.711 & 1.584 & 1.586 & 1.465 & 1.031 & 710 & 1.200 \\
\hline 25 Js Adm Recursos & 0 & 0 & 1.609 & 3.181 & 3.611 & 112 & 362 & 453 & 0 & 1.036 \\
\hline 26 Santander Asset Management Dtvm & 8.936 & 0 & 0 & 0 & 0 & 0 & 0 & 0 & 0 & 993 \\
\hline 27 Santander Securities Services Brasil & 0 & 0 & 0 & 0 & 0 & 0 & 0 & 3.195 & 4.546 & 860 \\
\hline 28 Santander Brasil Asset Manag Dtvm SA & 1.946 & 567 & 2.044 & 0 & 0 & 0 & 0 & 0 & 0 & 506 \\
\hline 29 Schroder Invest. Manag. Brasil Dtvm & 65 & 4.360 & 0 & 0 & 0 & 0 & 0 & 0 & 0 & 492 \\
\hline 30 Infinity Cctvm SA & 0 & 0 & 0 & 538 & 1.150 & 1.316 & 0 & 0 & 0 & 334 \\
\hline Subtotal 2 & 1.485 .401 & 1.467 .890 & 2.553.759 & 3.514 .020 & 2.342 .198 & 2.383 .406 & 2.169 .883 & 1.936 .842 & 1.481 .564 & 2.148 .329 \\
\hline Total & 7.325 .305 & 7.631 .194 & 14.017 .308 & 20.075 .341 & 16.322 .404 & 16.395 .939 & 13.047 .821 & 11.006 .416 & 8.187 .609 & 12.667 .704 \\
\hline
\end{tabular}

Adicionalmente, é possível observar por meio da Tabela 5 anterior que a posição acionária consolidada dessas carteiras quase triplicou entre 2007 e 2010. No entanto, os reflexos da persistente instabilidade política e econômica do país, a partir de 2013, também puderam ser verificados via redução da posição acionária consolidada dos fundos PGBL/VGBL nos últimos três anos do período analisado. Nesses anos, o Ibovespa sofreu desvalorizações sucessivas. 
Destaca-se ainda que, já a partir de 2011, as captações líquidas (prêmio/aportes pagos menos retiradas dos cotistas) dos fundos PGBL/VGBL que mantiveram posições acionárias foram negativas, conforme mostra o Gráfico 2, a seguir:

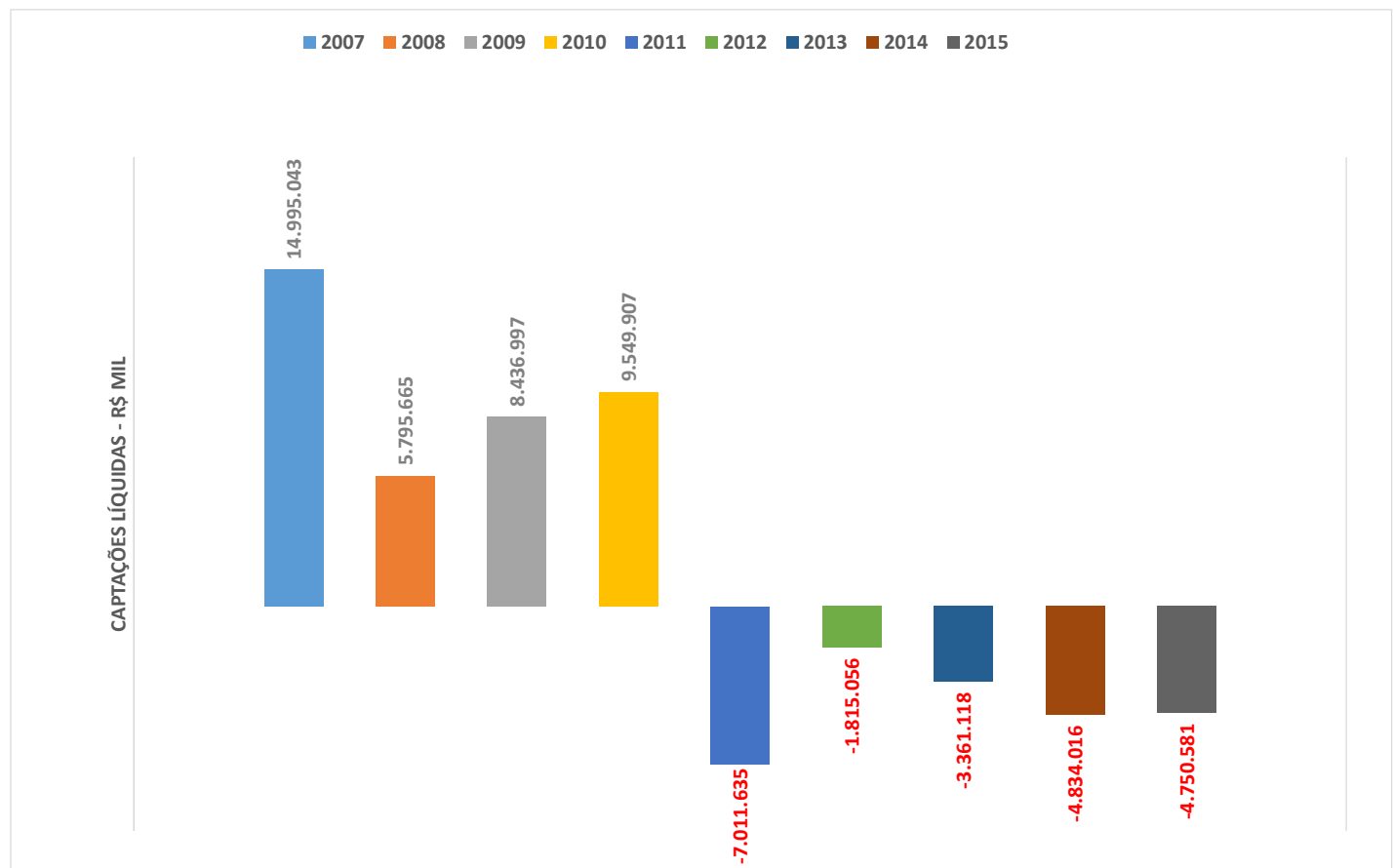

Gráfico 2 - Evolução das Captações Líquidas do Fundos PGBL/VGBL com Renda Variável Fonte: Economática

Gráfico elaborado pelo autor

No entanto, esse fenômeno foi específico às categorias de fundos aqui pesquisadas. Isso porque, no mesmo período, as captações líquidas anuais consolidadas de todas as modalidades de fundos abertos de previdência ofertados no país foram positivas, relevantes e consistentemente crescentes, como pode ser visto no seguinte Gráfico 3. 


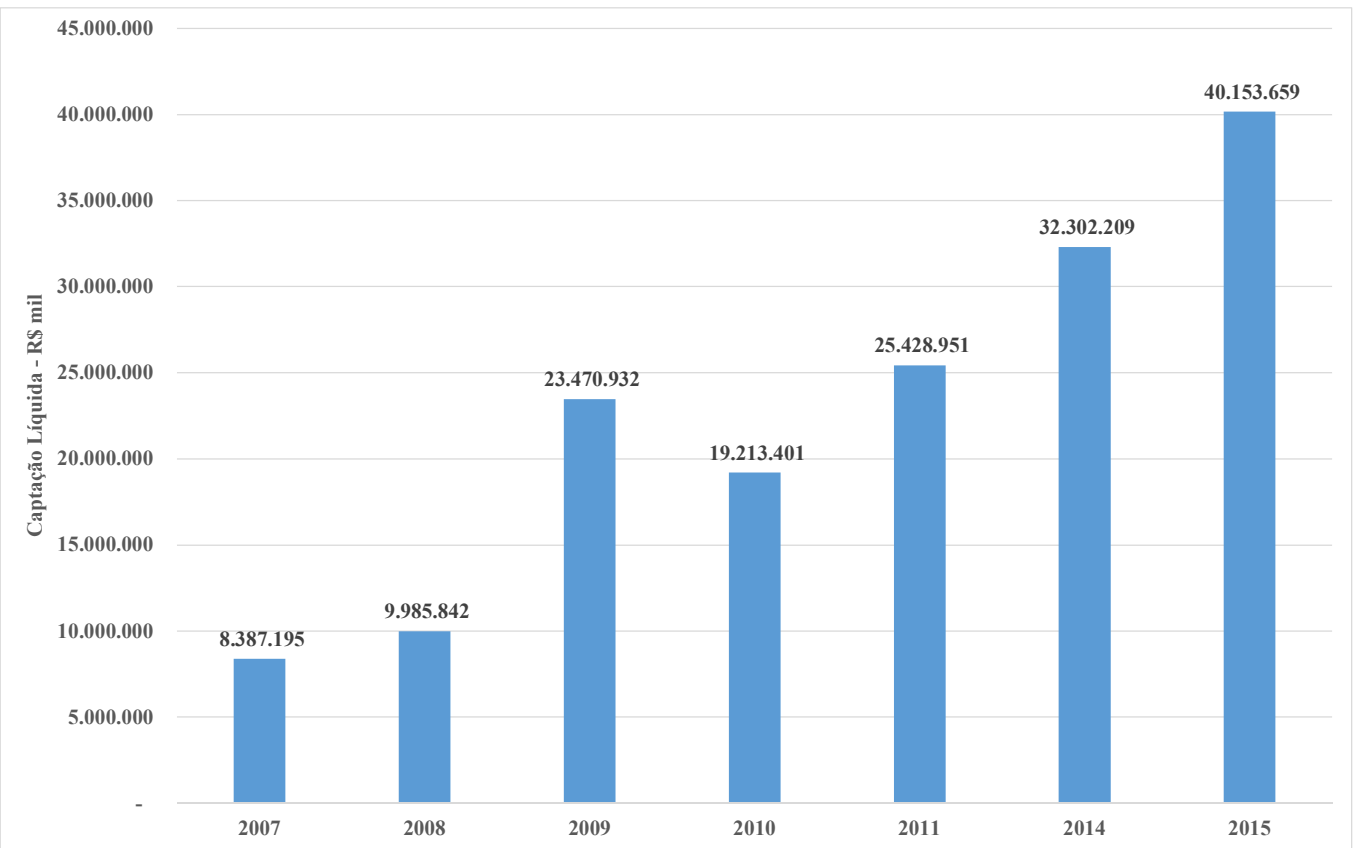

Gráfico 3 - Captações Líquidas Todas as Modalidades de Fundos Abertos de Previdência Fonte: ANBIMA

Gráfico elaborado pelo autor

Tal comportamento das captações líquidas dos fundos PGBL/VGBL com investimentos em renda variável sugere a existência de razões objetivas. Em especial, no período analisado, a valorização bruta da SELIC foi mais de $150 \%$ superior à valorização do Ibovespa, como mostra o Gráfico 4, a seguir. Por exemplo, sem considerar taxas e impostos, quem investiu, em 31/12/2006, R\$ 100.000 em títulos remunerados pela SELIC, teria um patrimônio ao redor de R\$ 252 mil, em 31/12/2015. Por outro lado, um investidor que tivesse investido a mesma quantia em uma carteira que emulasse o Ibovespa teria, ao final do mesmo período, cerca de R\$ 98,4 mil, ou seja, menos que o valor investido inicialmente. Cabe destacar que, em ambos os casos ilustrativos, os valores são nominais e não consideram o efeito inflacionário ou qualquer ajuste em função da relação de retorno pelo risco assumido em cada tipo de ativo. 


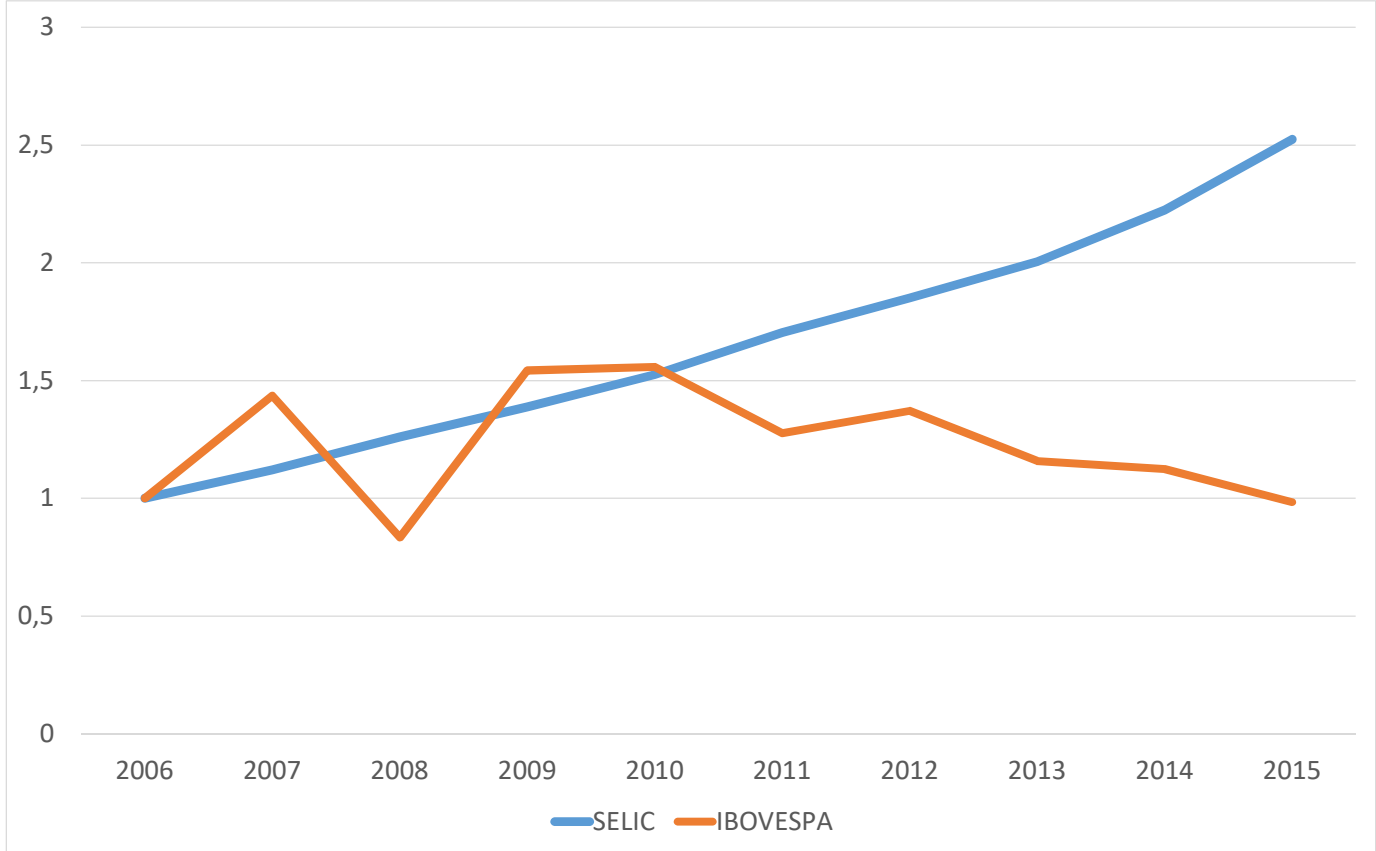

Gráfico 4 - Fator de rentabilidade acumulada SELIC x Ibovespa - Base: 31/12/2006 = 1 Fonte: Economática

Gráfico elaborado pelo autor

De todo modo, as administradoras ligadas aos principais bancos comerciais brasileiros têm mantido, consistentemente, ao longo do período analisado, fatia ao redor de $80 \%$ do total de investimentos em renda variável realizados pelos fundos PGBL/VGBL, indicando evidente concentração nessa modalidade de produto financeiro, conforme mostra a Tabela 6 , a seguir.

Tabela 6 - Posição Acionária sobre o Total - Principais Administradoras - Fundos PGBL/VGBL com RV

\begin{tabular}{|c|c|c|c|c|c|c|c|c|c|c|c|}
\hline \multicolumn{12}{|c|}{5 Principais Administradoras em Posição Acionária Consolidada (direta ou indireta) por Administradora dos Fundos PGBL/VGBL (ao final do ano) } \\
\hline \# & Administradora & 2007 & 2008 & 2009 & 2010 & 2011 & 2012 & 2013 & 2014 & 2015 & Média \\
\hline 1 & Bradesco & $47,8 \%$ & $40,6 \%$ & $37,9 \%$ & $33,5 \%$ & $28,7 \%$ & $26,7 \%$ & $27,2 \%$ & $27,6 \%$ & $27,9 \%$ & $32,1 \%$ \\
\hline 2 & BB Dtvm S.A & $8,0 \%$ & $10,9 \%$ & $14,7 \%$ & $19,2 \%$ & $23,5 \%$ & $27,0 \%$ & $29,5 \%$ & $30,8 \%$ & $28,7 \%$ & $22,1 \%$ \\
\hline & Itau Unibanco SA & $14,6 \%$ & $16,8 \%$ & $13,3 \%$ & $13,7 \%$ & $19,0 \%$ & $17,0 \%$ & $12,5 \%$ & $10,5 \%$ & $10,3 \%$ & $14,5 \%$ \\
\hline 4 & Caixa & $7,5 \%$ & $8,4 \%$ & $7,6 \%$ & $8,0 \%$ & $8,2 \%$ & $7,8 \%$ & $8,3 \%$ & $8,0 \%$ & $9,0 \%$ & $8,1 \%$ \\
\hline & Banco Santander (Brasil) SA & $1,9 \%$ & $4,1 \%$ & $8,4 \%$ & $8,0 \%$ & $6,2 \%$ & $6,9 \%$ & $5,9 \%$ & $5,5 \%$ & $6,0 \%$ & $6,4 \%$ \\
\hline
\end{tabular}

Fonte: Economática

Tabela preparada pelo autor

Assim, por representarem parte relevante dos fundos PGBL/VGBL com parcela do patrimônio investida em ativos de renda variável e, pela possibilidade de maior aprofundamento das análises exploratórias dos dados coletados, esta pesquisa, como já mencionado, em muitas ocasiões se dedicará a entender mais detalhadamente as características das carteiras acionárias mantidas pelos fundos PGBL/VGBL dessas cinco administradoras. Entretanto, esse foco em nada prejudicará a formulação de um modelo econométrico mais abrangente, como mais adiante ficará demonstrado. 
Ao serem analisadas as estatísticas descritivas dos fundos PGBL/VGBL que detinham posições em renda variável, observa-se, ao longo do período, tanto o aumento significativo no número de fundos quanto o aumento na diversificação das carteiras. A Tabela 7, a seguir, apresenta estatísticas descritivas consolidadas de todos os fundos PGBL/VGBL, população desta pesquisa, ao longo do período. A quantidade dessas modalidades de fundos cresceu mais de $150 \%$ entre 2007 e 2015 . O número médio de ações distintas de empresas por carteira desses fundos praticamente duplicou, no período, assim como a quantidade mais frequente - moda, a mediana e o número máximo de ações em carteira, indicando um aumento na diversificação dos investimentos.

Tabela 7 - Descrição Carteiras Acionárias - Fundos PGBL/VGBL com Renda Variável (Todas Administradoras)

\begin{tabular}{lrrrrrrrrr}
\hline Estatística & $\mathbf{2 0 0 7}$ & $\mathbf{2 0 0 8}$ & $\mathbf{2 0 0 9}$ & $\mathbf{2 0 1 0}$ & $\mathbf{2 0 1 1}$ & $\mathbf{2 0 1 2}$ & $\mathbf{2 0 1 3}$ & $\mathbf{2 0 1 4}$ & $\mathbf{2 0 1 5}$ \\
\hline Qtde Fundos & 178 & 230 & 277 & 349 & 400 & 476 & 501 & 488 & 446 \\
Qtde Média de Ações por Carteira & 26 & 28 & 37 & 53 & 52 & 55 & 55 & 50 & 45 \\
Qtde + Frequente de Ações por Carteira & 30 & 30 & 46 & 68 & 67 & 67 & 71 & 67 & 58 \\
Mediana Qtde de Ações por Carteira & 30 & 30 & 41 & 58 & 56 & 63 & 64 & 54 & 49 \\
Qtde Mínima de Ações por Carteira & 1 & 1 & 1 & 2 & 2 & 2 & 1 & 1 & 1 \\
Qtde Máxima de Ações por Carteira & 51 & 52 & 56 & 90 & 105 & 141 & 127 & 108 & 93 \\
\hline
\end{tabular}

Fonte: Economática

Tabela preparada pelo autor

A título de comparação, o número de ações distintas presentes no principal índice acionário brasileiro, o Ibovespa, oscilou entre 63 e 73, ao final dos anos contidos no período analisado. Especificamente, a partir de 2010, como pode ser visto no Gráfico 5, a seguir, houve uma aproximação quase perfeita entre o número de ações distintas presentes no Ibovespa e a quantidade mais frequente de ações distintas nas carteiras dos fundos PGBL/VGBL, indicando, mais uma vez, um possível padrão na gestão desses fundos. 


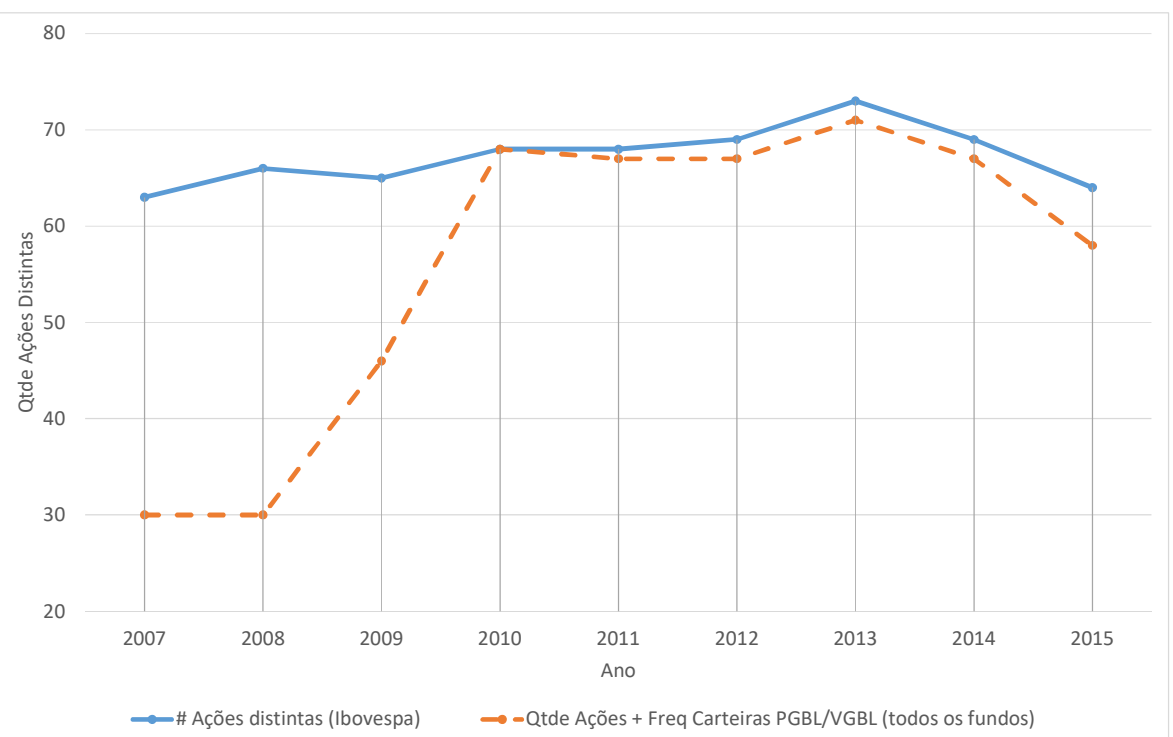

Gráfico 5 - Quantidade de Ações Distintas Mais Frequentes - Fundos PGBL/VGBL x Quantidade de Ações no

Fonte: Economática / BM\&F Bovespa Ibovespa

Gráfico elaborado pelo autor

As estatísticas descritivas das carteiras acionárias dos fundos PGBL/VGBL administrados pelas cinco principais administradoras de fundos do país não diferem muito das já apresentadas estatísticas consolidadas, conforme mostra a Tabela 8 seguir. Trata-se de mais um elemento a reforçar a relevância do estudo dessa subpopulação. Na realidade, uma hipótese plausível a ser ainda testada é que as características dos fundos das principais administradoras tenderiam a funcionar como proxies das características mais gerais desse mercado de fundos.

Tabela 8 - Descrição Carteiras Acionárias - Fundos PGBL/VGBL com Renda Variável (5 Maiores Administradoras)

\begin{tabular}{lrrrrrrrrr}
\hline Estatística & $\mathbf{2 0 0 7}$ & $\mathbf{2 0 0 8}$ & $\mathbf{2 0 0 9}$ & $\mathbf{2 0 1 0}$ & $\mathbf{2 0 1 1}$ & $\mathbf{2 0 1 2}$ & $\mathbf{2 0 1 3}$ & $\mathbf{2 0 1 4}$ & $\mathbf{2 0 1 5}$ \\
\hline Qtde Fundos & 84 & 103 & 130 & 162 & 192 & 256 & 274 & 256 & 213 \\
Qtde Média de Ações por Carteira & 28 & 29 & 42 & 63 & 63 & 64 & 67 & 65 & 58 \\
Qtde + Frequente de Ações por Carteira & 30 & 30 & 46 & 68 & 67 & 67 & 71 & 67 & 58 \\
Mediana Qtde de Ações por Carteira & 30 & 30 & 42 & 68 & 67 & 67 & 71 & 67 & 58 \\
Qtde Mínima de Ações por Carteira & 1 & 4 & 7 & 9 & 11 & 7 & 8 & 3 & 11 \\
Qtde Máxima de Ações por Carteira & 33 & 39 & 56 & 83 & 98 & 133 & 127 & 108 & 93 \\
\hline
\end{tabular}

Fonte Economática

Tabela preparada pelo autor

A Tabela 9, a seguir, apresenta listas das 25 ações, ordenadas decrescentemente em cada ano, que mostram posições acionárias consolidadas detidas pelos fundos abertos de previdência complementar VGBL/PGBL. Juntas, essas ações de empresas representaram percentual relevante da posição acionária de todos esses fundos. Em especial, observou-se a diminuição 
da concentração das 25 empresas mais investidas pelos fundos PGBL/VGB entre os anos de 2008 e 2013, com alguma recuperação nos anos de 2014 e 2015.

Tabela 9 - Ações Mais Relevantes na Carteira Consolidada de Todos os Fundos PGBL/VGBL

\begin{tabular}{|c|c|c|c|c|c|c|c|c|c|c|c|c|c|c|c|c|c|c|}
\hline Ordem & Papel & 2007 & Papel & 2008 & Papel & 2009 & Papel & 2010 & Papel & 2011 & Papel & 2012 & Papel & 2013 & Papel & 2014 & Papel & 2015 \\
\hline 1 & PETR4 & $25,76 \%$ & PETR4 & $21,42 \%$ & PETR4 & $16,38 \%$ & VALE5 & $10,51 \%$ & PETR4 & $8,67 \%$ & VALE5 & $10,53 \%$ & VALE5 & $9,64 \%$ & ITUB4 & $10,74 \%$ & ITUB4 & $9,46 \%$ \\
\hline 2 & VALE5 & $15,29 \%$ & VALE5 & $13,94 \%$ & VALE5 & $13,28 \%$ & PETR4 & $9,71 \%$ & VALE5 & $8,63 \%$ & PETR4 & $6,66 \%$ & PETR4 & $6,13 \%$ & ABEV3 & $7,21 \%$ & ABEV 3 & $08 \%$ \\
\hline 3 & GGBR4 & $4,64 \%$ & ITUB4 & $5,58 \%$ & ITUB4 & $6,03 \%$ & ITUB4 & $5,05 \%$ & ITUB4 & $6,20 \%$ & ITUB4 & $4,94 \%$ & ITUB4 & $5,69 \%$ & BBDC4 & $5,58 \%$ & BBDC4 & $5,96 \%$ \\
\hline 4 & VALE3 & $4,25 \%$ & BBDC4 & $5,28 \%$ & PETR3 & $5,45 \%$ & PETR3 & $4,16 \%$ & OGXP3 & $5,27 \%$ & BVMF3 & $3,89 \%$ & BBAS3 & $3,27 \%$ & VALE5 & $5,29 \%$ & ITSA4 & ,58\% \\
\hline 5 & ITUB4 & $4,08 \%$ & VALE3 & $4,86 \%$ & VALE3 & $5,35 \%$ & OGXP3 & $3,85 \%$ & BVMF3 & $3,48 \%$ & VALE3 & $3,64 \%$ & BVMF3 & $3,03 \%$ & ITSA4 & $4,78 \%$ & BRFS3 & $4,18 \%$ \\
\hline 6 & BBDC4 & $3,16 \%$ & BBAS3 & $4,42 \%$ & BVMF3 & $3,56 \%$ & VALE3 & $3,76 \%$ & GGBR4 & $3,42 \%$ & BBAS3 & $3,24 \%$ & BBDC4 & $2,85 \%$ & PETR4 & $4,24 \%$ & CIEL3 & $3,49 \%$ \\
\hline 7 & ITSA4 & $3,07 \%$ & PETR3 & $3,30 \%$ & BBAS3 & $3,54 \%$ & BVMF3 & $3,73 \%$ & PETR3 & $3,18 \%$ & OGXP3 & $2,93 \%$ & ITSA4 & $2,77 \%$ & BRFS3 & $4,08 \%$ & PETR4 & $2,98 \%$ \\
\hline 8 & PETR3 & $3,05 \%$ & GGBR4 & $3,17 \%$ & BBDC4 & $3,37 \%$ & GGBR4 & $3,15 \%$ & VALE3 & $2,93 \%$ & PDGR3 & $2,51 \%$ & ABEV 3 & $2,70 \%$ & KROT3 & $3,04 \%$ & BVMF3 & $2,95 \%$ \\
\hline 9 & GOAU4 & $2,68 \%$ & ITSA4 & $3,07 \%$ & GGBR4 & $3,07 \%$ & BBAS3 & $2,81 \%$ & BBDC4 & $2,68 \%$ & BBDC4 & $2,47 \%$ & VALE3 & $2,53 \%$ & BVMF3 & $2,82 \%$ & UGPA3 & $2,80 \%$ \\
\hline 10 & CSNA3 & $2,68 \%$ & CMIG4 & $2,76 \%$ & CSNA3 & $3,06 \%$ & PDGR3 & $2,75 \%$ & ITSA4 & $2,66 \%$ & ITSA4 & $2,46 \%$ & USIM5 & $2,50 \%$ & UGPA3 & $2,46 \%$ & VALE5 & $2,77 \%$ \\
\hline 11 & USIM5 & $2,58 \%$ & USIM5 & $2,52 \%$ & ITSA4 & $2,57 \%$ & CSNA3 & $2,53 \%$ & BBAS3 & $2,65 \%$ & PETR3 & $2,41 \%$ & PETR3 & $2,45 \%$ & BBSE3 & $2,39 \%$ & CTIP3 & $2,71 \%$ \\
\hline 12 & BBAS3 & $2,45 \%$ & GOAU4 & $2,50 \%$ & USIM5 & $2,25 \%$ & ITSA4 & $2,20 \%$ & RDCD3 & $2,18 \%$ & USIM5 & $2,37 \%$ & GGBR4 & $2,42 \%$ & VALE3 & $2,30 \%$ & JBSS3 & $2,64 \%$ \\
\hline 13 & CPLE6 & $2,27 \%$ & BVMF3 & $2,21 \%$ & GOAU4 & $1,90 \%$ & USIM5 & $2,12 \%$ & BRFS3 & $1,95 \%$ & GGBR4 & $2,28 \%$ & CSNA3 & $2,20 \%$ & PETR3 & $2,24 \%$ & VIVT4 & $2,58 \%$ \\
\hline 14 & EGIE3 & $1,92 \%$ & CSNA3 & $2,03 \%$ & ELET3 & $1,82 \%$ & BBDC4 & $2,01 \%$ & PDGR3 & $1,89 \%$ & AMBV4 & $1,87 \%$ & CCRO3 & $1,91 \%$ & CIEL3 & $2,11 \%$ & PETR3 & $2,45 \%$ \\
\hline 15 & BRFS3 & $1,41 \%$ & CPLE6 & $1,81 \%$ & CYRE3 & $1,45 \%$ & CYRE3 & $1,65 \%$ & AMBV4 & $1,87 \%$ & MRVE3 & $1,77 \%$ & CIEL3 & $1,80 \%$ & BBAS3 & $1,99 \%$ & BBSE3 & $2,36 \%$ \\
\hline 16 & CMIG4 & $1,39 \%$ & ELET3 & $1,80 \%$ & PCAR4 & $1,41 \%$ & RDCD3 & $1,36 \%$ & CYRE3 & $1,70 \%$ & CSNA3 & $1,73 \%$ & CMIG4 & $1,65 \%$ & CCRO3 & $1,97 \%$ & VALE3 & $2,10 \%$ \\
\hline 17 & BRAP4 & $1,24 \%$ & EGIE3 & $1,78 \%$ & USIM3 & $1,22 \%$ & MRVE3 & $1,35 \%$ & USIM5 & $1,70 \%$ & CCRO3 & $1,65 \%$ & BRFS3 & $1,53 \%$ & VIVT4 & $1,73 \%$ & FIBR3 & $1,95 \%$ \\
\hline 18 & ELPL4 & $1,19 \%$ & BRFS3 & $1,52 \%$ & CMIG4 & $1,20 \%$ & BRFS3 & $1,32 \%$ & CSNA3 & $1,62 \%$ & GFSA3 & $1,62 \%$ & UGPA3 & $1,29 \%$ & PCAR4 & $1,71 \%$ & BBAS3 & $1,92 \%$ \\
\hline 19 & USIM3 & $1,11 \%$ & ELPL4 & $1,47 \%$ & BRFS3 & $1,12 \%$ & GFSA3 & $1,24 \%$ & CMIG4 & $1,48 \%$ & BRFS3 & $1,54 \%$ & BRML3 & $1,25 \%$ & EMBR3 & $1,67 \%$ & KROT3 & $1,87 \%$ \\
\hline 20 & ELET3 & $0,95 \%$ & CPLFE3 & $1,29 \%$ & MRVE3 & $1,12 \%$ & RSID3 & $1,19 \%$ & MRVE3 & $1,32 \%$ & HYPE3 & $1,53 \%$ & VIVT4 & $1,25 \%$ & JBSS3 & $1,64 \%$ & EMBR3 & $1,77 \%$ \\
\hline 21 & LREN3 & $0,86 \%$ & USIM3 & $1,17 \%$ & LAME4 & $1,03 \%$ & PCAR4 & $1,17 \%$ & VIVT4 & $1,21 \%$ & CYRE3 & $1,52 \%$ & CYRE3 & $1,20 \%$ & CTIP3 & $1,45 \%$ & CCRO3 & $1,74 \%$ \\
\hline 22 & ВтоW3 & $0,84 \%$ & BRAP4 & $0,87 \%$ & OGXP3 & $1,03 \%$ & MMXM: & $1,14 \%$ & ELPL4 & $1,15 \%$ & VIVT4 & $1,26 \%$ & HYPE3 & $1,17 \%$ & CMIG4 & $1,09 \%$ & SUZB5 & $1,41 \%$ \\
\hline 23 & OIBR4 & $0,83 \%$ & CCRO3 & $0,87 \%$ & CESP6 & $0,99 \%$ & AMBV4 & $1,11 \%$ & TIMP3 & $1,02 \%$ & BRML3 & $1,20 \%$ & PDGR3 & $1,08 \%$ & VLID3 & $1,01 \%$ & LREN3 & $1,38 \%$ \\
\hline 24 & RENT3 & $0,76 \%$ & ELET6 & $0,83 \%$ & CCRO3 & $0,93 \%$ & CMIG4 & $1,03 \%$ & PCAR4 & $1,02 \%$ & OIBR4 & $1,09 \%$ & GFSA3 & $1,08 \%$ & EGIE3 & $1,01 \%$ & EGIE3 & $1,23 \%$ \\
\hline \multirow[t]{2}{*}{25} & LAME4 & $0,74 \%$ & TRPL4 & $0,74 \%$ & LREN3 & $0,84 \%$ & GOLL4 & $1,01 \%$ & CCRO3 & $0,96 \%$ & LREN3 & $1,04 \%$ & TIMP3 & $1,04 \%$ & TIMP3 & $0,94 \%$ & BBDC3 & $1,12 \%$ \\
\hline & & $89,20 \%$ & & $91,22 \%$ & & $83,97 \%$ & & $71,90 \%$ & & $70,84 \%$ & & $68,15 \%$ & & $64,43 \%$ & & $75,49 \%$ & & $76,50 \%$ \\
\hline
\end{tabular}

Fonte: Economática

Tabela preparada pelo autor

Vale destacar que, em 2011, a OGX Petróleo - OGXP3 - foi a quarta colocada em termos de participação na carteira acionária consolidada de todos os fundos PGBL/VGBL. Registre-se ainda que tal empresa, ao final daquele ano, apresentava-se em estágio essencialmente préoperacional, e que anos mais tarde enfrentou sérias dificuldades, passando inclusive por processo de recuperação judicial, situação amplamente divulgada pela imprensa nacional e internacional em função da relevância das perdas causadas a seus investidores. Outro registro: em 2011, a OGXP3 era a terceira ação distinta mais relevante no Ibovespa, com o peso de aproximadamente 5,25\% na carteira teórica do índice, ficando atrás apenas das ações: Petrobras PN (PETR4) e Vale PN (VALE5). Mais ainda, em 2011 e 2012, o coeficiente beta desse ativo, conforme definido na metodologia deste trabalho, foi de 1,35 e 1,65, respectivamente.

Outro aspecto bastante interessante, que talvez mereça maior investigação em outro trabalho acadêmico, é a participação da ação preferencial da Petrobrás - PETR4 - principal ativo historicamente negociado na bolsa de valores brasileira - na carteira acionária consolidada dos fundos PGBL/VGBL. Verificou-se a flutuação dessa participação em relação à sua participação na carteira teórica do Ibovepa. Nos anos de 2007 a 2009, os fundos PGBL/VGBL mantiveram 
em sua carteira consolidada percentual acima da participação do ativo no Ibovespa. Entre 2010 e 2013, houve um comportamento mais passivo dos fundos, quase como que acompanhando a participação do papel no Ibovespa, com leve descolamento para baixo da participação consolidada dos fundos, que se ampliou nos anos de 2014 e 2015. Em 2014, especificamente, observou-se que a participação da PETR4 na carteira consolidada dos fundos se descola ainda mais da participação do ativo no Ibovespa, período esse que coincide com a deflagração da operação da Polícia Federal brasileira de combate à corrupção em contratos da empresa, operação de grande repercussão nacional e internacional, batizada de Lava Jato. É o que mostra o Gráfico 6, a seguir.

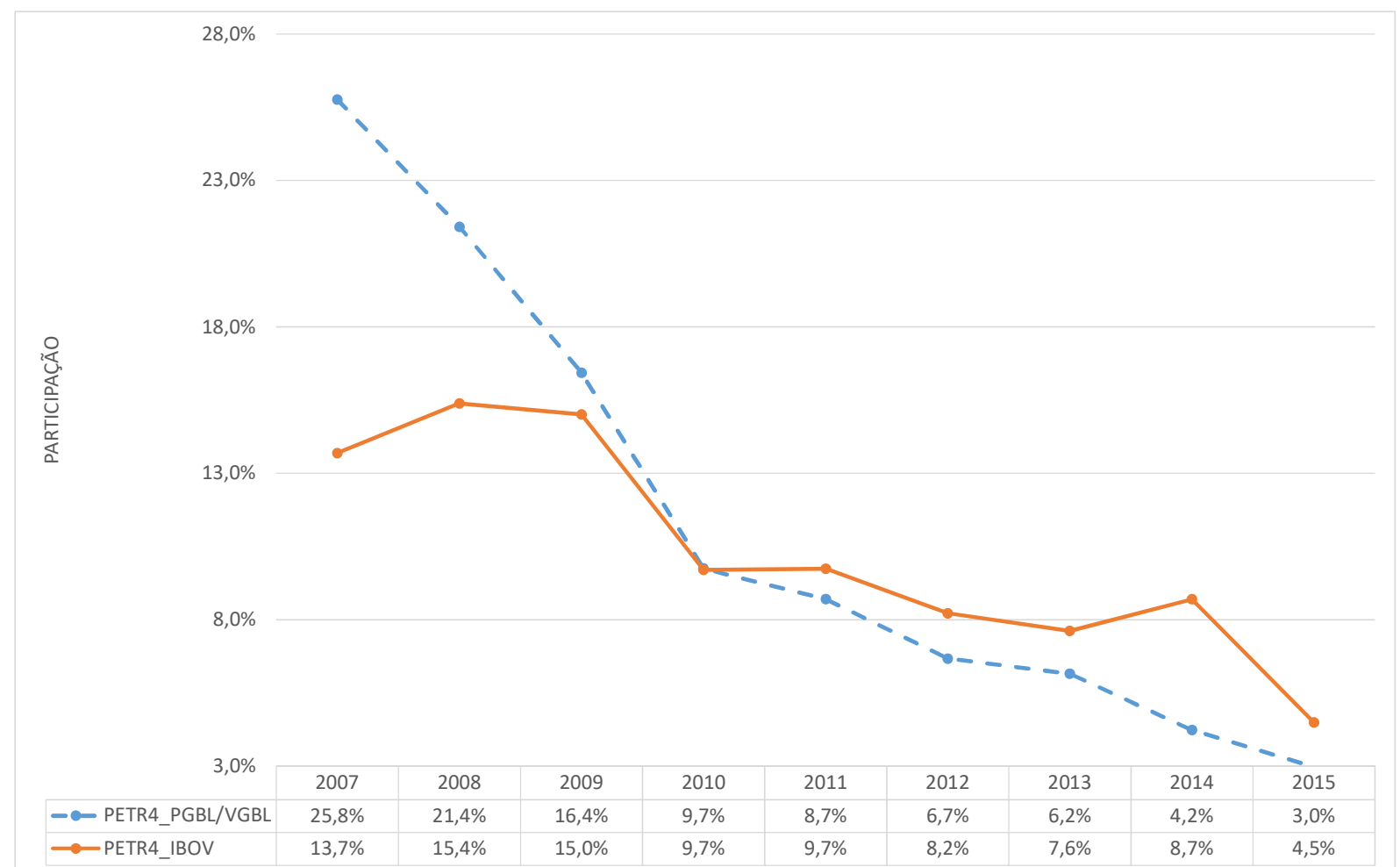

Gráfico 6 - Participação da Ação Petrobrás PN (PETR4) na Carteira Consolidada dos Fundos x Participação da Fonte: Economática / BM\&FBovespa PETR4 no Ibovespa

Vale lembrar que entre 2007 e 2009, como já apresentado, o número mais frequente de ações distintas nas carteiras dos fundos ficou abaixo do número de ações distintas presentes no Ibovespa, nos respectivos anos. A partir de 2010, como já mencionado, esses números convergiram. 
Até aqui, com base no que foi apresentado, tem-se as seguintes evidências:

a) Que o mercado de fundos previdenciários PGBL/VGBL com parcela de seus investimentos em renda variável é altamente concentrado. E está nas mãos de instituições financeiras controladas pelos principais bancos comerciais de varejo do país - de sorte que o comportamento dos fundos controlados por essas instituições tende a ter peso relevante na discriminação do mercado estudado, no período;

b) Que houve convergência do número mais frequente de ações distintas presentes nas carteiras dos fundos PGBL/VGBL ao número de ações distintas presentes no Ibovespa a partir de 2010;

c) Que a captação líquida consolidada desses fundos foi negativa a partir do início do surgimento de perdas acumuladas do Ibovespa em relação à valorização da SELIC, indicando uma possível aversão ao risco de curto prazo apesar do investimento em previdência ter características, teoricamente, de longo prazo;

d) Que a ação de uma empresa pré-operacional e de alto risco como OGXP3 foi a quarta mais investida pelos fundos PGBL/VGBL ao mesmo tempo em que também fazia parte do Ibovespa como terceira ação distinta mais relevante no referido índice.

e) Que, em 2010, houve convergência na participação de um dos principais ativos de renda variável do país, a ação da Petrobrás (PETR4), entre a posição consolidada dos fundos PGBL/VGBL e o peso desse ativo no Ibovespa. A partir de 2011 observou-se uma diminuição relativa da participação dos fundos comparada ao peso do ativo no Ibovespa, que se acentuou em 2014, como uma possível consequência de um evento, a Operação

\section{Lava Jato.}

Sendo assim, pela composição dos ativos mantidos pelos fundos objeto deste trabalho, tornouse fundamental a realização da análise consolidada da evolução dos retornos desses fundos em relação a dois indicadores referência do mercado brasileiro. Um ligado à renda fixa, no caso a valorização da SELIC. E outro, ligado ao mercado acionário: o Ibovespa. O Gráfico 7, a seguir, mostra a presença de forte correlação entre o retorno consolidado dos fundos PGBL/VGBL investidos em renda variável e a valorização do Ibovespa. 


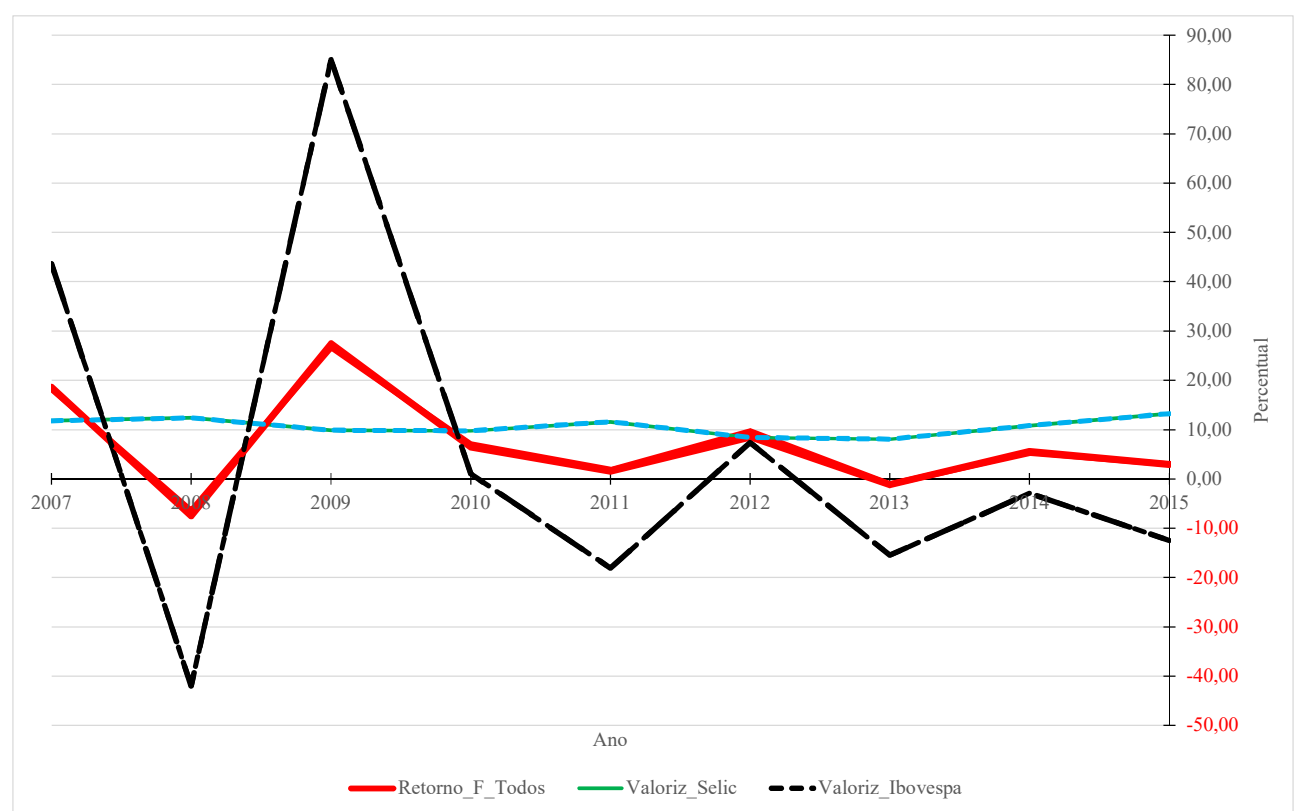

Gráfico 7- Retornos Médios de Todos os Fundos PGBL/VGBL com RV x SELIC x Ibovespa Fonte: Economática

Gráfico elaborado pelo autor

Se é verdadeira a hipótese aventada de que a subpopulação formada por fundos administrados pelas cinco maiores administradoras de fundos PGBL/VGBL com investimentos em renda variável é uma proxy adequada para representar o comportamento de todo o mercado dessa modalidade de fundos, então, o retorno médio ponderado dos fundos administrados pelas cinco maiores administradoras tenderia a ter um padrão similar ao retorno apresentado no gráfico anterior. É exatamente o que mostra o Gráfico 8, a seguir: os retornos são extremamente semelhantes durante todo o período analisado. 


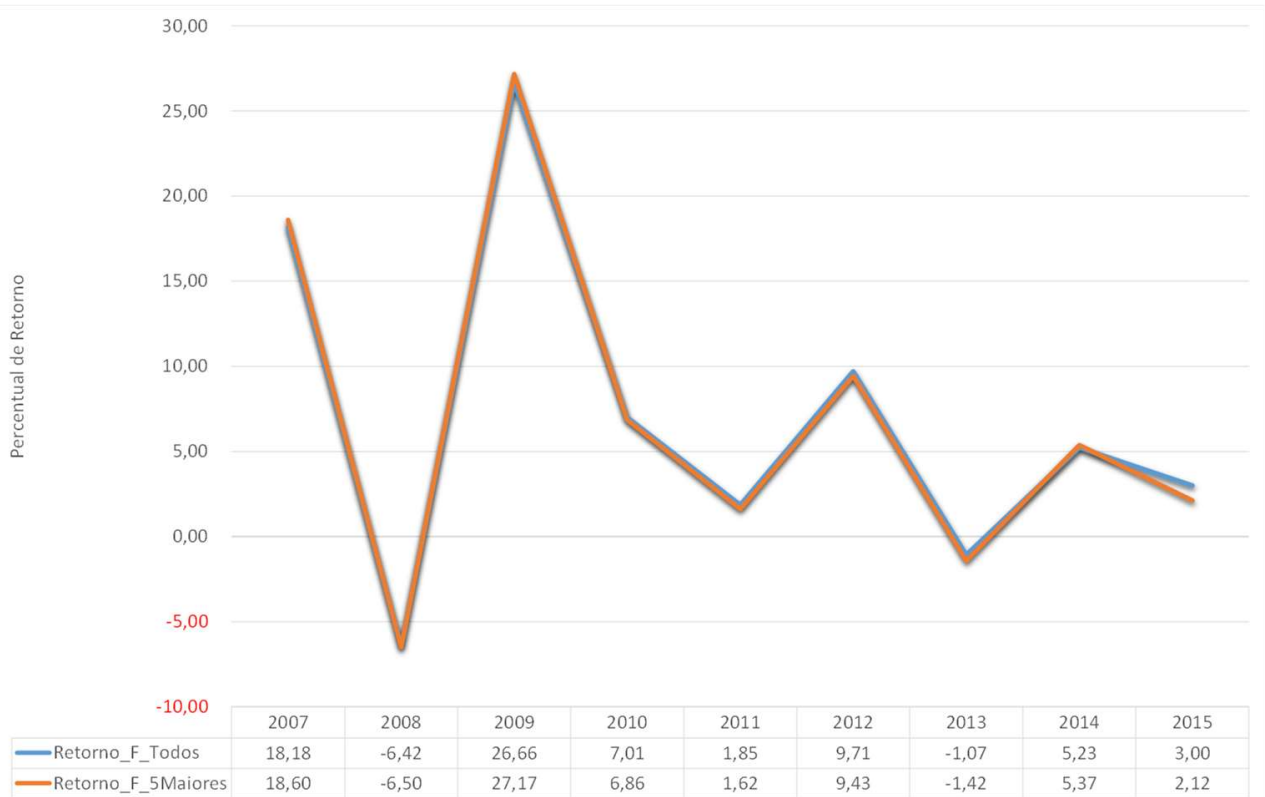

Gráfico 8 - Comparação entre os Retornos Médios Anuais (Todos os Fundos x Fundos das 5 Maiores

Fonte: Economática Administradoras)

Gráfico elaborado pelo autor

Portanto, neste ponto de análise, aguça-se a curiosidade para se conhecer mais detalhadamente o perfil das carteiras de investimento em renda variável das principais administradoras de fundos PGBL/VGBL com RV do país. Como estão agrupados os seus fundos? Quais os seus números? Quanto proporcionalmente dos seus patrimônios é investido em renda variável? Quais sãos as ações de empresas que, direta ou indiretamente, fazem parte de suas carteiras? Essas carteiras variam muito de fundo para fundo, dentro de uma mesma administradora? Quais as taxas de administração máximas que são cobradas dos seus clientes? As taxas de administração estariam correlacionadas aos retornos obtidos pelos fundos? Seria possível se especificar um modelo que aponte os fatores mais relevantes para explicação dos retornos dos fundos, no período estudado? Essas entre outras questões serão respondidas nas próximas seções.

\subsection{Explorando os Dados das 5 Principais Administradoras de Fundos PGBL/VGBL}

Ao se investigar as composições acionárias das carteiras de cada um dos fundos PGBL/VGBL das cinco principais administradoras dessa modalidade de fundos, um padrão na gestão ficou nitidamente exposto: relevante parte dos fundos PGBL/VGBL de cada administradora possuía, 
ao final de cada ano analisado, carteiras acionárias com diversificação idêntica ou extremamente semelhantes entre si. Nesse ponto, cabe um esclarecimento: a definição de carteira extremamente semelhante diz respeito a carteiras que possuem, ao final de cada ano, as mesmas ações presentes na carteira idêntica mais frequente de dada administradora de fundos, com variações mínimas em seus percentuais de participação em relação à carteira mais frequente, como poderá ser visto adiante.

Cabe destacar que o uso de fundos espelhos que são investidos por outros fundos com intuito de se replicar uma estratégia de diversificação macro é prática conhecida no mercado de fundos brasileiro, especialmente pelas principais administradoras de fundos. No entanto, a extensão dessa prática, até onde o autor deste trabalho conseguiu verificar, é uma das contribuições adicionais desta pesquisa.

De todo modo, para efeito de exemplificação, serão apresentadas mais adiante tabelas, referentes ao final do ano de 2015, que apresentam a composição das carteiras idênticas ou extremamente semelhantes de diferentes fundos PGBL/VGBL administrados pelas cinco maiores instituições administradoras dessa modalidade de fundos. Para facilitar a visualização das tabelas, serão mostradas somente as 15 primeiras ações distintas mais relevantes de cada carteira.

A Tabela 10, a seguir, referente à administradora Bradesco e ao ano de 2015, mostra o perfil da carteira acionária mais frequente presente nos fundos da administradora. De um total de 53 fundos existentes PGBL/VGBL com investimentos em renda variável, administrados pelo Bradesco, foram encontrados 42 fundos que detinham composição acionária idêntica ou extremamente semelhante. Desses, 35 possuíam carteiras totalmente idênticas. 
Tabela 10 - Carteira Acionária Mais Frequente - Bradesco - Dezembro de 2015

\begin{tabular}{|c|c|c|c|c|c|c|c|c|c|c|c|c|c|c|c|c|}
\hline \begin{tabular}{|l|} 
Nome do Fundo \\
\end{tabular} & ITUB4 & ABEV3 & BBDC4 & BRFS3 & PETR4 & ITSA4 & CIEL3 & PETR3 & UGPA3 & JBSS3 & VALE5 & BVMF3 & VALE3 & VIVT4 & BBSE3 & Subtotal \\
\hline Brad Corporate FICFI Mult Pgbl Vgbl Rv49 & $11,7 \%$ & $8,1 \%$ & $6,0 \%$ & $5,0 \%$ & $3,8 \%$ & $4,2 \%$ & $3,2 \%$ & $3,4 \%$ & $3,1 \%$ & $3,0 \%$ & $2,8 \%$ & $2,9 \%$ & $2,7 \%$ & $2,6 \%$ & $2,6 \%$ & $65,1 \%$ \\
\hline Brad FIC Mult Pgbl Hi & $11,7 \%$ & $\%$ & $\%$ & 5 & $\%$ & $4,2 \%$ & $2 \%$ & $3,4 \%$ & & $3,0 \%$ & 3\% & & $2,7 \%$ & $2,6 \%$ & $6 \%$ & \\
\hline ad FIC Mult Pgbl H & ,7\% & 70 & & $5,0 \%$ & $3,8 \%$ & $4,2 \%$ & $3,2 \%$ & $3,4 \%$ & & $3,0 \%$ & $2,8 \%$ & $2,9 \%$ & $2,7 \%$ & $2,6 \%$ & $2,6 \%$ & $\%$ \\
\hline ad FIC Mult Pgbl Y & ,7\% & $\%$ & $\%$ & $5,0 \%$ & 8\% & $4,2 \%$ & $3,2 \%$ & $3,4 \%$ & $1 \%$ & $3,0 \%$ & $8 \%$ &, $9 \%$ & $2,7 \%$ & $2,6 \%$ & $6 \%$ & $\%$ \\
\hline ad FICFI Mult Pgbl V & ,7\% & $1 \%$ & $\%$ & $5,0 \%$ & 8\% & $2 \%$ & $3,2 \%$ & $3,4 \%$ & $1 \%$ & $3,0 \%$ & $8 \%$ & $9 \%$ & $2,7 \%$ & $2,6 \%$ & $6 \%$ &, $1 \%$ \\
\hline FII & $7 \%$ & $\%$ & & $0 \%$ & & $2 \%$ & $3,2 \%$ & $4 \%$ & $\%$ & $3,0 \%$ & $8 \%$ & $\%$ & $2,7 \%$ & $2,6 \%$ & $5 \%$ & \\
\hline ad FICFI Mult Pgb & $7 \%$ & $\%$ & $\%$ & $5,0 \%$ & $3 \%$ & $4,2 \%$ & $3,2 \%$ & $3,4 \%$ & $3,1 \%$ & $3,0 \%$ & $8 \%$ & $9 \%$ & $2,7 \%$ & $2,6 \%$ & $6 \%$ & \\
\hline ad Priv FICFI Mul & $7 \%$ & $\%$ & $6,0 \%$ & $5,0 \%$ & $3,8 \%$ & $4,2 \%$ & $3,2 \%$ & $3,4 \%$ & $3,1 \%$ & $3,0 \%$ & $2,8 \%$ &, $9 \%$ & $2,7 \%$ & $2,6 \%$ & $2,6 \%$ & \\
\hline adesco FIC Mult P & ,7\% & $8,1 \%$ & $6,0 \%$ & $5,0 \%$ & $3,8 \%$ & $4,2 \%$ & $3,2 \%$ & $3,4 \%$ & $3,1 \%$ & $3,0 \%$ & $2,8 \%$ & $2,9 \%$ & $2,7 \%$ & $2,6 \%$ & $2,6 \%$ &, $1 \%$ \\
\hline adesco FIC Mult $\mathrm{F}$ &, $7 \%$ & $8,1 \%$ & $6,0 \%$ & $5,0 \%$ & $3,8 \%$ & $4,2 \%$ & $3,2 \%$ & $3,4 \%$ & $3,1 \%$ & $3,0 \%$ & $2,8 \%$ & $2,9 \%$ & $2,7 \%$ & $2,6 \%$ & $2,6 \%$ &, $1 \%$ \\
\hline FIC Mu & ,7\% & $8,1 \%$ & $6,0 \%$ & $5,0 \%$ & $3,8 \%$ & $4,2 \%$ & $3,2 \%$ & $3,4 \%$ & $3,1 \%$ & $3,0 \%$ & $2,8 \%$ & $2,9 \%$ & $2,7 \%$ & $2,6 \%$ & $2,6 \%$ &, $1 \%$ \\
\hline ade & $7 \%$ & $8,1 \%$ & $6,0 \%$ & $5,0 \%$ & $3,8 \%$ & $4,2 \%$ & $3,2 \%$ & $3,4 \%$ & $3,1 \%$ & $3,0 \%$ & $2,8 \%$ &, $9 \%$ & $2,7 \%$ & $2,6 \%$ & $2,6 \%$ & $5,1 \%$ \\
\hline ade & ,7\% & $8,1 \%$ & $6,0 \%$ & $5,0 \%$ & $3,8 \%$ & $4,2 \%$ & $3,2 \%$ & $3,4 \%$ & $3,1 \%$ & $3,0 \%$ & $2,8 \%$ & $\%$ & $2,7 \%$ & $2,6 \%$ &, $6 \%$ &, $1 \%$ \\
\hline de &, $7 \%$ & $8,1 \%$ & $6,0 \%$ & $5,0 \%$ & $\%$ & $4,2 \%$ & $3,2 \%$ & $3,4 \%$ & & $3,0 \%$ & $2,8 \%$ & & $2,7 \%$ & $\%$ & $\%$ & \\
\hline ade & $\%$ & $\%$ & $6,0 \%$ & $5,0 \%$ & & $4,2 \%$ & $3,2 \%$ & & & $3,0 \%$ & $\%$ & & $\%$ & $\%$ & $\%$ & $\%$ \\
\hline d & $\%$ & $81 \%$ & $6,0 \%$ & & & $4,2 \%$ & $3,2 \%$ & & & $3,0 \%$ & $2,8 \%$ & & $\%$ & $2,6 \%$ & $\%$ & $\%$ \\
\hline & & & & & & & $3,2 \%$ & & & $3,0 \%$ & $\%$ & & $\%$ & $2,6 \%$ & $\%$ & \\
\hline & & & & & & & $3,3 \%$ & & & $2,9 \%$ & $\%$ & & & $\%$ & $\%$ & \\
\hline & & & & & & & $3,2 \%$ & & & 3, & 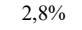 & & & $2,6 \%$ & $\%$ & \\
\hline ades & & & 6 , & $5,0 \%$ & & $4,2 \%$ & $3,2 \%$ & 3, & & 3,0 & $\%$ & 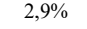 & $\%$ & $2,6 \%$ &, $6 \%$ & $\%$ \\
\hline adesc & $7 \%$ & 8 & 6,0 & 5,0 & $3,8 \%$ & $4,2 \%$ & $3,2 \%$ & 3,4 & 3 & $3,0 \%$ & $2,8 \%$ & $\%$ & $\%$ & $2,6 \%$ & $2,6 \%$ & $\%$ \\
\hline FI & $\%$ & 8, & $6,0^{\circ}$ & 5,0 & 3, & $4,2 \%$ & $3,2 \%$ & $3,4 \%$ & 3 , & $3,0 \%$ & 2,8 & $\%$ & $2,7 \%$ & $2,6 \%$ & $2,6 \%$ & $\%$ \\
\hline FI I & $11,7 \%$ & $8,1 \%$ & $6,0 \%$ & $5,0 \%$ & $3,8 \%$ & $4,2 \%$ & $3,2 \%$ & $3,4 \%$ & $3,1 \%$ & $3,0 \%$ & $2,8 \%$ &, $9 \%$ & $2,7 \%$ & $2,6 \%$ & $2,6 \%$ &, $1 \%$ \\
\hline 12 & $\%$ & 8 & $6,0 \%$ & $5,0 \%$ & 3, & $4,2 \%$ & $3,2 \%$ & $3,4 \%$ & 3 , & $3,0 \%$ & $2,8 \%$ & $\%$ & $2,7 \%$ & $2,6 \%$ & $2,6 \%$ &, $1 \%$ \\
\hline $\mathrm{F} 1 \mathrm{~T}$ & $\%$ & $8,1 \%$ & 6, & 5,0 & $3,8 \%$ & $4,2 \%$ & $3,2 \%$ & $3,4^{\circ}$ & 3 & $3,0 \%$ & $2,8 \%$ & $\%$ & $2,7 \%$ & $2,6 \%$ & $2,6 \%$ &, $1 \%$ \\
\hline & & 8, & , & $5,0 \%$ & & $4,2^{2}$ & $3,2 \%$ & 3 & $3,1 \%$ & $3, \mathrm{C}$ & $2,8 \%$ & $\%$ & $7 \%$ & $2,6 \%$ & ,6\% & $1 \%$ \\
\hline & $1 \%$ & $1 \%$ & 6,0 & 5,0 & $3,8 \%$ & $4,2^{2}$ & $3,2 \%$ & 3,4 & 3,1 & $3,0 \%$ & $\%$ & $\%$ & $2,7 \%$ & $2,6 \%$ & $2,6 \%$ & \\
\hline & $7 \%$ & $8,1 \%$ & 6,0 & $5,0 \%$ & & $4,2 \%$ & $3,2 \%$ & & & $3,0 \%$ & $2,8 \%$ & $\%$ & & $2,6 \%$ & $2,6 \%$ & $1 \%$ \\
\hline 19 & $11,7 \%$ & $8,1 \%$ & $6,0 \%$ & $5,0 \%$ & & $4,2 \%$ & $3,2 \%$ & $3,4 \%$ & & $3,0 \%$ & $2,8 \%$ & $\%$ & $2,7 \%$ & $2,6 \%$ & $2,6 \%$ & $1 \%$ \\
\hline 24 & 7\% & $8,1 \%$ & $6,0 \%$ & $5,0 \%$ & & $4,2 \%$ & $3,2 \%$ & $3,4 \%$ & & $3,0 \%$ & $2,8 \%$ & $\%$ & $2,7 \%$ & $2,6 \%$ & $2,6 \%$ &, $1 \%$ \\
\hline & & $\%$ & & & & $4,2 \%$ & $3,2 \%$ & & & $3,0 \%$ & $2,8 \%$ & $\%$ & $\%$ & $2,6 \%$ & $\%$ & $\%$ \\
\hline & & & & & & & 3,2 & & & 3, & 2,8 & & & $2,6 \%$ & & \\
\hline & & & & & & & 3,2 & & & 3, & 2,8 & & & $2,6 \%$ & $\%$ & \\
\hline & & & & & & & 3,2 & & & 3, & 2,07 & & & $2,6 \%$ & $\%$ & \\
\hline & & $8,1 \%$ & $6,0 \%$ & 5,0 & $3,8 \%$ & 4,2 & $3,2 \%$ & $3,4 \%$ & $3,1 \%$ & $3,0 \%$ & $2,8 \%$ & $2,9 \%$ & $2,7 \%$ & $2,6 \%$ & $2,6 \%$ & $65,1 \%$ \\
\hline Bradesc & & & & & & & 3,3 & & & 2, & 2,8 & & & $2,5 \%$ & & $63,8 \%$ \\
\hline & & & & & & & 3,3 & & & $2,9 \%$ & 2, & & & $2,5 \%$ & & \\
\hline 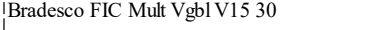 & & & & & & & 3,3 & & & 2, & 2, & & & $2,5 \%$ & $\%$ & \\
\hline Brade & & , & & & & & 3,3 & & & $2,9 \%$ & 2, & & & $2,5 \%$ & $4 \%$ & \\
\hline $\mathrm{Brad} \mathrm{F}$ & & & & & & & (3, & & & & 2, & & & $2,5 \%$ & $4 \%$ & \\
\hline & & & & & & & 3,3 & & & & & & & $2,5 \%$ & & \\
\hline radesco FIA Master I & $11,0 \%$ & $8,0 \%$ & $7,0 \%$ & $5,1 \%$ & $3,9 \%$ & $3,4 \%$ & $3,8 \%$ & $3,4 \%$ & $3,0 \%$ & $3,0 \%$ & $2,9 \%$ & $2,8 \%$ & $2,8 \%$ & $2,5 \%$ &, $4 \%$ & \\
\hline and & $11,3 \%$ & $8,0 \%$ & &, $0 \%$ & $8 \%$ & $3,8 \%$ & $3,5 \%$ & & & $7 \%$ & 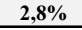 & $2,8 \%$ & & $2,5 \%$ & $\%$ & 07 \\
\hline
\end{tabular}

Fonte: Economática

Tabela elaborada pelo autor

A Tabela 11 , a seguir, referente à administradora $B B$ Dtvm S.A e ao ano de 2015 , mostra a carteira idêntica ou extremamente semelhante mais frequente, presente em 23 de 36 fundos distintos da referida administradora. Nota-se a presença de cinco subgrupos de carteiras totalmente idênticas internamente aos grupos e semelhantes entre os grupos. 
Tabela 11 - Carteira Acionária Mais Frequente - BB Dtvm S.A - Dezembro de 2015

\begin{tabular}{|c|c|c|c|c|c|c|c|c|c|c|c|c|c|c|c|c|}
\hline e & 84 & ABEV3 & $\mathrm{C} 4$ & $\mathbf{A 4}$ & BRFS3 & $\mathrm{F3}$ & PETR4 & CIEL3 & VALE5 & - & UGPA3 & CTIP3 & VIVT4 & JBSS3 & VALE3 & Subt \\
\hline Rt Comp 49 FICFI Mult & $0 \%$ & $7,25 \%$ & $7 \%$ & $99 \%$ & $427^{\circ}$ & & $3,27 \%$ & $3,14 \%$ & $2,87 \%$ & $2,82 \%$ & $2,70^{\circ}$ & $2,28 \%$ & $2,44^{\circ}$ & $2,50 \%$ & $2,32 \%$ & \\
\hline Mult & & $25 \%$ & & & & & & & & & & & & & & \\
\hline t 49 III FICFI Mult & $\%$ & $7,25 \%$ & $7 \%$ & $99 \%$ & $4,27 \%$ & $3,09 \%$ & $3,27 \%$ & $3,14 \%$ & $87 \%$ & $2,82 \%$ & $2,70 \%$ & $28 \%$ & $44 \%$ & $50 \%$ &, $32 \%$ & $8,0 \%$ \\
\hline Vida 2020 FIC Mult & $51 \%$ & $7,42 \%$ &, $75 \%$ & $4,54 \%$ & $18 \%$ & $45 \%$ &, $20 \%$ & $3,07 \%$ & $3,08 \%$ & $2,76 \%$ & $2,75 \%$ & $2,77 \%$ & $61 \%$ & $45 \%$ & $27 \%$ & $9,3 \%$ \\
\hline FICFI Mult & & t & & & & & & $3,07 \%$ & & $\%$ & $5 \%$ & & $\%$ & $5 \%$ & $27 \%$ & $3 \%$ \\
\hline & & & & & & & & & & & & & & & & \\
\hline & & $\%$ & & $\%$ & $\%$ & & $\%$ & $3,07 \%$ & $08 \%$ & $2,76 \%$ & $2,75 \%$ & $\%$ & $1 \%$ & $45 \%$ &, $27 \%$ & $59,3 \%$ \\
\hline FI Mult & $01 \%$ & $42 \%$ & $75 \%$ & $\%$ & $4,18 \%$ & $\%$ &, $20 \%$ & $3,07 \%$ & $3,08 \%$ &, $76 \%$ & $2,75 \%$ & $7 \%$ & & &, $27 \%$ & $59,3 \%$ \\
\hline & & & & & & & & & & & & & & & $\%$ & $2 \%$ \\
\hline & & & & & & & & & & & & & & & $\%$ & $\%$ \\
\hline & & $\%$ & & & & & & $\%$ & & & $\%$ & & & & $\%$ & $2 \%$ \\
\hline & & & & & & & & & & & & & & & $9 \%$ & $56,2 \%$ \\
\hline Mult & $\%$ & $\%$ & & & 4,0 & $\%$ & $3,09 \%$ & $2,97 \%$ & $2,85 \%$ & $2,66 \%$ & $2,61 \%$ & & $\%$ & $\% \%$ & $19 \%$ & $56,2 \%$ \\
\hline & & 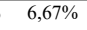 & & & & & & $92 \%$ & $60^{\circ}$ & 2,63 & $2,48 \%$ & & & & $\%$ & $53,5 \%$ \\
\hline & & 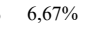 & & & & & & $\%$ & $60 \%$ & & & & & & $\%$ & $5 \%$ \\
\hline & & & & & & & & & $\%$ & & & & & & $\%$ & $53,5 \%$ \\
\hline & & & & & & & & & 0 & & & & & & & $53,5 \%$ \\
\hline & & $\%$ & $\%$ & & $\%$ & & $05 \%$ & $92 \%$ & $60 \%$ & $3 \%$ &, $48 \%$ & $\%$ & $21 \%$ & $3 \%$ & $16 \%$ & $3,5 \%$ \\
\hline Mult & $\%$ & $\%$ & $\%$ & & $\%$ & $\%$ & $2,70 \%$ & $2,59 \%$ & $2,68 \%$ & $2,32 \%$ & $2,36 \%$ & $2,81 \%$ & $2,27 \%$ & $6 \%$ & $91 \%$ & $51,1 \%$ \\
\hline & & & & & & & & $2,59 \%$ & $2,68 \%$ & 2,3 & $2,36 \%$ & & $\%$ & & $1 \%$ & $51,1 \%$ \\
\hline & & & & & & & & & & & & & & & & $1,1 \%$ \\
\hline & & & & & & & & & & & & & & & $1 \%$ & $51,1 \%$ \\
\hline Rt Ciclo Vida 2030 FIC Mul & $9 \%$ & $35 \%$ & $4,84 \%$ & $4,02 \%$ & $3,52 \%$ & $3,04 \%$ &, $70 \%$ & $2,59 \%$ & $2,68 \%$ & $2,32 \%$ & $2,36 \%$ & $2,81 \%$ & $2,27 \%$ & $2,06 \%$ & $1,91 \%$ & $51,1 \%$ \\
\hline & $1 \%$ & $8 \%$ & $51 \%$ &, $10 \%$ & $01 \%$ & $4 \%$ & $07 \%$ & $94 \%$ & $2,84 \%$ & , & $2,59 \%$ & $2,54 \%$ &, $41 \%$ &, $34 \%$ & $2,18 \%$ & $55,9 \%$ \\
\hline
\end{tabular}

Fonte: Economática

Tabela elaborada pelo autor

A Tabela 12, a seguir, referente à administradora Itaú Unibanco $S A$ e ao ano de 2015, mostra a carteira mais frequente presente em 67 de 93 fundos distintos. Desses 67 fundos, 66 têm carteiras totalmente idênticas. A única distinta está destacada no final da tabela. 
Tabela 12 - Carteira Acionária Mais Frequente - Itaú Unibanco SA - Dezembro de 2015

\begin{tabular}{|c|c|c|c|c|c|c|c|c|c|c|c|c|c|c|c|c|}
\hline Nome do Fundo & ABEV3 & BBDC4 & UB4 & CIEL3 & SA4 & BRFS3 & JBSS3 & KROT3 & LREN3 & VALE3 & VALE5 & FIBR3 & WEGE3 & T4 & CTIP3 & Subtotal \\
\hline lexprev Templario Mult FICFI & $13,7 \%$ & $10,8 \%$ & $6,2 \%$ & $5,9 \%$ & $5,7 \%$ & $4,8 \%$ & $4,8 \%$ & $3,1 \%$ & $2,5 \%$ & $2,4 \%$ & $2,2 \%$ & $2,1 \%$ & $2,0 \%$ & $2,0 \%$ & $2,0 \%$ & $70,2 \%$ \\
\hline u Flex Corp Plat II Rv49 FICFI Mult &, $7 \%$ & $\%$ & $\%$ & $5,9 \%$ & $7 \%$ & $8 \%$ & $4,8 \%$ & & $\%$ & $2,4 \%$ & $2,2 \%$ & $\%$ & $2,0 \%$ & $2,0 \%$ & $\%$ & \\
\hline u Flex Corp Plati Rv49 FICFI Mult & $7 \%$ & & $\%$ & $\%$ & $\%$ & $4,8 \%$ & $\%$ & & $\%$ & $4 \%$ & $2,2 \%$ & $2,1 \%$ & $2,0 \%$ & $2,0 \%$ & & $\%$ \\
\hline u Flex Corp Platinum Rv25 Mult FICFI & $.7 \%$ & $\%$ & $\%$ & $9 \%$ & $7 \%$ & $4,8 \%$ & $4,8 \%$ & $\%$ & $5 \%$ & $2,4 \%$ & $2,2 \%$ & $2,1 \%$ & $2,0 \%$ & $2,0 \%$ & & $\%$ \\
\hline u Flex Corporate III Rv 49 FICFI Mult &, $7 \%$ & $8 \%$ & $2 \%$ & $9 \%$ & $7 \%$ & $8 \%$ & $4,8 \%$ & $1 \%$ & $5 \%$ & $2,4 \%$ & $2,2 \%$ & $2,1 \%$ & $2,0 \%$ & $2,0 \%$ & &, $2 \%$ \\
\hline u Flex Omega I Mult Cred Priv FICFI &, $7 \%$ & $8 \%$ & $2 \%$ & $9 \%$ & $7 \%$ & $4,8 \%$ & $4,8 \%$ & $1 \%$ & $5 \%$ & $2,4 \%$ & $2,2 \%$ & $2,1 \%$ & $2,0 \%$ & $2,0 \%$ & & \\
\hline Flex Padanelex &, $7 \%$ & $8 \%$ &, $2 \%$ & $5,9 \%$ & $5,7 \%$ & $4,8 \%$ & $4,8 \%$ & $1 \%$ & $5 \%$ & $2,4 \%$ & $2,2 \%$ & $2,1 \%$ & $2,0 \%$ & $2,0 \%$ & $\%$ & $\%$ \\
\hline Fu Flex Prem Fas. Vida 2020 Mult FICFI & $3,7 \%$ & $10,8 \%$ & $6,2 \%$ & $5,9 \%$ & $5,7 \%$ & $4,8 \%$ & $4,8 \%$ & $3,1 \%$ & $2,5 \%$ & $2,4 \%$ & $2,2 \%$ & $2,1 \%$ & $2,0 \%$ & $2,0 \%$ & $0 \%$ & $70,2 \%$ \\
\hline au Flex Prem Fas. Vida 2030 Mult FICFI & $13,7 \%$ & $10,8 \%$ & $6,2 \%$ & $5,9 \%$ & $5,7 \%$ & $4,8 \%$ & $4,8 \%$ & $3,1 \%$ & $2,5 \%$ & $2,4 \%$ & $2,2 \%$ & $2,1 \%$ & $2,0 \%$ & $2,0 \%$ & $2,0 \%$ & $70,2 \%$ \\
\hline u Flex Prem Fas. Vida $2040 \mathrm{~N}$ & $13,7 \%$ & $10,8 \%$ & $6,2 \%$ & $5,9 \%$ & $5,7 \%$ & $4,8 \%$ & $4,8 \%$ & $3,1 \%$ & $2,5 \%$ & $2,4 \%$ & $2,2 \%$ & $2,1 \%$ & $2,0 \%$ & $2,0 \%$ & $0 \%$ & $70,2 \%$ \\
\hline u Flex Turquesa Mult Cred Priv FICFI & $13,7 \%$ & $10,8 \%$ & $6,2 \%$ & $5,9 \%$ & $5,7 \%$ & $4,8 \%$ & $4,8 \%$ & $3,1 \%$ & $2,5 \%$ & $2,4 \%$ & $2,2 \%$ & $2,1 \%$ & $2,0 \%$ & $2,0 \%$ & $2,0 \%$ & $70,2 \%$ \\
\hline u Flexp Chalten Mult Cred Priv FICFI & $13,7 \%$ & $10,8 \%$ & $6,2 \%$ & $5,9 \%$ & $5,7 \%$ & $4,8 \%$ & $4,8 \%$ & $3,1 \%$ & $2,5 \%$ & $2,4 \%$ & $2,2 \%$ & $2,1 \%$ & $2,0 \%$ & $2,0 \%$ & $2,0 \%$ & $70,2 \%$ \\
\hline u Flexp Corp Platinum Rv10 Mult FICFI & $13,7 \%$ & $10,8 \%$ & $6,2 \%$ & $5,9 \%$ & $5,7 \%$ & $4,8 \%$ & $4,8 \%$ & $3,1 \%$ & $2,5 \%$ & $2,4 \%$ & $2,2 \%$ & $2,1 \%$ & $2,0 \%$ & $2,0 \%$ & $2,0 \%$ & $70,2 \%$ \\
\hline u Flexp Quadrato Mult Cred Priv FICFI & $13,7 \%$ & $10,8 \%$ & $6,2 \%$ & $5,9 \%$ & $5,7 \%$ & $4,8 \%$ & $4,8 \%$ & $3,1 \%$ & $2,5 \%$ & $2,4 \%$ & $2,2 \%$ & $2,1 \%$ & $2,0 \%$ & $2,0 \%$ & $2,0 \%$ & $70,2 \%$ \\
\hline Flexp Rex 27 Mult Cred Priv FICFI & $13,7 \%$ & $10,8 \%$ & $6,2 \%$ & $5,9 \%$ & $5,7 \%$ & $4,8 \%$ & $4,8 \%$ & $3,1 \%$ & $2,5 \%$ & $2,4 \%$ & $2,2 \%$ & $2,1 \%$ & $2,0 \%$ & $2,0 \%$ & $2,0 \%$ & $70,2 \%$ \\
\hline Iu Flexp Valencia & $3,7 \%$ & $10,8 \%$ & $6,2 \%$ & $5,9 \%$ & $5,7 \%$ & $4,8 \%$ & $4,8 \%$ & $3,1 \%$ & & $2,4 \%$ & $2,2 \%$ & $2,1 \%$ & $2,0 \%$ & $2,0 \%$ & $0 \%$ & $2 \%$ \\
\hline $\mathrm{u} \mathrm{Fl}$ &, $7 \%$ & $\%$ & $\%$ & $5,9 \%$ & $5,7 \%$ & $4,8 \%$ & $4,8 \%$ & & & & & $2,1 \%$ & $\%$ & $2,0 \%$ & $\%$ & \\
\hline $\mathrm{Fl}$ &, $7 \%$ & $\%$ & $\%$ & $5,9 \%$ & & $4,8 \%$ & & & & & & $2,1 \%$ & & $\%$ & $\%$ & \\
\hline tau Fl & & & & & & $4,8 \%$ & $4,8 \%$ & & & $2,4 \%$ & & $2,1 \%$ & $2,0 \%$ & $2,0 \%$ & $0 \%$ & $\%$ \\
\hline tau Fl & 1 & & $\%$ & & & $4,8 \%$ & $4,8 \%$ & 3 , & 2,5 & $2,4 \%$ & $2,2 \%$ & $2,1 \%$ & $2,0 \%$ & $2,0 \%$ & $2,0 \%$ & $2 \%$ \\
\hline $\mathrm{Fl}$ & 13 & & & & & $4,8 \%$ & $4,8 \%$ & & & $2,4^{\circ}$ & $2,2 \%$ & $2,1 \%$ & $2,0 \%$ & $2,0 \%$ & $2,0 \%$ & \\
\hline $\mathrm{uF}$ & & & & & & 4,8 & 4, & & & 2,4 & & $2,1 \%$ & & $2,0 \%$ & $\%$ & \\
\hline $\mathrm{uF}$ & $\%$ & & & & & 4,8 & & & & & & & & $\%$ & & \\
\hline $\mathrm{uFl}_{\mathrm{F}} \mathrm{C}_{\mathrm{C}}$ & ${ }_{0}$ & & & & $5,7 \%$ & 4,8 & & & & 2 , & & $2,1 \%$ & & $\%$ & & \\
\hline $\mathrm{Fl}$ & $7 \%$ & & 6,2 & $5,9 \%$ & $5,7 \%$ & 4,8 & $4,8 \%$ & & & 2 , & 2 & $2,1 \%$ & $\%$ & $\%$ & & \\
\hline $\mathrm{auFl}$ & 1 & $10,8 \%$ & 6,2 & 5,9 & $5,7 \%$ & 4,8 & 4,8 & 3 & & 2,4 & $\%$ & $2,1 \%$ & $2,0 \%$ & $2,0 \%$ & $\%$ & \\
\hline tau Fl & 1 & $10,8 \%$ & 6,2 & 5,9 & $5,7 \%$ & 4,8 & 4,8 & 3 & & 2,4 & 0 & $2,1 \%$ & $\%$ & $\%$ & $0 \%$ & \\
\hline $\mathrm{au} \mathrm{Fl}$ & $\%$ & $10,8 \%$ & 6,2 & $5,9 \%$ & $5,7 \%$ & 4,8 & 4,8 & 3 & & 2,4 & $\%$ & $2,1 \%$ & $2,0 \%$ & $\%$ &, $0 \%$ & \\
\hline tau Fle & $13,7 \%$ & $10,8 \%$ & $6,2 \%$ & $5,9 \%$ & $5,7 \%$ & $4,8 \%$ & $4,8 \%$ & 3,1 & 2,5 & $2,4 \%$ & $2,2 \%$ & $2,1 \%$ & $2,0 \%$ & $\%$ & $\%$ & $\%$ \\
\hline au Fl & $1 \%$ & $10,8 \%$ & $6,2^{\circ}$ & $5,9 \%$ & $5,7 \%$ & $4,8 \%$ & $4,8 \%$ & 3 & $2,5 \%$ & $2,4 \%$ & $2,2 \%$ & $2,1 \%$ & $2,0 \%$ & $2,0 \%$ & $\%$ & $\%$ \\
\hline tau Fl & $.7 \%$ & $10,8 \%$ & $6,2 \%$ & $5,9 \%$ & $5,7 \%$ & $4,8 \%$ & $4,8 \%$ & 3, & 2,5 & $2,4 \%$ & $2,2 \%$ & $2,1 \%$ & $2,0 \%$ & $2,0 \%$ & $\%$ & $\%$ \\
\hline tau Fl & $13,7 \%$ & $10,8 \%$ & $6,2 \%$ & $5,9 \%$ & $5,7 \%$ & $4,8 \%$ & $4,8 \%$ & $3,1 \%$ & $2,5 \%$ & $2,4 \%$ & $2,2 \%$ & $2,1 \%$ & $2,0 \%$ & $2,0 \%$ & $\%$ & $\%$ \\
\hline $\mathrm{uFl}$ & $\% \%$ & $10,8 \%$ & $6,2^{\circ}$ & $5,9 \%$ & $5,7 \%$ & $4,8 \%$ & $4,8 \%$ & $3,1 \%$ & 2, & $2,4 \%$ & $2,2 \%$ & $2,1 \%$ & $2,0 \%$ & $2,0 \%$ & $\%$ & $\%$ \\
\hline $\mathrm{u} \mathrm{Fle}$ & $\%$ & $10,8 \%$ & $6,2^{\circ}$ & $5,9 \%$ & $5,7 \%$ & 4,8 & $4,8 \%$ & o & $2,5 \%$ & $2,4 \%$ & $2,2 \%$ & $2,1 \%$ &, $0 \%$ & $2,0 \%$ & $\%$ & $\%$ \\
\hline $\mathrm{H} F$ & $7 \%$ & $10,8 \%$ & $6,2 \%$ & $5,9 \%$ & $5,7 \%$ & $4,8 \%$ & $4,8 \%$ & $3,1 \%$ & 70 & $2,4 \%$ & $2,2 \%$ & $2,1 \%$ & $2,0 \%$ & $2,0 \%$ & $0 \%$ & $\%$ \\
\hline $\mathrm{Fl}$ & $7 \%$ & $10,8 \%$ & 62 & $5,9 \%$ & $5,7 \%$ & 4,8 & $4,8 \%$ & & & $2,4 \%$ & $2,2 \%$ & $2,1 \%$ & $2,0 \%$ & $2,0 \%$ & $\%$ & $\%$ \\
\hline $\mathrm{uFl}$ & $\%$ & 3\% & $6,2^{\circ}$ & 5,9 & 5,7 & 48 & 4,8 & & & & & & & & & \\
\hline $\mathrm{uFl}$ & $\%$ & 10 & $6,2 \%$ & $\%$ & 5,7 & 1 & $4,8 \%$ & & & 2, & & & & 0 & $\%$ & \\
\hline $\mathrm{uFl}$ & & & & & & & & & & & & & & & & \\
\hline $\mathrm{uFl}$ & & & & & & & & & & & & & & & & \\
\hline UT & & & & & & 4,8 & & & & & & $\%$ & & & & \\
\hline u & & & & & & 4,8 & & & & & & & & 2 , & & \\
\hline $\mathrm{uF}$ & & & & & & 4,8 & & & & & & & & & & \\
\hline $\mathrm{Fl}$ & & & & & & 4, & & & & & & & & & & \\
\hline $\mathrm{uF}$ & & & & & & 4, & & & & & & & & & & \\
\hline $\mathrm{uFl}$ & & & & & & 4 , & & & & & & & & & & \\
\hline uF & & & & & & 4, & & & & & & & & $\%$ & & \\
\hline $\mathrm{AF}$ & & & & & & 4,8 & 4, & & & & & & $\%$ & $\%$ & & \\
\hline $\mathrm{uP}$ & & 10 & 6,5 & 5,8 & 5 & 4,8 & 4, & $3+2>>>>3$ & & 2, & $\%$ & $\%$ & $2,0 \%$ & $2,0 \%$ & & \\
\hline upre & & & & & 5, & 4,8 & 4 & & & 2. & $\%$ & $\%$ & $\%$ & $\%$ & & \\
\hline upre & & & $6,2^{\circ}$ & 5 , & 5 , & 4,8 & 4 , & $1 \%$ & & 2 , & $\%$ & $\%$ & $2,0 \%$ & $\%$ & $\%$ & \\
\hline uprev Annuity V & $\%$ & 10 & 6,2 & 5,9 & $5,7 \%$ & 4,8 & $4,8 \%$ & 3, & $\%$ & $2,4 \%$ & $2,2 \%$ & $2,1 \%$ & $2,0 \%$ & $2,0 \%$ & $\%$ & $\%$ \\
\hline c V10 Mult FICFI & $\%$ & 10 & 6,2 & 5,9 & $5,7 \%$ & 4,8 & $4,8 \%$ & $3,1 \%$ & $\%$ & $2,4 \%$ & $2,2 \%$ & $2,1 \%$ & $2,0 \%$ & $2,0 \%$ & $\%$ & $70,2 \%$ \\
\hline ult FICFI & $\%$ & 10 & 6,2 & 5,9 & $5,7 \%$ & 4,8 & $4,8 \%$ & $\%$ & $2,5 \%$ & $2,4 \%$ & $2,2 \%$ & $2,1 \%$ & $2,0 \%$ & $2,0 \%$ & $\%$ & $\%$ \\
\hline sic V40 Mult FICFI & & 10 & 6,2 & 5, & $5,7 \%$ & 4,8 & $4,8 \%$ & $\%$ & $2,5 \%$ & $2,4 \%$ & $2,2 \%$ & $2,1 \%$ & $2,0 \%$ & $2,0 \%$ & $\%$ & $\%$ \\
\hline Master V10 Mult FICFI & $\%$ & $10,8 \%$ & 6,2 & 5,9 & $5,7 \%$ & 4,8 & $4,8 \%$ & $\%$ & $2,5 \%$ & $2,4 \%$ & $2,2 \%$ & $2,1 \%$ & $2,0 \%$ & $2,0 \%$ & $\%$ & $\%$ \\
\hline uprev Master V20 Mult FICFI & $7 \%$ & $10,8 \%$ & 6,2 & $5.9 \%$ & $5,7 \%$ & $4.8>3$ & $4,8 \%$ & 3. & $\%$ & $2,4 \%$ & $2,2 \%$ & $2,1 \%$ & $2,0 \%$ & $2,0 \%$ & $\%$ &, $2 \%$ \\
\hline auprev Master V40 N & $7 \%$ & $10,8 \%$ & $6,2 \%$ & $5.9 \%$ & $5,7 \%$ & 4,8 & $4,8 \%$ & 3, & $2.5 \%$ & $2,4 \%$ & $2,2 \%$ & $2,1 \%$ & $2,0 \%$ & $2,0 \%$ &, $0 \%$ &, $2 \%$ \\
\hline 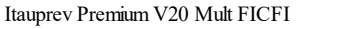 & $7 \%$ & $3 \%$ & 6,2 & 5. & 5,7 & 4.8 & 4,8 & 3. & $2,5 \%$ & $2,4 \%$ & $2,2 \%$ & $2,1 \%$ & $2,0 \%$ & $2,0 \%$ & $0 \%$ & $2 \%$ \\
\hline V40 Mult FICFI &, $7 \%$ & 18 & 6,2 & $5,9 \%$ & 5, & 4,8 & 4, & 3 & $2,5 \%$ & 2 & $\%$ & $2,1 \%$ & $2,0 \%$ & $2,0 \%$ & $\%$ & $\%$ \\
\hline FICFI & $\%$ & 10 & 6,2 & $5,9 \%$ & 5,7 & 4,8 & 4 , & $1 \%$ & & & $2,2 \%$ & $\%$ & $\%$ & $2,0 \%$ & $0 \%$ & $\%$ \\
\hline 0 Fiafic & & $10,8 \%$ & 6,2 & $5,9 \%$ & $5,7 \%$ & $4,8 \%$ & $4,8 \%$ & $3,1 \%$ & $2,5 \%$ & $2,4 \%$ & $2,2 \%$ & $2,1 \%$ & $2,0 \%$ & $2,0 \%$ & $2,0 \%$ & $70,2 \%$ \\
\hline ibanco Prever IV Rv 30 FICFI e C Mul & $13,7 \%$ & $10,8 \%$ & $6,2 \%$ & $5,9 \%$ & $5,7 \%$ & $4,8 \%$ & $4,8 \%$ & $3,1 \%$ & $2,5 \%$ & $2,4 \%$ & $2,2 \%$ & $2,1 \%$ & $2,0 \%$ & $2,0 \%$ & $2,0 \%$ & $70,2 \%$ \\
\hline iclass Prever Rv 49 II FICFI Ec Mult & $13,7 \%$ & $10,8 \%$ & $6,2 \%$ & 5,9 & $5,7 \%$ & 4,8 & $4,8 \%$ & $3,1 \%$ & $2,5 \%$ & $2,4 \%$ & $2,2 \%$ & $2,1 \%$ & $2,0 \%$ & $2,0 \%$ & $2,0 \%$ & $70,2 \%$ \\
\hline FICFI e Co & $13,7 \%$ & $10,8 \%$ & $6,2^{\circ}$ & 5,9 & $5,7 \%$ & 4,8 & 4,8 & $3,1 \%$ & 2,5 & 2,4 & 2,2 & $2,1 \%$ & $2,0 \%$ & $2,0 \%$ & $2,0 \%$ & $70,2 \%$ \\
\hline niclass Prever Rv49 I FICFI e C Mult & $13,7 \%$ & $10,8 \%$ & $6,2 \%$ & $5,9 \%$ & $5,7 \%$ & $4,8 \%$ & $4,8 \%$ & $3,1 \%$ & $2,5 \%$ & $2,4 \%$ & $2,2 \%$ & $2,1 \%$ & $2,0 \%$ & $2,0 \%$ & $2,0 \%$ & $70,2 \%$ \\
\hline vPer 2 & $13,5 \%$ & $0,7 \%$ & $4 \%$ & $8 \%$ & $6 \%$ & $4,8 \%$ & $4,7 \%$ & $3,1 \%$ & $2,4 \%$ & $2,4 \%$ & $2,2 \%$ & $2,1 \%$ & $2,0 \%$ & $2,0 \%$ & $2,0 \%$ & $9,7 \%$ \\
\hline
\end{tabular}

Fonte: Economática

Tabela elaborada pelo autor

A Tabela 13, a seguir, referente à administradora Caixa e ao ano de 2015, mostra a carteira mais frequente presente em 16 dos 16 fundos distintos mantidos pela Caixa. 
Tabela 13 - Carteira Acionária Mais Frequente - Caixa - Dezembro de 2015

\begin{tabular}{|c|c|c|c|c|c|c|c|c|c|c|c|c|c|c|c|c|}
\hline Nome do Fundo & ITUB4 & ABEV3 & BBDC4 & BRFS3 & ITSA4 & PETR4 & JBSS3 & PETR3 & CIEL3 & CTIP3 & BBSE3 & BVMF3 & VALE5 & BBAS3 & UGPA3 & Subtotal \\
\hline Caixa FI Previnvest Rv 49 Mult & $12,5 \%$ & $9,2 \%$ & $8,5 \%$ & $4,5 \%$ & $4,0 \%$ & $3,9 \%$ & $3,8 \%$ & $3,4 \%$ & $3,2 \%$ & $3,1 \%$ & $3,0 \%$ & $2,9 \%$ & $2,9 \%$ & $2,6 \%$ & $2,5 \%$ & $70,1 \%$ \\
\hline Caixa FIC Prev 300 Mult Rv 15 & $12,5 \%$ & $9,2 \%$ & $8,5 \%$ & $4,5 \%$ & $4,0 \%$ & $3,9 \%$ & $3,8 \%$ & $3,4 \%$ & $3,2 \%$ & $3,1 \%$ & $3,0 \%$ & $2,9 \%$ & $2,9 \%$ & $2,6 \%$ & $2,5 \%$ & $70,1 \%$ \\
\hline Caixa FIC Prev 300 Mult Rv 30 & $12,5 \%$ & $9,2 \%$ & $8,5 \%$ & $4,5 \%$ & $4,0 \%$ & $3,9 \%$ & $3,8 \%$ & $3,4 \%$ & $3,2 \%$ & $3,1 \%$ & $3,0 \%$ & $2,9 \%$ & $2,9 \%$ & $2,6 \%$ & $2,5 \%$ & $70,1 \%$ \\
\hline Caixa FIC Prev 150 Mult Rv 30 & $12,5 \%$ & $9,2 \%$ & $8,5 \%$ & $4,5 \%$ & $4,0 \%$ & $3,9 \%$ & $3,8 \%$ & $3,4 \%$ & $3,2 \%$ & $3,1 \%$ & $3,0 \%$ & $2,9 \%$ & $2,9 \%$ & $2,6 \%$ & $2,5 \%$ & $70,1 \%$ \\
\hline Caixa FIC Prev 150 Mult Rv 15 & $12,5 \%$ & $9,2 \%$ & $8,5 \%$ & $4,5 \%$ & $4,0 \%$ & $3,9 \%$ & $3,8 \%$ & $3,4 \%$ & $3,2 \%$ & $3,1 \%$ & $3,0 \%$ & $2,9 \%$ & $2,9 \%$ & $2,6 \%$ & $2,5 \%$ & $70,1 \%$ \\
\hline Caixa FIC Prev 300 Mult Rv 49 & $12,5 \%$ & $9,2 \%$ & $8,5 \%$ & $4,5 \%$ & $4,0 \%$ & $3,9 \%$ & $3,8 \%$ & $3,4 \%$ & $3,2 \%$ & $3,1 \%$ & $3,0 \%$ & $2,9 \%$ & $2,9 \%$ & $2,6 \%$ & $2,5 \%$ & $70,1 \%$ \\
\hline Caixa FIC Prev 150 Mult Rv 49 & $12,5 \%$ & $9,2 \%$ & $8,5 \%$ & $4,5 \%$ & $4,0 \%$ & $3,9 \%$ & $3,8 \%$ & $3,4 \%$ & $3,2 \%$ & $3,1 \%$ & $3,0 \%$ & $2,9 \%$ & $2,9 \%$ & $2,6 \%$ & $2,5 \%$ & $70,1 \%$ \\
\hline Caixa FIC Prev 125 Mult Rv 049 & $12,5 \%$ & $9,2 \%$ & $8,5 \%$ & $4,5 \%$ & $4,0 \%$ & $3,9 \%$ & $3,8 \%$ & $3,4 \%$ & $3,2 \%$ & $3,1 \%$ & $3,0 \%$ & $2,9 \%$ & $2,9 \%$ & $2,6 \%$ & $2,5 \%$ & $70,1 \%$ \\
\hline Caixa FIC Prev 125 Mult Rv 30 & $12,5 \%$ & $9,2 \%$ & $8,5 \%$ & $4,5 \%$ & $4,0 \%$ & $3,9 \%$ & $3,8 \%$ & $3,4 \%$ & $3,2 \%$ & $3,1 \%$ & $3,0 \%$ & $2,9 \%$ & $2,9 \%$ & $2,6 \%$ & $2,5 \%$ & $70,1 \%$ \\
\hline Caixa FIC Prev 125 Mult Rv 15 & $12,5 \%$ & $9,2 \%$ & $8,5 \%$ & $4,5 \%$ & $4,0 \%$ & $3,9 \%$ & $3,8 \%$ & $3,4 \%$ & $3,2 \%$ & $3,1 \%$ & $3,0 \%$ & $2,9 \%$ & $2,9 \%$ & $2,6 \%$ & $2,5 \%$ & $70,1 \%$ \\
\hline Caixa FIC Prev 200 Mult Rv 15 & $12,5 \%$ & $9,2 \%$ & $8,5 \%$ & $4,5 \%$ & $4,0 \%$ & $3,9 \%$ & $3,8 \%$ & $3,4 \%$ & $3,2 \%$ & $3,1 \%$ & $3,0 \%$ & $2,9 \%$ & $2,9 \%$ & $2,6 \%$ & $2,5 \%$ & $70,1 \%$ \\
\hline Caixa FIC Prev 200 Mult Rv 30 & $12,5 \%$ & $9,2 \%$ & $8,5 \%$ & $4,5 \%$ & $4,0 \%$ & $3,9 \%$ & $3,8 \%$ & $3,4 \%$ & $3,2 \%$ & $3,1 \%$ & $3,0 \%$ & $2,9 \%$ & $2,9 \%$ & $2,6 \%$ & $2,5 \%$ & $70,1 \%$ \\
\hline Caixa FIC Prev 250 Mult Rv 15 & $12,5^{\circ}$ & $9,2 \%$ & 8,5 & $4,5 \%$ & $4,0 \%$ & $3,9 \%$ & $3,8 \%$ & $3,4 \%$ & $3,2 \%$ & $3,1 \%$ & $3,0 \%$ & $2,9 \%$ & $2,9 \%$ & $2,6 \%$ & $2,5 \%$ & $70,1 \%$ \\
\hline Caixa FIC Prev 200 Mult Rv 049 & $12,5 \%$ & $9,2 \%$ & $8,5 \%$ & $4,5 \%$ & $4,0 \%$ & $3,9 \%$ & $3,8 \%$ & $3,4 \%$ & $3,2 \%$ & $3,1 \%$ & $3,0 \%$ & $2,9 \%$ & $2,9 \%$ & $2,6 \%$ & $2,5 \%$ & $70,1 \%$ \\
\hline Caixa FIC Prev 250 Mult Rv 30 & $12,5 \%$ & $9,2 \%$ & $8,5 \%$ & $4,5 \%$ & $4,0 \%$ & $3,9 \%$ & $3,8 \%$ & $3,4 \%$ & $3,2 \%$ & $3,1 \%$ & $3,0 \%$ & $2,9 \%$ & $2,9 \%$ & $2,6 \%$ & $2,5 \%$ & $70,1 \%$ \\
\hline Caixa FIC Prev 250 Mult Rv 049 & $12,5 \%$ & $9,2 \%$ & $8,5 \%$ & $4,5 \%$ & $4,0 \%$ & $3,9 \%$ & $3,8 \%$ & $3,4 \%$ & $3,2 \%$ & $3,1 \%$ & $3,0 \%$ & $2,9 \%$ & $2,9 \%$ & $2,6 \%$ & $2,5 \%$ & $70,1 \%$ \\
\hline Média & $12,5 \%$ & $9,2 \%$ & $8,5 \%$ & $4,5 \%$ & $4,0 \%$ & $3,9 \%$ & $3,8 \%$ & $3,4 \%$ & $3,2 \%$ & $3,1 \%$ & $3,0 \%$ & $2,9 \%$ & $2,9 \%$ & $2,6 \%$ & $2,5 \%$ & $70,1 \%$ \\
\hline
\end{tabular}

Fonte: Economática

Tabela elaborada pelo autor

A Tabela 14, a seguir, referente à administradora Banco Santander (Brasil) $S A$ e ao ano de 2015, mostra a carteira acionária mais frequente em 12 de 15 fundos distintos mantidos pela administradora. Os 12 fundos nessa modalidade apresentaram composição acionária idêntica.

Tabela 14 - Carteira Acionária Mais Frequente - Banco Santander (Brasil) SA - Dezembro de 2015

\begin{tabular}{|c|c|c|c|c|c|c|c|c|c|c|c|c|c|c|c|c|}
\hline $\begin{array}{l}\text { Nome do Fundo } \\
\end{array}$ & ITUB4 & ABEV3 & BBDC4 & BRFS3 & PETR4 & CIEL3 & ITSA4 & PETR3 & 3 UGPA3 & JBSS3 & VALE5 & BVMF3 & VALE3 & VIVT4 & BBSE & Subtotal \\
\hline Sant FICFI 20 I Mult Cred Priv & $10,9 \%$ & $8,0 \%$ & $7,1 \%$ & $5,2 \%$ & $3,9 \%$ & $3,8 \%$ & $3,5 \%$ & $3,3 \%$ & $3,0 \%$ & $3,0 \%$ & $2,8 \%$ & $2,8 \%$ & $2,7 \%$ & $2,5 \%$ & $2,4 \%$ & $64,7 \%$ \\
\hline Sant FICFI 20 II Mult Cred Priv & $10,9 \%$ & $8,0 \%$ & $7,1 \%$ & $5,2 \%$ & $3,9 \%$ & $3,8 \%$ & $3,5 \%$ & $3,3 \%$ & $3,0 \%$ & $3,0 \%$ & $2,8 \%$ & $2,8 \%$ & $2,7 \%$ & $2,5 \%$ & $2,4 \%$ & $64,7 \%$ \\
\hline Sant FICFI 49 I Mult Cred Priv & $10,9 \%$ & $8,0 \%$ & $7,1 \%$ & $5,2 \%$ & $3,9 \%$ & $3,8 \%$ & $3,5 \%$ & $3,3 \%$ & $3,0 \%$ & $3,0 \%$ & $2,8 \%$ & $2,8 \%$ & $2,7 \%$ & $2,5 \%$ & $2,4 \%$ & $64,7 \%$ \\
\hline Sant FICFI 49 Mult Cre Priv & $10,9 \%$ & $8,0 \%$ & $7,1 \%$ & $5,2 \%$ & $3,9 \%$ & $3,8 \%$ & $3,5 \%$ & $3,3 \%$ & $3,0 \%$ & $3,0 \%$ & $2,8 \%$ & $2,8 \%$ & $2,7 \%$ & $2,5 \%$ & $2,4 \%$ & $64,7 \%$ \\
\hline Sant FICFI Prev Agres Sup Mult Cred Priv & $10,9 \%$ & $8,0 \%$ & $7,1 \%$ & $5,2 \%$ & $3,9 \%$ & $3,8 \%$ & $3,5 \%$ & $3,3 \%$ & $3,0 \%$ & $3,0 \%$ & $2,8 \%$ & $2,8 \%$ & $2,7 \%$ & $2,5 \%$ & $2,4 \%$ & $64,7 \%$ \\
\hline Sant FICFI Prev Mod Mult Cred Priv & $10,9 \%$ & $8,0 \%$ & $7,1 \%$ & $5,2 \%$ & $3,9 \%$ & $3,8 \%$ & $3,5 \%$ & $3,3 \%$ & $3,0 \%$ & $3,0 \%$ & $2,8 \%$ & $2,8 \%$ & $2,7 \%$ & $2,5 \%$ & $2,4 \%$ & $64,7 \%$ \\
\hline Sant FICFI Prev Mod Sup Mult Cred Priv & $10,9 \%$ & $8,0 \%$ & $7,1 \%$ & $5,2 \%$ & $3,9 \%$ & $3,8 \%$ & $3,5 \%$ & $3,3 \%$ & $3,0 \%$ & $3,0 \%$ & $2,8 \%$ & $2,8 \%$ & $2,7 \%$ & $2,5 \%$ & $2,4 \%$ & $64,7 \%$ \\
\hline Sant FICFI T Brasil Mult Cred Priv & $10,9 \%$ & $8,0 \%$ & $7,1 \%$ & $5,2 \%$ & $3,9 \%$ & $3,8 \%$ & $3,5 \%$ & $3,3 \%$ & $3,0 \%$ & $3,0 \%$ & $2,8 \%$ & $2,8 \%$ & $2,7 \%$ & $2,5 \%$ & $2,4 \%$ & $64,7 \%$ \\
\hline Santander FIA Prev & $10,9 \%$ & $8,0 \%$ & $7,1 \%$ & $5,2 \%$ & $3,9 \%$ & $3,8 \%$ & $3,5 \%$ & $3,3 \%$ & $3,0 \%$ & $3,0 \%$ & $2,8 \%$ & $2,8 \%$ & $2,7 \%$ & $2,5 \%$ & $2,4 \%$ & $64,7 \%$ \\
\hline Santander FICFI 49 II Mult Cred Priv & $10,9 \%$ & $8,0 \%$ & $7,1 \%$ & $5,2 \%$ & $3,9 \%$ & $3,8 \%$ & $3,5 \%$ & $3,3 \%$ & $3,0 \%$ & $3,0 \%$ & $2,8 \%$ & $2,8 \%$ & $2,7 \%$ & $2,5 \%$ & $2,4 \%$ & $64,7 \%$ \\
\hline Santander FICFI Prev Cma Mult Cred Priv & $10,9 \%$ & $8,0 \%$ & $7,1 \%$ & $5,2 \%$ & $3,9 \%$ & $3,8 \%$ & $3,5 \%$ & $3,3 \%$ & $3,0 \%$ & $3,0 \%$ & $2,8 \%$ & $2,8 \%$ & $2,7 \%$ & $2,5 \%$ & $2,4 \%$ & $64,7 \%$ \\
\hline Média & $10,9 \%$ & $8,0 \%$ & $7,1 \%$ & $5,2 \%$ & $3,9 \%$ & $3,8 \%$ & $3,5 \%$ & $3,3 \%$ & $3,0 \%$ & $3,0 \%$ & $2,8 \%$ & $2,8 \%$ & $2,7 \%$ & $2,5 \%$ & $2,4 \%$ & $64,7 \%$ \\
\hline
\end{tabular}

Fonte: Economática

Tabela elaborada pelo autor

Uma análise mais minuciosa sobre a composição das carteiras acionárias dos fundos PGBL/VGBL das cinco maiores administradoras apresenta um claro padrão no seu processo de gestão. Os dados comprovam que relevante parcela, em termos de quantidade, dos fundos de cada administradora mantém, consistentemente no período analisado, a mesma composição acionária, como se a administradora definisse uma única política de aquisição de ativos e realizasse o rateio proporcional à parcela de renda variável presente nesse conjunto de fundos. A Tabela 15, a seguir, apresenta esse padrão. 
Tabela 15 - Fundos PGBL/VGBL das Cinco Administradoras - Percentual de Uso da Carteira Mais Frequente (\% sobre Quantidade)

\begin{tabular}{|c|c|c|c|c|c|c|c|c|c|c|}
\hline Administradora & 2007 & 2008 & 2009 & 2010 & 2011 & 2012 & 2013 & 2014 & \multicolumn{2}{|c|}{2015 Média } \\
\hline Bradesco & $95,7 \%$ & $95,7 \%$ & $100,0 \%$ & $100,0 \%$ & $100,0 \%$ & $85,7 \%$ & $74,6 \%$ & $76,4 \%$ & $79,2 \%$ & $86,7 \%$ \\
\hline BB Dtvm S.A & $84,6 \%$ & $85,7 \%$ & $82,6 \%$ & $76,9 \%$ & $77,8 \%$ & $43,3 \%$ & $41,0 \%$ & $46,2 \%$ & $63,9 \%$ & $62,6 \%$ \\
\hline Itau Unibanco SA & $82,4 \%$ & $67,5 \%$ & $55,4 \%$ & $60,8 \%$ & $62,0 \%$ & $34,6 \%$ & $35,7 \%$ & $42,1 \%$ & $72,0 \%$ & $51,3 \%$ \\
\hline Caixa & $100,0 \%$ & $100,0 \%$ & $100,0 \%$ & $100,0 \%$ & $100,0 \%$ & $100,0 \%$ & $100,0 \%$ & $100,0 \%$ & $100,0 \%$ & $100,0 \%$ \\
\hline Banco Santander (Brasil) SA & $40,0 \%$ & $58,3 \%$ & $64,7 \%$ & $72,2 \%$ & $72,2 \%$ & $92,0 \%$ & $76,5 \%$ & $55,0 \%$ & $73,3 \%$ & $69,7 \%$ \\
\hline Média & $82,1 \%$ & $78,6 \%$ & $73,1 \%$ & $74,1 \%$ & $74,5 \%$ & $55,1 \%$ & $51,1 \%$ & $54,7 \%$ & $74,6 \%$ & $65,1 \%$ \\
\hline
\end{tabular}

Fonte: Economática

Tabela elaborada pelo autor

De todo modo, a concentração do uso de carteiras acionárias idênticas e/ou semelhantes como estratégia comum na gestão dos fundos PGBL/VGBL é mais um padrão consistentemente mensurado nesta pesquisa. Por isso, o próximo passo foi descobrir quanto dos investimentos em ações dos fundos PGBL/VGBL dessas administradoras pertenciam aos fundos com a carteira idêntica e/ou semelhante mais frequente. A Tabela 16, a seguir, mostra esses números.

Tabela 16 - Fundos PGBL/VGBL das Cinco Administradoras - Percentual de Uso da Carteira Mais Frequente (\% sobre Valor da Posição Acionária)

\begin{tabular}{lrrrrrrrrrr}
\hline Administradora & $\mathbf{2 0 0 7}$ & $\mathbf{2 0 0 8}$ & $\mathbf{2 0 0 9}$ & $\mathbf{2 0 1 0}$ & $\mathbf{2 0 1 1}$ & $\mathbf{2 0 1 2}$ & $\mathbf{2 0 1 3}$ & $\mathbf{2 0 1 4}$ & $\mathbf{2 0 1 5}$ & Média \\
\hline Bradesco & $99,8 \%$ & $99,9 \%$ & $100,0 \%$ & $100,0 \%$ & $100,0 \%$ & $99,2 \%$ & $97,5 \%$ & $89,8 \%$ & $90,4 \%$ & $98,2 \%$ \\
BB Dtvm S.A & $85,3 \%$ & $74,6 \%$ & $75,1 \%$ & $70,5 \%$ & $72,1 \%$ & $60,8 \%$ & $57,4 \%$ & $21,9 \%$ & $33,6 \%$ & $57,9 \%$ \\
Itau Unibanco SA & $98,4 \%$ & $94,7 \%$ & $95,4 \%$ & $90,3 \%$ & $89,1 \%$ & $78,2 \%$ & $64,6 \%$ & $61,7 \%$ & $78,5 \%$ & $84,3 \%$ \\
Caixa & $100,0 \%$ & $100,0 \%$ & $100,0 \%$ & $100,0 \%$ & $100,0 \%$ & $100,0 \%$ & $100,0 \%$ & $100,0 \%$ & $100,0 \%$ & $100,0 \%$ \\
Banco Santander (Brasil) SA & $47,8 \%$ & $96,9 \%$ & $82,4 \%$ & $75,9 \%$ & $77,0 \%$ & $99,8 \%$ & $88,8 \%$ & $92,2 \%$ & $95,2 \%$ & $85,3 \%$ \\
\hline Média & $\mathbf{9 6 , 9 \%}$ & $\mathbf{9 5 , 3 \%}$ & $\mathbf{9 3 , 0 \%}$ & $\mathbf{8 9 , 2 \%}$ & $\mathbf{8 8 , 2} \%$ & $\mathbf{8 3 , 0} \%$ & $\mathbf{7 8 , 0} \%$ & $\mathbf{6 2 , 0} \%$ & $\mathbf{7 0 , 4 \%}$ & $\mathbf{8 4 , 2 \%}$ \\
\hline
\end{tabular}

Fonte: Economática

Tabela elaborada pelo autor

Exceto nos anos de 2014 e 2015, com efeitos mais concentrados na BB Dtvm S.A, em função da adoção de critério mais restrito para categorização das carteiras, a maior parte do investimento em ações realizado pelos fundos PGBL/VGBL, em nome de seus cotistas, segue uma mesma composição acionária, dentro de cada administradora.

Se a composição da carteira acionária de grande parte dos fundos distintos mantidos por uma administradora é essencialmente igual, pressupõem-se que o comportamento dos retornos dos fundos PGBL/VGBL mantidos pelas cinco principais administradoras com carteira mais frequente tenderia a ser bastante semelhante ao da curva de retornos da totalidade de fundos PGBL/VGBL dessas cinco administradoras, que, como já visto, é semelhante à curva dos retornos de todos os fundos $\mathrm{PGBL} / \mathrm{VGBL}$ com renda variável mantidos por todas as administradoras. É o que mostra o Gráfico 9, a seguir. 


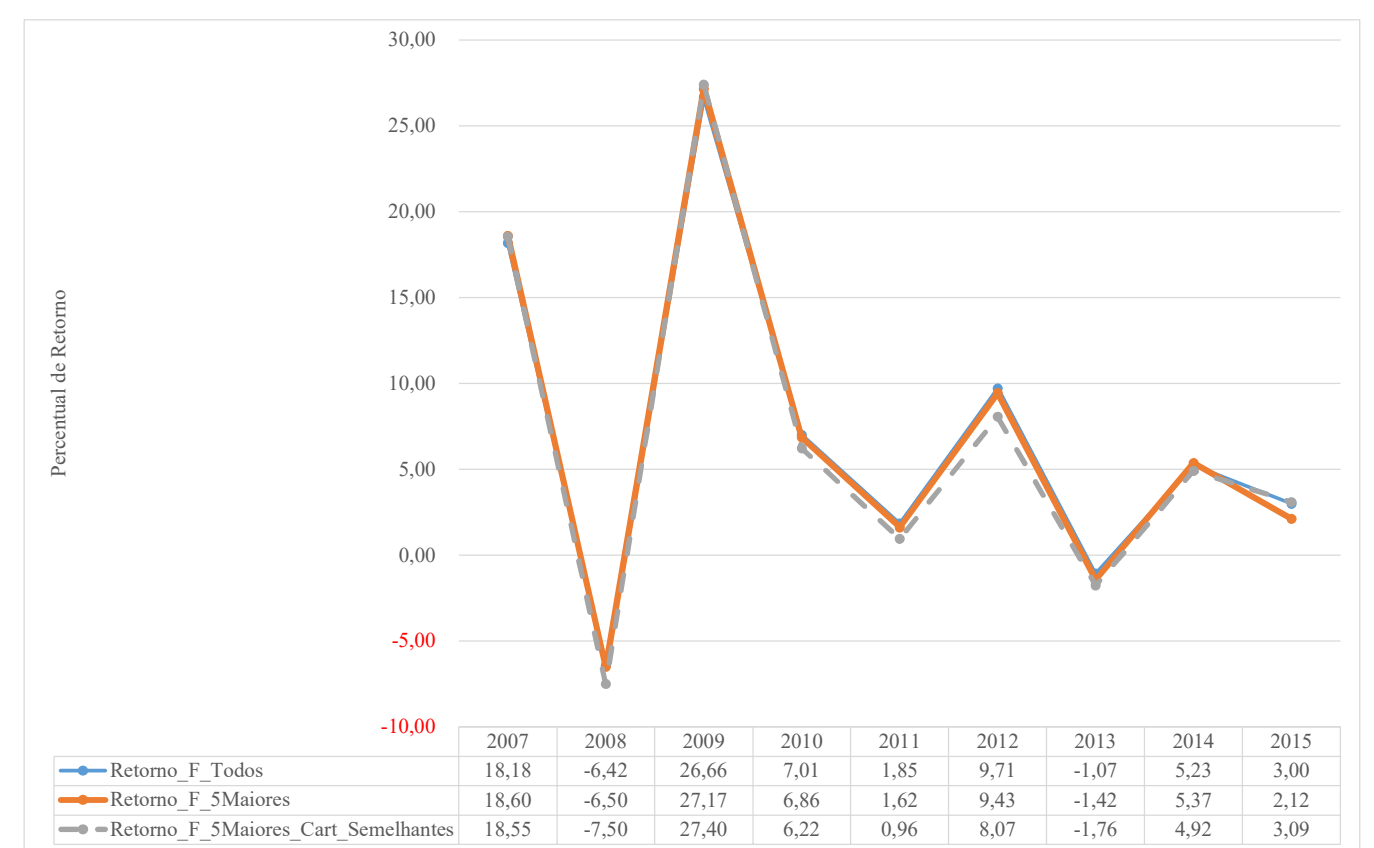

Gráfico 9 - Comparação entre os Retornos Médios Anuais (Todas as Administradoras x 5 Maiores Administradoras x Carteiras Iguais ou Semelhantes das 5 Maiores Administradoras) Fonte: Economática

Gráfico elaborado pelo autor

Evidentemente, a curva de retorno dos fundos com carteiras comuns mais frequentes de cada administradora, pela relevância já demonstrada, segue a respectiva curva de retorno médio de todos os fundos PGBL/VGBL com renda variável mantidos pelas administradoras. Essas curvas de cada administradora, apesar de aqui mencionadas, não serão apresentadas.

\subsection{Análise Estatística das Estratégias de Gestão Adotadas pelas 5 Maiores Administradoras de Fundos PGBL/VGBL}

\subsubsection{Análise dos Betas Médios das Carteiras Acionárias}

O Gráfico 10, a seguir, apresenta os betas médios das carteiras dos fundos das cinco principais administradoras de fundos PGBL/VGBL com investimentos em renda variável. Notadamente, observa-se que os betas médios da das carteiras da BB Dtvm S.A apontam para uma postura mais conservadora na gestão dos fundos. 


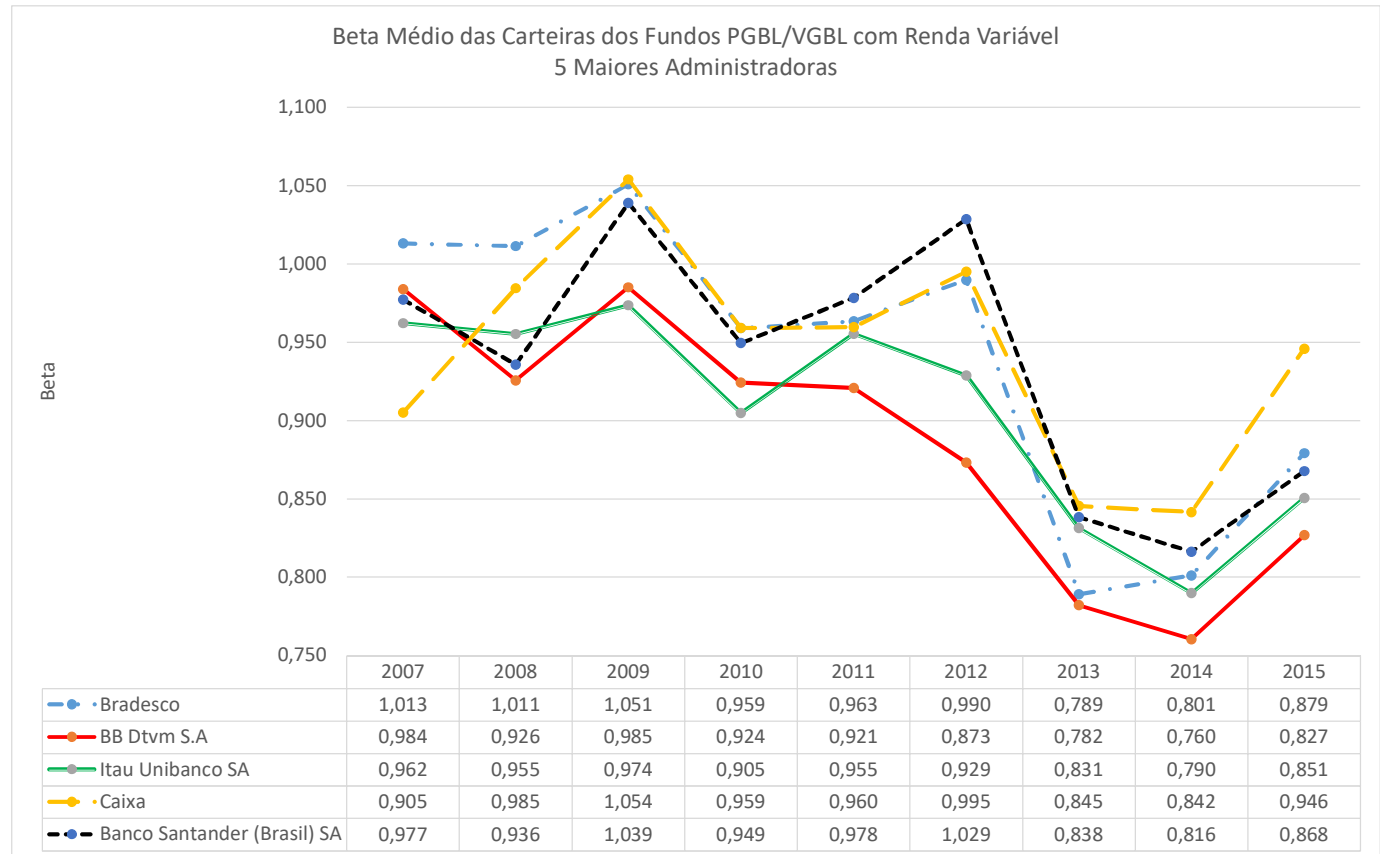

Gráfico 10 - Beta Médio das Carteiras dos Fundos PGBL/VGBL com Renda Variável (5 Maiores Administradoras)

Fonte: Economática (com dados calculados pelo autor) Gráfico elaborado pelo autor

A Tabela 17, a seguir, apresenta os testes para verificação de igualdade das médias dos betas das carteiras dos fundos entre as cinco principais administradoras listadas no gráfico anterior. Os resultados dos testes, em cada um dos anos analisados, indicam que ao menos uma administradora apresentou fundos com betas médios das carteiras estatisticamente diferentes, dentro de um intervalo de confiança de $95 \%$. Ou seja, apesar de certo padrão na montagem das carteiras acionárias e forte correlação entre os retornos médios anuais, há ao menos uma administradora que se diferenciou das demais em sua estratégia de composição do portfólio de renda variável. Apesar da passividade dos fundos apontada por Brito (2016) e Amaral (2013), há diferença na estratégia de seleção das ações para as carteiras dos fundos entre as principais administradoras - resultado não esperado com base na literatura. 
Tabela 17 - Testes de Igualdade - Betas Médios dos Fundos

-> Ano $=\mathbf{2 0 0 7}$
Test for equality of 5 group means, allowing for heterogeneity
Wald chi2 $(4)=1851.15$
Prob $>$ chi $2=0.0000$ (chi-squared approximation)
Prob $>$ chi $2=0.0000$ (James' approximation)
$\rightarrow \mathbf{A n o}=\mathbf{2 0 0 9}$

Test for equality of 5 group means, allowing for heterogeneity

Wald chi2 $(4)=1.61 \mathrm{e}+10$

Prob $>$ chi2 $=0.0000$ (chi-squared approximation)

Prob $>$ chi2 $=0.0000$ (James' approximation)

$->A n o=2011$

Test for equality of 5 group means, allowing for heterogeneity

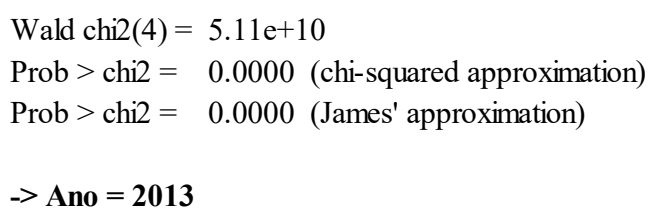

Test for equality of 5 group means, allowing for heterogeneity

Wald chi2 $(4)=20.21$

Prob $>$ chi2 $=0.0005$ (chi-squared approximation)

Prob $>$ chi $2=0.0014$ (James' approximation)

$\rightarrow$ Ano $=2015$

Test for equality of 5 group means, allowing for heterogeneity

Wald chi2 $(4)=227.54$

Prob $>$ chi2 $=0.0000$ (chi-squared approximation)

Prob $>$ chi2 $=0.0000$ (James' approximation)

Tabela elaborada pelo autor a partir dos resultados de testes multivariados de Wald obtidos pelo software Stata 13.1.

No entanto, outros fatores, em tese, também deveriam explicar a variação dos retornos, possivelmente, até com maior intensidade. São eles, a se verificar: a taxa de administração cobrada dos cotistas e o percentual do patrimônio dos fundos que é investido em renda variável.

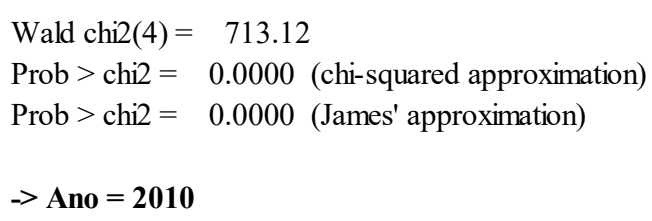

Test for equality of 5 group means, allowing for heterogeneity

Wald chi2 $(4)=1.56 \mathrm{e}+08$

Prob $>$ chi2 $=0.0000$ (chi-squared approximation)

Prob $>$ chi2 $=0.0000$ (James' approximation)

$\rightarrow$ Ano $=2012$

Test for equality of 5 group means, allowing for heterogeneity

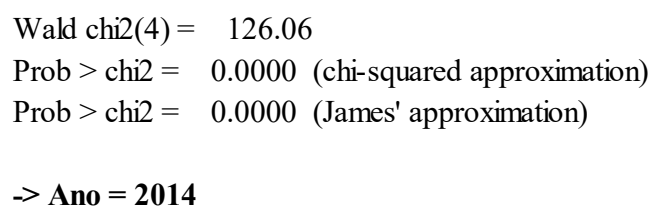

Test for equality of 5 group means, allowing for heterogeneity

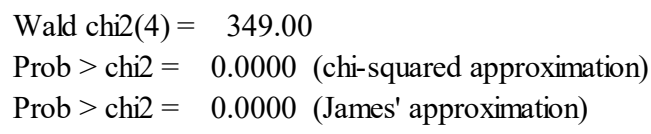




\subsubsection{Análise das Médias das Taxas de Administração}

Vale lembrar que a base de dados deste estudo contém a taxa de administração máxima cobrada pelo fundo. Tal taxa é aqui utilizada como uma variável proxy para representar a taxa média de administração cobrada pelo fundo, dado que a informação da média efetivamente cobrada não faz parte do banco de dados utilizado nesta pesquisa.

Os dados da Tabela 18, a seguir, mostram que as taxas cobradas pelos fundos que investem na carteira acionária mais frequente de cada administradora variaram em até 4 pontos percentuais dependendo da administradora. 
Tabela 18 - Estatísticas Descritivas - Taxas de Administração Máximas (5 Maiores Administradoras)

\begin{tabular}{|c|c|c|c|c|c|c|}
\hline \multicolumn{7}{|c|}{$\begin{array}{l}\text { Análise do \% de Taxa de Administração Máxima - Fundos PGBL/VGBL } \\
\text { Fundos com a Carteira Acionária Igual ou Semelhante + Frequente }\end{array}$} \\
\hline & Nr Obs. & Taxa Mínima & Taxa Média & Taxa Máxima & Amplitude & Desvio Padrão \\
\hline Bradesco & 313 & 0,00 & 1,71 & 3,00 & 3,00 & 0,91 \\
\hline 2007 & 22 & 0,00 & 1,87 & 3,00 & 3,00 & 0,97 \\
\hline 2008 & 22 & 0,00 & 1,87 & 3,00 & 3,00 & 0,97 \\
\hline 2009 & 27 & 0,00 & 1,84 & 3,00 & 3,00 & 0,95 \\
\hline 2010 & 32 & 0,00 & 1,69 & 3,00 & 3,00 & 0,94 \\
\hline 2011 & 40 & 0,00 & 1,56 & 3,00 & 3,00 & 0,93 \\
\hline 2012 & 42 & 0,00 & 1,68 & 3,00 & 3,00 & 0,89 \\
\hline 2013 & 44 & 0,00 & 1,65 & 3,00 & 3,00 & 0,87 \\
\hline 2014 & 42 & 0,00 & 1,68 & 3,00 & 3,00 & 0,86 \\
\hline 2015 & 42 & 0,35 & 1,72 & 3,00 & 2,65 & 0,83 \\
\hline BB Dtvm S.A & 159 & $\mathbf{0 , 0 0}$ & 2,15 & 3,50 & 3,50 & 0,94 \\
\hline 2007 & 11 & 0,00 & 2,14 & 3,50 & 3,50 & 0,88 \\
\hline 2008 & 18 & 0,00 & 2,15 & 3,50 & 3,50 & 0,96 \\
\hline 2009 & 19 & 0,00 & 2,09 & 3,50 & 3,50 & 0,97 \\
\hline 2010 & 20 & 0,00 & 2,02 & 3,50 & 3,50 & 0,99 \\
\hline 2011 & 21 & 0,00 & 1,92 & 3,50 & 3,50 & 1,06 \\
\hline 2012 & 13 & 0,00 & 2,03 & 3,50 & 3,50 & 0,99 \\
\hline 2013 & 16 & 0,00 & 2,09 & 3,50 & 3,50 & 0,94 \\
\hline 2014 & 18 & 1,25 & 2,41 & 3,50 & 2,25 & 0,73 \\
\hline 2015 & 23 & 1,25 & 2,41 & 3,50 & 2,25 & 0,74 \\
\hline Itau Unibanco SA & 414 & $\mathbf{0 , 0 0}$ & 1,62 & 4,00 & 4,00 & 0,97 \\
\hline 2007 & 28 & 0,00 & 1,55 & 4,00 & 4,00 & 1,04 \\
\hline 2008 & 27 & 0,00 & 1,78 & 4,00 & 4,00 & 1,05 \\
\hline 2009 & 31 & 0,00 & 1,67 & 4,00 & 4,00 & 1,03 \\
\hline 2010 & 48 & 0,00 & 1,45 & 4,00 & 4,00 & 0,93 \\
\hline 2011 & 62 & 0,00 & 1,53 & 4,00 & 4,00 & 0,96 \\
\hline 2012 & 47 & 0,00 & 1,82 & 4,00 & 4,00 & 0,94 \\
\hline 2013 & 51 & 0,00 & 1,73 & 4,00 & 4,00 & 0,96 \\
\hline 2014 & 53 & 0,00 & 1,70 & 4,00 & 4,00 & 0,95 \\
\hline 2015 & 67 & 0,00 & 1,52 & 4,00 & 4,00 & 0,92 \\
\hline Caixa & 96 & 0,00 & 1,94 & 3,00 & 3,00 & 0,90 \\
\hline 2007 & 4 & 0,00 & 2,25 & 3,00 & 3,00 & 1,30 \\
\hline 2008 & 7 & 0,00 & 1,93 & 3,00 & 3,00 & 1,05 \\
\hline 2009 & 7 & 0,00 & 1,93 & 3,00 & 3,00 & 1,05 \\
\hline 2010 & 7 & 0,00 & 1,93 & 3,00 & 3,00 & 1,05 \\
\hline 2011 & 7 & 0,00 & 1,93 & 3,00 & 3,00 & 1,05 \\
\hline 2012 & 16 & 0,00 & 1,92 & 3,00 & 3,00 & 0,79 \\
\hline 2013 & 16 & 0,00 & 1,92 & 3,00 & 3,00 & 0,79 \\
\hline 2014 & 16 & 0,00 & 1,92 & 3,00 & 3,00 & 0,79 \\
\hline 2015 & 16 & 0,00 & 1,92 & 3,00 & 3,00 & 0,79 \\
\hline Banco Santander (Brasil) & 106 & 0,00 & 1,83 & 3,20 & 3,20 & 0,98 \\
\hline 2007 & 4 & 0,70 & 1,85 & 3,20 & 2,50 & 0,91 \\
\hline 2008 & 7 & 0,00 & 1,80 & 3,20 & 3,20 & 1,10 \\
\hline 2009 & 11 & 0,00 & 2,01 & 3,20 & 3,20 & 0,96 \\
\hline 2010 & 13 & 0,00 & 1,88 & 3,20 & 3,20 & 0,93 \\
\hline 2011 & 13 & 0,00 & 1,88 & 3,20 & 3,20 & 0,93 \\
\hline 2012 & 23 & 0,00 & 1,49 & 3,20 & 3,20 & 0,99 \\
\hline 2013 & 13 & 0,00 & 1,85 & 3,20 & 3,20 & 0,96 \\
\hline 2014 & 11 & 0,00 & 2,01 & 3,20 & 3,20 & 0,96 \\
\hline 2015 & 11 & 0,00 & 2,01 & 3,20 & 3,20 & 0,96 \\
\hline Total Geral & 1.088 & 0,00 & 1,77 & 4,00 & 4,00 & 0,96 \\
\hline
\end{tabular}

Fonte: Economática

Tabela elaborada pelo autor

Exceto pela proporção do patrimônio que é aplicada em renda variável, tais fundos de cada administradora detinham, no período, o mesmo sortimento de ações. Portanto, entre dois 
cotistas de fundos distintos com o mesmo percentual aplicado em renda variável, o cotista que pagou ao fundo uma taxa de administração maior obteve em média retornos menores.

A Tabela 19, a seguir, apresenta os testes para verificação de igualdade das médias das taxas de administração máximas cobradas pelos fundos - não somente os com carteira igual ou semelhante - entre as cinco principais administradoras, os resultados dos testes apontam o seguinte: nos anos de 2010, 2012, 2013 e 2014, ao menos uma administradora praticou taxas de administração médias distintas das demais, dentro de um intervalo de confiança de $95 \%$. Nos demais anos, 2007, 2008, 2009, 2011 e 2015 não foi possível rejeitar a hipótese de igualdade entre as médias. Considerando que, na base analisada, as taxas de administração máximas de dado fundo são praticamente invariáveis no tempo, quando se realiza os testes com os dados agregados - sem segmenta-los por ano, há presença de diferença estatisticamente significante entre as médias, dentro de um intervalo de confiança de 95\%, sendo uma evidência de estratégia de diferenciação comercial entre as administradoras. 
Tabela 19 - Testes de Igualdade - Média das Taxas de Administração Máximas

\begin{tabular}{|c|c|}
\hline$->$ Ano $=2007$ & \\
\hline Test for equality & $y$ of 5 group means, allowing for heterogeneity \\
\hline Wald chi2 $(4)=$ & 4.04 \\
\hline Prob $>$ chi $2=$ & 0.4001 (chi-squared approximation) \\
\hline Prob $>$ chi $2=$ & 0.4842 (James' approximation) \\
\hline
\end{tabular}

Test for equality of 5 group means, allowing for heterogeneity

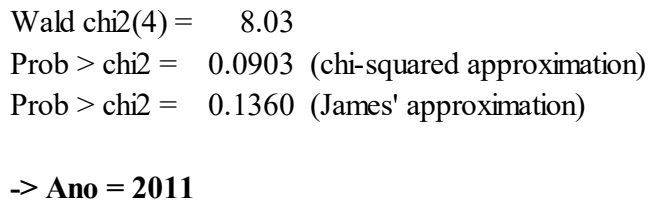

Test for equality of 5 group means, allowing for heterogeneity

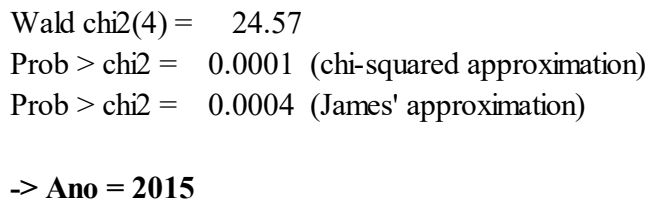

Test for equality of 5 group means, allowing for heterogeneity

Wald chi2 $(4)=7.19$

Prob $>$ chi2 $=0.1263$ (chi-squared approximation)

Prob $>$ chi $2=0.1564$ (James' approximation)

Tabela elaborada pelo autor a partir dos resultados de testes multivariados de Wald obtidos pelo software Stata 13.1.

\subsubsection{Análise do Percentual Médio do Patrimônio Investido em Renda Variável}

Quando se analisa a evolução do percentual de renda variável dos fundos PGBL/VGBL com carteiras idênticas ou semelhantes mais frequentes, observa-se que a administradora Itaú Unibanco SA se posicionou, consistentemente ao longo do período, de maneira mais 
conservadora, ou seja, dedicando menor parcela do patrimônio do fundo a investimentos em ações, como mostra o Gráfico 11, a seguir.

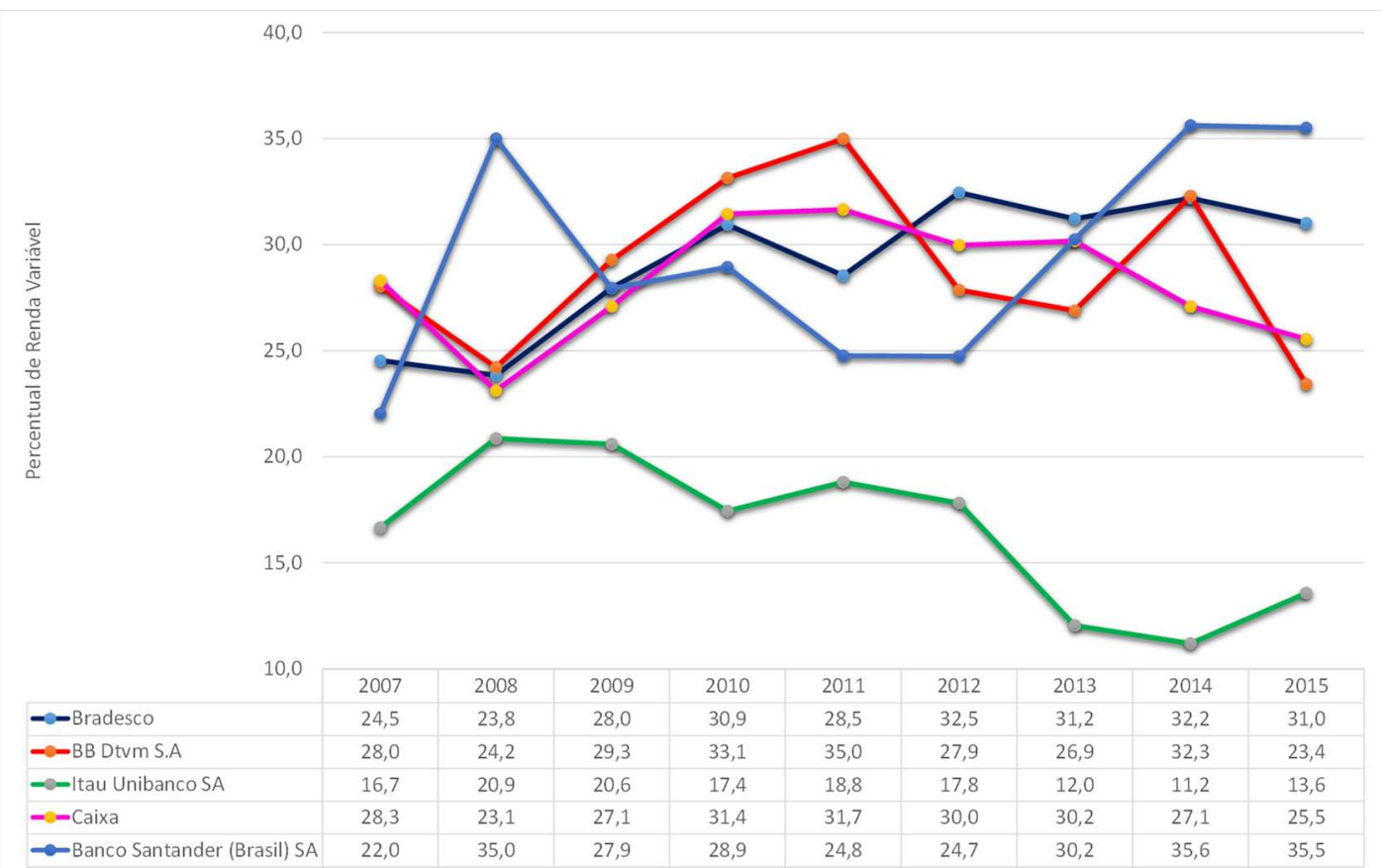

Gráfico 11 - Percentual Médio de Renda Variável - Carteiras Iguais ou Semelhantes - Fundos PGBL/VGBL Fonte: Economática (com dados calculados pelo autor)

Gráfico elaborado pelo autor

O mesmo ocorre quando se observam os percentuais aplicados em renda variável de todos os fundos de cada uma das cinco principais administradoras de fundos, conforme mostra o Gráfico 12, a seguir. Interessante observar que as estratégias de BB Dtvm S.A e Caixa parecem estar bastante correlacionadas, assim como Bradesco e Banco Santander (Brasil) SA. Em patamar distinto, no período analisado, operou o Itaú Unibanco $S A$, de forma mais conservadora. 


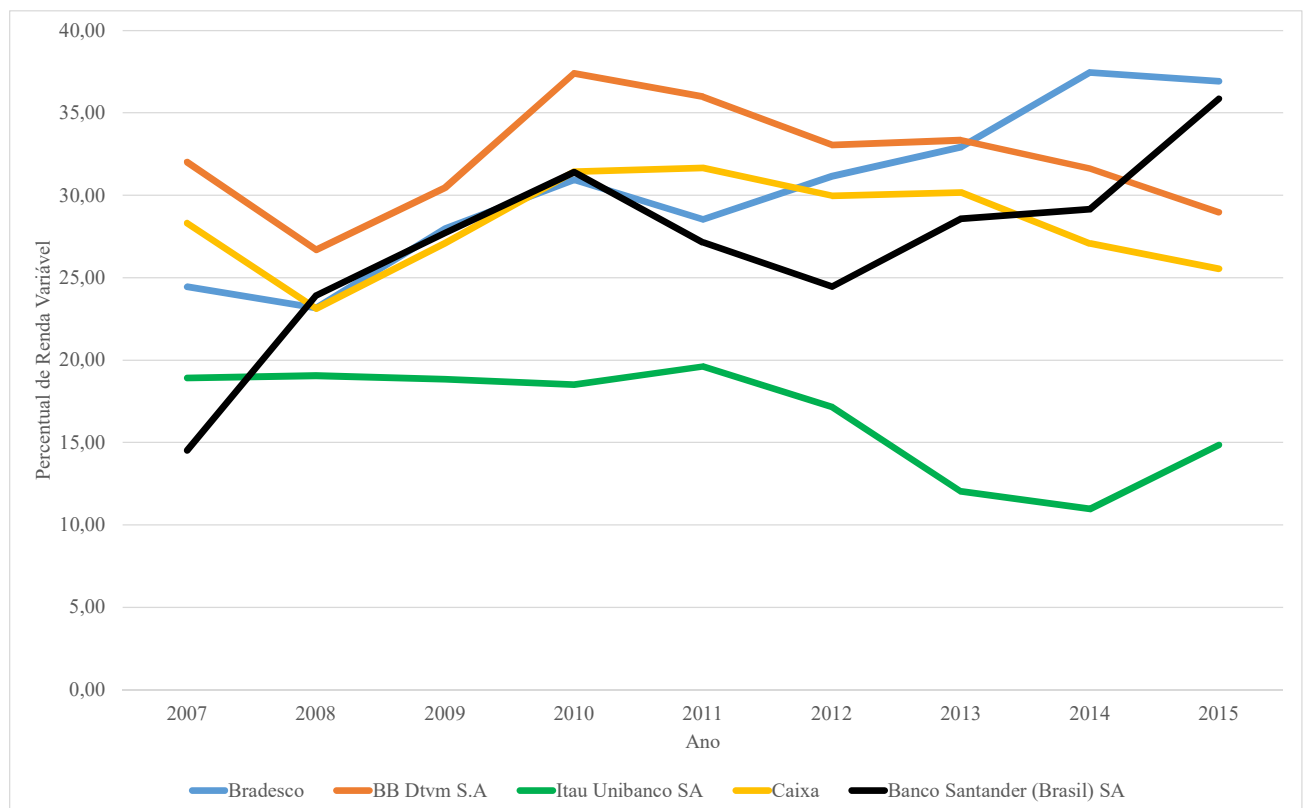

Gráfico 12 - Percentual Médio de Renda Variável dos Fundos PGBL/VGBL- 5 Maiores Administradoras Fonte: Economática (com dados calculados pelo autor)

Gráfico elaborado pelo autor

A Tabela 20, a seguir, apresenta os testes para verificação de igualdade das médias dos percentuais investidos em renda variável entre as principais administradoras de PGBL/VGBL que mantiveram carteiras acionárias, direta ou indiretamente. Com exceção do ano de 2008, os resultados, em cada um dos anos analisados, apontam que ao menos uma administradora apresentou percentuais aplicados em renda variável estatisticamente diferentes, dentro de um intervalo de confiança de $95 \%$, representando outra evidência de diferenciação de estratégia de gestão. 
Tabela 20 - Testes de Igualdade - Média do Percentual do Patrimônio do Fundo Investido em Renda Variável

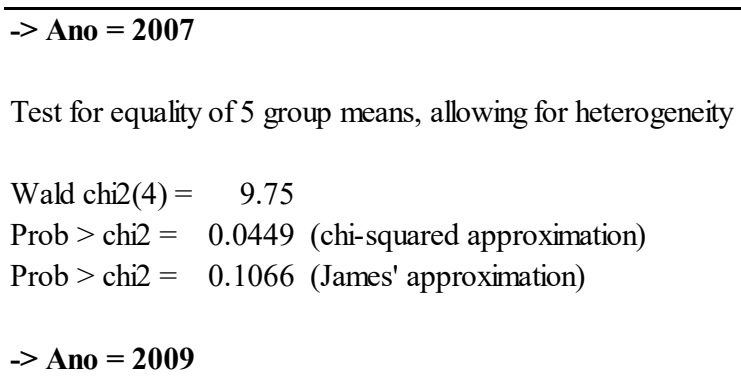

Test for equality of 5 group means, allowing for heterogeneity

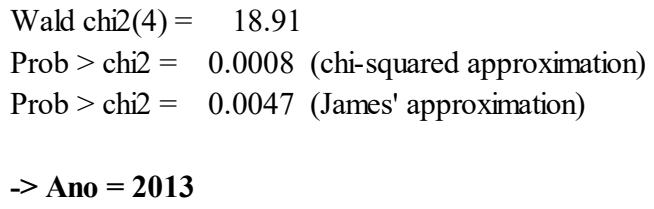

Test for equality of 5 group means, allowing for heterogeneity

Wald chi2 $(4)=56.63$

Prob $>$ chi2 $=0.0000$ (chi-squared approximation)

Prob $>$ chi $2=0.0000$ (James' approximation)

Tabela elaborada pelo autor a partir dos resultados de testes multivariados de Wald obtidos pelo software Stata 13.1.

\section{$->A n o=2008$}

Test for equality of 5 group means, allowing for heterogeneity

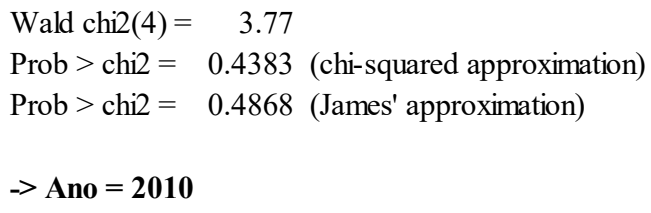

Test for equality of 5 group means, allowing for heterogeneity

Wald chi2 $(4)=25.72$

Prob $>$ chi2 $=0.0000$ (chi-squared approximation)

Prob $>$ chi2 $=0.0007$ (James' approximation)

$\rightarrow$ Ano $=2012$

Test for equality of 5 group means, allowing for heterogeneity

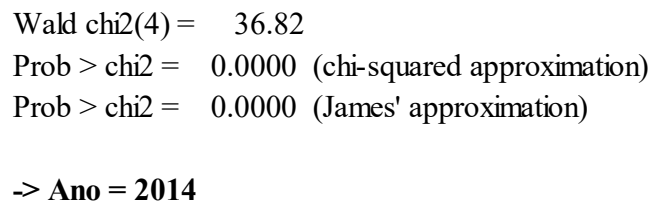

Test for equality of 5 group means, allowing for heterogeneity

Wald chi2 $(4)=99.76$

Prob $>$ chi $2=0.0000$ (chi-squared approximation)

Prob $>$ chi2 $=0.0000$ (James' approximation)

\subsubsection{Análise dos Retornos Médios Anuais}

No entanto, o comportamento dos retornos médios anuais mantidos pelas cinco principais administradoras apresenta diferenças entre as curvas. Por exemplo, a variação dos retornos 
médios da $B B$ Dtvm S.A, no período analisado, é superior à do Itaú Unibanco SA, como pode ser visto no Gráfico 13, a seguir.

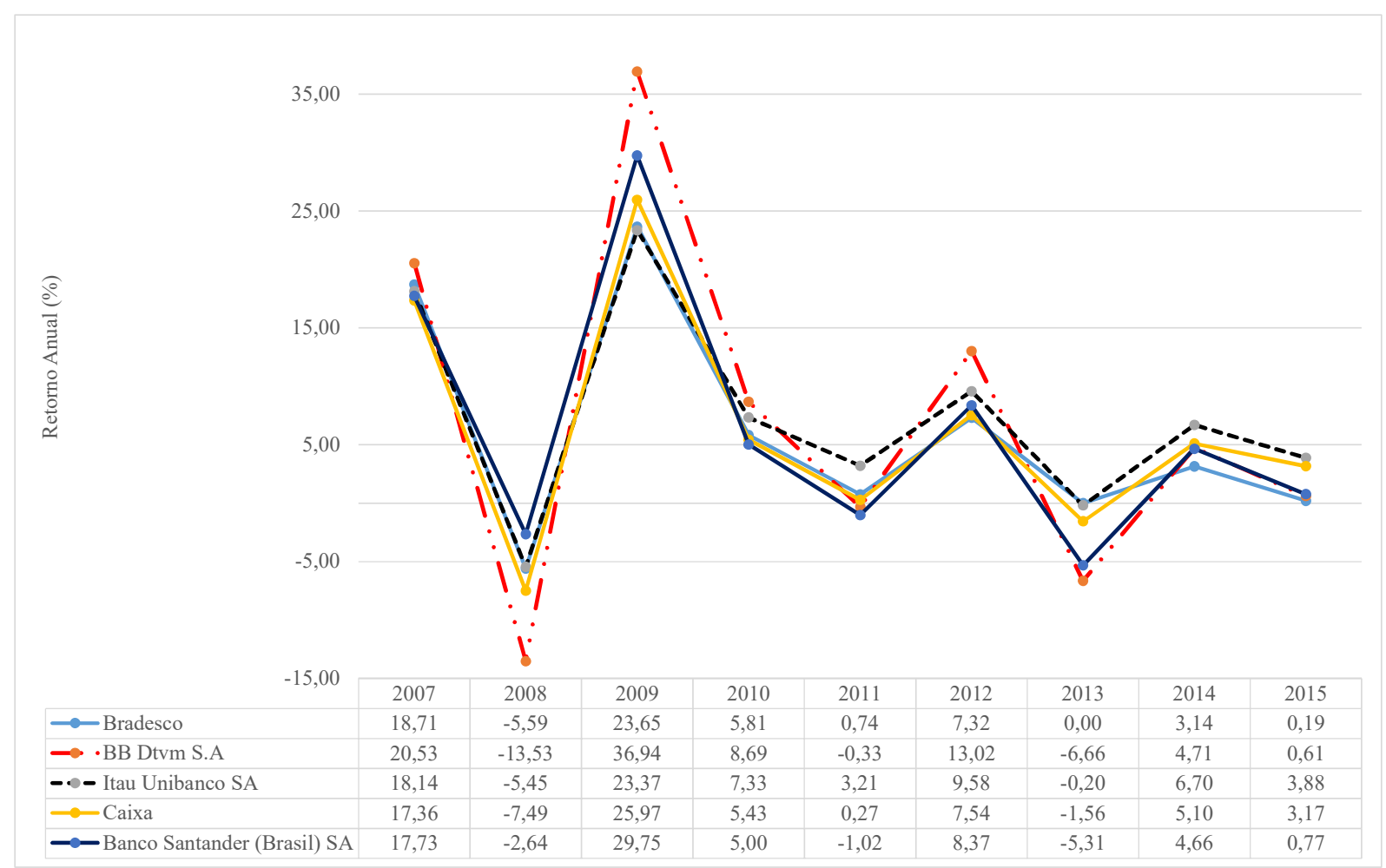

Gráfico 13 - Retorno Médio Anual dos Fundos PGBL/VGBL com Renda Variável (5 Maiores Administradoras) Fonte: Economática

Gráfico elaborado pelo autor

A Tabela 21, a seguir, apresenta os testes para verificação de igualdade das médias dos retornos anuais dos fundos entre as cinco principais administradoras listadas no gráfico anterior. Os resultados apontam que somente nos anos de 2007 e 2008 não se pôde rejeitar a hipótese de que existiam diferenças nos retornos médios anuais entre os fundos das cinco principais administradoras. Nos demais anos analisados - 2009 a 2015 - os resultados dos testes apontam que ao menos uma administradora apresentou fundos com retornos médios anuais estatisticamente diferentes, dentro de um intervalo de confiança de 95\%. Portanto, apesar de curvas extremamente correlacionadas entre as principais administradoras, como mostrou o gráfico anterior, há evidências de presença de retornos médios distintos em ao menos uma delas, diferentemente do que era esperado na formulação das hipóteses, embora ainda não tenha sido realizado qualquer ajuste ao risco assumido pelos fundos. Tais testes para identificação da administradora que apresentou melhor desempenho será apresentado mais adiante. 
Tabela 21 - Testes de Igualdade - Retorno Anual dos Fundos

\begin{tabular}{|c|c|}
\hline \multicolumn{2}{|l|}{$->$ Ano $=2007$} \\
\hline \multicolumn{2}{|c|}{ Test for equality of 5 group means, allowing for heterogeneity } \\
\hline Wald chi2 $(4)=$ & 0.64 \\
\hline Prob $>$ chi $2=$ & 0.9590 (chi-squared approximation) \\
\hline Prob $>$ chi $2=$ & 0.9669 (James' approximation) \\
\hline \multicolumn{2}{|l|}{$->$ Ano $=2009$} \\
\hline \multicolumn{2}{|c|}{ Test for equality of 5 group means, allowing for heterogeneity } \\
\hline Wald chi2 $(4)=$ & 14.92 \\
\hline Prob $>$ chi $2=$ & 0.0049 (chi-squared approximation) \\
\hline Prob $>$ chi $2=$ & 0.0159 (James' approximation) \\
\hline \multicolumn{2}{|l|}{$->$ Ano $=2011$} \\
\hline \multicolumn{2}{|c|}{ Test for equality of 5 group means, allowing for heterogeneity } \\
\hline Wald chi2 $(4)=$ & 13.68 \\
\hline Prob $>$ chi $2=$ & 0.0084 (chi-squared approximation) \\
\hline Prob $>$ chi $2=$ & 0.0227 (James' approximation) \\
\hline \multicolumn{2}{|l|}{$->A n o=2013$} \\
\hline \multicolumn{2}{|c|}{ Test for equality of 5 group means, allowing for heterogeneity } \\
\hline Wald chi2(4) = & 44.19 \\
\hline Prob $>$ chi $2=$ & 0.0000 (chi-squared approximation) \\
\hline Prob $>$ chi $2=$ & 0.0000 (James' approximation) \\
\hline
\end{tabular}

$\rightarrow$ Ano $=2008$

Test for equality of 5 group means, allowing for heterogeneity

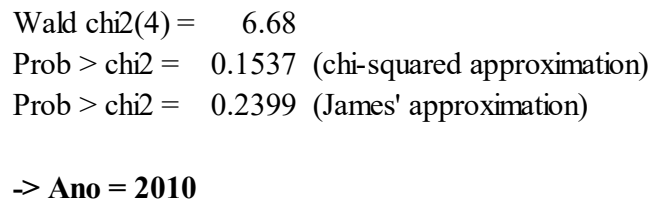

Test for equality of 5 group means, allowing for heterogeneity

Wald chi2 $(4)=48.73$

Prob $>$ chi2 $=0.0000$ (chi-squared approximation)

Prob $>$ chi2 $=0.0000$ (James' approximation)

$\rightarrow$ Ano $=2012$

Test for equality of 5 group means, allowing for heterogeneity

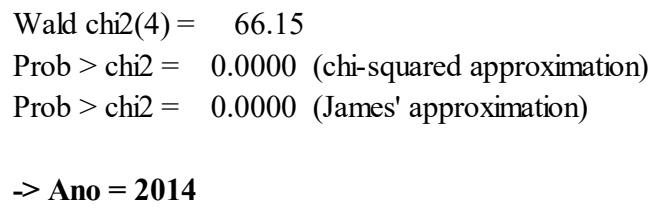

Test for equality of 5 group means, allowing for heterogeneity

Wald chi2 $(4)=14.93$

Prob $>$ chi2 $=0.0049$ (chi-squared approximation)

Prob $>$ chi2 $=0.0105$ (James' approximation)

Tabela elaborada pelo autor a partir dos resultados de testes multivariados de Wald obtidos pelo software Stata 13.1.

Por fim, a Tabela 22, a seguir, mostra o fator de retorno médio acumulado dos fundos das cinco principais administradoras, entre 31/12/2006 e 31/12/2015, em ordem decrescente tomada pelo retorno acumulado em 2015. Na comparação, foram acrescentados os retornos médios acumulados de outras 4 carteiras fictícias que representam estratégias distintas que um gestor de um fundo PGBL/VGBL poderia ter adotado, dependendo da classificação do fundo e, assumindo, aqui, para essas carteiras fictícias, a cobrança de uma taxa de administração de $1 \%$ ao ano. As carteiras fictícias são: a) 100\% investida em SELIC; b) 100\% investida em Ibovespa; 
c) $75 \%$ investida em SELIC e 25\% investida em Ibovespa, e d) $50 \%$ investida em SELIC e 50\% investida em Ibovespa.

Tabela 22 - Comparação do Fator de Retorno Médio Acumulado - Fundos PGBL/VGBL com Renda Variável

\begin{tabular}{clcccccccccc}
\hline Posição & Indicador / Administradora & Início & $\mathbf{2 0 0 7}$ & $\mathbf{2 0 0 8}$ & $\mathbf{2 0 0 9}$ & $\mathbf{2 0 1 0}$ & $\mathbf{2 0 1 1}$ & $\mathbf{2 0 1 2}$ & $\mathbf{2 0 1 3}$ & $\mathbf{2 0 1 4}$ & $\mathbf{2 0 1 5}$ \\
\hline 1 & 100\% Selic (com 1\% taxa adm) & 1,00 & 1,11 & 1,24 & 1,35 & 1,47 & 1,63 & 1,75 & 1,88 & 2,07 & 2,33 \\
2 & 75\% Selic + 25\% Ibovespa (com 1\% taxa adm) & 1,00 & 1,19 & 1,16 & 1,49 & 1,59 & 1,64 & 1,76 & 1,78 & 1,90 & 2,01 \\
3 & Itau Unibanco SA & 1,00 & 1,18 & 1,12 & 1,38 & 1,48 & 1,53 & 1,67 & 1,67 & 1,78 & 1,85 \\
4 & MÉDIA TODAS AS ADMIN. & 1,00 & 1,18 & 1,11 & 1,40 & 1,50 & 1,53 & 1,68 & 1,66 & 1,74 & 1,80 \\
5 & MÉDIA 5 PRINCIPAIS ADMIN. & 1,00 & 1,19 & 1,11 & 1,41 & 1,51 & 1,53 & 1,68 & 1,65 & 1,74 & 1,78 \\
6 & BB Dtvm S.A & 1,00 & 1,21 & 1,04 & 1,43 & 1,55 & 1,55 & 1,75 & 1,63 & 1,71 & 1,72 \\
7 & Banco Santander (Brasil) SA & 1,00 & 1,18 & 1,15 & 1,49 & 1,56 & 1,55 & 1,68 & 1,59 & 1,66 & 1,67 \\
8 & Caixa & 1,00 & 1,17 & 1,09 & 1,37 & 1,44 & 1,45 & 1,55 & 1,53 & 1,61 & 1,66 \\
9 & 50\% Selic + 50\% Ibovespa (com 1\% taxa adm) & 1,00 & 1,27 & 1,07 & 1,57 & 1,64 & 1,57 & 1,68 & 1,60 & 1,65 & 1,64 \\
10 & Bradesco & 1,00 & 1,19 & 1,12 & 1,39 & 1,47 & 1,48 & 1,59 & 1,59 & 1,64 & 1,64 \\
11 & IBOVESPA (com 1\% taxa adm) & 1,00 & 1,43 & 0,81 & 1,50 & 1,50 & 1,21 & 1,29 & 1,08 & 1,03 & 0,89 \\
\hline
\end{tabular}

Fonte: Economática

Tabela elaborada pelo autor (Início 31/12/2006 =1,00)

Os resultados sugerem algumas considerações:

i) Primeiro, que seria facilmente possível se obter ganhos superiores aos retornos médios acumulados pelas administradoras com a adoção uma estratégia extremamente simples, assumindo a cobrança de taxa de administração mais adequada à passividade de gestão - no caso, $1 \%$ ao ano. Por exemplo, a carteira com $75 \%$ de investimentos em SELIC e 25\% em Ibovespa teve desempenho acumulado superior à média de todas as cinco principais administradoras;

ii) Segundo, que a Administradora Itaú Unibanco $S A$ possui fundos que produziram, no período analisado, retornos acumulados médios superiores aos das demais principais administradoras de fundos PGBL/VGBL com investimentos em renda variável que atuam no país;

iii) Terceiro, que os retornos médios acumulados de 4 das principais administradoras puxam o retorno médio acumulado do mercado como um todo para baixo.

Enfim, com base nas análises realizadas nas duas primeiras seções deste capítulo, chega-se ao ponto da busca por um modelo econométrico que ajude a explicar parte relevante das variações nos retornos dos fundos PGBL/VGBL com investimentos em renda variável, contidos no domínio desta pesquisa. 


\subsubsection{Análise dos Retornos Ajustados ao Risco}

Entretanto, um elemento de análise ainda não foi considerado até aqui: como distinguir o desempenho dos fundos em função dos riscos que assumiram? Nesse sentido, assumindo-se por premissa que a parcela do patrimônio de qualquer fundo PGBL/VGBL composto que não esteja investida em renda variável é realizada em ativos livres de risco, que por definição, possui desvio padrão dos retornos igual a zero, tem-se que o beta dessa parcela investida é, por decorrência, igual a zero. Sabendo-se que o beta de qualquer carteira de investimento é obtido pela média ponderada dos betas dos ativos que a compõe, conclui-se que o beta de dado fundo de previdência PGBL/VGBL é o resultado da multiplicação entre o seu percentual de investimento em renda variável e o beta de sua carteira acionária.

Portanto, teoriza-se aqui que o retorno anual ajustado ao risco de dado fundo aberto de previdência PGBL/VGBL, com investimentos em renda variável, possa ser obtido pela divisão do seu retorno anual pelo beta do fundo, sendo esse, como dito, obtido pela multiplicação do percentual do patrimônio do fundo investido em renda variável pelo respectivo beta da carteira acionária do fundo. De maneira que fundos que apresentem valores mais altos para esse indicador são os fundos de melhor desempenho.

Cabe observar que não existe aqui, no cálculo de retorno ajustado ao risco, uma comparação com um determinado benchmark. De forma que a medida de ajuste ao risco ora proposta não possui o alcance de capturar retornos anormais, como seria possível por meio do uso do alpha de Jensen ou do índice de Sharpe, por exemplo. Já se sabe, dos estudos acadêmicos apresentados, que os fundos abertos de previdência não produzem, em média, ganhos anormais aos seus cotistas, ao contrário, têm sido frequentemente superados por outras modalidades de fundos de investimentos passivos. Portanto, o objetivo da metodologia de ajuste proposta, ao se dividir o retorno do fundo pela interação entre percentual de renda variável e o beta da carteira acionária, como proxy do beta do fundo, é tão somente o de ordenar, ranquear, os fundos em função dessa métrica. Por exemplo, entre dois fundos distintos que tenham obtido retornos iguais para um dado ano, e que tenham adicionalmente o mesmo beta da carteira acionária, aquele que apresentar o maior percentual de investimentos do seu patrimônio em renda variável será o que o produzirá o menor retorno ajustado ao risco. 
A explicação econômica para essa proposta de ajuste é simples: o retorno anual obtido por dado fundo $i$ ao final do ano $t$ é fruto do retorno dado por uma combinação de ativos, sendo parte em renda variável - porção arriscada - e parte, por premissa adotada, em renda fixa - porção não arriscada ou de baixíssima exposição ao risco. Portanto, quanto maior é a parcela do patrimônio do fundo dedicada a investimentos em renda variável, maior será a sua exposição ao risco. Ao mesmo tempo, sabe-se que quanto maior o beta de uma carteira acionária, maior o seu risco. Assim, a partir das evidências aqui encontradas, defende-se que a interação entre essas duas variáveis (perc_rv x BetaCart), como divisora do retorno anual do fundo - representando o beta da carteira composta do fundo - teria o sentido de ordenar os fundos em função do seu desempenho ajustado a decisões de risco que estão sob o controle de cada gestor.

Formalizando, o retorno anual ajustado ao risco de fundo $i$ ao final do ano $t$ é dado pela seguinte fórmula:

$$
\text { RetornoFundoAjustado }_{i t}=\text { RetornoFundo }_{i t} /\left(\text { perc_rv }_{i t} x \text { BetaCart }_{i t}\right) \text {; }
$$

onde:

RetornoFundoAjustado $_{i t}$ : É o retorno anual ajustado ao risco do fundo $i$ ao final do tempo $t$, sendo $\mathrm{t}=2007,2008,2009,2010,2011,2012,2013,2014$ e 2015;

RetornoFundo $_{i t}$ : É o retorno anual do fundo $i$ ao final do tempo $t$, sendo $\mathrm{t}=2007$, 2008, 2009, 2010, 2011, 2012, 2013, 2014 e 2015;

perc_rvit: É o percentual do patrimônio do fundo $i$ investido em renda variável ao final do ano $t$, e

BetaCart $_{i t}$ : É o beta da carteira acionária do fundo $i$ ao final do ano $t$.

A Tabela 23, a seguir, que ordena decrescentemente as cinco principais administradoras de fundos PGBL/VGBL, aqui estudados, pela média dos retornos anuais ajustados ao risco dos fundos, conforme definido, apresenta a administradora Itaú Unibanco SA em primeira posição no ranking. Cabe destacar apenas que foram retirados das análises os fundos com participação percentual de renda variável sobre seu patrimônio menor do que um por cento por distorcerem os resultados. 
Tabela 23 - Média do Retorno Médio Anual Ajustado ao Risco - Fundos PGBL/VGBL com Renda Variável

\begin{tabular}{|c|c|c|c|c|c|c|c|c|c|c|}
\hline \multicolumn{11}{|c|}{ Tabela - Média do Retorno Médio Anual Ajustado ao Risco - Fundos PGBL/VGBL com Renda Variável * } \\
\hline Adminis tradora & 2007 & 2008 & 2009 & 2010 & 2011 & 2012 & 2013 & 2014 & 2015 & Média \\
\hline Itau Unibanco SA & 1,43 & 0,31 & 1,79 & 0,87 & 0,98 & 1,44 & 0,56 & 2,81 & 1,68 & 1,42 \\
\hline Banco Santander (Brasil) SA & 1,03 & 0,19 & 1,07 & 0,23 & 0,07 & 0,31 & $-0,23$ & 1,15 & 0,16 & 0,43 \\
\hline BB Dtvm S.A & 0,87 & $-0,47$ & 1,23 & 0,42 & 0,21 & 0,72 & $-0,13$ & 0,35 & 0,27 & 0,37 \\
\hline Bradesco & 0,85 & $-0,14$ & 0,93 & 0,28 & 0,51 & 0,47 & 0,15 & 0,34 & 0,15 & 0,35 \\
\hline Caixa & 0,87 & $-0,20$ & 0,98 & 0,25 & 0,10 & 0,30 & $-0,01$ & 0,34 & 0,27 & 0,28 \\
\hline Total Geral & 1,07 & $\mathbf{0 , 0 3}$ & 1,35 & 0,56 & 0,64 & 1,00 & 0,29 & 1,62 & $\mathbf{0 , 8 2}$ & 0,86 \\
\hline
\end{tabular}

* eliminados 238 registros de fundos com percentual de renda variável abaixo de $1 \%$ e com betas da carteira inexistentes Total de observações analisadas $=1432$

Tabela elaborada pelo autor

Vale destacar que os resultados já apresentados mostraram os fundos da administradora Itaú Unibanco $S A$ posicionados consistentemente, no período analisado, em menor patamar de investimentos em renda variável, bem como seus betas médios das carteiras acionárias nunca estiveram entre os mais altos. Portanto, sua posição no ranking é corroborada pelas evidências encontradas neste estudo.

O teste escolhido para verificação de igualdade entre as médias dos retornos ajustados ao risco dos fundos, em função da heterogeneidade das covariâncias entre as séries, foi o teste de Wald. A Tabela 24, a seguir, apresenta os resultados dos testes para os fundos das cinco principais administradoras. Com base neles, pode-se afirmar, com uma confiança de $99 \%$, que ao menos uma das administradoras apresentou retornos médios anuais ajustados ao risco estatisticamente diferentes, ao longo de todo o período. 
Tabela 24 - Teste de Igualdade - Retorno Médio Ajustado ao Risco

$->A n o=2007$

Test for equality of 5 group means, allowing for heterogeneity

Wald chi2 $(4)=23.48$

Prob $>$ chi $2=0.0001$ (chi-squared approximation)

Prob $>$ chi $2=0.0081$ (James' approximation)

$->A n o=2009$

Test for equality of 5 group means, allowing for heterogeneity

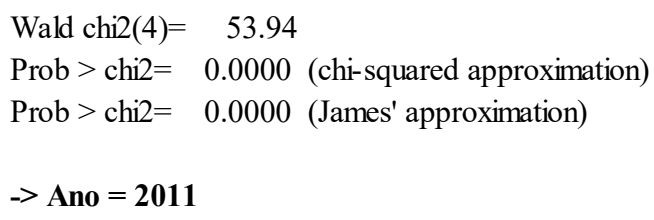

Test for equality of 5 group means, allowing for heterogeneity

Wald chi2 $(4)=28.62$

Prob $>$ chi2 $=0.0000$ (chi-squared approximation)

Prob $>$ chi $2=0.0002$ (James' approximation)

$->$ Ano $=2013$

Test for equality of 5 group means, allowing for heterogeneity

Wald chi2 $(4)=46.10$

Prob $>$ chi $=0.0000$ (chi-squared approximation)

Prob $>$ chi $2=0.0000$ (James' approximation)

$\rightarrow$ Ano $=2015$

Test for equality of 5group means, allowing for heterogeneity

Wald chi2 $(4)=25.63$

Prob $>$ chi $2=0.0000$ (chi-squared approximation)

Prob $>$ chi $2=0.0003$ (James' approximation)

Tabela elaborada pelo autor a partir dos resultados de testes multivariados de Wald obtidos pelo software Stata 13.1.

Para confirmar se a administradora Itaú Unibanco $S A$ foi a que produziu retornos ajustados ao risco estatisticamente maiores que as demais administradoras, durante o período analisado, rodou-se novamente o teste de Wald pareando os retornos médios anuais dos fundos da administradora Itaú Unibanco SA a cada uma das demais administradoras.
Test for equality of 5 group means, allowing for heterogeneity

Wald chi2 $(4)=29.49$

Prob $>$ chi $2=0.0000$ (chi-squared approximation)

Prob $>$ chi $2=0.0011$ (James' approximation)

$\rightarrow$ Ano $=2010$

Test for equality of 5 group means, allowing for heterogeneity

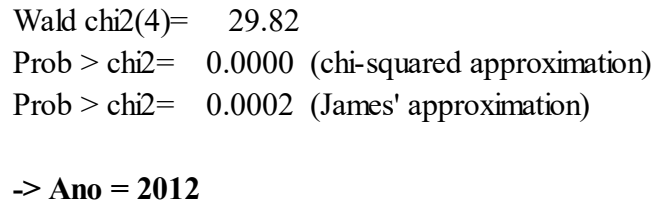

Test for equality of 5 group means, allowing for heterogeneity

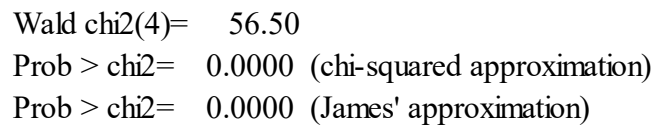

Test for equality of 5 group means, allowing for heterogeneity

Wald chi2 $(4)=72.07$

Prob $>$ chi $2=0.0000$ (chi-squared approximation)

Prob $>$ chi $2=0.0000$ (James' approximation) 
A Tabela 25, a seguir, apresenta os testes de igualdade dos retornos médios anuais ajustados ao risco entre os fundos PGBL/VGBL com investimentos em renda variável das administradoras Itaú Unibanco SA e Bradesco. Os resultados permitem rejeitar a hipótese de igualdade entre os retornos para todos os anos, exceto 2011, dentro de um intervalo de confiança de $95 \%$. Os fundos Itaú Unibanco tiveram desempenho ajustado ao risco superior ao apresentado pela administradora Bradesco em 2007, 2008, 2009, 2010, 2012, 2013, 2014 e 2015.

Tabela 25 - Teste de Igualdade - Retorno Médio Ajustado ao Risco (Itaú Unibanco SA e Bradesco)

\begin{tabular}{|c|c|}
\hline$->$ Ano $=2007$ & $->A n o=2008$ \\
\hline Test for equality of 2 group means, allowingfor heterogeneity & Test for equality of 2 group means, allowingfor heterogeneity \\
\hline $\operatorname{MNVF}(1,23.5)=11.31$ & $\operatorname{MNVF}(1,37.2)=5.41$ \\
\hline Prob $>F=0.0026$ & Prob $>F=0.0256$ \\
\hline$->$ Ano $=2009$ & $\rightarrow$ Ano $=2010$ \\
\hline Test for equality of 2 group means, allowingfor heterogeneity & Test for equality of 2 group means, allowingfor heterogeneity \\
\hline $\operatorname{MNVF}(1,45.7)=19.70$ & $\operatorname{MNV} F(1,72.7)=23.61$ \\
\hline Prob $>F=0.0001$ & Prob $>F=0.0000$ \\
\hline$->$ Ano $=2011$ & $\rightarrow$ Ano $=2012$ \\
\hline Test for equality of 2 group means, allowingfor heterogeneity & Test for equality of 2 group means, allowingfor heterogeneity \\
\hline $\operatorname{MNV~F}(1,54.5)=1.98$ & $\operatorname{MNVF}(1,122.5)=20.88$ \\
\hline Prob $>F=0.1646$ & Prob $>F=0.0000$ \\
\hline$->$ Ano $=2013$ & $\rightarrow$ Ano $=2014$ \\
\hline Test for equality of 2 group means, allowingfor heterogeneity & Test for equality of 2 group means, allowingfor heterogeneity \\
\hline $\begin{array}{l}\text { MNV F }(1,148.8)=6.96 \\
\text { Prob }>F=0.0092\end{array}$ & $\begin{array}{l}\operatorname{MNV} F(1,149)=61.50 \\
\text { Prob }>F=0.0000\end{array}$ \\
\hline \multicolumn{2}{|l|}{$->$ Ano $=2015$} \\
\hline \multicolumn{2}{|l|}{ Test for equality of 2 group means, allowingfor heterogeneity } \\
\hline $\begin{array}{l}\operatorname{MNV} F(1,89.5)=24.14 \\
\operatorname{Prob}>F=0.0000\end{array}$ & \\
\hline
\end{tabular}

Tabela elaborada pelo autor a partir dos resultados de testes multivariados de Wald obtidos pelo software Stata 13.1.

Os resultados testes de igualdade dos retornos médios anuais ajustados ao risco entre os fundos PGBL/VGBL com investimentos em renda variável das administradoras Itaú Unibanco SA e BB Dtvm S.A permitem rejeitar a hipótese de igualdade entre os retornos para todos os anos, 
dentro de um intervalo de confiança de $95 \%$. Os resultados dos testes, pela similaridade com o já mostrado, também não serão apresentados.

Os resultados testes de igualdade dos retornos médios anuais ajustados ao risco entre os fundos PGBL/VGBL com investimentos em renda variável das administradoras Itaú Unibanco SA e Caixa permitem rejeitar a hipótese de igualdade entre os retornos para todos os anos, exceto para o ano de 2008 - que apresentou significância estatística de 0,0563 - dentro de um intervalo de confiança de $95 \%$. Os resultados dos testes, pela similaridade com o já mostrado, também não serão apresentados.

Os resultados testes de igualdade dos retornos médios anuais ajustados ao risco entre os fundos PGBL/VGBL com investimentos em renda variável das administradoras Itaú Unibanco SA e Banco Santander (Brasil) SA permitem rejeitar a hipótese de igualdade entre os retornos para todos os anos, exceto para o ano de 2008 - que apresentou significância estatística de 0,7190 dentro de um intervalo de confiança de $95 \%$. Os resultados dos testes, pela similaridade com o já mostrado, também não serão apresentados.

Portanto, pode-se afirmar que os retornos médios anuais ajustados ao risco dos fundos da administradora Itaú Unibanco SA, com exceção dos anos de 2008 e 2011, foram estatisticamente superiores aos das demais administradoras. Como já dito, é um resultado em linha com a análise exploratória apresentada neste trabalho.

Uma última verificação, no entanto, é necessária. Estariam os fundos da administradora Itaú Unibanco $S A$ concentrados em classificações ANBIMA com maiores restrições quanto ao percentual do patrimônio investido em renda variável e, por isso, tenham apresentado menor percentual médio de alocação do patrimônio em ativos de renda variável? A Tabela 26, a seguir, mostra que não é esse o caso. A estratégia da administradora Itaú Unibanco SA é consistentemente mais conservadora que as demais administradoras. Seu percentual de alocação do patrimônio em renda variável é relativamente baixo mesmo dentro de cada classificação de fundos ANBIMA. Merece especial destaque o posicionamento da administradora nos anos de 2013 a 2015, denotando uma adequada leitura do cenário econômico. 
Tabela 26- Percentual do Patrimônio Investido em Renda Variável por Classificação Anbima

\begin{tabular}{|c|c|c|c|c|c|c|c|c|c|}
\hline & 2007 & 2008 & 2009 & 2010 & 2011 & 2012 & 2013 & 2014 & 2015 \\
\hline Previdência Balanceados até 15 & 9,17 & 9,12 & 9,71 & 11,39 & 11,15 & 11,58 & 10,39 & 9,96 & $\mathbf{9 , 5 9}$ \\
\hline Bradesco & 11,83 & 11,52 & 12,52 & 14,56 & 13,69 & 14,49 & 13,44 & 14,16 & 13,43 \\
\hline Itau Unibanco SA & 6,62 & 7,24 & 7,81 & 8,78 & 9,24 & $8,45[$ & 6,20 & 5,21 & 5,73 \\
\hline Caixa & 11,24 & 8,72 & 11,25 & 13,63 & 13,13 & 13,20 & 13,28 & 11,89 & 11,19 \\
\hline Previdência Balanceados de 15-30 & 17,63 & 16,83 & 17,99 & 19,70 & 21,02 & 21,86 & 19,73 & 17,97 & 17,61 \\
\hline Bradesco & 23,41 & 22,44 & 24,74 & 28,42 & 26,82 & 27,84 & 27,41 & 28,17 & 27,03 \\
\hline BB Dtvm S.A & 15,39 & 12,86 & 15,55 & 16,68 & 16,88 & 16,37 & 16,00 & 16,63 & 14,88 \\
\hline Itau Unibanco SA & 13,74 & 14,42 & 14,80 & 15,74 & 20,68 & $18,74[$ & 13,20 & 9,91 & 11,13 \\
\hline Caixa & 23,01 & 18,91 & 23,33 & 27,21 & 27,60 & 26,94 & 27,19 & 24,37 & 22,43 \\
\hline Banco Santander (Brasil) SA & 16,09 & 15,67 & 14,53 & 15,39 & 12,40 & 17,57 & 16,25 & 15,78 & 15,22 \\
\hline Previdência Balanceados $>\mathbf{3 0}$ & 28,47 & 29,14 & 31,97 & 36,92 & 36,42 & 36,41 & $\mathbf{3 0 , 0 0}$ & 29,07 & 29,64 \\
\hline Bradesco & 31,42 & 30,45 & 36,35 & 41,26 & 35,15 & 41,76 & 37,70 & 41,97 & 39,77 \\
\hline BB Dtvm S.A & 30,77 & 24,65 & 29,79 & 33,98 & 32,20 & 32,05 & 32,45 & 33,34 & 30,73 \\
\hline Itau Unibanco SA & 25,54 & 27,19 & 28,61 & 34,39 & 37,37 & 34,76 & 23,31 & 18,89 & 21,18 \\
\hline Caixa & 39,47 & 35,53 & 40,17 & 46,13 & 46,70 & 46,41 & 46,71 & 42,00 & 40,11 \\
\hline Banco Santander (Brasil) SA & 25,20 & 35,36 & 32,87 & 35,32 & 29,70 & 29,41 & 27,82 & 32,38 & 37,56 \\
\hline Previdência Data-Alvo & 31,02 & 25,89 & 30,54 & 35,55 & 35,57 & 32,49 & 30,89 & 28,33 & 24,07 \\
\hline BB Dtvm S.A & 31,02 & 25,94 & 31,35 & 37,11 & 36,44 & 33,24 & 33,35 & 31,26 & 25,70 \\
\hline Itau Unibanco SA & & 25,77 & 28,10 & 30,90 & 32,96 & 30,24 & 18,58 & 13,67 & 15,93 \\
\hline Previdência Multimercados & 15,08 & 15,59 & 19,78 & 18,47 & 16,03 & 14,69 & 13,45 & 13,33 & 18,75 \\
\hline Bradesco & 22,21 & 21,91 & 26,65 & 28,83 & 25,94 & 26,45 & 22,44 & 27,89 & 29,56 \\
\hline BB Dtvm S.A & 35,50 & 30,81 & 25,69 & 30,53 & 28,78 & 27,90 & 28,95 & 25,09 & 24,70 \\
\hline Itau Unibanco SA & 7,32 & 7,93 & 11,77 & 9,65 & 9,04 & - $9,04[$ & 7,13 & 6,63 & 9,95 \\
\hline Caixa & & & & & & 46,55 & 46,74 & 42,03 & 40,13 \\
\hline Banco Santander (Brasil) SA & 12,99 & 15,65 & 25,65 & 32,11 & 27,86 & 19,61 & 26,12 & 18,66 & 29,17 \\
\hline Previdência Ações & 76,72 & 71,41 & 75,84 & 89,41 & 87,97 & 88,23 & 86,48 & 85,18 & 81,21 \\
\hline Bradesco & 81,30 & 79,05 & 86,15 & 97,77 & 95,14 & 93,77 & 92,88 & 92,13 & 86,33 \\
\hline BB Dtvm S.A & 72,35 & 62,80 & 70,86 & 89,96 & 90,84 & 86,70 & 91,90 & 88,63 & 84,58 \\
\hline Itau Unibanco SA & 76,62 & 69,79 & 74,90 & 92,45 & 89,37 & 85,38 & 66,31 & 59,88 & 64,45 \\
\hline Banco Santander (Brasil) SA & & 75,62 & 72,39 & 73,34 & 69,40 & 90,27 & 92,40 & 93,62 & 83,37 \\
\hline Total Geral & 21,94 & 22,29 & 24,13 & 26,25 & 25,17 & 23,41 & 21,82 & 22,35 & 25,06 \\
\hline
\end{tabular}

Fonte: Economática

Tabela elaborada pelo autor 


\section{MODELO PROPOSTO}

\subsection{Evidências sobre as Características dos Fundos PGBL/VGBL Estudados}

No capítulo anterior, foram apresentadas características e evidências acerca do comportamento dos fundos abertos de previdência complementar, nas modalidades PGBL/VGBL, com investimentos em renda variável, no período analisado. Sabe-se até aqui:

a) Que o mercado esteve concentrado. Poucas administradoras de fundos representaram a maior parte dos volumes investidos em ações, durante o período.

b) Que os retornos anuais médios dos fundos estiveram correlacionados à evolução percentual do Ibovespa.

c) Que o número de ações investidas pelos fundos foi a partir de 2010 próximo ao número de ações que compõe o Ibovespa.

d) Que existiram diferenças estatísticas entre os retornos médios dos fundos PGBL/VGBL das cinco principais administradoras de fundos destacadas, entre 2009 e 2015.

e) Que cada administradora parece adotar uma composição de carteira acionária mais comum (mais frequente) para os investimentos em renda variável, que é replicada para um número elevado de seus fundos, quando não para a totalidade deles, como é o caso da administradora Caixa.

f) Que ao menos uma das cinco principais administradoras apresentam betas médios das carteiras de seus fundos estatisticamente diferentes das demais, denotando uma estratégia particular.

g) Que as taxas de administração máximas cobradas pelos fundos não estiveram associadas aos esforços dos gestores ou às suas capacidades de gerar melhores resultados ao cotista, dado que a maior parte dos fundos de cada uma das principais administradoras tem carteiras acionárias com composição idêntica.

h) Que há evidência de diferença estatística das taxas médias de administração máximas cobradas pelos fundos controlados pelas principais administradoras de fundos do país.

i) Que o percentual médio do patrimônio investido em ações, direta e indiretamente, variou entre as principais administradoras durante o período, indicando ser esse um possível discriminante da estratégia adotada pelas administradoras. 
j) Que esse percentual (perc_rv) deve ter exercido influência sobre os retornos dos fundos. Investir maior ou menor parcela do patrimônio do fundo em renda variável em dado ano, a depender do respectivo retorno do Ibovespa, pode ter representado ganhos ou perdas marginais.

k) Que os retornos médios acumulados dos fundos apresentam diferenças entre as principais administradoras, em especial, com a administradora Itaú Unibanco $S A$, apresentando desempenho relativo superior aos das principais concorrentes, porém aquém do que poderia ter sido obtido para quem, consistentemente no período analisado, tivesse operado com os menores percentuais de investimento em renda variável sobre o total do patrimônio dos fundos.

\subsection{Modelo de Regressão Multinível Longitudinal}

Os modelos tradicionais de regressão linear podem ser genericamente apresentados da seguinte forma:

$$
Y_{i j}=\beta_{0 j}+\beta_{1 j}\left(X_{i j}\right)+r_{i j}
$$

Considerando: $i=1,2,3 \ldots n$ e $j=1,2,3 . . J$

onde:

$Y_{i j}=$ Variável dependente (estudada) referente à unidade $i$ que se pretende estudar, a qual é pertencente a um agrupamento $j$ qualquer;

$X_{i j}=$ É o vetor de variáveis explicativas associadas à unidade $i$ estuda pertencente ao grupo $j$

$\beta_{0 j}=$ Intercepto da equação de nível 1 para todos os indivíduos pertencentes ao grupo $j$ : representa média do grupo $j$ quando $X_{i j}=0$

$\beta_{1 j}=$ Coeficiente angular da equação de primeiro nível, identificando quanto que as variáveis de primeiro nível afetam o comportamento de $Y_{i j}$ no aumento de uma unidade de $X_{i j}$.

$r_{i j}=$ Erro randômico relacionado ao primeiro nível. 
Nos modelos multinível, testa-se a possibilidade do efeito grupo explicar o comportamento dos interceptos e dos coeficientes associados a cada variável explicativa. Assim, se houver influência do agrupamento no intercepto e nos coeficientes das variáveis explicativas, então, tanto o intercepto quanto os demais coeficientes poderiam ser expressos em função das características do grupo - no caso, nível. Logo, como mostram Fávero e Belfiore (2017), os coeficientes da equação original poderiam ser expressos das seguintes formas:

$\beta_{0 j}=\gamma_{00}+\gamma_{01}\left(W_{j}\right)+u_{0 j}$

$\beta_{1 j}=\gamma_{10}+\gamma_{11}\left(W_{j}\right)+u_{1 j}$

Onde:

$W_{j}=$ conjunto de variáveis explicativas associadas ao grupo $j$

$\gamma_{00}=\mathrm{o}$ intercepto da equação que explica o intercepto da equação original;

$\gamma_{01}=$ coeficiente que diferencia os interceptos das regressões quando da presença de uma variável de grupo $W_{j}$;

$\gamma_{10}=$ é o intercepto da equação que busca explicar a influência do agrupamento nos coeficientes da equação original;

$\gamma_{11}=$ é o coeficiente que diferencia os coeficientes do modelo original em função da presença de variáveis ligadas ao grupo $W_{j}$;

$u_{0 j}=$ efeito aleatório vinculado à característica de grupo $j$ no intercepto da equação original

$u_{1 j}=$ efeito aleatório vinculado à característica de grupo $j$ nos coeficientes angulares da equação original.

Assim, a equação original pode ser reescrita da seguinte forma, conforme Fávero e Belfiore (2017):

$$
Y_{i j}=\gamma_{00}+\gamma_{01} \cdot\left(W_{j}\right)+u_{0 j}+\left(\gamma_{10}+\gamma_{11} \cdot\left(W_{j}\right)+u_{1 j}\right) \cdot\left(X_{i j}\right)+r_{i j}
$$


Reordenando,

$Y_{i j}=\gamma_{00}+\gamma_{01} \cdot\left(W_{j}\right)+\gamma_{10} \cdot\left(X_{i j}\right)+\gamma_{11} \cdot\left(W_{j} \cdot X_{i j}\right)+u_{0 j}+u_{1 j}\left(X_{i j}\right)+r_{i j}$

Sendo esse o modelo multinível com interceptos e coeficientes aleatórios de dois níveis.

Sobre esse modelo, é importante analisar que a estrutura de erros apresenta um ponto interessante de discussão: observa-se que parte dos erros podem estar correlacionados com as variáveis ligadas ao indivíduo observado; ao mesmo tempo, parte também pode estar associada ao agrupamento.

De todo modo, a técnica de regressão multinível será adequada se ao menos um entre os coeficientes $\gamma_{\mathbf{0 1}}$ e $\boldsymbol{\gamma}_{\mathbf{1 1}}$ for estatisticamente diferente de zero. Ou seja, os coeficientes da equação original também são dependentes de características ligadas ao agrupamento. Para isso é realizado o LR test, - Likehood-ratio test.

Mais detalhes sobre a técnica podem ser encontrados no apêndice a este trabalho.

Por fim, cabe esclarecer que por construção matemática, a aplicação de modelos de regressão multinível não está sujeita à observância de alguns pressupostos exigidos por modelos clássicos de regressão por mínimos quadrados ordinários, tais como a ausência heterocedasticidade e a necessidade de presença de normalidade nos resíduos. Esse é uma vantagem adicional de modelos obtidos por máxima verossimilhança (BICKEL, 2007; SANTOS, 2013; FÁVERO E BELFIORE, 2017).

\subsection{Desenvolvimento do Modelo de Regressão Multínvel Longitudinal}

A partir dessas evidências e considerando que os fundos, de modo geral, investiram parcela (perc_rv) de seus patrimônios em renda variável, assumiu-se neste trabalho, por simplificação, que a outra parcela $(100 \%$ - perc_rv) foi investida em ativos de renda fixa. De sorte que pode ser teorizado que o retorno dos fundos também deveria ser dependente desse percentual (perc_rf $=100 \%$ - perc_rv) e da evolução da rentabilidade da SELIC, nesse caso, uma proxy da rentabilidade dos títulos de renda fixa. Cabe destacar que a premissa adotada neste estudo é que 
a parcela do patrimônio do fundo não investida em renda variável é investida em ativos livre de risco e está atrelada à taxa Selic. Esta é, de fato, uma limitação do estudo dado que seu objeto de concentração foi a parcela investida em renda variável, direta ou indiretamente.

Como já comentado, a estrutura dos dados desta pesquisa apresenta diferentes níveis de agrupamento. Em especial, os fundos estudados estão organizados dentro de uma estrutura hierárquica. Como visto, fundos pertencem a administradoras. Administradoras, por sua vez, adotam, em alguns aspectos, como visto, padrões semelhantes de gestão uma das outras, porém, possuem outras características de estratégia na gestão de seus fundos que tendem a lhe conferir alguma diferenciação em termos de resultado ao cotista, no caso, o retorno anual do fundo. Além disso, os dados analisados também apresentam uma dimensão temporal: fundos produziram retornos anualmente.

De modo que é possível se observar a evolução das características variáveis - retorno anual, percentual do patrimônio investido em renda variável, etc - de um dado indivíduo, fundo $i$, com $i$ variando de 1 a 671 = número de fundos analisados, pertencente a uma administradora $j$, com $j$ variando de 1 a 29 = número de administradoras de fundos observados, ao final de cada ano $t$ contido no período estudado.

Essa particularidade da estrutura de dados, ou do fenômeno estudado, enseja a verificação da eficácia do uso da técnica de regressão multinível para dados em painel, ainda pouco explorada em trabalhos acadêmicos na área de finanças no Brasil.

Lembrando que a variável dependente a ser analisada, conforme objetivo definido, é o retorno anual de cada fundo PGBL/VGBL pertencente a uma determinada administradora, ao longo do tempo.

Com base nas evidências até aqui apresentadas, o modelo teórico que será testado é representado pela seguinte equação:

$$
\begin{gathered}
\text { RetornoFundo }_{i t}=\beta_{0 i}+\beta_{1 i}\left(\text { TaxaAdmMáx }_{i t}\right)+\beta_{2 i}\left(\text { perc_rv }_{i t} x \text { Ibovespa }_{t}\right)+ \\
\beta_{3 i}\left(\text { perc_rf }_{i t} x \text { Selic }_{t}\right)+\beta_{4 i}\left(\text { BetaCart }_{i t}\right)+r_{i t}+u_{i j}
\end{gathered}
$$

Onde:

RetornoFundo $_{i t}$ : É o retorno anual do fundo $i$ ao final do tempo $t$, sendo $\mathrm{t}=2007$, 2008, 2009, 2010, 2011, 2012, 2013, 2014 e 2015; 
TaxaAdmMá $x_{i t}$ : É a taxa de administração máxima cobrada pelo fundo $i$ ao final do ano $t$ (proxy da taxa de administração média);

perc_rv $v_{i t}$ É E percentual do patrimônio do fundo $i$ investido em renda variável ao final do ano $t$;

perc_rffit: É o percentual do patrimônio do fundo i investido em renda variável ao final do ano $t$, sendo igual a $\left(100 \%\right.$ - perc_rv $\left.v_{i t}\right)$

Ibovespa : É o percentual de valorização/desvalorização do Ibovespa no ano t;

$\boldsymbol{S E L I C}$ : É o percentual de valorização do SELIC no ano t;

BetaCart $_{i t}$ : É o beta da carteira acionária do fundo $i$ ao final do ano $t$;

$\boldsymbol{\beta}_{\mathbf{0} i}$ : Intercepto da equação para todas as observações pertencentes ao indivíduo $i$ : representa o retorno anual esperado do fundo $i$, quando todas as demais variáveis assumem valor igual a zero;

$\boldsymbol{\beta}_{1 i}$ : É o coeficiente linear da taxa de administração máxima cobrada pelo fundo $i$ no tempo $t$, identificando quanto que o RetornoFundo $o_{i t}$ aumenta ou diminui em função da mudança na taxa de administração máxima cobrada dos cotistas do fundo $i$;

$\boldsymbol{\beta}_{2 i}$ : É o coeficiente linear da interação (multiplicação) entre o percentual do fundo $i$ investido em renda variável no tempo $t$ e a valorização do Ibovespa em $t$, identificando quanto que os valores de RetornoFundo $o_{i t}$ aumentam ou diminuem em função dessa interação;

$\boldsymbol{\beta}_{3 i}$ : É o coeficiente linear da interação (multiplicação) entre o percentual do fundo $i$ investido em renda fixa no tempo $t$ e a valorização da $S E L I C$ em $t$, identificando quanto que os valores de RetornoFundo $o_{i t}$ aumentam ou diminuem em função dessa interação;

$\boldsymbol{\beta}_{4 i}$ : É o coeficiente linear do beta da carteira (BetaCart) do fundo $i$ ao final do ano $t$, identificando quanto que o RetornoFundo ${ }_{i t}$ aumenta ou diminui em função da mudança no beta carteira do do fundo $i$ em $t$;

$\boldsymbol{r}_{i t}$ : É o erro randômico relacionado ao primeiro nível (observações do indivíduo $i$ ao longo do tempo $t$ ) 
$\boldsymbol{u}_{\boldsymbol{i j}}=$ É a parcela do erro aleatório vinculada ao retorno do fundo referente ao nível Administradora $j$.

Em adição, observa-se a partir da estruturação da base de dados que as variáveis estão ligadas a características dos fundos transacionados, e das observações levantadas, porém possuem variação ao longo do tempo. Características invariantes tanto de administradoras, quanto de fundos não são observados na estrutura de dados apresentada.

Como mais detalhado no apêndice, a abordagem step-up strategy desenvolvida por West, Welch e Galecki (2014) para aplicação de técnicas de modelagem multinível será aqui utilizada. Como primeiro passo, apresenta-se, a seguir, a análise do chamado modelo nulo, quando não há a inclusão de nenhuma das variáveis explicativas ao modelo de dois níveis em questão.

$$
\text { RetornoFundo } o_{i t}=\beta_{0 i}+u_{0 j}+\boldsymbol{r}_{i t} \quad \text {; onde: }
$$

RetornoFundo $_{i t}$ : É o retorno anual do fundo $i$ ao final do tempo $t$, sendo $\mathrm{t}=2007$, 2008, 2009, 2010, 2011, 2012, 2013, 2014 e 2015;

$\boldsymbol{\beta}_{\mathbf{0} i}$ : Intercepto do modelo nulo - sem a inclusão de variáveis explicativas;

$\boldsymbol{u}_{\mathbf{0}}=$ É a parcela do erro aleatório vinculada à característica de grupo $j$;

$\boldsymbol{r}_{i t}$ : É o erro randômico relacionado ao primeiro nível (retorno do fundo $i$ ao longo do tempo $t$ ), ou seja, sem o agrupamento em segundo nível, no caso, a Administradora.

Os resultados dessa regressão em painel em dois níveis (fundo-administradora) são apresentados, a seguir, conforme Tabela 27 gerada pelo software Stata ${ }^{\circledR}$ : 
Tabela 27 - Resultados Regressão Multinível - Modelo Nulo Mixed-effects REML regression

$\begin{array}{lr}\text { Number of obs }= & 2870 \\ \text { Number of groups } & =29\end{array}$

Group variable: Administradora

Number of groups $=29$

Obs per group: $\min =1$

$\operatorname{avg}=99.0$

$\max =686$

Log restricted-likelihood $=-10905.179 \quad$ Pald chi2 $(0)=$
Prob $>$ chi2 $=$.

$\begin{array}{llllll}\text { RetornoFundo } & \text { Coef. } & \text { Std. Err. } & \mathrm{z} & \mathrm{P}>\mathrm{z} & \text { [95\% Conf. Interval }]\end{array}$

$\begin{array}{lllllll}\text { cons } & 5.944242 & .2835612 & 20.96 & 0.000 & 5.388472 & 6.500012\end{array}$

\begin{tabular}{cccccc}
\hline Random-effects Parameters & Estimate & $\begin{array}{c}\text { Std. Err. } \\
\text { Administradora Identity }\end{array}$ \\
var(_cons) & .5456944 & .4206959 & .1204278 & 2.472704 \\
& & & & \\
var(Residual) & 116.5699 & 3.084264 & 110.6789 & 122.7744 \\
\hline LR test vs. linear regression: chibar2(01) $=$ & 4.68 Prob $>=$ chibar2 $=0.0152$ \\
Tabela preparada pelo autor
\end{tabular}

O resultado do LR test aponta, dentro de um intervalo de confiança de $95 \%$, que o uso da técnica de regressão multinivel com dados em painel, tendo a administradora como o segundo nível, tende a produzir um melhor ajuste ao valor do intercepto - que captura os efeitos das variáveis não observáveis e/ou incluídas no modelo, quando comparado a técnicas de regressão que utilizam MQO - Mínimos Quadrados Ordinários, motivo pelo qual a técnica será usada para especificação e validação do modelo proposto.

No entanto, cabe salientar que a correlação intraclasse - ICC (mais detalhes no apêndice), que mede o acréscimo de explicação ao se introduzir mais um nível ao modelo - é baixa, 0,0046595, apesar de significativa dentre de um intervalo de confiança de $95 \%$, indicando ajustes moderados no intercepto.

Em complemento, como já observado, a aplicação de regressão multinível oferece outra vantagem: sua menor restrição quanto às premissas para validação do modelo. Nas regressões obtidas por MQO - Mínimos Quadrados Ordinários - há a necessidade de os resíduos serem aleatórios e terem distribuição normal, bem como necessita que os resíduos não apresentem 
heteroscedasticidadee e que não exista multicolinearidade entre as variáveis explicativas. No caso de modelos gerados por regressão multinível, por construção matemática, para sua validação, somente a premissa de ausência de multicolinearidade deve ser obrigatoriamente observada para validação dos parâmetros.

Sendo assim, o modelo teórico, com efeitos aleatórios somente sobre o intercepto em função do agrupamento pela variável Administradora, foi testado com base nos dados coletados nesta pesquisa e os resultados encontram-se na Tabela 28, a seguir, conforme output do software Stata ${ }^{\circledR}$.

Tabela 28 - Resultados Regressão Multinível - Modelo Empírico

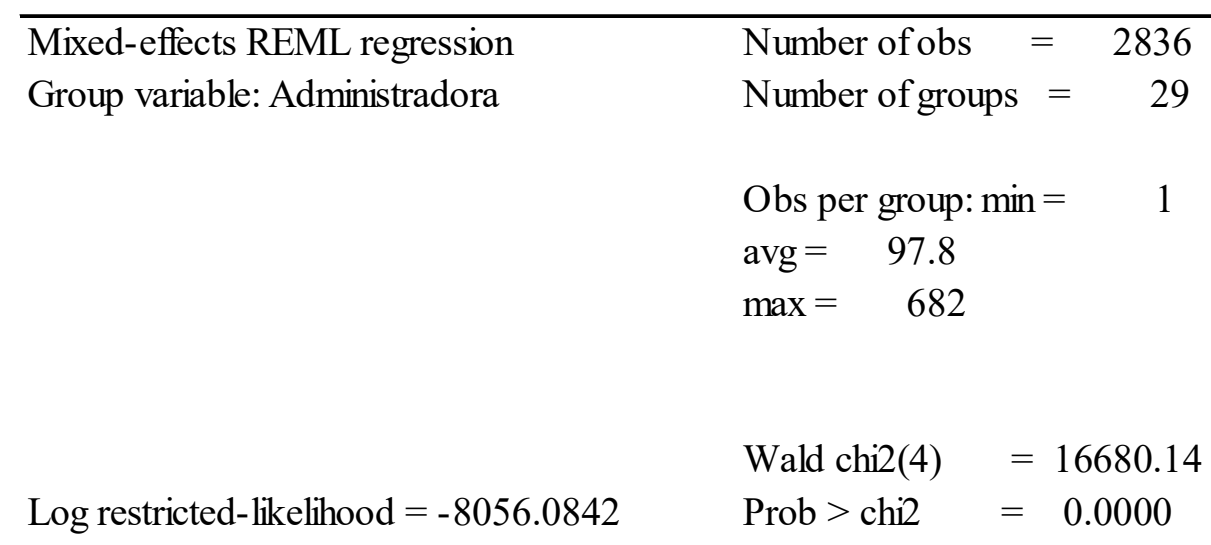

\begin{tabular}{rrrrrrr}
\hline RetornoFundo & Coef. & Std. Err. & $\mathbf{z}$ & $\mathbf{P}>\mathbf{z}$ & [95\% Conf. Interval] \\
\hline & & & & & & \\
TaxaAdmMax & $\mathbf{- 1 . 0 0 4 4 7 1}$ & .0879306 & -11.42 & 0.000 & -1.176812 & -.8321303 \\
int_bov_perc_rv & $\mathbf{1 . 0 7 8 5 5 9}$ & .0086174 & 125.16 & 0.000 & 1.061669 & 1.095449 \\
Selic_perc_rf & $\mathbf{. 7 8 1 7 0 3 6}$ & .0313687 & 24.92 & 0.000 & .720222 & .8431851 \\
BetaCart & $\mathbf{- 2 . 6 0 9 3 7 3}$ & .6301458 & -4.14 & 0.000 & -3.844436 & -1.374309 \\
cons & $\mathbf{3 . 4 7 8 4 3 1}$ & .5974192 & 5.82 & 0.000 & 2.307511 & 4.649352 \\
\hline
\end{tabular}

Random-effects Parameters Estimate Std. Err. [95\% Conf. Interval]

\begin{tabular}{|c|c|c|c|c|}
\hline \multicolumn{2}{|c|}{ Administra a: Identity } & \multirow[b]{2}{*}{.2241149} & \multirow[b]{2}{*}{.2034206} & \multirow[b]{2}{*}{1.20211} \\
\hline $\operatorname{var}($ cons $)$ & .4945037 & & & \\
\hline var(Residual) & 16.93156 & .4517233 & 16.06895 & 17.84048 \\
\hline
\end{tabular}


A Tabela 29 de correlação apresentada, a seguir, mostra a ausência de multicolinearidade entre as variáveis explicativas. O retorno anual do fundo, variável dependente do modelo, correlaciona-se positiva e fortemente com a interação entre o percentual do patrimônio do fundo que está investido em renda variável (perc_rv) e a valorização anual do Ibovespa (Ibovespa). Tal resultado já foi apresentado graficamente, portanto, a força dessa relação já era esperada. Essa forte correlação, combinada ao alto valor da estatística $z$, indica que há forte influência da variável perc_rv $x$ Ibovespa na explicação das variações do retorno anual do fundo.

Tabela 29 - Correlação entre as Variáveis do Modelo

\begin{tabular}{lccccr}
\hline & RetornoFundo & TaxaAdmMax & perc_rv*Ibovespa & perc_rf*Selic & BetaCart \\
\hline RetornoFundo & $\mathbf{1 , 0 0 0 0}$ & $-0,0278$ & 0,9027 & 0,1321 & 0,1745 \\
TaxaAdmMax & $-0,0278$ & $\mathbf{1 , 0 0 0 0}$ & 0,0343 & 0,1604 & 0,1635 \\
perc_rv*Ibovespa & 0,9027 & 0,0343 & $\mathbf{1 , 0 0 0 0}$ & $-0,0392$ & 0,2267 \\
perc_rf*Selic & 0,1321 & 0,1604 & $-0,0392$ & $\mathbf{1 , 0 0 0 0}$ & 0,0960 \\
BetaCart & 0,1745 & 0,1635 & 0,2267 & 0,0960 & $\mathbf{1 , 0 0 0 0}$ \\
\hline
\end{tabular}

Tabela elaborada pelo autor

Logo, o modelo empírico, com efeitos aleatórios somente sobre o intercepto pela inclusão do nível Administradora, para explicar a variação do retorno anual do fundo, ficou com a seguinte especificação:

$$
\begin{aligned}
& \text { yhat }_{i t}=3,48-1,00 x\left(\text { TaxaAdmMáx }_{i t}\right)+1,08 x\left(\text { perc }_{r v_{i t}} * \text { Ibovespa }_{t}\right)+ \\
& 0,78 x\left(\operatorname{perc}_{r f} * \text { Selic }_{t}\right)-2,61 x\left(\text { BetaCart }_{i t}\right)
\end{aligned}
$$

Onde:

$\boldsymbol{y h a t}_{i t}$ : É a estimativa do retorno anual do fundo $i$ ao final do tempo $t$, sendo $\mathrm{t}=2007$, 2008, 2009, 2010, 2011, 2012, 2013, 2014 e 2015.

Demais variáveis já foram descritas no modelo teórico.

Os principais destaques do modelo empírico formulado são:

a) Taxas de administração, em média, diminuem a perspectiva de retorno do cotista do fundo. Para cada um ponto percentual de taxa cobrado a mais, a expectativa é que o cotista, mantidas as demais variáveis constantes, perca a totalidade dessa taxa como expectativa de retorno médio. Como visto, fundos de uma mesma administradora são extremamente parecidos e seguem uma carteira acionária com composição comum ou 
semelhante. A concentração observada no mercado de fundos, provavelmente, inibe o surgimento de prêmios, na forma de maiores taxas de administração, a serem pagos às administradoras e aos gestores mais eficazes, aqueles que produzissem maiores retornos ajustados ao risco aos seus cotistas;

b) Para cada 1 unidade de aumento no percentual do patrimônio investido em renda variável multiplicado pela valorização do Ibovespa, o retorno anual esperado do fundo varia, aproximadamente, 1,08 ponto percentual. Essa variação segue o sinal do retorno do Ibovespa no ano. Aqui, cabe uma observação adicional: o percentual de alocação do patrimônio em renda variável é um dos elementos chave para geração de retornos. No período analisado, especificamente, o Ibovespa teve fraco resultado acumulado, com retornos muito voláteis no período. Em tese, gestores que tivessem a capacidade de antecipar às movimentações do mercado acionário brasileiro, alocando mais ou menos recursos em renda variável, em momentos adequados, teriam/tiveram maior probabilidade de obter maiores retornos;

c) Em contrapartida, como já visto, a expectativa de retorno anuais dos fundos, mantidas as demais variáveis constantes, também depende da interação entre o percentual do patrimônio investido em renda fixa (100\% - perc_rv) e a valorização da SELIC. Para cada 1 unidade de variação combinação SELIC x perc_rf, a expectativa de retorno anual do fundo é alterada em aproximadamente 0,78 pontos percentuais;

d) Por fim, a cada variação de 0,1 de unidade no beta da carteira do fundo, mantidas as demais variáveis constantes, a expectativa de retorno anual do fundo cai em 0,26 pontos percentuais, aproximadamente. Aqui, também cabe o comentário feito no item c) sobre o timing do gestor: betas altos indicam maior risco - quando Ibovespa cai, a perda do fundo tende a ser maior.

Cabe observar que a correlação intraclasse (ICC) relativa ao modelo empírico foi de 0,02837. Apesar de pouco relevante na explicação da variância dos resíduos, tal resultado é ainda sim significante dentro de um intervalo de confiança de 95\%. Ou seja, o intercepto do modelo empírico em nível é estatisticamente diferente do intercepto obtido por modelos de regressão por mínimos quadrados ordinários, na presença das variáveis explicativas incluídas no modelo. 
Adicionalmente, como visto, há diferença estatística entre as médias de variáveis explicativas, para a maioria dos anos, que discriminam as estratégias das cinco maiores administradoras de fundo. Essa é a razão econômica, ainda mais importante do que a estatística, para a inclusão do nível Administradora no modelo.

Por fim, o ICC do modelo que incluí efeitos aleatórios, controlados pela variável Administradora, para os coeficientes das variáveis independentes não apresenta diferença em relação ao ICC do modelo em nível já especificado, motivo pelo qual esse modelo alternativo não é aqui apresentado.

Muito embora o modelo de regressão linear por MQO com dados em painel - cujos resultados são apresentados na Tabela 30, a seguir - não atenda a premissa de normalidade dos resíduos provavelmente pela omissão de variáveis não observáveis - ele oferece uma medida adequada da magnitude do poder explicativo das variáveis independentes, em especial da interação perc_rv x Ibovespa, sobre a variável dependente. Pouco mais que $85 \%$ da variação do retorno anual dos fundos é explicada pela inclusão das variáveis explicativas especificadas no modelo. Desses, cerca de $81 \%$ é explicado por perc_rv x Ibovespa.

Tabela 30 - Modelo Empírico - Regressão MQO

\begin{tabular}{|c|c|c|c|}
\hline RetornoFundo & Coef & $\mathbf{t}$ & $P>t$ \\
\hline TaxaAdmMax & $-0,9608691$ & $-11,17$ & 0,000 \\
\hline perc_rv*Ibovespa & 1,079956 & 123,87 & 0,000 \\
\hline perc_rf*Selic & 0,7698583 & 25,16 & 0,000 \\
\hline BetaCart & $-3,15742$ & $-5,13$ & 0,000 \\
\hline cons & 3,9229496 & 6,88 & 0,000 \\
\hline \multicolumn{4}{|l|}{$\mathrm{Nr} \mathrm{Obs}=2836$} \\
\hline \multicolumn{4}{|c|}{$F(4,2831)=4067,33 /$ Prob $>F=0,000$} \\
\hline \multicolumn{4}{|l|}{$\mathrm{R} 2=0.8519$} \\
\hline
\end{tabular}

O Gráfico 14, a seguir, apresenta a eficácia do modelo empírico obtido pela técnica de regressão multinível em painel de dados, representada pela reta fitted values, em comparação aos retornos anuais reais obtidos pelos fundos analisados no período. 


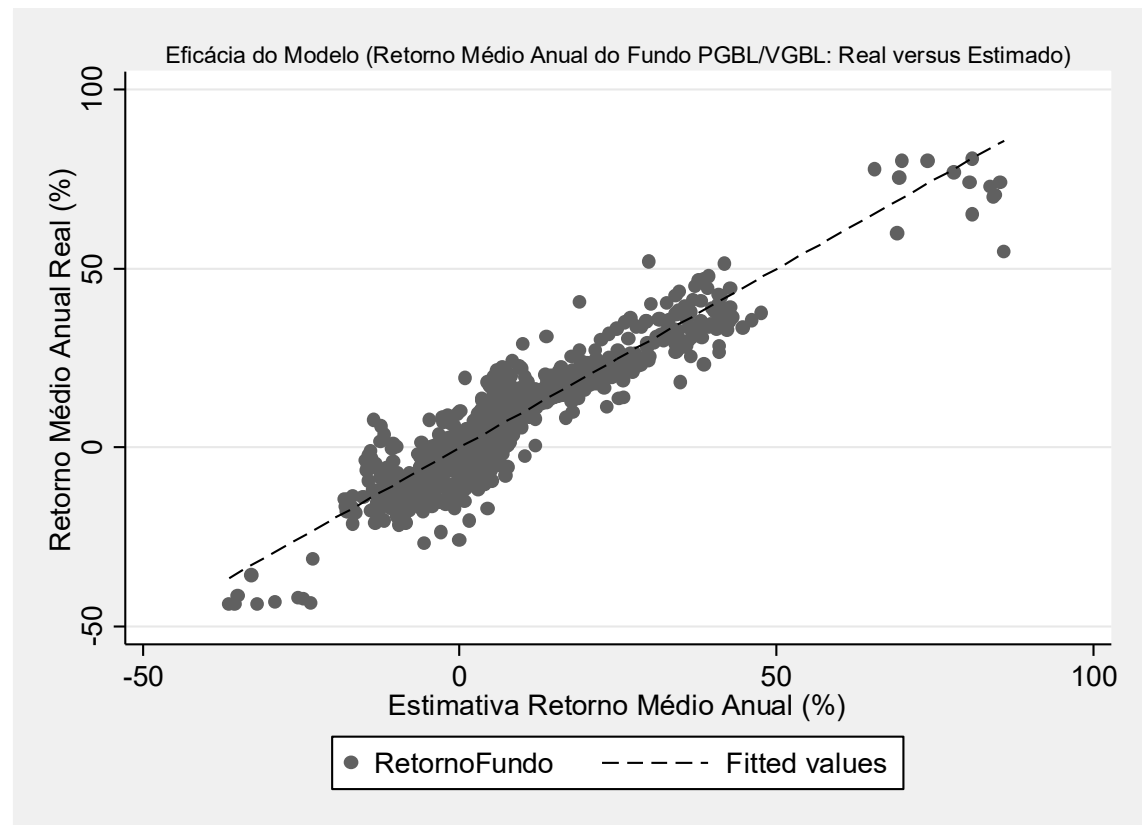

Gráfico 14 - Eficácia do Modelo Empírico (Todos os Fundos) Gráfico elaborado pelo autor

A distribuição dos retornos anuais reais dos fundos ao redor da reta gerada pelo modelo empírico especificado apresenta considerável dispersão. Mesmo com o intercepto sendo controlado pelo agrupamento por administradora, observou-se relativa heterogeneidade entre as administradoras de fundos (30 administradoras no total, sendo 29 com dados completos para o modelo). Pela análise detalhada dos fundos das cinco maiores administradoras, foram identificadas diferenças entre as estratégias adotas na gestão dos fundos. Por exemplo, a administradora Itaú Unibanco $S A$ manteve postura mais conservadora na alocação dos recursos dos fundos em renda variável, sendo a que menos se posicionou nesse mercado relativamente ao patrimônio dos fundos. BB Dtvm S.A também atuou, na maior parte do período, de forma conservadora na seleção do seu portfólio de investimentos em ações, com beta médio das carteiras mais baixo, em especial a partir de 2011. Assim, o modelo empírico funciona como uma curva média entre todas as curvas que poderiam ser geradas caso o modelo de regressão fosse obtido repetidas vezes tomando-se individualmente os dados de cada administradora. Pelo visto até aqui, apesar de não ser escopo deste trabalho, imagina-se que seria possível formar clusters para a geração de modelos empíricos distintos mais aderentes a cada um deles, com parâmetros diferentes, melhorando ainda mais a capacidade de estimação da variável resposta.

O Gráfico 15, a seguir, mostra o histograma dos resíduos de todas as observações em todos os anos, gerados a partir do modelo empírico. Apesar da aparência da curva ser de uma normal, 
de fato, não é. Em especial, nota-se que a média dos resíduos é diferente de zero. Uma das possibilidades desse deslocamento da média dos resíduos pode ter sido a omissão de variáveis não observáveis, ou a adoção, nesta pesquisa, de premissa simplificadora para a parcela do patrimônio não investida em renda variável. Seja como for, trata-se de situação que foge ao escopo definido neste trabalho. Entretanto, a normalidade dos resíduos, como já dito, não é uma pré-condição para validação da significância estatística dos parâmetros do modelo proposto.

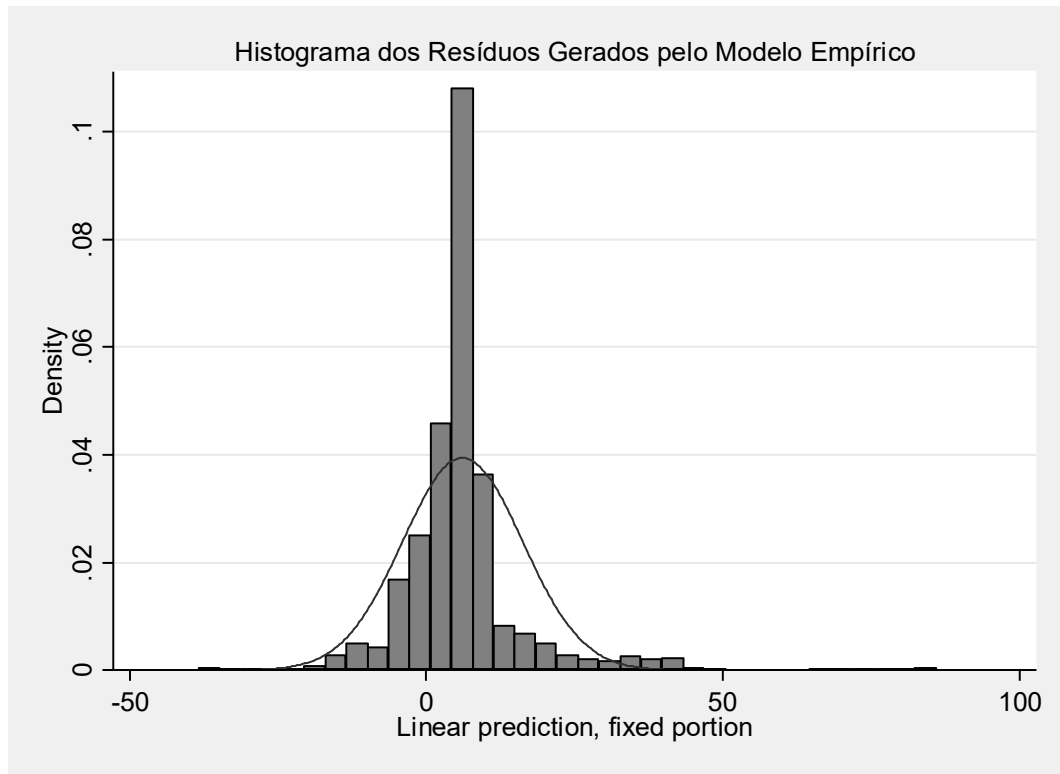

Gráfico 15 - Histograma dos Resíduos - Modelo Empírico Gráfico elaborado pelo autor

Aparentemente quanto mais homogênea foi a estratégia utilizada pela administradora ao longo do período, melhor foi o ajuste das estimativas do modelo empírico aos retornos anuais dos fundos PGBL/VGBL. Notadamente, a administradora Caixa foi a que apresentou a gestão de fundos de forma mais homogênea. A cada ano analisado, todos os fundos administrados pela Caixa seguiram exatamente a mesma composição de carteira acionária, o que se viu menos nos casos de BB Dtvm S.A e Itaú Unibanco SA. São apresentados, a seguir, os Gráficos 16, 17, 18, 19 e 20 de eficácia do modelo empírico aplicado a cada uma das cinco principais administradoras. 


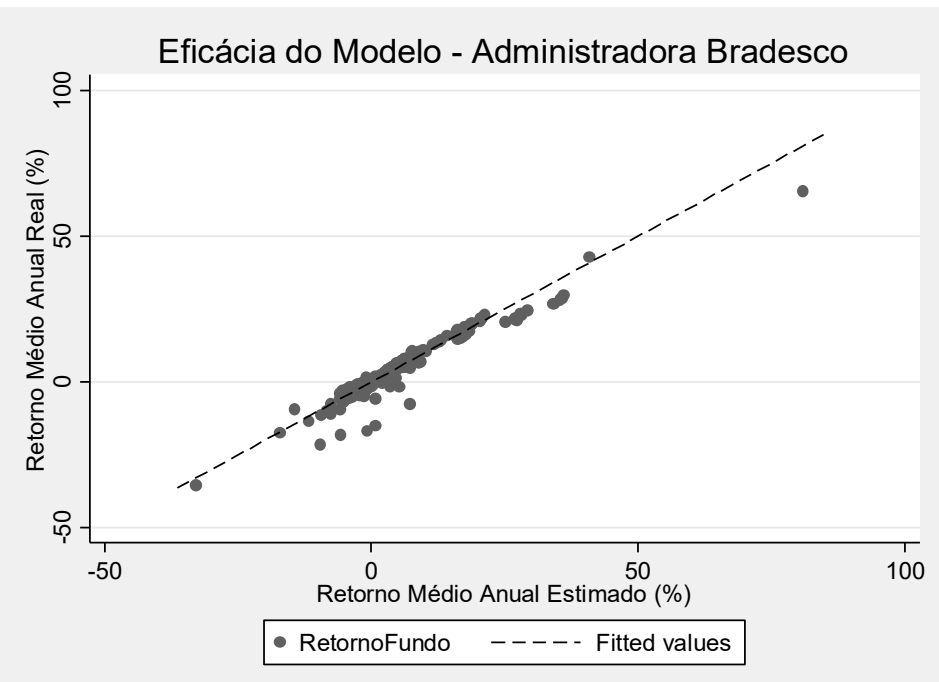

Gráfico 16 - Eficácia do Modelo Empírico (Bradesco) Gráfico elaborado pelo autor

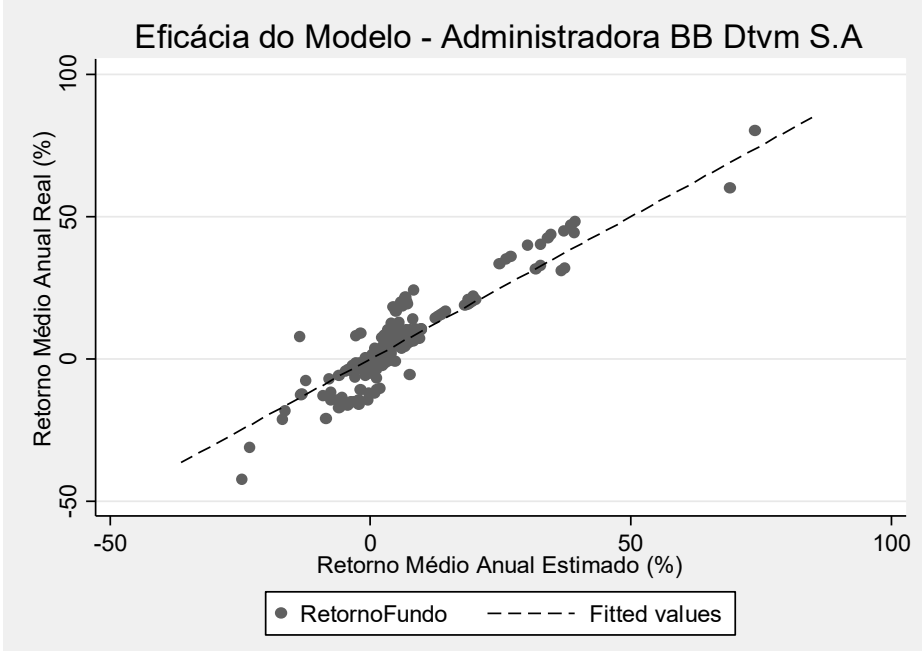

Gráfico 17 - Eficácia do Modelo Empírico (BB Dvtm S.A) Gráfico elaborado pelo autor 


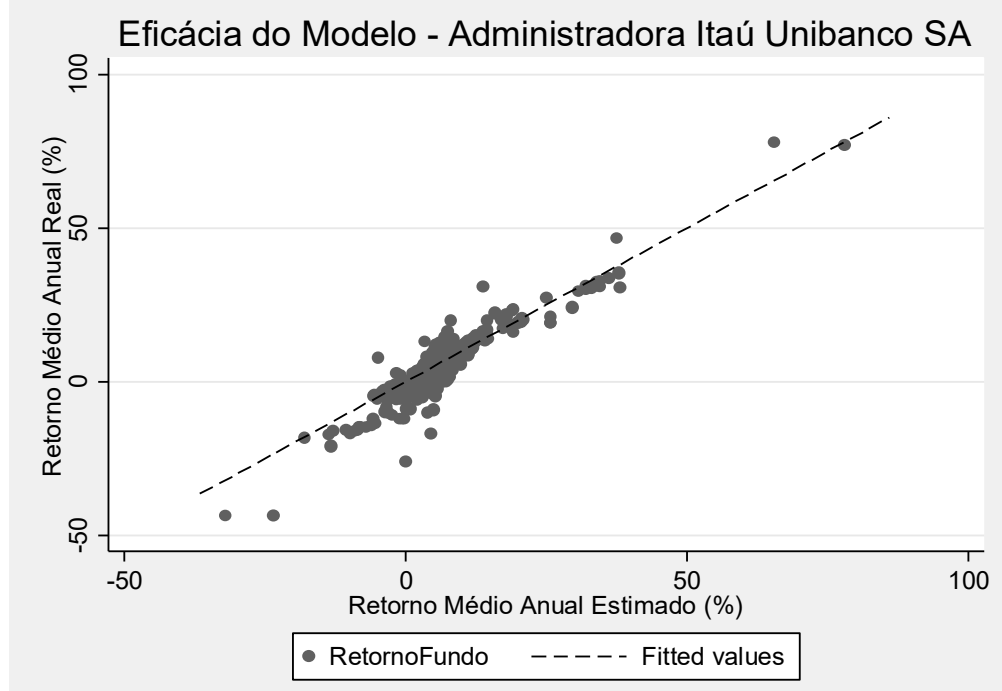

Gráfico 18 - Eficácia do Modelo Empírico (Itaú Unibanco SA) Gráfico elaborado pelo autor

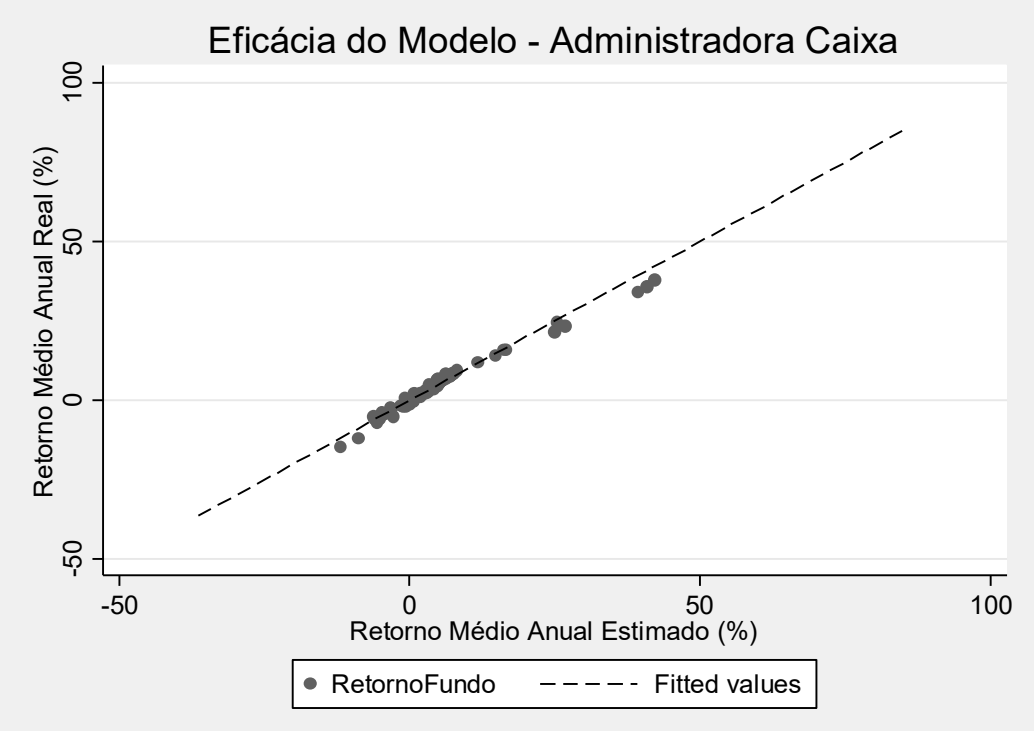

Gráfico 19 - Eficácia do Modelo Empírico (Caixa)

Gráfico elaborado pelo autor 


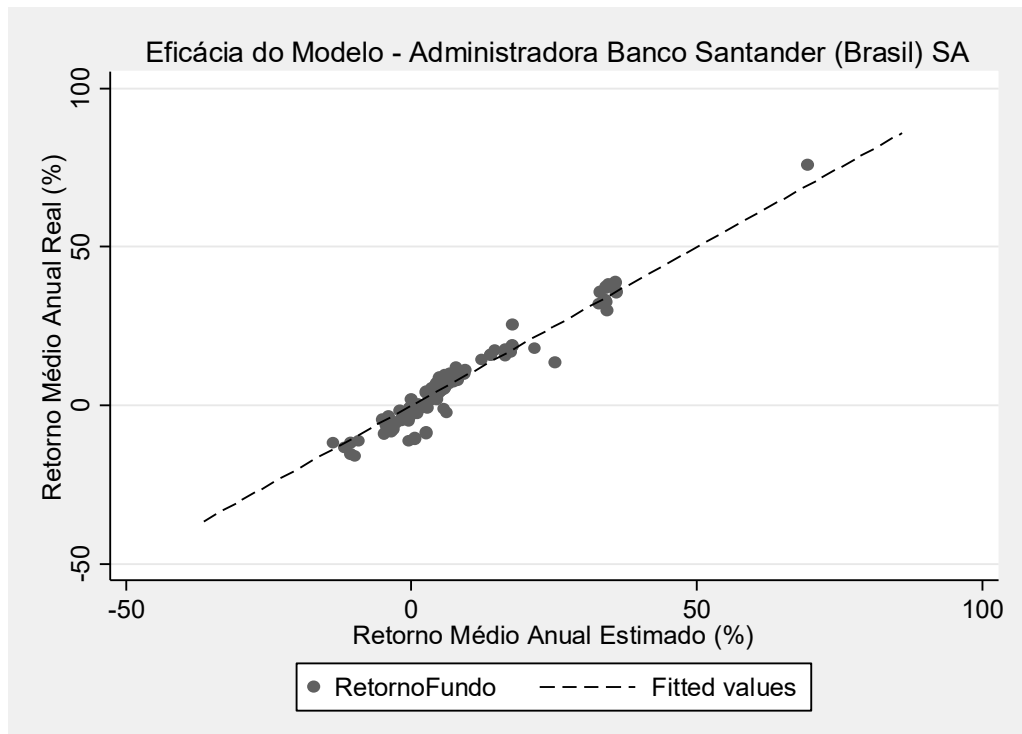

Gráfico 20 - Eficácia do Modelo Empírico (Banco Santander (Brasil) SA) Gráfico elaborado pelo autor

Finalmente, quando se analisa a capacidade do modelo empírico em explicar os retornos médios anuais consolidados de todos os fundos estudados, o ajuste demonstra boa aderência, como mostra o Gráfico 21, a seguir.

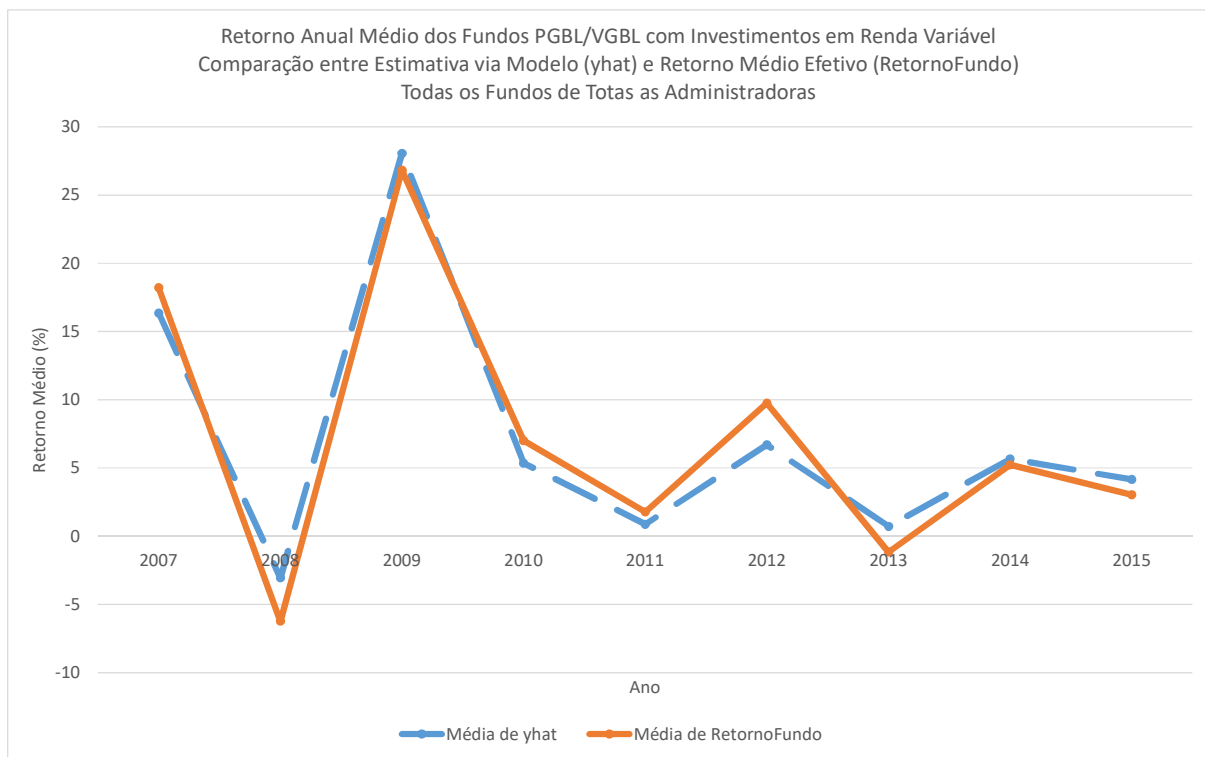

Gráfico 21 - Eficácia do Modelo Empírico - Retornos Médios (Todos os Fundos) Gráfico elaborado pelo autor

Essa qualidade de ajuste mantém o padrão quando agrupados os retornos médios anuais dos fundos geridos pelas cinco principais administradoras de fundos. O resultado era o esperado dada a relevância da participação de mercado dessas administradoras, conforme mostra o Gráfico 22, a seguir. 


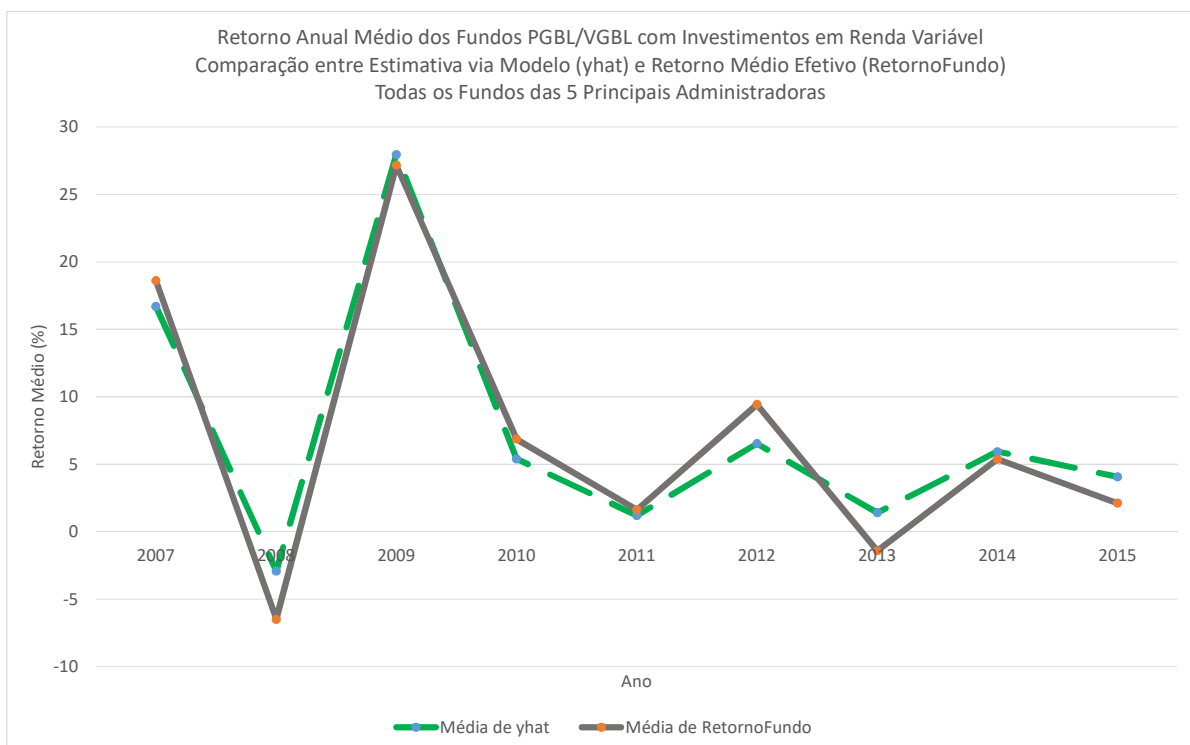

Gráfico 22 - Eficácia do Modelo Empírico - Retornos Médios (5 Maiores Administradoras) Gráfico elaborado pelo autor

A eficácia do modelo para explicar a variação da média consolidada anual dos retornos dos fundos controlados pelas administradoras também é elevada. Confrontado aos retornos médios reais consolidados de cada uma das cinco principais administradoras, destacadas neste trabalho, o modelo empírico apresenta grande capacidade de ajuste, como pode ser observado nos Gráficos 23, 24, 25, 26 e 27, a seguir.

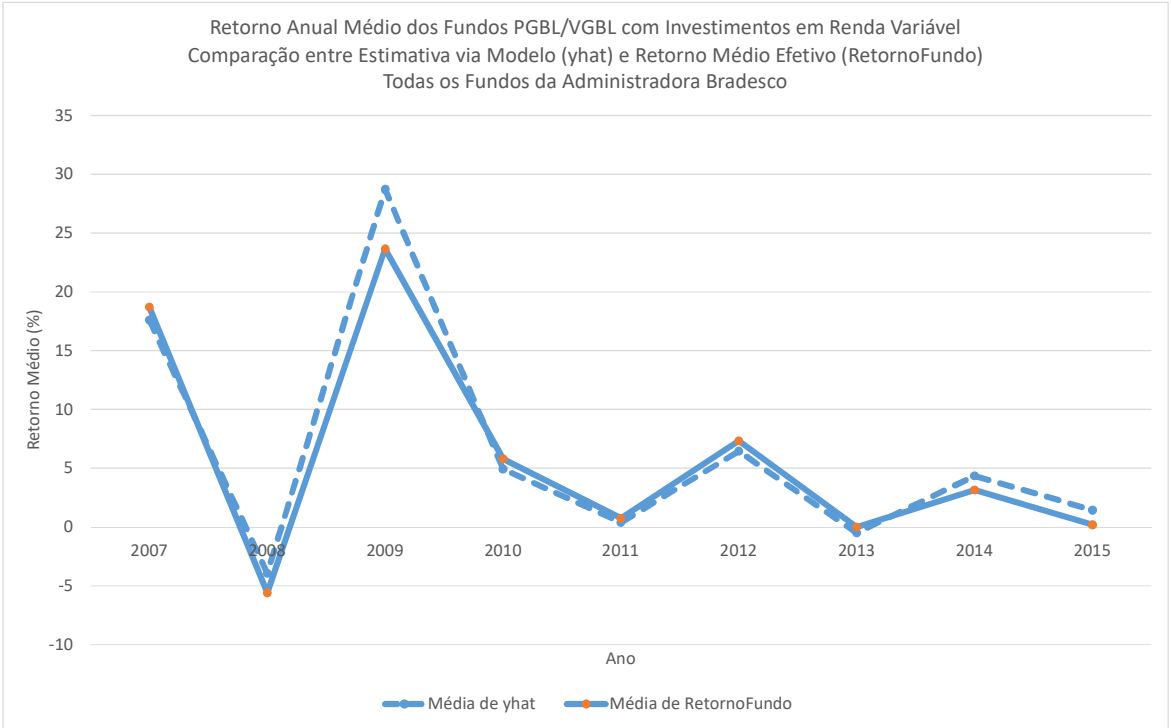

Gráfico 23 - Eficácia do Modelo Empírico - Retornos Médios (Bradesco) Gráfico elaborado pelo autor 


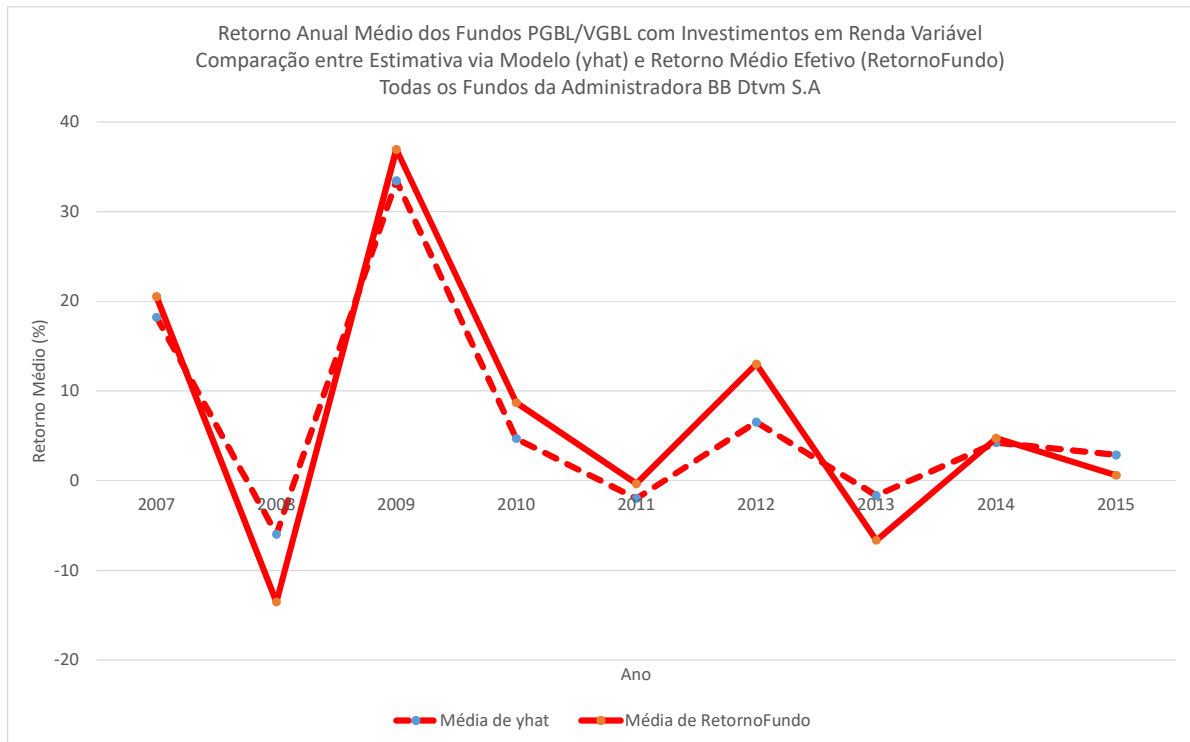

Gráfico 24 - Eficácia do Modelo Empírico - Retornos Médios (BB Dtvm S.A) Gráfico elaborado pelo autor

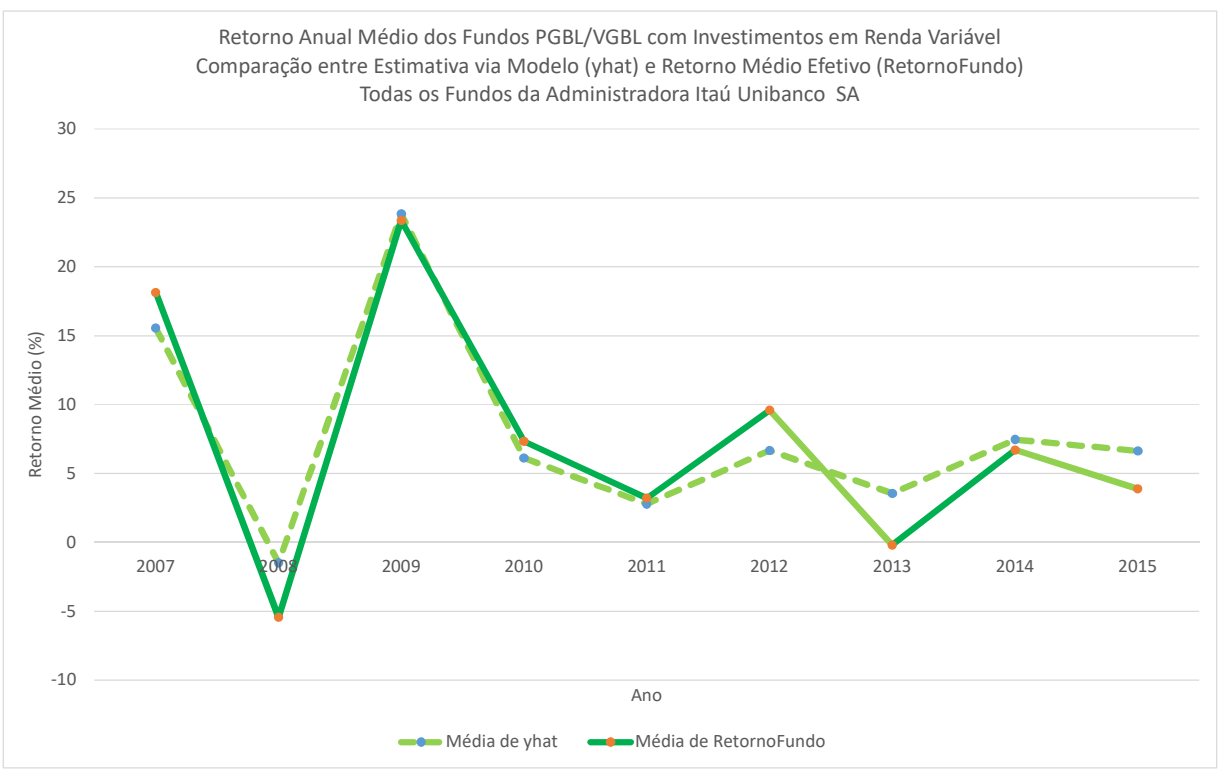

Gráfico 25 - Eficácia do Modelo Empírico - Retornos Médios (Itaú Unibanco SA) Gráfico elaborado pelo autor 


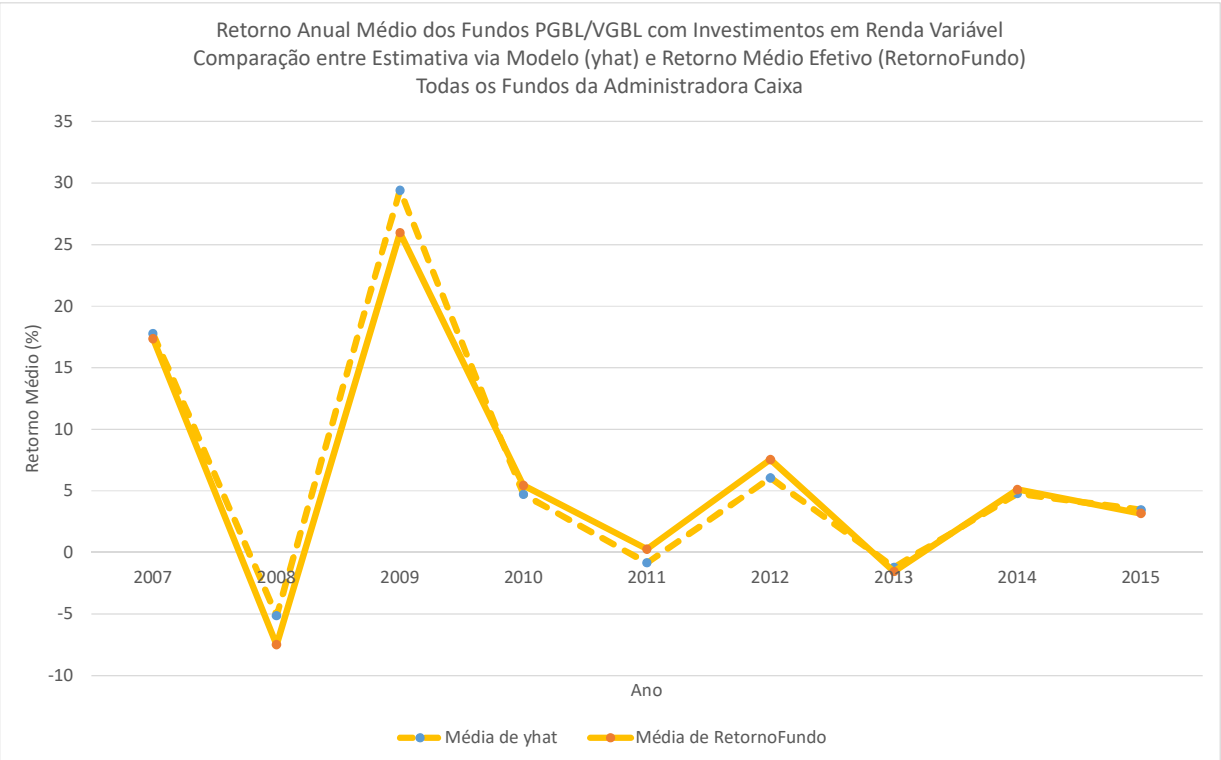

Gráfico 26 - Eficácia do Modelo Empírico - Retornos Médios (Caixa) Gráfico elaborado pelo autor

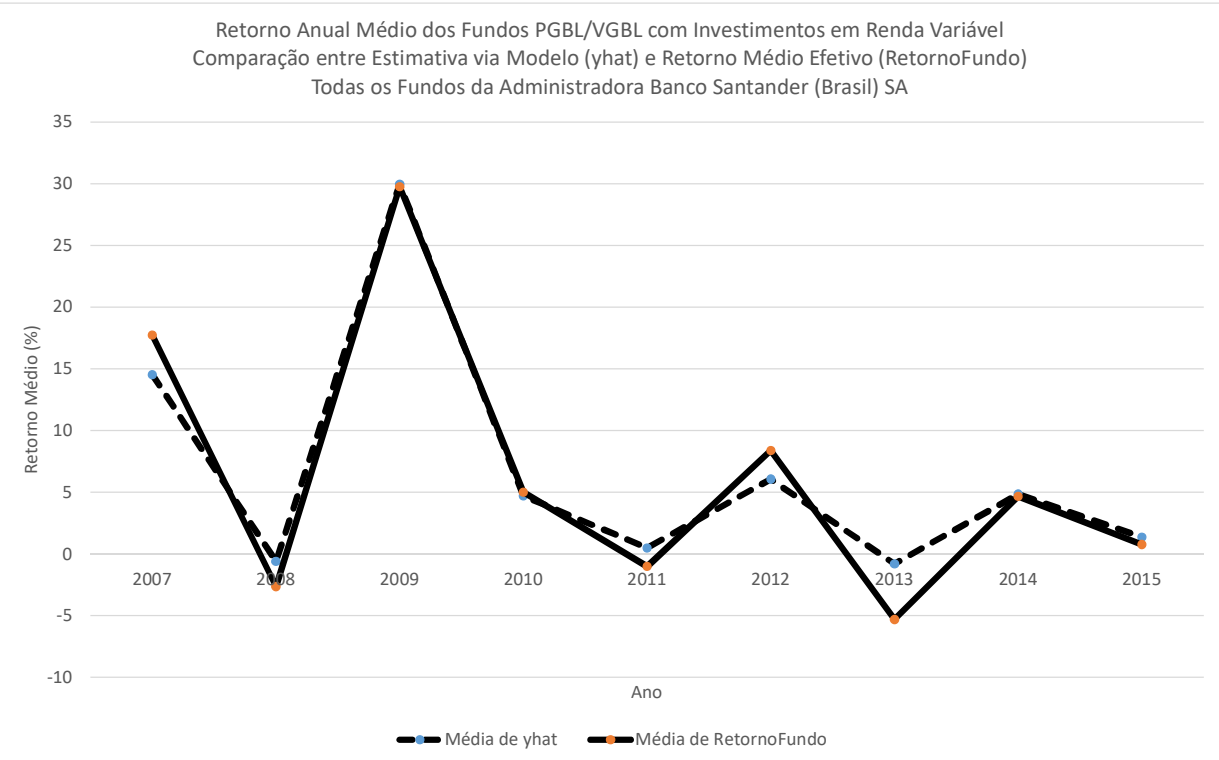

Gráfico 27 - Eficácia do Modelo Empírico - Retornos Médios (Banco Santander (Brasil) SA) Gráfico elaborado pelo autor

Em resumo, não obstante os resultados generalizados que foram apresentados, o ajuste do modelo empírico às curvas de retornos médios consolidados de cada uma das administradoras mostra, no período analisado, uma maior capacidade de estimação para as administradoras Caixa, Bradesco e Banco Santander (Brasil) SA. Esses resultados parecem indicar maior grau de passividade na gestão dos fundos. Por construção, o modelo implicitamente pressupõe maior poder de ajuste a fundos que acompanhem os índices, tanto a Selic quanto o Ibovespa. 


\section{CONCLUSÕES}

\subsection{Principais Descobertas e Respostas às Perguntas de Pesquisa}

Estre trabalho teve como objetivo principal desenvolver um modelo de estimativa do retorno anual dos fundos PGBL/VGBL com investimentos em renda variável, entre 2007 e 2015. Tal modelo foi especificado e testado, utilizando-se técnica ainda pouco explorada em trabalhos acadêmicos no Brasil: regressão multinível longitudinal. Os resultados foram apresentados no capítulo anterior, tendo como base fatores que discriminam as estratégias adotadas pelas administradoras de fundos. As variáveis ligadas às estratégias dos fundos foram o beta da carteira acionária, a taxa de administração praticada e o percentual do patrimônio do fundo aplicado em renda variável. A variável independente, usada no modelo, que apresentou maior poder de explicação para variações dos retornos anuais dos fundos analisados, foi a interação entre o percentual do patrimônio do fundo aplicado em renda variável e o retorno do índice acionário Ibovespa. Por volta de $81 \%$ da variação dos retornos anuais dos fundos foi explicada por essa interação, sendo, portanto, mais um indício de passividade na gestão dos fundos abertos de previdência complementar PGBL/VGBL, conforme já apontavam os trabalhos de Amaral (2013) e Brito (2016).

As análises dos dados dos 671 fundos distintos, no período, mostraram ainda alto grau de similaridade entre as carteiras acionárias mantidas direta ou indiretamente pelos fundos das principais administradoras que atuam no mercado brasileiro. Em média, no período analisado, mais de $65 \%$ do total de fundos PGBL/VGBL de cada administradora mantiveram carteiras acionárias idênticas ou semelhantes. Há administradoras, como a Caixa, por exemplo, que apresentou, em todos os anos analisados, fundos cujas composições das carteiras acionárias foram $100 \%$ idênticas entre si, ou seja, independentemente do fundo escolhido, a composição da carteira acionária foi a mesma. A identificação da extensão dessa prática pelas principais administradoras de fundos foi, sem dúvida, uma das principais contribuições deste estudo. Com isso, o primeiro objetivo secundário desta pesquisa foi atingido.

Conforme resultados apresentados, refutou-se a hipótese de que os betas médios das carteiras acionárias dos fundos vinculados às principais administradoras eram estatisticamente iguais entre si. O mesmo aconteceu com o percentual médio do patrimônio dos fundos investido em 
ativos de renda variável, e, com menor poder de discriminação das estratégias, refutou-se ainda a igualdade, em alguns dos anos observados, das taxas médias de administração cobradas pelos fundos mantidos pelas principais administradoras. Assim, o melhor desempenho em termos de retorno médio anual ajustado ao risco, obtido pelos fundos administrados pelo Itáu Unibanco $S A$, comparativamente às demais principais administradoras, pôde ser explicado, em boa parte, pela adoção de estratégia de gestão diferenciada, em especial quanto ao seu posicionamento, consistentemente mais conservador, na alocação do patrimônio dos seus fundos em ativos de renda variável. Portanto, todas as hipóteses ligadas aos objetivos secundários deste trabalho foram testadas. Destaca-se que, apesar da aparente similaridade nos padrões de gestão dos fundos entre as principais administradoras, comprovou-se que existem, de fato, diferenças entre elas. Assim, os demais objetivos secundários deste trabalho foram endereçados e cumpridos.

Cabe salientar que o mercado de fundos abertos de previdência complementar PGBL/VGBL com investimentos em renda variável mostrou-se bastante concentrado, no período analisado, sob o domínio de administradoras ligadas aos cinco maiores bancos de varejo que atuam no país. Taxas de administração cobradas pelas administradoras, embora distintas entre si, em alguns anos analisados, mostraram-se elevadas, principalmente quando se comprovou que uma estratégia simples de alocação de recursos na proporção de $75 \%$ em Ibovespa, um ETF Exchange Trade Fund - um fundo que sintetiza um índice acionário, e de 25\% em títulos públicos atrelados à taxa Selic produziriam, no período analisado, de forma cumulativa, retornos superiores à média obtida pelas principais administradoras.

Mais ainda, o modelo empírico proposto para se estimar os retornos anuais dos fundos apontou que a cada um ponto percentual adicional pago a título de taxa de administração à entidade gestora, o cotista/segurado tem sua expectativa de retorno anual diminuída em um ponto percentual. Ou seja, as taxas de administração não estariam vinculadas ao esforço ou a competência do gestor. No Brasil, as taxas de administração cobradas pelos fundos estão mais ligadas a aspectos de reciprocidade e relacionamento, conforme apontado por Brito (2016). Amaral (2013) já havia demonstrado que o desempenho dos fundos abertos de previdência de renda fixa foi inferior ao dos fundos de renda fixa tradicionais - apesar das vantagens extraordinárias gozadas pelos fundos previdenciários, como a ausência do come-cotas, por exemplo. Parte do motivo: a cobrança excessiva de taxas de administração para os fundos abertos de previdência pelas instituições financeiras. 


\subsection{Limitações da Pesquisa}

Em resumo, o objetivo principal e os cinco objetivos secundários propostos neste trabalho foram atendidos. No entanto, a extensão ou generalização dos resultados apresentados provavelmente estão limitados aos pressupostos simplificadores aqui adotados, bem como à extensão e periodicidade dos dados utilizados nesta pesquisa.

Por exemplo, a premissa de que a parcela não investida em ativos de renda variável era composta exclusivamente por ativos livres de risco, atrelados à variação da taxa Selic, não deve ser aderente à realidade de alguns fundos. Gestores podem tomar risco na compra e venda de títulos de dívidas pública e privada. Portanto, o cálculo simplificado do beta do fundo pode ter sofrido influência da adoção desse pressuposto, especialmente nos casos de fundos que tomam mais risco na gestão da parcela do patrimônio investida em ativos de renda fixa.

O uso de dados relativos ao final do período, tais como o beta da carteira e o percentual do patrimônio do fundo aplicado em ativos de renda variável, como componentes do modelo de regressão, também pode ter ocasionado alguma distorção nos resultados, uma vez que os retornos são produzidos ao longo do período.

A escolha do período de análise, 2007 a 2015, também é um fator limitante, pois o período foi caracterizado por muita oscilação no mercado acionário brasileiro em função de instabilidades políticas e econômicas vividas pelo país, em especial a partir de 2013.

\subsection{Sugestões de Melhoria para Próximos Estudos}

As sugestões de melhoria desta pesquisa e recomendações para trabalhos futuros passam pela resolução dos fatores limitantes desta pesquisa. Por exemplo, uma das melhorias sugeridas para trabalhos futuros é o detalhamento mais minucioso da parcela não investida em renda variável dos fundos PGBL/VGBL. Além disso, sugere-se extensão do período analisado, bem como a redução da periodicidade dos dados, tomando-os minimamente em base trimestral. Esses ajustes tenderiam a minimizar a extensão de distorções nos resultados.

O próprio uso de valores médios das variáveis independentes ligadas à estratégia dos fundos, calculados com dados das datas de início e fim dos períodos que compreendem o retorno, 
tenderia a capturar mais adequadamente o efeito econômico desses fatores sobre a variável resposta. Assim, ao invés da utilização do beta da carteira acionária e do percentual do patrimônio investido em renda variável, tomados no final do período, considerar-se-ia os seus valores médios para explicar o retorno anual dos fundos.

Um ponto importante de discussão para trabalhos futuros é a estrutura de classificação cruzada das observações de nível, não abordada neste trabalho. Atenta-se que a observação analisada é relativa ao retorno anual de determinado fundo ao longo do tempo, que por sua vez também está vinculado a uma administradora, dentro de uma clara hierarquia - cada fundo só pode pertencer a uma administradora. Entretanto, cada fundo também possui classificações e subclassificações. Por exemplo, um fundo pode ser classificado como de Ações ou Multimercado. Pode ser classificado ainda como Balanceado com até $15 \%$ de investimento em renda variável, ou Balanceado entre 15 e 30\% de renda variável, e assim por diante. Ou seja, existem repetidas informações sobre o mesmo fundo no mesmo instante de tempo, porém, vistas sob diferentes dimensões ou formas de agrupamentos, que não obedeçam diretamente a hierarquia das administradoras de fundos. Ou seja, uma administradora X pode administrar os fundos A; B e C. A administradora Y pode administrar os fundos E e F. No entanto, os fundos A, C e F podem pertencer ao grupo Multimercado, enquanto B e D, ao grupo Ações. Esse é um exemplo de estrutura de análise multinível com classificação cruzada que poderia perfeitamente ser usada em futuros trabalhos, aproveitando a mesma forma de organização de dados que foi desenvolvida neste estudo. 


\section{REFERÊNCIAS BIBLIOGRÁFICAS ${ }^{1}$}

Amaral, T. R. (2013). Análise de Performance dos Fundos de Investimento em Previdência. Dissertação (Mestrado em Administração), Universidade de São Paulo, São Paulo.

ANBIMA - Associação Brasileira das Entidades dos Mercados Financeiras e de Capitais. (2015). Classificação dos fundos de previdência.

ANBIMA - Associação Brasileira das Entidades dos Mercados Financeiras e de Capitais. (2017). Consolidado Histórico de Fundos. Disponível em: http://www.anbima.com.br/pt_br/informar/estatisticas/fundos-de-investimento/ficonsolidado-diario.htm. Acessado em 23/nov/2017.

Banco Central do Brasil. (2017). Histórico da Taxa Selic. Disponível em: http://www.bcb.gov.br/pt-br/\#!/n/SELICTAXA. Acessado em 12/abr/2017.

Beltrão, K. I., Leme, F. P., Mendonça, J. L., \& Sugahara, S. (2004). Análise da Estrutura da Previdência Privada Brasileira: Evolução do Aparato Legal. Discussion Papers, Instituto de Pesquisa Econômica Aplicada - IPEA. Disponível em: http://www.ipea.gov.br/portal/images/stories/PDFs/TDs/td_1043.pdf

Bickel, R. (2007). Multilevel Analysis for Applied Research: It's just regression! US: The Guilford Press.

BM\&F-Bovespa. (2016). Histórico da Composição do Ibovespa. Arquivo enviado por email. São Paulo.

BRASIL. (1923). Decreto 4.682, em 24 de janeiro de 1923, conhecido com Lei Elói Chaves . Disponível em: http://www.planalto.gov.br/ccivil_03/decreto/Historicos/DPL/DPL4682-1923.htm. Acessado em 18/set/2016.

BRASIL. (1998). Emenda Constitucional no 20/1998. Disponível em: http://www.planalto.gov.br/ccivil_03/constituicao/emendas/emc/emc20.htm. Acessado em $18 /$ set/2016.

BRASIL. (2003). Emenda Constitucional no 41/2003. Disponível em: http://www.planalto.gov.br/ccivil_03/constituicao/emendas/emc/emc41.htm. Acessado em $18 /$ set/2016.

BRASIL. (2005). Emeda Constitucional no 47/2005. Disponível em: http://www.planalto.gov.br/ccivil_03/constituicao/emendas/emc/emc47.htm. Acessado em $18 /$ set/2016.

\footnotetext{
${ }^{1}$ Referências seguem normas da American Psychological Association - APA
} 
BRASIL. (2005). Ministério da Previdência. Resolução no 16/05 do Conselho de Gestão de Previdência Complementar - CGPC. Disponível em: http://www.previdencia.gov.br/arquivos/office/3_081014-110808-216.pdf. Acessado em $23 /$ set/2017.

BRASIL. (2007). Lei no 8.213, de 24 de julho de 1991 e suas alterações. Disponível em: http://www.planalto.gov.br/Ccivil_03/leis/L8213cons.htm. Acessado em: 5/out/2016.

BRASIL. (2017). Artigo 40 da Constituição Federal e suas alterações. Fonte: Disponível em: http://www.planalto.gov.br/ccivil_03/constituicao/constituicao.htm. Acessado em 9/out/2017

BRASIL. (2017). Lei no 6.435 de 15 de julho de 1977 e suas alterações. Disponível em: http://www.planalto.gov.br/ccivil_03/leis/16435.htm. Acessado em 17/ago/2017.

BRASIL. (2018). Ministério da Previdência - Déficit da Previdência em 2017. Disponível em: http://www.previdencia.gov.br/2018/01/rgps-previdencia-social-fecha-2017-comdeficit-de-r-1824-bilhoes/. Acessado. em 05/fev/2018.

BRASIL. (2017). Lei no 6.435, de 15 de julho de 1977 e suas alterações. Disponível em: http://www.planalto.gov.br/ccivil_03/leis/16435.htm. Acessado em 21/dez/2017.

Brito, L. M. (2016). Análise dinâmica de estilo de fundos brasileiros de previdência privada. Dissertação (Mestrado em Administração), Instituto COPPEAD de Administração, Universidade Federal do Rio de Janeiro, RIo de Janeiro.

Campani, C. H., \& Brito, L. M. (2018). Fundos de previdência privada: passividade a preços de fundos ativos. Revista de Contabilidade e Finanças USP, pp. 148-163.

Cardoso, A. C. (2006). Análise de persistência de performance nos fundos de previdência compementar entre 2001 e 2004. Ibmec, Administração e Economia, Rio de Janeiro.

Cremers, M., Ferreira, M. A., Matos, P., \& Starks, L. (2016). Indexing and active fund management: International evidences. Journal of Financial Economics, Vol. 120, issue 3, June, pp. 539-560.

Doellman, T. W., \& Sardarli, S. H. (2016). Investment Fees, Net Returns, and Conflict of Interest in 401(k) Plans. The Journal of Financial Research, Spring Vol. XXXIX, No. 1, Pages 5-33.

Fávero, L., \& Belfiore, P. (2017). Manual de Análise de Dados, Estatística e Modelagem Multivariada Com Excel, SPSS e Stata. São Paulo: Editora Campus Elsevier.

Fenaprevi - Federação Nacional de Previdência Privada e Vida. (2017). Previdência Aberta. Fonte: Disponível em http://www.fenaprevi.org.br/fenaprevi/estatisticas/. Acessado em $19 /$ set/2016.

Gil, A. C. (2008). Métodos e técnicas de pesquisa social (6a ed.). São Paulo: Atlas. 
Grinnell Jr, R. M., \& Unrau, Y. A. (2010). Social work research and evaluation: Foundations of evernce-based practice. GRINNELL JR, Richard M.; UNRAU, Yvonne A. Social work research and evaluationOxford University Press, USA,. Disponível em: https://books.google.com.br/books?hl=en\&lr=\&id=XEoq04hUpt8C\&oi=fnd\&pg=PR1 $2 \& d q=$ grinnell

INSS - Instituto Nacional de Seguridade Social. (2018). Disponível em: http://www.previdencia.gov.br/2018/01/beneficios-indice-de-reajuste-para-seguradosque-recebem-acima-do-minimo-e-de-207-em-2018/. Acessado em 23/jan/2018.

Jensen, M. C. (1968). The performance of mutual funds in the period 1945-1964. The Journal of Finance, v.23(May n.2), pp. 389-416.

Jornal El País. (2017). Modelo pioneiro de previdência privada adotado no Chile enfrenta crise. Publicada em 18/02/2017. Disponível em: https://brasil.elpais.com/brasil/2017/01/17/internacional/1484673838_832258.html. Acessado em 28/dez/2017.

Jornal O Estado de São Paulo. (2017). Por que há protestos no Chile contra o sistema de previdência? Publicado em 02/08/2017. Disponível em: http://economia.estadao.com.br/noticias/geral,por-que-ha-protestos-no-chile-contra-osistema-de-previdencia,70001919359. Acessado em 28/dez/2017.

Kinsella, K., \& He, W. (2009). An Aging World: 2008. Washington, DC: National Institute on Aging and U.S. Census Bureau.

Marconi, M. d., \& Lakatos, E. M. (2010). Fundamentos de metodologia cientifica. São Paulo: Atlas.

Markowitz, H. (1952). Portfolio Selection. The Journal of Finance, March. Vol. 7, No. 1, pp. 77-91.

Modigliani, F., \& Modigliani, L. (Winter de 1997). Risk adjusted performance. Journal of Portfolio Management, v.23, n.2, pp.45-54.

Pool, V. K., Sialm, C., \& Stefanescu, I. (2016). It Pays to Set the Menu: Mutual Fund Investment Options in 401(k) Plans. The Journal of Finance, Vol.71(4), pp.1779-1812.

Raudenbush, S., \& Bryk, A. (2002). Hierarchical Linear Models, Applications and Data Analysis Methods. Second Edition. Sage Publications.

Ross, S. A., Westerfield, R. W., Jordan, B. D., \& Lamb, R. (2013). Fundamentos de Administração Financeira. Porto Alegre: McGraw Hill. Bookman.

Santos, M. A. (2013). Determinantes da estrutura de capital de empresas em diferentes cenários econômicos e institucionais: um estudo comparativo. Dissertação de Mestrado, 
Universidade de São Paulo, Faculdade de Economia, Administração e Contabilidade, Ribeirão Preto.

Sharpe, W. F. (1964). Capital Asset Price: A theory of market equilibrium under conditions of Risk. The Journal of Finance(n. 19), pp. 425-442.

Sharpe, W. F. (1966). Mutual funds performance. The Journal of Business, v.39(Jan n.1, part 2), pp.119-138.

Sharpe, W. F. (1992). Asset allocation: management style and performance measurement. Journal of Portfolio Management. 18(2), pp. 7-19.

Sharpe, W. F. (1994). The Sharpe ratio. Journal of Portfolio Management, v. 21, pp. 49-58.

Sialm, C., \& Starks, L. (2012). Mutual funds tax clienteles. The Journal of Finance, Vol. LXVII n.4, August, pp. 1397-1421.

Sialm, C., Starks, L., \& Zhang, H. (2015). Defined contribution pension plan: Stick or Discerning Money? The Journal of Finance, Vol. LXX, n.2, Apr, pp. 805-838.

Silva, F. L. (2010). Impacto do risco de longevidade em planos de previdência complementar. Tese de Doutorado, Universidade de São Paulo, FEA, São Paulo.

Snijders, T. (1996). Analysis of Longitudinal Data using the Hierarchical Linear Model. Quality \& Quantity, pp. 405-426.

Sortino, F. A., \& Van Der Meer, R. (1991). The Dutch triangle. Journal of Portfolio Management, Summer, v.18, pp. 27-31.

SUSEP - Superintendência de Seguros Privados. (2001). Resolução CNSP no 49/2001. Disponível em: http://www2.susep.gov.br/bibliotecaweb/docOriginal.aspx?tipo=1\&codigo=9618. Acessado em 17/out/2017.

SUSEP - Superintendência de Seguros Privados. (2005). Resolução CNSP no 140/2005. Disponível em: http://www2.susep.gov.br/bibliotecaweb/docOriginal.aspx?tipo=1\&codigo=19888. Acessado em 17/out/2017.

SUSEP - Superintendência de Seguros Privados. (2007). Circular SUSEP 338/2007. Disponível em:

http://www2.susep.gov.br/bibliotecaweb/docOriginal.aspx?tipo=1\&codigo=21777. Acessado em 17/out/2017.

SUSEP - Superintendência de Seguros Privados. (2006). Resolução CNSP no 148/2006. : Disponível em: http://www.susep.gov.br/menu/textos/resol148.pdf. Acessado em 17/out/2017. 
SUSEP - Superintendência de Seguros Privados. (2017). Previdência Complementar Aberta. : Disponível em: http:/www.susep.gov.br/menu/informacoes-ao-publico/planos-eprodutos/previdencia-complementar-aberta. Acessado em 17/out/2017.

SUSEP - Superintendência de Seguros Privados. (2017). Relatório de Acompanhamento de Mercado - Jul/2017. Disponível em: http://www.susep.gov.br/menuestatistica/SES/Relat_Acomp_Mercado_2016.pdf. Acessado em 17/out/2017.

Treynor, Jack L (1965). How to Rate Management of Investment Funds. Harvard Business Review, v. 43, p. 63-75, Jan./Feb.

West, B., Welch, K., \& Galecki, A. (2014). Linear Mixed Models: A practical Guide using statistical software. Second Edition. CRC Press - Taylor and Francis Group, US. Capítulos 5, 6 e 7 .

World Bank. (2017). DataBank - World Development Indicators. DataBank - World Development Indicadors. Acesso em 2017, disponível em http://databank.worldbank.org/data/reports.aspx?source=world-developmentindicators. Acesso em 20/set/2017. 


\section{APÊNDICE}

\section{Apêndice A - Modelos de regressão multinível longitudinais}

\section{Conceito}

Nas diferentes ciências, com maior ênfase nas ciências sociais, é comum observar que os objetos de pesquisa, sejam indivíduos, empresas, produtos, entre outras unidades de pesquisa tendem a apresentar um comportamento de agrupamento, formando grupos com características comuns entre si.

Empresas podem pertencer a agrupamentos como setor de atuação; pessoas podem ser agrupadas de acordo com sua vizinhança ou localização; escolas podem ser agrupadas por municípios, e assim sucessivamente. O fator de agrupamento dos indivíduos em diferentes grupos pode apresentar muitas informações não diretamente observáveis sobre esses indivíduos e como esses se diferenciam. Desta forma, informações sobre os grupos podem servir como explicação para características dos indivíduos em análise.

Contudo, os modelos de regressão tradicionais não conseguem capturar essa característica de grupo dentro das análises estatísticas. Desta forma, características latentes que poderiam ser agrupadas em comportamentos de grupo acabam não sendo observadas e assim, modelos tradicionais de análise acabam por não representar de forma mais clara as relações entre os diferentes construtos de pesquisa. (Fávero e Belfiore, 2017)

Observa-se que são recorrentes as pesquisas que envolvem a análise de agrupamentos de forma hierárquica atreladas a área educacional. Um exemplo são as que procuram mensurar o desempenho do alunado em relação a características não somente dos alunos, mas também da classe e das escolas onde estudam.

Desta forma, tem-se uma característica de agrupamento que pode ser observada como na figura, a seguir, que apresenta um modelo de agregação de dois níveis (alunos em escolas). 


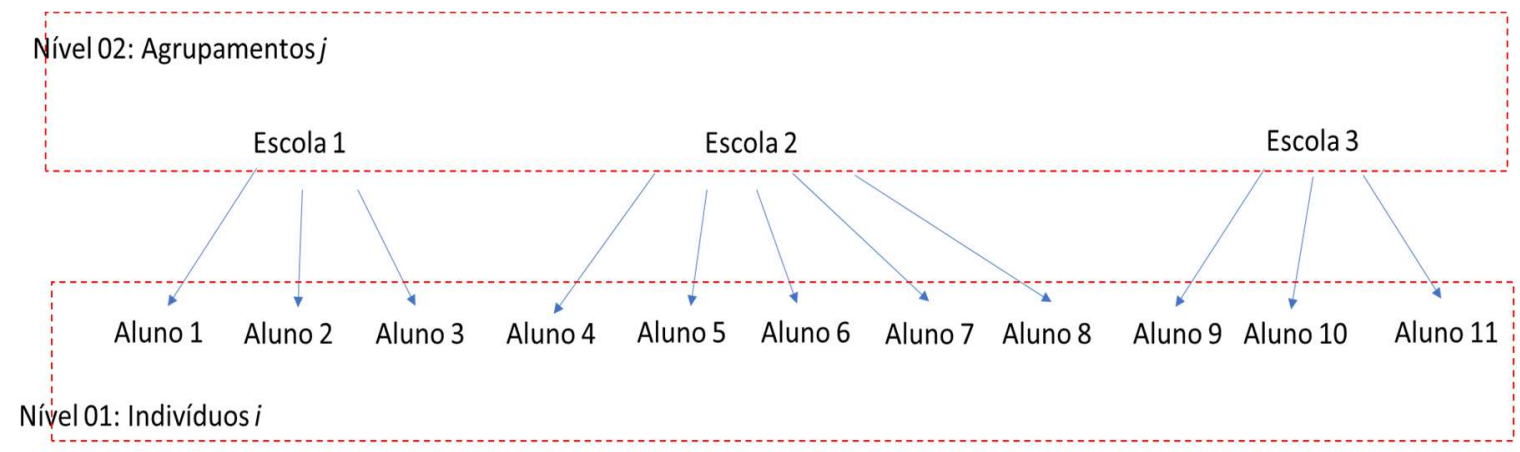

Figura 2 - Esquema de agregação dos objetos de pesquisa em níveis (Raudenbush e Bryk, 2002)

Outro ponto importante de destaque nesses modelos de regressão refere-se à capacidade de análise dos comportamentos de erro do modelo de acordo com a estrutura de agrupamentos dos objetos de pesquisa, particionando o comportamento de erros de acordo com os agrupamentos existentes. A estrutura particionada de erros pode auxiliar a compreender melhor como as estruturas de erros estão distribuídas, assim como quanto que cada agrupamento pode explicar da variação da variável analisada.

O conceito de modelos lineares hierárquicos, ou modelos de regressão multinível, se dá pela estruturação de modelos de regressão por níveis, ou seja, as retas de regressão representativas de indivíduos são agregadas por grupos e assim sucessivamente. Desta forma, características de grupos invariantes entre indivíduos tendem a explicar o comportamento dos interceptos e/ou coeficientes das regressões ao nível individual.

Exemplos de aplicação dessa técnica são apresentados por Raudenbush e Bryk (2002), Santos (2013) e Fávero e Belfiore (2017), quando do estudo de performance acadêmica de alunos do sistema educacional americano. Neste caso, em específico, os pesquisadores consideraram uma análise da performance dos alunos em provas anuais existentes no sistema de ensino americano, e buscaram por objetivo verificar quais eram os determinantes de tal comportamento, identificando assim uma estrutura de organização dos dados de alunos agrupados por escolas. (No caso, 2 níveis - alunos e escolas)

Assim, uma primeira equação de regressão linear para as observações de primeiro nível alunos é encontrada.

$$
Y_{i j}=\beta_{0 j}+\beta_{1 j}\left(X_{i j}\right)+r_{i j}
$$


Considerando: $i=1,2,3 \ldots n$ e $j=1,2,3 . . J$

Onde:

$Y_{i j}=$ Variável dependente (estudada) referente ao aluno $i$ da escola $j$

$X_{i j}=$ Variável explicativa (determinante) associada ao aluno $i$ da escola $j$

$\beta_{0 j}=$ Intercepto da equação de nível 1 para todos os indivíduos pertencentes ao grupo $j$ : representa média do grupo $j$ quando $X_{i j}=0$

$\beta_{1 j}=$ Coeficiente angular da equação de primeiro nível, identificando quanto que as variáveis de primeiro nível afetam o comportamento de $Y_{i j}$ no aumento de uma unidade de $X_{i j}$.

$r_{i j}=$ Erro randômico relacionado ao primeiro nível (alunos em escolas)

Nos modelos multinível, o efeito grupo pode explicar o comportamento dos interceptos e coeficientes das equações individuais. Desse modo, são especificadas duas equações diferentes para análise de grupo:

$$
\begin{aligned}
& \beta_{0 j}=\gamma_{00}+\gamma_{01}\left(W_{j}\right)+u_{0 j} \\
& \beta_{1 j}=\gamma_{10}+\gamma_{11}\left(W_{j}\right)+u_{1 j}
\end{aligned}
$$

Que, segundo Raudenbush e Bryk (2002), Santos (2013) e Fávero e Belfiore (2017), tem-se:

$W_{j}=$ variáveis explicativas ao nível de grupo $j$ não variante entre indivíduos do mesmo grupo. (no caso, escolas)

$\gamma_{00}=$ trata-se da média total da amostra em estudo quando todas as variáveis explicativas forem iguais a zero.

$\gamma_{01}=$ coeficiente que diferencia os interceptos das regressões de nível 01 quando da presença de uma variável de grupo $W_{j}$ 
$\gamma_{10}=$ valor esperado dos coeficientes sem a presença da variável explicativa $W_{j}$ (média dos coeficientes das regressões de nível 01.

$\gamma_{11}=$ coeficiente que diferencia os coeficientes angulares de nível 01 com a presença de uma variável explicativa de grupo $W_{j}$

$u_{0 j}=$ efeito aleatório vinculado a característica de grupo $j$ no intercepto

$u_{1 j}=$ efeito aleatório vinculado a característica de grupo $j$ no coeficiente

Para analisar o modelo completo, é feita a substituição das equações de grupo dentro da equação de nível 01, obtendo assim um modelo de interceptos e coeficientes aleatórios (Fávero e Belfiore, 2017)

$Y_{i j}=\gamma_{00}+\gamma_{01} \cdot\left(W_{j}\right)+u_{0 j}+\left(\gamma_{10}+\gamma_{11} \cdot\left(W_{j}\right)+u_{1 j}\right) \cdot\left(X_{i j}\right)+r_{i j}$

Reordenando,

$Y_{i j}=\gamma_{00}+\gamma_{01} \cdot\left(W_{j}\right)+\gamma_{10} \cdot\left(X_{i j}\right)+\gamma_{11} \cdot\left(W_{j} \cdot X_{i j}\right)+u_{0 j}+u_{1 j}\left(X_{i j}\right)+r_{i j}$

Sendo esse o modelo multinível com interceptos e coeficientes aleatórios de dois níveis.

Sobre esse modelo, é importante analisar que a estrutura de erros apresenta um ponto interessante de discussão: observa-se que parte dos erros podem estar correlacionados com uma variável de nível 01, o que cria uma estrutura complexa e de melhor análise de como os erros são estruturados de acordo com os níveis apresentados.

A heterocedasticidade (que tem como uma de suas causas variáveis omitidas, ou relações entre variáveis explicativas e o termo de erro) é implícita a esse modelo. Da mesma forma, as diferentes estruturas podem não apresentar normalidade dos resíduos dada a estrutura de decomposição dos erros, o que faz com que a estimação por meio de mínimos quadrados ordinários (MQO ou OLS) seja preterida a modelos com máxima verossimilhança, que 
suportam a violação de tais pressupostos no processo de estimação dos parâmetros do modelo indicado. (Bickel, 2007; Santos, 2013; Fávero e Belfiore, 2017)

Em adição a essa estrutura de análise de dados, é importante salientar que nem sempre os modelos precisarão obedecer a esse comportamento, dado que nem sempre as variáveis independentes de grupo explicam comportamento do intercepto e/ou comportamento do coeficiente das regressões de níveis inferiores, podendo possuir somente os interceptos, ou somente os coeficientes aleatórios, de acordo com o grau de influência das variáveis e do comportamento de grupo dentro da análise de dados, considerando também a teoria subjacente aos dados analisados. Isso amplia a capacidade do pesquisador em observar não apenas a relação entre as variáveis explicativas e a dependente, mas como que as variáveis em diferentes níveis se relacionam e impactam a variável estudada, o que é um dos pontos positivos da técnica utilizada.

Em complemento, um ponto importante é entender que, assim como a estrutura de erros que está segregada e associada a cada nível, a estrutura de variância e covariância também está, o que pode ajudar a compreender quanto que cada nível se associa para explicar variabilidade da variável dependente em estudo.

No exemplo citado sobre o desempenho dos alunos, observa-se que a estrutura analisada foi de dois níveis (alunos-escolas), contudo, é importante frisar que a técnica pode ser aplicada também a modelos com mais níveis, considerando o mesmo modelo de pensamento e os pontos anteriores já destacados.

West, Welch e Galecki (2014) apresentam um framework de análise de dados, quando da aplicação de técnicas de modelagem multinível, chamado step-up strategy. Nesse roteiro apresentado, os autores recomendam, como primeira etapa, a análise do chamado modelo nulo, quando não há a inclusão de nenhuma das variáveis explicativas ao modelo em questão. $\mathrm{O}$ modelo nulo, ou modelo completamente incondicional, apresenta somente a análise da média, da estrutura de erros e da variância entre os níveis, servindo de início para verificar se existem diferenças estatisticamente significantes entre os agrupamentos e assim, identificar se o nível de agrupamento tende a ser significante para explicar a variância da variável dependente.

Considerando a não existência de nenhuma variável explicativa, o modelo nulo apresenta-se da seguinte forma, em um modelo de dois níveis: 
Para o primeiro nível:

$Y_{i j}=\beta_{0 j}+r_{i j}$

E para o segundo nível:

$\beta_{0 j}=\gamma_{00}+u_{0 j}$

Em conjunto, tem-se:

$Y_{i j}=\gamma_{00}+u_{0 j}+r_{i j}$

Considerando as variâncias referente à população de interceptos por grupo e por indivíduo desse modelo, pode-se observar quanto da porcentagem da variância global do modelo (o somatório das variâncias calculadas de cada um dos níveis) é devida a cada um dos níveis, considerando o índice de correlação intraclasse (ou ICC) dado pela seguinte fórmula:

rho $=\frac{\tau_{00}+\tau_{11}}{\tau_{00}+\tau_{11}+\sigma^{2}}$

$r h o=$ índice de correlação intraclasse

$\tau_{00}=$ variância referente a população de interceptos dado agrupamento $j$

$\tau_{11}=$ variância referente a população de coeficientes dado agrupamento $j$

$\sigma^{2}=$ Variância do termo de erro $r_{i j}$

Essa correlação interclasse, segundo Fávero e Belfiore (2017), mede a proporção da variância total que é devida aos níveis 1 e 2. Portanto, dada a correlação intraclasse, é possível identificar o número de níveis relevantes para análise, podendo, caso haja mais níveis superiores, desconsiderar alguns deles por não haver diferença significante na variância, simplificando o modelo a ser analisado, quando da construção do modelo final. 
Para verificação sobre a pertinência ou não da aplicação do modelo de regressão multinível é testada a hipótese de que $\gamma_{00}=\gamma_{11}=0$. O teste aplicado para se confirmar essa hipótese é o de razão de verossimilhança (LR test). Caso haja rejeição dessa hipótese sobre o modelo nulo, tem-se uma primeira evidência de que há diferença estatística entre os interceptos obtidos via modelo tradicional de regressão e por meio de modelo multinível. Ou seja, o(s) grupo(os) definido(s) para controle da regressão em nível(is) afeta(m) o intercepto da regressão.

Em complemento, ao serem incluídas as variáveis explicativas no modelo, seus coeficientes também podem ser influenciados pelos níveis definidos, de forma que a inclinação da reta do modelo gerado também pode ser afetada, sendo mais um motivo para a adoção da técnica de regressão multinível.

\section{Aplicação da técnica de regressão multinível com dados em painel}

Dentro das diferentes estruturas de análise de modelos multinível, uma das que mais são trabalhadas e discutidas são os modelos multinivel longitudinais. Esses modelos apresentam, por especificidade, a aplicação dentro da estrutura de dados com uma dimensão temporal, e uma ou mais dimensões espaciais. Os modelos multinível longitudinais ou modelos mistos longitudinais, assemelham-se aos modelos em painel de efeitos aleatórios, porém, apresentam como principal diferencial a possibilidade observar indivíduos, considerando seu agrupamento, ao longo do tempo quando de sua existência, assim como a possível observação das relações entre os diferentes níveis de agrupamento ao longo do tempo.

Desta forma, modelos longitudinais têm como primeiro nível as observações de indivíduos ou de grupos (caso sejam modelos de três ou mais níveis) ao longo do tempo $t$. Ou seja, as covariáveis que possuem variação temporal estão relacionadas a esse nível.

Já para variáveis de indivíduos e/ou grupos que não possuem variação ao longo do tempo, ou seja, que não variam entre observações no tempo do mesmo indivíduo, estas encontram-se em níveis superiores, sendo incluídas como explicativas seja do intercepto ou dos coeficientes das regressões de primeiro nível, assim como os modelos multinível já observados.

Snijders (1996) apresenta um processo de estruturação de um modelo multinível longitudinal onde destaca um processo passo a passo de construção de um modelo com observações do mesmo indivíduo ao longo do tempo. Nesse artigo, destaca que os modelos longitudinais não 
precisam necessariamente seguir um padrão linear de comportamento no tempo, podendo o analista aplicar outros padrões de análise (como por exemplo, curvas quadráticas) de acordo com sua observação dos dados.

Desta forma, a estruturação dos modelos longitudinais multinível segue o seguinte padrão:

$Y_{i t}=\beta_{0 i}+\beta_{1 i}\left(\right.$ tempo $\left._{i t}\right)+r_{i t}$

Onde:

$Y_{i t}=$ É a observação da variável dependente relativa ao indivíduo $i$ no instante de tempo $t$ indicado em $t=1,2,3 \ldots \mathrm{T}$

$\beta_{0 i}=$ Intercepto da equação de nível 1 para todas as observações pertencentes ao indivíduo $i$ : representa valor inicial do indivíduo $i$, assumindo demais variáveis igual a zero;

$\beta_{1 i}=$ Coeficiente de crescimento/decrescimento linear em função do tempo de $Y_{i t}$, identifícando quanto que os valores de $Y_{i t}$ aumentam ou diminuem quanto do aumento de uma unidade de tempo observado;

tempo $_{i t}=$ Conjunto de variáveis vinculadas à variação temporal das observações dentro do período de estudo (crescimento ou decrescimento temporal)

$r_{i t}=$ Erro randômico relacionado ao primeiro nível (observações do indivíduo $i$ ao longo do tempo $t$ )

Estruturando as equações referentes ao segundo nível, tem-se:

$$
\begin{aligned}
& \beta_{0 i}=\gamma_{00}+u_{0 i} \\
& \beta_{1 i}=\gamma_{11}+u_{1 j}
\end{aligned}
$$


Desta forma, observa-se o modelo completo sem a inclusão de variáveis variantes e não variantes ao longo do tempo.

$Y_{i t}=\gamma_{00}+\gamma_{11}\left(\right.$ tempo $\left._{i t}\right)+u_{0 i}+u_{1 j}\left(\right.$ tempo $\left._{i t}\right)+r_{i t}$

Dentro do modelo apresentado, observa-se que parte da estrutura dos erros é variante de acordo com a estrutura temporal. A partir dessa estrutura básica, cabe a análise do pesquisador quanto a inclusão de mais fatores aleatórios de acordo com a inclusão de covariáveis fixas ou variantes ao longo do tempo, assim como a verificação de como a estrutura temporal deve apresentar na estrutura de parâmetros fixos. (West, Welch e Galecki; 2014). Para essa análise, recomenda-se a aplicação do teste de razão de verossimilhança.

Snijders (1996) aponta como exemplo de inclusão de covariáveis fixas e variantes ao longo do tempo os dados de West, Welch e Galecki (2014) apresentam um estudo referente a forma de tratamento dental de pacientes. Para explicação prática neste trabalho, foi incluída uma variável variante e uma não variante ao longo do tempo, atentando ao conceito de que variáveis variantes estão relacionadas ao primeiro nível (indivíduos no tempo) e constantes ao segundo nível (indivíduos).

Desta forma, tem-se a seguinte equação em primeiro e segundo nível, não possuindo relação entre as variáveis constante e variante ao longo do tempo:

$Y_{i t}=\beta_{0 i}+\beta_{1 i}\left(\right.$ tempo $\left._{i t}\right)+\beta_{2 i}\left(\right.$ variante $\left._{i t}\right)+r_{i t}$

$\beta_{0 i}=\gamma_{00}+\gamma_{01}\left(\right.$ constante $\left._{i}\right)+u_{0 i}$

$\beta_{1 i}=\gamma_{10}+\gamma_{11}\left(\right.$ constante $\left._{i}\right)+u_{1 i}$

$\beta_{2 i}=\gamma_{20}$

Formalizando o modelo final, temos: ${ }^{2}$

\footnotetext{
${ }^{2}$ Cabe destacar que a variável tempo it pode ser transformada e incluída como novas variáveis (n-1) dummies, como mostrado do Snijders (1996), no caso apresentado.
} 


$$
\begin{aligned}
Y_{i t}=\gamma_{00}+ & \gamma_{01}\left(\text { constant }_{i}\right)+\gamma_{10}\left(\text { tempo }_{i t}\right)+\gamma_{11}\left(\text { constante }_{i} \times \text { tempo }_{i t}\right)+ \\
& \gamma_{20}\left(\text { variante }_{i t}\right)+u_{0 i}+u_{1 i}\left(\text { tempo }_{i t}\right)+r_{i t}
\end{aligned}
$$

A análise da variância dentro desse modelo assemelha-se ao modelo multinível padrão, utilizando-se do cálculo do coeficiente e correlação intraclasse já apresentado anteriormente.

Dentro da análise de quais modelos multinivel utilizar, quando da inclusão, modificação ou exclusão de variáveis explicativas dos diversos níveis, o teste mais utilizado é o teste de razão do logaritmo de verossimilhança ou log likelihood ratio test. A partir desse teste, é possível observar se a inclusão de uma nova variável melhora ou não o poder preditivo do modelo apresentado, podendo assim desenvolver o modelo de melhor ajuste aos dados reais apresentados.

Volta-se a frisar aqui que o modelo apresentado, pela conceituação matemática da técnica, possui menor restrição aos problemas apresentados pelas estimações por mínimos quadrados ordinários (MQO), tais como como a necessidade de normalidade dos resíduos e a ausência heterocedasticidade. 